Portland State University

PDXScholar

\title{
Total Quality Management: the Case for the Public Sector: a Comparative Study of the Implementation of Total Quality Management in Three Health Care Organizations
}

Zayed Mohammed Abu

Portland State University

Follow this and additional works at: https://pdxscholar.library.pdx.edu/open_access_etds

Part of the Public Policy Commons

Let us know how access to this document benefits you.

\section{Recommended Citation}

Abu, Zayed Mohammed, "Total Quality Management: the Case for the Public Sector: a Comparative Study of the Implementation of Total Quality Management in Three Health Care Organizations" (1994).

Dissertations and Theses. Paper 1313.

https://doi.org/10.15760/etd.1312

This Dissertation is brought to you for free and open access. It has been accepted for inclusion in Dissertations and Theses by an authorized administrator of PDXScholar. Please contact us if we can make this document more accessible: pdxscholar@pdx.edu. 
TOTAL QUALITY MANAGEMENT

THE CASE FOR THE PUBLIC SECTOR;

A COMPARATIVE STUDY OF THE IMPLEMENTATION OF TOTAL QUALITY MANAGEMENT IN THREE HEALTH CARE ORGANIZATIONS

By

Mohammed Abu Zayed

A dissertation submitted in partial fulfillment of the requirements for the degree of

DOCTOR OF PHIILOSOPHY

in

PUBLIC ADMINISTRATION AND POLICY

Portland State University

1994 


\section{DISSERTATION APPROVAL}

The abstract and dissertation of Mohammed Abu Zayed for the Doctor of Philosophy in Public Administration and Policy were presented April 29, 1994, and accepted by the dissertation committee and the doctoral program.

\section{COMMITTEE APPROVALS:}

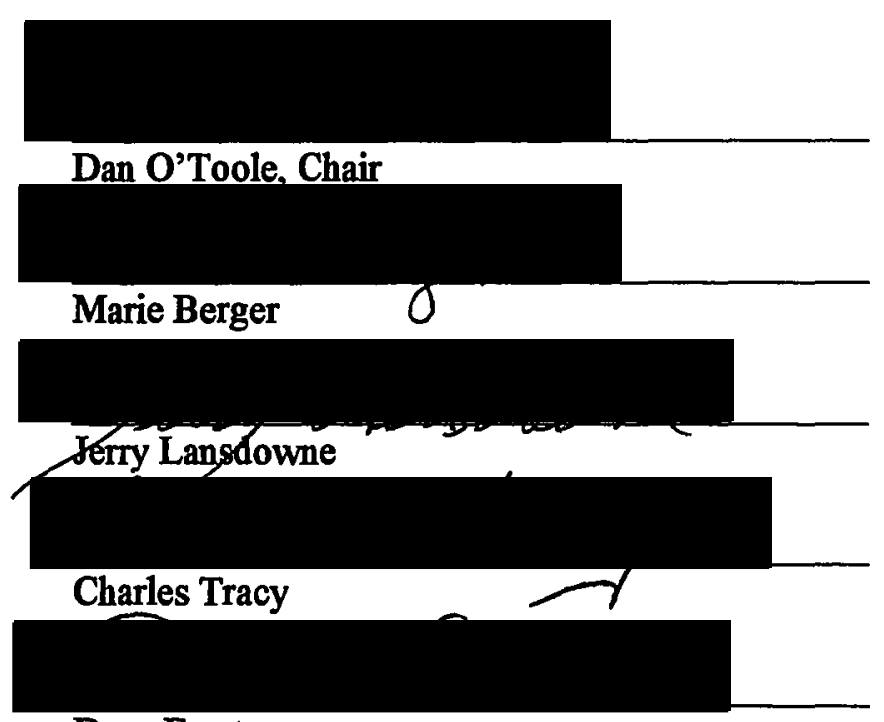

Dean Frost

Representative of the Office of Graduate Studies

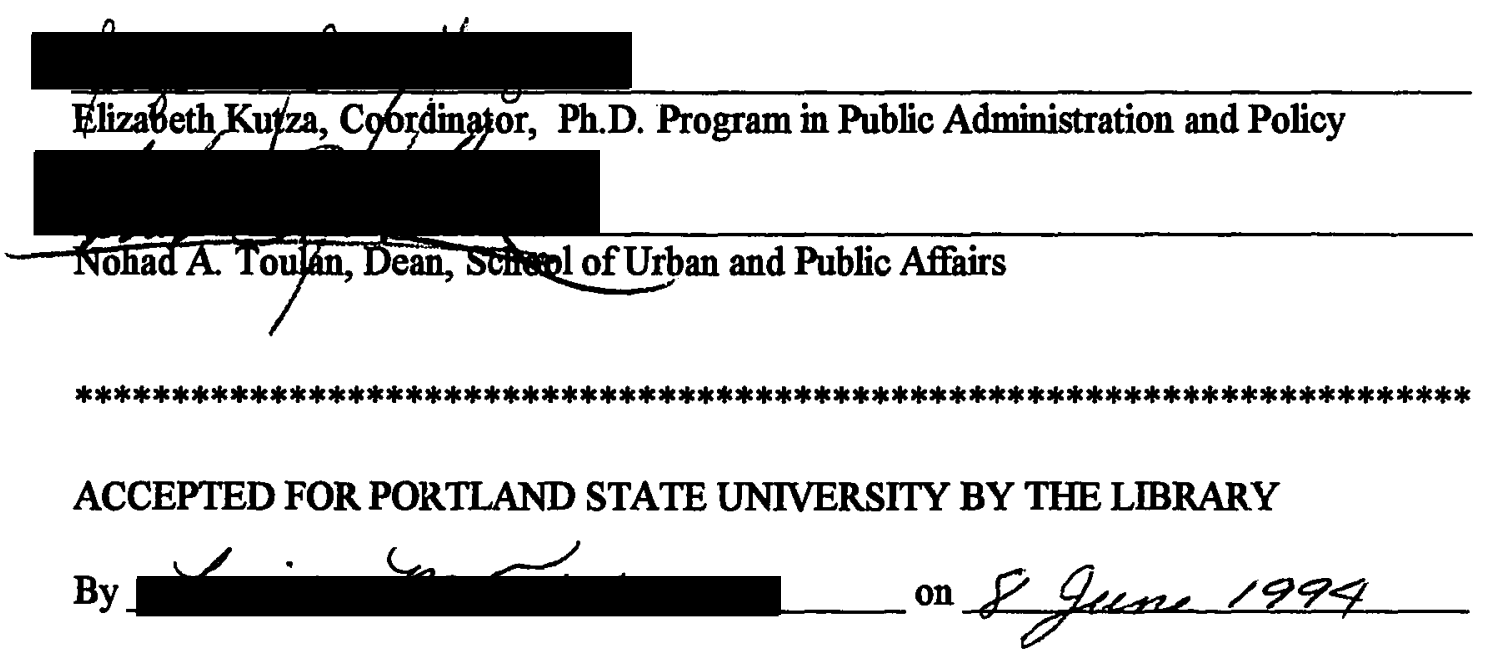




\begin{abstract}
An abstract of the dissertation of Mohammed Abu Zayed for the Doctor of philosophy in Public Administration and Policy presented April 29, 1994.
\end{abstract}

Title: Total Quality Management: the case for the public sector; a comparative study of the implementation of Total Quality Management in three health care organizations.

Total quality management [TQM] is an approach to improving the competitiveness, effectiveness and flexibility of the whole organization through the improvement of the organizational processes and those who perform them. There has been a rising interest among public sector professionals in examining the applicability and usefulness of TQM methods to public organizations.

This research provides descriptive information about the experience of three health care organizations that vary in terms of ownership, whether being publicly or privately owned, with implementing TQM. Participants at these organizations were interviewed, and/or surveyed and observed. The study provides a narrative description of each organization's experience with TQM (their Quality Story) and it compares the 
implementation of TQM in the three organizations. Moreover, the study explores what role, if any, does ownership have on the implementation of TQM. Finally, the study presents some lessons that could be derived from the experience of these organizations.

Conclusions are drawn that TQM could be successfully implemented in both sectors, provided that the process of implementation follows the specific guidelines and principles established in the field. Moreover, difference in ownership between public and private organizations, though important, is not the major factor influencing the implementation and possible outcomes of a TQM innovation effort. It is rather the involvement and commitment of top management that seem to have the upper hand in influencing the implementation and any possible outcomes of TQM, in public as well as private organizations. However, the research suggests that public sector organizations are more challenged in implementing TQM, due to the multiplicity of their customers and more scrutiny of the tax payer and the media. 


\section{ACKNOWLEDGMENT}

I would like to thank my committee for their guidance, suggestions, and patience. Special thanks to all those who participated in this study. Recognition and thanks go to my advisor, Dr. O'Toole, for his insightful comments and encouragement. I thank my parents who ingrained in me the love for knowledge. Finally, I thank God for granting me the ability to complete such an arduous task. To all those who believed in me, I extend my deep gratitude. 


\section{PABLE OF CONTENTS}

ACKNOWLEDGMENTS

LIST OF TABLES

LIST OF FIGURES

LIST OF CHARTS iv

LIST OF ABBREVIATIONS

CHAPTER

I INTRODUCTION 3

$\begin{array}{lll}\text { II } & \text { CONCEPTS OF TQM } & 17\end{array}$

III GENERAL IMPLEMENTATION RESEARCH 51

$\begin{array}{ll}\text { IV TQM IN HEALTH CARE } & 83\end{array}$

V METHODOLOGY AND INSTRUMENTS 103

$\begin{array}{lll}\text { VI } & \text { QUALITY STORIES } & 130\end{array}$

VII CROSSECTIONAL DATA: PRESENTATION AND FINDINGS 202

VIII LESSONS TO BE LEARNED 243

IX IMPLICATIONS AND CONCLUSIONS 263

$\begin{array}{lr}\text { REFERENCES } & 288\end{array}$

APPENDICES

Appendix A 301

$\begin{array}{ll}\text { Appendix B } & 306\end{array}$

Appendix C $\quad 318$

$\begin{array}{ll}\text { Appendix D } & 330\end{array}$ 


\section{LIST OF TABLES}

Table I

Table II

Table III

Table IV

Table V

Table VI

Table VII

Table VIII

Table IX
Malcolm Baldrige Criteria

303

Presidential Award Criteria and Categories

Tabulations of participants in the study

Tabulations of instruments used in the study

Breakdown of participants according to hospital

TQM vs other Quality Assuranse approaches

Where should TQM effort start?

Ranking/Rating of key organizational players in TQM process.

Expected outcomes of TQM
212

214

305

113

114

122

209

222 


\section{LIST OF FIGURES}

Figure 1

Malcolm Baldrige Model

302

Figure 2

Reinventing Government Model 


\section{LIST OF CHARTS}

Chart I

Chart II
Key Organizational Characteristics

109

Comparative Summary of implementation/results at the three organizations. 


\section{List of Abbreviations and Relevant Terms}

CQI: Continuos Quality Improvement; sometimes is called Total Quality

Management.

FQI: Federal Quality Institute.

MBNDP: Malcolm Baldrige National Award Program.

NDP: National Demonstration Project

PIT: $\quad$ Process Improvement Team and some time is referred to as Quality

Improvement Teams (QITs).

PPA: $\quad$ Presidential Prototype Awards.

TQM: Total Quality Management, sometimes is also called Continuos Quality Improvement. 


\section{CHAPTER I}

\section{INTRODUCTION}

Organizations were developed to serve society's collective needs efficiently and effectively. They reflect, not only our desire to have a coordinated collective societal effort, but are also a reflection of our ability to coordinate diverse capabilities and talents to produce a useful product. The word, organization, is derived from the Greek word, organon. meaning a "tool" or "instrument." Organizations, then, are instruments created to "achieve other ends" (Morgan, 1986, pp. 22-23) and are as diverse as their creators and the society they serve. Because organizations reflect the values of a particular leader and/or the society in which they operate, exploring their culture and dynamics can be a useful way of gaining better understanding of the operations that affect the efficiency and effectiveness of their management practices and productivity (Morgan, 1986).

It is generally agreed that the essence of any organization is the human factor and the center of any organizational activity is the human behavior. The final goal of all organizational processes and functions is to meet the needs of those whom they serve. By the same token in viewing the performance and the dynamics of a certain organization, one has to refer to the larger picture: the demographic and/or cultural environment affecting that organization (Krefting, 1985). 
In this world of changing powers and merging new orders, it is important to consider the interacting factors that produced particular organizational structures within the context of the ever-changing needs and expectations of societies. Factors previously believed to contribute to the success of an organization may have to be viewed differently as the dynamics of societal and organizational cultures and environment change. Quinn (1990) supports this view when he states that, "As societal values change and existing viewpoints alter, new models of management emerge." (p. 3). It could be derived from the above that our views of organizations have changed as their operations and dynamics become more complex over time. A new kind of organizational thinking has emerged to address the changing organizational dynamics and processes. The focus of managers and leaders has also changed which led to the development of new management models and approaches. As organizational operations and structures became more complex and diverse the need for controlling their processes has become increasingly important as a way of ensuring better outcomes. Attention to cost and efficiency has increased among organizations, competing for customers, markets, and other sources of revenue. Managing quality has become a central function and a primary responsibility for any organization that is serious about success. Quality Assurance and Quality Control departments assumed the responsibility for ensuring the adherence to the quality standards set by the organization. As the macro-level view of systems and processes gained more followers so did our view of organizations and their environments; and ultimately did our view of quality management. Instead of looking at a partial segment of an operation or an organizational structure we now need to address the whole process and the total system in place if we want to achieve better performance and/or more 
efficient products and services. When it comes to quality management, there is a proliferation of approaches that demand improving the total system as a way of bringing about organizational change. These views are replacing the traditional approaches that stressed inspection and improving certain areas and/or functions in order to improve quality. The focus on quality management has been receiving more attention among leaders, managers, and professionals who are searching for new ways to meet the new challenges facing their organizations.

Total Quality Management (TQM) or Continuous Quality Improvement $(\mathrm{CQI})^{1}$, as it is sometimes called, is a holistic approach to organizational change that has been gaining an increasing attention in the field of Organization Development. Although quality improvement has been in existence for quite a while, many believe (Carr, 1993) that the 90s are indeed the age of quality improvement revolution. More and more organizations are taking quality improvements initiatives in hope of achieving organizational changes that will improve the processes of their organizational systems. Health care organizations in particular are paying more attention to quality improvement issues than before due to their rapidly changing environment and the new forces dictating their survival. An increasing number of studies in which various aspects of TQM are examined are starting to take place in OD literature. More and more professionals in the field are talking and writing about Total Quality Management or Continuous Quality Improvement.

Guided by the previous research and motivated by the timely need for such a study in the field of Total Quality Management / Continuous Quality Improvement (TQM/CQI), this project explores the implementation of TQM/CQI in three health

\footnotetext{
1. For the full text of the abbreviations included in the study please refer to the "List of Abbreviations and Relevant Terms" at the beginning of the document.
} 
care organizations that vary in ownership- being privately or publicly owned. The primary goal of this research is to provide relevant information about how TQM is being implemented in these organizations, by presenting their Quality Stories. The study presents a detailed description of the quality improvement efforts at these organizations. Moreover, this research establishes a comparative approach among them by comparing and contrasting data gathered at those participating organizations. An assessment of the role of ownership, being privately or publicly owned, over the implementation of TQM at these organizations will be also provided. Furthermore a discussion of the general ideas and principles that can be drawn from the experiences of these organizations is presented along with a rationale for their applicability to public sector organization. The purpose of this study then is to provide an answer to questions like: How is TQM carried out at each of these three organizations? What similarities or differences exist among these organizations, and what role does ownership play in these organizations?

At this point, however, it will be appropriate to provide a brief outline of the various evolutionary stages through which the organizational theory has gone. This could be justified on the basis that quality improvement approaches, such as TQM/CQI, did not come from vacuum but they are instead a product of an evolutionary process in organizational theory and behavior. A description of the various organizational and managerial approaches and models that have taken place throughout time will help provide an informative background about Total Quality Management itself. Moreover, this chronological rundown will help establish a cohesive connection between the time's three junctions: past, present, future as they relate to Organizational theory in general and Total Quality Management in particular. 
While there are numerous ways to represent these changing approaches and models, Quinn's (1990) approach is one of the clearest and most concise. He posits four major organizational and management models that could be identified through the history of the organizational theory: the rational goal approach, the human relations approach, the internal process approach, and the open systems approach (Quinn, et al, 1990). Each of these will be discussed in some detail in the following section to provide a foundation for the present research.

\section{0-1925, Rational Goal Approach}

Quinn characterizes this period as having rich resources and cheap labor with its beginning during the industrial revolution. At this time production of materials and products was shifted from individual craftsman's effort to the larger scale mass production, assembly line process. Other factors that characterized this were increasing technology and more sophisticated machinery. Moreover, the goal of organizations became more quantity rather than quality driven, and the "better" organization was one that coula increase production limits while simultaneously reducing production time. Social Darwinism, or the survival of the fittest (the quantity producer) was the guiding principle. Economic growth during this period was significant, resulting in an unprecedented period of prosperity during the first quarter of the twentieth century. (Quinn, 1990).

During this period, scientific management, described in the writings and practices of Frederick Taylor, has emerged as a powerful contender in organizational thought. Taylor's focus was on the detailed analysis of a specific task. The purpose of this analysis was to construct step by step instructions for employees to follow so 
that maximum production levels could be achieved. Employees were given comprehensive training in the specific steps they were to follow. Scientific management focused on "rationalizing work and making it as efficient as possible" (Quinn, 1990, p. 3), while completely ignoring the human factor. Henry Ford used this approach by introducing the assembly line for the production of automobiles and reducing the car assembly time from 728 hours to 93 minutes. By accomplishing this efficiency, Ford's share of the automobile market grew from $10 \%$ to $50 \%$.

It was within this historical context that the rational goal model began to emerge. The ultimate criteria for organizational effectiveness within this model was productivity and profit maximization. The guiding principle of this model was that clear instructions and direction lead to increased productivity. Although many of the principles of scientific management were adhered to, there was great consideration given to goal clarification and the improvement of processes. Employees were recognized solely as implements of production and were expected to contribute $100 \%$ efficiency. If they fell short of this goal, they were in danger of being replaced. The manager's role was seen as one of enforcing the rules and regulations. The dollar, or the "bottom line" was the important concept. (Quinn, 1990).

The internal process model also began to emerge during the first 25 years of the 20th century but would not be fully implemented until the writings of Max Weber and Henry Fayol were transiated in the second quarter of the century. This model proposed a richer and more complex structure for organizations, their objectives, and their written policies and procedures (Quinn, 1990). The criteria for effectiveness within this model was stability and continuity. Although there were many advantages 
to the structure and stability the Weberian model brought to organizations, too little attention was given to the management of the human behavior.

The early period of the twentieth century has been identified by the desire for mass production, increased efficiency as defined by decreased production time, and more explicit rules. Society's primary requirement was increased availability of all of the new products that seemed so strange and fascinating to them. Competition was not that strong, because not many organizations existed. Mass production was a blessing, due to the creation of huge industrial and service organizations capable of furnishing products that added to the quality and the improvement of the human life. However, this same blessing was a painful curse, because it carried with it the seeds of exploitation. Workers became nothing but small pieces in a larger machine. According to Sharif(1982) the personal identity of the employee had to "fade away" to be replaced by the larger organizational rules and norms (pp. 63-65).

The attitude toward the employee was to provide them with minimum accommodation factors, while at the same time expecting maximum energy and effort for a minimum amount of money that barely covered basic needs (Sharif, 1982).

\section{5-1950, the Human Relation Approach}

During the second quarter of the century, two major events occurred that would have a great influence on society in general and management practices in particular. The first of these events was the stock market crash of 1929 and the second was World War II. There were economic swings from the crash of 1929 to boom caused by the war, unprecedented technological advances, and a post proliferation of new consumer products that were readily available to the higher paid 
workers. Though the internal process model had retained some of its power, it became apparent during this period, that viewing organizations as rigid hierarchical establishments was not advantageous in this new societal context. As the social values became more open and workers became more organized, leaders could no longer afford to maintain the same view of employees held previously (Quinn, 1990).

The movements in the various disciplines of human sciences had probed new dimensions of human personality. Organizational psychology placed greater importance on the influence of the human factor on efficiency in organizations. Motivation and participation became dominant concepts for many organizations and the human relations approach to examining and managing organizations emerged.

Within this approach, management was expected to not only have the goal of higher production quotas, but to view the employee as an important asset and an integral component that needed to be recognized to reach any desired goal. Winning and "sustaining employees' commitment" and maintaining high morale and group cohesion were among the manager's priorities. Training and education became wellknown requirements for companies who wanted to survive in the new society (Quinn, 1990).

\section{1-1975: The Open System Approach}

This period was characterized by the interaction of a variety of social forces including the emergence of the United States as a global leader and the rapid growth of Japanese quality products. Both of these forces dramatically influenced manufacturing practices in the US and societal values. By the 1970s educational preparation for US workers increased from 8 years to 12.6 years. Workers enjoyed 
considerable prosperity and were seeking not only interesting work, but selffulfillment. Women began to enter professions heretofore not open to them and labor organizations began to include social and political issues in their negotiations.

Spurred by the increasing rate of change in society and industry, it became clear that more dynamic organizations models were needed to adequately adapt to the changing external environment. One such model was developed by Katz and Kahn at Michigan and was called the open systems model. In this model, the organization was seen as interacting with the external environment be it another organization or the various elements in the production process. Survival of the organization was defined as the ability to adapt and compete in "an ambiguous as well as a competitive environment" (Qiunn, 1990, p..9). This required pooling all resources to stay afloat. Increased competition and the struggle to dominate wider markets caused organizations to pay greater attention to the quality of their products while maintaining efficient productivity. Innovation and risk taking were encouraged in order to compete and be distinguished. A decrease in an employee's efficiency/productivity level was no longer used as the primary excuse for firing $\mathrm{him} / \mathrm{her}$, which was done previously. Instead, managers and supervisors will take the time to evaluate his/her working condition in order to eliminate factors that contribute to lower efficiency and increase factors that promote efficiency.

The open system approach broadened our perception of organizations by presenting us a perspective that viewed organizations as living organisms actively interacting with their environments and seeking survival. The overemphasis on rules and hierarchical divisions in the organization were seen as insufficient for economic 
survival. Knowing how to maintain a state of balance, or a "state of ecology" as Morgan states is also a critical element to survive. (Morgan, 1986, pp. 66-69).

\section{6-1990s: The New Paradigm, and the Reemerging focus on quality}

This period is characterized by stiff regional and global competition, takeovers, organizational downsizing, and high unemployment. Controlling cost and increased focus on quality are seen as key issues for today's organizations. As organizations implement more vigorous downsizing strategies, calls for improving the quality of products and services are met with more and more positive response by organizations (Quinn, 1990).

Quality has become a valued ingredient for companies that have been competing in an already mature market with a multiplicity of competitors who are trying to acquire greater market shares. The best example for this is the auto industry. While in the past, cars produced in USA had few competitors, today the American auto industry is facing stiff competition from Japanese and European auto industry. The American automobile industry recognizes that attracting the American customer back to their cars will require a return to quality and customer service. Their products must meet Japanese quality standards and be competitively priced. The American public has found that Japanese cars performed better, because they undergo a much stricter quality control process (Carr, 1990).

The Total Quality Management movement has emerged not only in American private industry, but in the public sector as well. The primary purpose of all quality management techniques and strategies is to focus on quality improvement to reduce waste, improve the production process, and involve all members to the organization 
in the enterprise. In an age of shrinking resources and stiff competition, organizations are rushing to implement the tenets of TQM.

According to TQM, the responsibility for the failure of any product to meet the required quality standards, as serious as it could be, should not be blamed only on the employee because management should be blamed for that failure as well (Deming, 1986). Failure occurs because the process lacks the critical elemenis for success. This does not mean furnishing an excuse for workers and/or management. It is a new kind of assessment that is aimed at identifying the various factors that contribute to the flaw in the system and/or its processes. The organizational error occurs somewhere in the process and the first step in correcting it is to identify its location (Joiner, 1988). Moreover, there is a need to view quality improvement as not only a process to correct an error, but also as a process for self evaluation, growth, and progress. Organizations that have a vision for success and better services are those that pay attention to improving their performance. In other words, quality issues are for both successful and troubled organizations. Quality is not just a conceptual idea, it is rather a process that consists of systematic components that work together to reach a final goal. Thus, quality is a dynamic force in the organizational process (Oakland, 1989). It is a process that starts at the top and continues to the bottom, and from the first step of the production process to the final step. In later parts of this study an examination of the major writings and ideas of quality improvement "gurus", such as Deming, Juran, and others, will be reviewed.

The above approaches serve as a chronological recapitulation of the various forces that led to the reemergence of quality improvement approaches into organizational theory and behavior. An increasing focus on Total Quality 
Management and the need for further research serve as the primary justifications for this research. This study should be of special significance to those in the field who are involved in the implementation or planning to initiate TQM projects at their organizations. By providing a summary of the wealth of literature available on TQM this study will help demystify TQM and provide an idea about how is it carried out. In addition to the previous point, this study will offer the reader an opportunity to travel into these organizations and see the dynamics of TQM in action. This will be done through the narration of the quality stories, team observations, and the documented crossectional data gathered via survey responses. Finally this research is a pioneering effort that goes beyond describing the experience of a single organization with TQM. Instead it goes a step further by providing information on the experience of BOTH public and private health care organizations with TQM. It is hoped that OD professionals can find in the study significant information that will help them in carrying quality improvement initiatives in either sector. As quality improvement efforts take on new challenges and explore new areas, the need for this kind of study becomes vital to their success since it paves the way and provides some helpful insights that paves the way for those who will initiate and/or pioneer the quality improvement effort.

The first part of this study will offer a review of the literature which will provide a theoretical foundation for the research. the basic precepts of Total Quality Management (TQM) or Continuous Quality Improvement (CQI), including Deming's fourteen points will be reviewed. In addition a review of the relevant literature and documented research will be presented. This review will include a discussion of inherent differences between public and private organizations, and how these 
differences might affect the implementation and utilization of TQM/CQI in the public sector in general and in health care in particular. Moreover a description of the implementation of TQM in private (industry) sector, public sector, and health care organizations will be provided.

The second part of this study will present and justify the research design and will introduce the methodologies used for the operationalization of the research and data collection. This will be achieved through a) a presentation of the research goals and objectives in more detail, b) statement of research question and major assumptions, and b) description of major instrumeris and means of data collection that have been used in the research. A justification and a detailed description of the rationale behind adopting a qualitative approach will be offered by answering a series of Wh. Questions such Who has been studied, why, when, where, how, .. etc.

The third component of this dissertation is a presentation and reporting of the results. This section will assess and identify significant information that will help interpret and analyze the findings of the study. First a description of how these organizations go about implementing TQM (the process) is provided in Chapter VI through a narrative description of their experience which will be called Quality Stories. These Quality Stories represent a case study approach modeled after the Prototype Awards Reports provided by the Federal Quality Institute for the year 1993. Responses gathered through interviews, answers to completed surveys, and documentation of team observations will be used to write these Quality Stories. The second section, Chapter VII, provides a comparative approach among these three organizations according to the data gathered from their responses to surveys. 
Included in this section is a presentation and tabulation of data gathered that helps compare and contrast these organizations in their experience with TQM. Examining these data provides an answer to the second question about what differences, if any, exist between public and private organizations in relation to TQM. Also what role does ownership have, if any, on the planning, implementation, and outcomes (when / where possible) of TQM.

The final part of the study is dedicated to conclusions and implications. First, an analysis and a discussion of major results is included. These are the major findings of the research. Then, the major lessons that could be learned from the research will be presented. Finally, this part concludes by discussing what implications these conclusions have in relation to TQM. The final component of this research will discuss the challenges and limitations encountered in doing the research, discuss the need for further research, and provide an overall closing summary of major recommendations. The previous paragraphs offer a road map to this study. The next step is to put this road map into action. 


\section{CHAPTER II}

\section{MAJOR CONCEPTS OF TOTAL QUALITY MANAGEMENT}

"Quality is every one's responsibility." [ Deming, Out of the Crisis, 1986]

Much has been said and written about TQM. The interest in TQM, as a new approach of organizational change and development, is mounting. In the previous chapter we introduced the reader, briefly, to the chronological evolution of organizational and managerial models. By observing the development of these models and approaches we have seen how the new focus on quality and process improvement has emerged as a new paradigm in organizational theory and practice. It seems relevant for this study to start by providing the reader with a theoretical assessment of the major concepts of TQM as well as some of the documented literature describing its implementation. The following pages will introduce some fundamental theoretical concepts that will assist the reader in attaining a better understanding of this approach and familiarize him/her with TQM as a concept and a practice.

First, various definitions of TQM will be introduced along with a historical evolution of the quality improvement. Moreover, this section will present the ideas of one of the most important figures in the field, that is Dr. Deming. Deming's ideas (his 14 points) will be briefly discussed, and a host of additional principles that relate to TQM will also be mentioned. The second major part of this review consists of an introduction of key concepts that relate to TQM. These are: TQM principles, various implementation phases of TQM, and various tools and techniques used in TQM. The 
next section will focus on the obstacles that hinder the implementation of an effective TQM effort; and it will be followed by a brief discussion of challenges and limitation of TQM, as reflected through the writings of some of those in the field.

\section{Total Quality Management: Definitions and major concepts}

In his book, Total quality management, Oakland defines Total Quality Management (TQM) as an "approach to improving the effectiveness and flexibility of businesses as a whole." He goes on to say that TQM is seen as a "holistic approach aimed at improving the total system performance", that is achieved through the "improvement of the organizational processes and those who perform them." (Oakland, 1993, 14-15). Thus TQM is seen to involve the "whole" organization and is aimed at integrating the organizational processes and systems with its human resources: both employees and management for the improvement of the total effectiveness of the total organization (Oakland, 1993).

A second definition which supports that of Oakland is offered by Carr in his book, Excellence in Government. He defines TQM as "...involving everyone in an organization in controlling and continuously improving how the work is done." The final goal of the endeavor is to meet customer expectations of quality (1990).

In another definition, quality is seen as "...conformance to the requirements, and is objectively measurable." (McLaughlin, 1990, p.15) TQM should be focused around and driven by customer needs. Deming also states that: "The consumer is the most important part of the production line" and quality should be aimed at "the needs of the consumers, present and future." $(1986$, p. 5). Total quality management is an approach to manage the organizational processes and organizations are viewed as 
interactive systems, involved in a dynamic exchange process with their internal as well as external environments.

Top management support for TQM is critical, and according to Oakland, commitment to and implementation of TQM must start "at the top" that is by the CEO. Because TQM often requires a change in perceptions in the organizational culture, the CEO is a pivotal person in the enterprise. Furthermore, TQM is an attitude of mind, based on pride in the job, and requiring total commitment from the top that must then be extended to all employees. Although controls and techniques are important in TQM, they are not the primary requirement (Oakland, 1993). Total Quality Management, thus, is comprised of two parts: management and organizational culture and is an "integration between the management's need to be rational and its pursuit of a synoptic decision making model and the need to pursue a more realistic and integrated model of decision making." (Pindur, 1993, p.4). In other words, TQM is seen as an integration of the rational models with the human relation models in a comprehensive and systematic control of organizational processes. By combining the human relations perspectives, reflected in the writings of TQM leaders such as Juran and Crosby, with those of Statistical Process Control as reflected in the writings of Deming, we arrive at a more complete and comprehensive understanding of TQM.

Total Quality Management can also be viewed as a response to what Berwick calls the theory of the "Bad Apples" that includes inspection and blind conformance to stated rules (1989). He states that relying on inspection to improve quality is at best inefficient, and at worst a formula for failure. Quality can be improved much more when people are "assumed to be trying hard already, and are not accused of sloth." (Berwick, 1989). Fear and disciplinary action are not incentives for 
improvement in quality, since it inevitbly leads to dissatisfaction, distortion of information, and the loss of the chance to learn (Berwick, 1989). .

According to the principles of TQM, true improvement in quality depends on everyone's "understanding" (and the potential for) " revising the production processes on the basis of data about the processes themselves" (Berwick, 1989). The assumption is that every process provides information about how improvement can be made. The focus of TQM is on continuous improvement throughout the organization by maintaining an open mind and creating a climate wherein continual efforts to reduce waste, rework, and complexity are the norms of the organization.. When the purpose is clear and constant and when employees' fear is minimal, valid information can be obtained and learning is guided by accurate information and sound rules of inference. When suppliers of services "remain in dialogue with those who depend on them, and when the hearts and talents of all workers are enlisted in the pursuit of better ways, the potential for improvement in quality is nearly boundless," (Berwick, 1989). Translated into cultural norms in production systems and made real through sound statistical techniques, these lessons are at the core of the Japanese industrial revolution. They can be guiding principles for implementation of TQM in organizations (Berwick, 1989).

The use of Total Quality Movement principles has worked in Japanese organizations, in large part, because of the sound quantitative methods developed by TQM pioneers. It has also been successful because of the implicit power derived from "shifting the entire curve of production upward even slightly, as compared with a focus on trimming the tails." (Berwick, 1989). In other words, it is more successful when the focus is on improvement of the performance of the whole organization rather than on improving the performance of only select components of it. The 
Japanese call tne principle, "kaizen" meaning -- the continuous search for opportunities for all processes to get better," (Berwick, 1989).

It would be naive to imply that TQM calls for the total abandonment of surveillance and discipline. Politically, at least, it is absolutely necessary for regulators to continue to "ferret out the truly avaricious and the dangerously incompetent," (Berwick, 1989). For TQM to work properly, inspection has to be replaced by some responsible freedom. Ownership and empowerment are expected to drive out the fear and motivate the workers to give their best not because they have to but because they are made to feel that they are an integral part of the TQM process.

The historical evolution of TQM will be presented in the following section. One of the key figures in the TQM movement is W. Edward Deming, often called the genius who revitalized a moribund Japanese industry after World War II. His particular framework will be described in detail in the following sections. A brief historical evolution of TQM will also be presented.

\section{Historical Evolution of TOM}

Total Quality Management should be seen as an outgrowth of the rational models and the human relation models in organizations and management described in an earlier section. In addition, TQM is an evolution of the human relation models since it calls for building and improving commitment and empowerment of employees. The evolution of TQM has developed along the following four stages (Carr, 1990).

\section{Stage One: 1900-1959}

The beginning of TQM can be traced back to the 1920 s when Walter Shewhart developed the Statistical Process Control (SPC) system. This system was 
designed to measure variation in the processes of production in order to improve productivity and provide consistency in the process. Later, Deming improved on Shewhart's SPC techniques and implemented his improved methods in combination with what was called the Shewhart "PLAN-DO-CHECK-ACT "cycle as part of a TQM program in Japanese factories. The Shewhart cycle is focused on the continuous improvement of a process through a cycle of assessment, planning, implementation, and evaluation. By using this cycle as a guide, Carr maintains that a higher level of performance can be achieved and the final result will be an improved process (Carr, 1990). Hence is the term continuous quality improvement.

During World War II, the SPC was accepted and used by the American military. In fact, the Department of Defense hired Deming, Shewhart's student to teach SPC to the workers in the defense industry. Early in their careers, Deming and Juran, another one of the TQM "greats", were guided by a visionary group of mentors at Western Electric Laboratories (later AT\&T Bell Laboratories) who taught them to seek a deeper understanding of the general sources of problems in quality. Both discovered that problems, and therefore opportunities to improve quality, were usually built into the complex production processes they studied, and that furthermore, defects in quality were only rarely due to a lack of will, skill, or benign intention on the part of the people involved. Moreover, they learned that even when people were at the root of problems or defects, the problem was generally not due to lack of motivation or effort, but to poor job design, failure of leadership, or unclear purpose. In those early stages, TQM was examined closely by organizational "gurus" who pioneered a movement that has been building momentum ever since (Carr, 1990; Berwick, 1989). 


\section{Stage Two: 1960-1979}

Following World War II, and from 1960 to 1979, American companies lost interest in TQM and essentially stopped using the main principles of TQM as taught by Deming and others. Quality assurance departments were formed and assigned the responsibility of ensuring the quality of products and services. (Carr, 1990). The climate of continuous quality improvement involving all members of the organization was abandoned to the notion of a select few individuals who monitored quality. While this was occurring in US industry, in Japan the US occupation forces used SPC methods and TQM principles to help the Japanese to reconstruct their industry and hence their economy. Moreover, the US government also sent Deming to Japan to help the Japanese in their efforts to recover. Through lecturing and consulting, Deming educated Japanese industrial leaders on how to implement SPC methods. His methods were so successful that he became a hero in Japan. Even today, the highest award for excellence in industry is called the Deming Award. As Carr puts it , it is ironic, that US companies neither listened to Deming nor adopted his ideas as early and as readily as did the Japanese (Carr, 1990).

Not only did the Japanese take Deming's and Juran's ideas seriously, they also expanded on these ideas and provided new insights into their organizations. For example, the customer concept was expanded to included the internal customer, those in the organization "who depend on the output of others." (Carr, 1990, p.23). The Japanese also used ideas from the human behavior school, such as McGregors Theory $Y$, and formed quality circles. In general, this period was also distinguished by the continual improvement and popularity of Japanese products. The Japanese were able to reverse the dominant prewar stereotype that their products were cheap and of low quality. In fact, in the late seventies and early eighties, the Japanese auto 
industry and the electronic industry as well were able to capture wider market shares in both the US and international markets. By institutionalizing TQM and SPC methods in their daily activities Japanese companies were transformed and have been able to reach higher levels of performance.

\section{Stage Three: 1980s}

This stage witnessed a new interest in TQM and a rush toward implementing the methods and principles in American industry. Faced with decreasing market shares and a lack of ability to compete, American industry tried to learn from the Japanese example, and Deming ideas have been taken more seriously. Interest in Deming's theory and practice was heightened after an NBC televised interview with Deming, entitled, "If Japan can ... Why cannot we?" He became an "overnight" star and the dominant figure in TQM and a much sought after consultant. (Locken, 1992).

In the mid $80 \mathrm{~s}$, there was what Carr identifies as a "false quality revolution", one that employed a great deal of propaganda and an overabundance of slogans. Carr maintains that most of these were "lip service programs" that have failed because they did not recognize the basic nature of TQM as an organizational cultural change that requires total transformation and departure from the traditional ways of doing business. (Carr, 1990).

\section{Stage Four: The 1990s}

This stage involves the renaissance of true TQM. Realizing that quick fixes and short term programs had not delivered the desired results, American companies have concluded that they and each member of their organization must understand the true meaning of TQM and its requirements. When Deming talks about a "profound 
change", he is talking about a holistic system-wide approach that requires total commitment and involves everybody in the organization. (Deming 1986).

Investing in a TQM program means commitment on the part of top leadership and a long term perspective on the part of the organization as a whole. Quick fixes will only result in demoralizing employees. Total Quality Management is "the thing" in the 90 s. Faced with shrinking resources and the need for reducing waste and saving resources, organizations are turning to TQM for some working solutions. One might safely conclude that the 90 s will be the quality era.

As discussed above TQM has evolved through history as a strategy for improving organizations and their processes. One of the major contributors to TQM theory and applications is Dr. Deming. The following section presents his major ideas, as outlined in what he calls the fourteen points or principles.

\section{Deming's ideas on TOM/COI}

In his book "Out of the Crisis," Deming introduced the "Chain Reaction" model. It consists of the following cycle, (Deming, 1986, p.3). Improve quality $\Rightarrow$ Costs decrease because of less rework, fewer mistakes, fewer delays, and snags; better use of machine time and materials $\Rightarrow$ productivity improves $\Rightarrow$ capture the market with better quality and lower prices $\Rightarrow$ stay in business $\Rightarrow$ More jobs will be provided $=>$ Improve Quality

A TQM/CQI approach, according to Deming, starts with establishing a process model such as the following figure:

\section{SUPPLIER $\Longrightarrow$ PROCESS $\Longrightarrow$ CUSTOMER}

Input Task Output


This model assumes an exchangeable interactive role played by the various participants in the organizational setting. To define and identify the process we need to identify the customer to whom this service is targeted. Organizational participants are suppliers as well as customers, at the same time. Production (Input) is an interactive process between the organization and its customers (Output). The organization provides the product/service and the consumers provide the financial revenues. (Deming, 1986).

According to Deming (1986) quality does not come from inspection but from improvement of the process. In a hospital setting, for example, continuous improvement occurs through the design and the redesign of patient care systems and by inspecting final products of health care rather than blaming individual workers within the health care organization. In other words the processes of production and delivery need to be improved in order to achieve an improved outcome. Blaming the employees for all the quality failure does not go well with what Deming teaches. The following section will present Deming's ideas on TQM, as summarized in his 14 point.

\section{Deming's 14 Points (Principles)}

In his book Out of the Crisis, Deming outlines some critical guidelines for organizations who adopt TQM strategies. Deming strives to incorporate the systematic approach into the implementation of TQM. In addition Deming calls for more respect for the worker and calls upon the management to revolutionize its way of thinking about the employees. Long term perspective and the need to place the customer needs first are ground rules throughout Deming's writings. Combined with the writings and practices of Juran (1964) and Crosby (1979), who stressed the 
human relation model in TQM, Deming's teachings have far reaching effects on organization leaders and change agents of today's business world. Following is a brief presentation of his 14 points on Total Quality Management. It should be mentioned here that these 14 points serve as a guiding framework and reference to almost all $T Q M$ professionals and those who are active in TQM/CQI field, including the writer of this document .

The first point that Deming stresses is to "Create a constancy of purpose for the improvement of product and service" (Deming, 1986, p. 3). Dr. Deming suggests a radical new definition of a company's role. Instead of being in the market only to make money, it should be to stay in business and provide jobs through innovation, research, constant improvement, and maintenance (Walton, 1990, pp. 1718). Management should focus on the long term goals as well as the short term goals. They should "believe that they will be in business for a long time, and thus develop a business plan that is based on long term thinking." (Deming, 1986, pp. 3-5).

The second point that Deming stresses is to "Adopt the new philosophy". Successful results will be derived from a firm belief in the theoretical foundations of TQM as well as its practical implementation. TQM should signal an organizational transformation in the ways businesses is conducted in the organization. New values regarding quality should be adopted along with an intolerance to mistakes and errors, in other words TQM should bring a cultural change into the organization. (Oakland, 1993, p.444).

The third point is a call for managers and leaders to "Cease dependence on mass inspection." Look for the root and actual causes of problems to correct them, in order for the right remedial actions to be taken. Quality comes not from inspection but from improvement of the process (Walton, 1990, p.17). Continuous improvement 
occurs through the design and the redesign of systems and by inspecting final products rather than blaming individual workers within the organization (Berwick, 1989). Employees should be encouraged to take initiative and try to improve their work instead of being enslaved with blame and punishment.

In his fourth point Deming calls for an "End to the practice of awarding business on the price tag alone. Cultivate long-term supplier relationships based on loyalty and trust. Establishing such a relationship requires that a supplier consistently meet the needs of the organization and be willing to continually improve. (1986, pp. 23-24). Suppliers could be external and/or internal. In a hospital setting, for example, "Labor" is the hospital's largest input. Cultivating loyalty and trust and providing a secure environment for physicians and employees will result in long-term relationships between the hospital and its employees and medical staff. (Berwick, 1989).

In its quest to reach excellence an organization has to, according to Deming, "Improve constantly and forever the system of production and service." Improvement is not a one-time effort. Management is obligated to continually look for ways to reduce waste and improve quality. Quality must be built in the "design stage", (1986, p.49). Teamwork becomes essential to achieve the stated goals. The team approach will allow each individual to participate in the decision making process, facilitate the performance of the group or unit, and enhance the overall commitment within the organization. (Walton, 1990).

TQM is an approach that relies, to a great extent, on education and training. Deming calls on organizations to "Institute Training and more training." Education and training are essential to continuous improvement and establishing constancy of purpose. Too often workers have learned their job from another worker who was 
never trained properly. They are forced to follow unintelligible instructions (1988, 52-54). They can't do their job because no one showed them how to do it. Management should encourage and provide for continuing education to assure better performance based on better knowledge of the job. Training for a job must "teach the customer's need" Deming says. (Deming, 1986, p.53).

The seventh point is a critical one. Deming demands that organizations must "Institute leadership" (1986, p.54) if they want to achieve tangible results with TQM. The job of the supervisor is not to tell people what to do, nor to punish them. His/her job is to lead. Leading consists of helping people do a better job and of learning by objective methods who is in need of individual help (Berwick, 1989). Management should take the role of the leadership, and should remove the barriers that inhibit the employees' commitment to the organization, and their pride in their work.

"Drive out fear" is another point stressed by Deming. Fear of failure, embarrassment, blame, or retaliation inhibits our ability to capitalize on opportunity and prevent people from asking questions and/or suggesting new ideas. To assure better quality and productivity, it is necessary that people feel secure. (1986 pp. 5861).

The ninth point, according to Deming, is to "break down barriers between departments." Top management's role in fostering teamwork means dismantling systems that destroy teamwork. Often a company's departments or units are competing with each other or have goals that conflict. They do not work as a team so they can solve or foresee problems. Worse, one department's goals may cause trouble for another. (Walton, 1990). 
As mentioned previously, in the third stage of the evolution of TQM (mid eighties), the false revolution in TQM relied on empty slogans that did nothing but demoralize the work force (Carr, 1990, p. 25). Deming has called for "an elimination of slogans, exhortations, and targets for the work force" (1986, p. 65). These never helped anybody do a good job. Let workers come up with their own slogans (Walton, 1990). As well, management should not generate frustration among employees by adopting slogans that require the impossible, such as "zero defects" .. etc.

"Eliminate Numerical Quotas". Quotas take into consideration numbers, not quality or method (Walton, 1990, p.18). They are usually a guarantee of inefficiency and high cost. A person, to hold a job, will meet quotas at any cost, without any regard to damage to his company.

In his twelfth point Deming urges leaders and managers to "remove barriers to pride of workmanship" (Deming, 1986, p.70). People are eager to do a good job and they are distressed when they cannot. Too often misguided supervisors, faulty equipment and defective materials stand in their way of good performance, (Walton, 1990, p. 18). These barriers should be removed. Pride in workmanship and a sense of ownership of improvement efforts will foster the employee's sense of commitment to TQM.

Once again Deming (1986, pp. 86-87) stresses the value of education by calling on leaders and organizations to "institute a vigorous program of education and retraining." Both management and the work force should be educated in the new methods, including teamwork and statistical techniques.

Finally, organizations need to "Take action to accomplish the transformation." They need to design an action plan that takes in to consideration the 
major foundations of CQI and what have been outlined above. (Deming, 1986, p. 87). It will require a special top management team with a plan of action to carry out the quality mission. Workers cannot do it on their own nor can the manager. A critical mass of people in the company must understand the Fourteen Points.

In conclusion, it could be realized that Deming has focused on integrating the intermal and external customers of the organization and has called for a more open organizational environment. Pindur, (1993) affirms that Deming's teachings stress the use of "statistical tools, rational decision making, and elimination of inspection to achieve quality." The following sections will continue exploring some of the critical TQM concepts.

\section{Other Principles}

\section{The 85-15 rule}

The $85-15$ rule holds that $85 \%$ of what goes wrong is with the system, and only $15 \%$ with the individual person or thing. In this connection, we do well to remember that any group of people not all, nor even the majority, can be above average. In fact, exactly half will be below average (Walton, 1990). This rule helps us understand things better instead of pointing the accusation finger at the employees. In fact management is seen as responsible system design and administration, and by applying this rule management holds $85 \%$ of the responsibility for both success or failure. (Carr, 1990). 
Know Thy Customer

The quality effort requires a new way of thinking about the customer. In quality minded organizations, the word "customer" (Walton, 1990 ) describes more than a relationship in which money merely changes hands. It describes the exchange of services as well. There are two kinds of customers: external as well as internal. Walton (1990) defines the external customers as those who are more likely to be the end users, who use or consume the product or service. The internal customers are those employees in the organization who furnish products and/or services to one another during the production process (Carr, 1990).

\section{The Plan-Do-Check-Act Cycle (P.D.C.A.)}

The was introduced by Shewhart while he was at Bell Labs in the 1920s. P-DC-A. is aimed at "improving how the work is done", according to Carr (1990, p.21). It employs the scientific methods and the Statistical Process Control methodologies in order to reach the previous goal. Walton (1990) states four stages that comprise the P-D-C-A cycle. The first step is to PLAN. In this step a company plans a change, after a comprehensive survey of what is needed to be improved. Then it IMPLEMENTS it. The third step is when it CHECKS/EVALUATES the results. Finally the organization ACTS on the results by Standardizing the change outcomes and/or begins another cycle of improvement. In the following section we will focus on some of the key principles in TQM. 


\section{Key Concepts in TOM/COI}

\section{Six Principles of TQM/CQI}

The first principle is a Customer Focus. As mentioned previously, one of the major requirements and principles guiding TQM is its focus on commitment to meeting customers' needs. Japlonski distinguishes between two kinds of customers: the external customer "with a big C" and the internal customer "with the small c" (1992). External customers are those who receive and buy the company's products or who are affected by the quality of those products; whereas internal customers are participants in the organization who are affected by the company's output. The final goal for any TQM effort should be to meet the needs of both the internal and external customer. TQM stresses the need to gather information, through a variety of sources, about what the customer requires and expects, through all phases of the quality improvement process. For example, TQM employs Quality Function Deployment (QFD) strategies in order to design the product or service based on what the customer wants (Oakland). These strategies are aimed at communicating the customer's needs to the supplier in order to design the product or service that will meet those customers' needs. In other words, QFD is designed to help "... align the goals of a stream of related processes with the expectations of both, external and internal customers." (Carr, 1990, pp. 88-90). By forming QFD teams and utilizing special kind of matrix tables, called the House of quality tables, an organization will be able to answer questions about who is our customer? What does the customer need? How can those needs be met. (Oakland, 1993).

The second principle as presented by Japloski, is a focus on the process as well as the results. In other words, TQM stresses the need to be aware of how things are being done rather than just looking at what has been done. Charting the process 
enables us to better understand and more easily identify sources of conflict in the process itself. TQM implies a systematic approach toward understanding processes and analyzing the various steps that comprise a process. (Japloski, 1992).

TQM/CQI also uses a variety of statistical techniques and strategies to analyze organizational processes. Other strategies, such as Just in Time (JIT), are also employed to ensure that the right resources are used for the right products. JT management as defined by Oakland, is " a series of operating concepts that allow the systematic identification of problems, and tools for correcting them." JT is aimed at reducing waste and saving rescurces by producing or operating in accordance with the customer requirements (Oakland, 1993). By doing so, TQM ensures that processes are flowing in the right direction, and that any variation in the system is identified and corrected as early as possible. This reduces rework and maintains higher quality levels.

As discussed earlier, TQM focuses on prevention rather than inspection, which is the third principle of TQM. Thus, TQM signals a critical departure from traditional management models that depend on inspecting and correcting errors after the fact. TQM takes a proactive approach in preventing errors from occurring. This is achieved through a rigorous process of eliminating errors by "improving the processes that make products and services to the point they are defect free." (Carr, 1990). By charting the processes and by implementing Statistical Process Control techniques, TQM ensures this proactive preventive philosophy is maintained.

The expertise of the work force is mobilized in TQM. This is the fourth principle. Teamwork and total participation of all those who are involved in the process is an essential requirement for TQM to succeed. Deming and Juran declare that "the best one to make a decision about a task are those who are involved in the 
it." (Deming, 1986, p. 19). In other words workers' views and expertise should be considered as a key ingredient to ensure the improvement of the process. Employees need to feel they are part of "a team- a winning team", as Jablonski (1992) puts it.

The fifth principle that distinguishes TQM from traditional management is that $\mathrm{TQM} / \mathrm{CQI}$ relies on fact based decision making processes rather than assumptions and gut feelings. (Carr, 1990). TQM calls for institutionalizing the scientific approach into all of its components and various phases. In this view TQM calls for developing a systematic approach to manage the implementation of processes.

Finally, TQM views the quest for quality as a continuous improvement process. Since its early beginnings TQM introduced the Plan-Do-Check-Act cycle, designed by Shewhart. Deming views quality improvement as an ongoing process that will never end. As long as the organization is in the market it should strive for improving the quality of its products and services. In his book "Closing the Quality Gap", Hiam states that " those who have TQM programs generally feel their work is only half-way done." In other words the quality improvement effort never ends since the cycle is renewed continuously. (Hiam, 1992). Those organizations using the continuous improvement model are always looking for opportunities for improvement and recognize the necessity to keep channels of communication with their external and internal customers open. They allow feedback and respond effectively to what is being communicated to them.

In summary, TQM is different from traditional approaches to quality improvement because of its focus on the customer, its reliance on scientific and statistical methods, and its emphasis on improvement as a continuous process.. In the following section, various phases for implementing TQM will be presented followed by a summary of the major ideas of Deming.. 


\section{Implementation phases of TOM}

In his book "Implementing TQM", Jablonski identifies the following five stages through which a TQM effort might go (1991): 1. preparation, 2. planning, 3. assessment, 4. implementation, and 5. diversification. These are similar to those outlined by Carr (1990): assessment, planning, implementation and institutionalization. Each of these stages will be discussed briefly in the following section.

Preparation is identified as the first phase of the TQM process. Jablonski calls this phase "phase 0 " because it "...actually precedes a building process involving the organization's key executives with the aid of a professional facilitator." In this stage, the opportunities for quality improvement are identified and top leadership develops the organization's quality vision statement, sets goals and draft quality policy. Top leadership and management commitment to TQM is an essential requirement for this stage. A major characteristic of this stage is an interest in quality among organizational participants and the establishing of educational programs about TQM. This stage is complete when the "commitment of the necessary resources to plan the implementation of TQM." have been provided (Jablonski ,1991).

During the second stage, called planning, a "...structured program of improvement projects and changes leading to TQM implementation is developed." (Carr, 1990, p. 207). Planning for quality is the top leadership's number one responsibility. However, information must be gathered from all organizational levels and from all those involved in the process including internal and external customers.

At this point, the Quality council should be formed. Among its responsibilities are: development of an implementation plan, commitment of needed resources, and 
initiation of recommended changes. Also during this stage, leadership decides on the vital issues for improvement, drafts strategies and plan of improvement to get to where they envision they want the organization to be. (Carr, 1991).

The third stage is assessment, during which information is shared among the various participants of the quality improvement innovation. It includes "surveys, evaluations, questionnaires, and interviews throughout the organization, and at all levels." (Jablonski, 1991, p. 39). This stage could be considered as the backbone of the endeavor that supports all of the other phases. Thus, it is vital that accurate information about the organization and its posture towards change is obtained. Essentially, the organization is assessing its state of readiness to implement TQM plans and what would be needed to secure everyone's commitment and to overcome any hindering forces.

The fourth phase is the implementation of TQM plans. This stage "introduces quality practices and their support systems" (Carr, 1990). Various process improvement teams (PITs) are formed and charged with the responsibility of evaluating and improving the processes in the organization. Process improvement teams (PITs) might introduce some recommendation to the quality council about what would be needed to improve processes. These recommendations are included in the implementation strategy. Organizations are encouraged to initiate pilot projects and short term TQM initiatives in order to gain information about the strategic plan and win you support among the organization participants. (Carr, 1990).

The final phase is diversification. After accomplishing all the previous phases the organization now strives to maintain and develop an " internal capacity to perpetuate TQM." (Carr, 1990, p. 207). In this stage TQM should be transferred to other parts of the organization. Aided by its acquired experience and the knowledge 
base developed through the implementation of TQM, the organization should institutionalize and carry the TQM innovation efforts throughout its various departments, subdivisions, or any of those levels involved in the production and/or the delivery of products and services. (Jablonski, 1991). The next section will introduce some tools used in variety of TQM efforts.

\section{Tools in TOM}

For organizations involved in the quality revolution, this continuous improvement has two components, according to Brassard (1988). The first one is the Philosophy of TQM, as described in the writings of TQM gurus such as Deming, Juran, Crosby, and others. In the Literature Review section of this study a coverage of TQM's principles has been provided. The second component of the quality improvement process is Problem- Solving and Graphical techniques that could be used in various stages of the problem-solving process. The following section will introduce some of these tools used by TQM professionals and OD specialists in their quest for quality improvement. The purpose of this section is to provide the reader with an idea about the nature of these tools and when are they used and why? Since some of these tools will be mentioned in the following parts of this study, especially those which describe the quality stories of some organizations, it will be beneficial to acquaint the reader with them and state the purpose behind using them. In her book, Deming Management at Work, Walton (1990) identifies some of the more widely used tools in TQM innovation efforts. 


\section{Cause and effect tables}

Cause and effect diagrams or fishbone diagrams, are used to explore, identify, and display the possible causes of a specific problem or condition. They are used to visually represent the relationship between an "effect" and the various "causes" influencing it.

\section{Flow Charts}

Flow charts are visual representation of the sequence of steps that comprise a process. Flow charts are used to map the process and help those involved in improving it to gain a better understanding of the various components of a particular process. Moreover, by charting the process we will be able to "uncover loop holes" that might be potential sources of trouble. Flow charts help identify unnecessary steps, rework loops, and unseen steps in the process. Therefore, flow charting is one of the important tools used by TQM to assess a process and analyze in order to improve it.

\section{Pareto Charts}

Pareto charts are used to prioritize among a set of causes of a particular problem or effect. They are used after data collection to "rank causes so that priorities can be assigned." Pareto charts are simply bar graphs that start with the highest cause/priority as its first bar and then moves to the lesser cause as the second one, and so forth. 


\section{Run (trend) Charts}

These are used to " show the results of a process plotted over a period of time." Run charts allow us to observe a process over a period of time and identify any possible trends that might be of importance to the quality improvement team. By constructing a run chart of a process we will be able to examine any variation in the sequence of the steps of a process, and thus try to correct them.

\section{Fistograms}

Histograms are similar to Pareto charts in terms of being bar graphs.

However, histograms are used to "display the distribution of data, by bar graphing the number of units in each category." (Brassard, 1988, 36). They are used to measure "the frequency with which something occurs." (Walton, 1990, p. 22).

\section{Scatter Diagram}

Scatter diagrams are used to display " what happens to one variable when another variable changes in order to test a theory that two variables are related." (Brassarsd, 1988, p. 44). Walton (1990) indicates that scatter diagrams are used to "illustrate the relationship between two variables." In correlation analysis for example scatter diagrams are used to illustrate the relationship between two variables, and to indicate what type of correlation exits between them. By drawing these diagrams quality improvement teams can visually represent relationships among various forces.

\section{Control Charts}

Control charts are used when we need to " discover how much variability is in a process and how much is due to unique events/individual actions in order to 
determine whether a process is in statistical control." (Brassard, 1988, p.50). In other words Control charts are Run Charts with "statistically determined upper and lower limits." (Walton, 1990, p. 22). Control charts help us observe the variation in the process, and as long as the variation is contained within the upper and lower limits the process is said to be "in statistical control" and the system is consistent. Variation between the two control limits are attributed to "common cause" (the day in day out activities) and the goal is to narrow the range between the two limits, in other words to reduce the amount of variation in the process by eliminating the common causes. Outlays beyond the control limits are attributed to "unique causes" (people errors, unplanned events, .. etc.) which require intervention and investigation. Once these unique causes are eliminated the system is back to be in "statistical control" and Control charts can be used again as a monitoring tool (Brassard, 1988). Control Charts are the comerstone of the Statistical Process Control (SPC) highly stressed by Deming and widely implemented in TQM improvement processes, especially in the industrial organizations.

\section{Force Field Analysis}

Change can be viewed as a dynamic process. It suggests a "movement" from point A to point $B$ or from condition $X$ to $Y$. Change is a movement that derives its energy from "the struggle between forces that are seeking to upset the status quo." (Brassard, 1988, 72). This approach is called force field analysis and it was developed by Kurt Lewin. Lewin sees change as a dynamic process between "driving forces" that push towards the change, but these forces are challenged by "restraining forces" that push against the change. When there is no change, the opposing forces are equal or stronger than the driving forces. To bring about change the driving forces should be 
strengthened, and/or the restraining forces should be weakened. Force field analysis encourages creative thinking, and according to Brassard, "forces people to think about the facets of a desired change." It also provides the process improvement team with a tool to identify the various factors that might help or hinder the change effort. In fact, force field analysis provides a "starting point" or strategic tool to identify key elements that might influence the TQM innovation effort."

TQM employs a variety of statistical tools to help analyze the process and design a strategic plan for change. These tools could be used by Process Improvement Teams (PITs) to help chart the road map to change-improved quality and to help them examine organizational processes to determine what could be changed and how to get there.

\section{Obstacles To an Effective TQM/COI Implementation}

Deming outlined some justifications and disbelieves that might hinder the success of a TQM/CQI effort. The first of these obstacles is the "hope for instant pudding", the idea that "improvement of quality and productivity is accomplished suddenly by affirmation of faith" (Walton, 1990). TQM requires hard work and constant effort to create a comprehensive cultural change. Relying on the hope that things will take care of themselves is foolish, at its best.

Deming (1986) cautions against "the supposition that solving problems, automation, gadgets and new machinery will transform the industry." Many organizations, mistakenly, believe that the introduction of more new and complex technology will bring about the desired changes and improves the system. This also is a false assumption. The processes will only improve if they are well understood by 
those who do them and technology will not by itself create the transformation; it is the education of the work force that will do that, according to Deming (1986).

"Search for examples," which companies undertake to find a ready-made recipe they can follow when they must instead map their own route to quality (Walton, 1990). TQM assumes that change comes from within. Viewing the experience of other organizations should assess the organization in charting its quality plans, but NOT solve its problems or get it transformed. As discussed earlier successful implementation of TQM requires going through a number of systematic phases (Jablonski, 1991). Each organization is unique, with a unique environment, leadership, and organizational forces. Blind borrowing and implementation of TQM experiences of other organizations' is also a dangerous mistake.

This obstacle might be the opposite of the previous point. Some managers might say: "Our problems are different", (Deming, 1986 ; Walton, 1990). This pretest is raised by managers who want to avoid dealing with quality issues. TQM includes methods and strategies that could be utilized by any organization to improve its processes. Another justification that managers and leaders might state to avoid quality is "our quality department takes care of all quality control issues." Though Quality Assurance is critical, TQM is a more comprehensive approach that requires the involvement of the whole organization (Oakland, 1993). No one single department could produce the organizational transformation to bring about a valid and a comprehensive change.

One of the excuses that I personally have heard is "We installed quality control." (Deming, 1986). Some leaders might think that what they have been doing all along is TQM, therefore they do not need to invest in it. Another way this obstacle could be damaging is when organizations assume that once they implement a TQM 
project they have arrived and no more work is needed. As Deming (1986) argues this assumption is wrong since TQM should be perceived as an ongoing effort, especially reflected through the P-D-C-A cycle.

Finally, some managers who are fearful of change might claim that: "It is only necessary to meet specifications ... everything is right within the specifications and wrong outside." This kind of logic, according to Deming "does not correspond to this world," (Deming 1986 ; Walton, 1990, p. 19). This perception is very narrow and it reflects a lack of understanding of the open system model. understanding the external environment in which an organization exist is crucial for its survival. Ignoring the outside world does not make problems disappear. This would be like burying one's head in the sand to avoid being seen. In conclusion, these obstacles should be dealt with as early as possible or better yet should be completely avoided, where is possible.

\section{Challenges and Limitations for TOM}

So far TQM has received a great deal of praise. It has been seen by many as a paradigm shift and as an organizational revolution. Many organizations, regardless of their type or ownership, are at least planning for adopting TQM practices sometime down the road if they have not already started the improvement program.

Nevertheless, some of TQM's major tenets could be a source of frustration and conflict for those organizations that fail to grasp the deeper meaning behind them. In the following section we will offer a brief summary of some challenges that TQM might pose for certain organizations, what causes TQM efforts to fail, and finally we will present some critics of TQM.

McLaughlin and Kidwell (1993) comment on the challenges facing the public manager who is exposed to TQM. They state that "adopting the principles of TQM is 
not easy for a manager exposed for years to the autocratic management methods inherent in any bureaucracy." TQM calls for a cultural transformation in the way the organization is managed and thus it signals a departure from the traditional ways of management. Moreover, TQM calls for empowering the employee, and this requires management to "relinquish vital elements of control." This "loss" of power might create a sense of frustration and resistance among managers.

TQM has a long term perspective. This might create problems for organizations who are used to short-term returns and "short-term management singular decisions." To deal with this challenge TQM should implement pilot projects and work on publicizing successful stories in order to build commitment to the quality improvement movement.

TQM calls for making information and knowledge available to all organizational participants in order to improve the processes. This might conflict with the interests of management or any other group who use this information as a source of power and control. TQM requires no hidden agenda and stresses the need to work as a team and calls for recognizing the achievements as "team accomplishments" rather that pointing out particular individuals, mostly managers, to be recognized as champions. McLaughlin indicates that such a view might conflict with the "ego of a manager who is accustomed to receiving the accolades for his staffs accomplishments."

Moreover, TQM might be seen as a threat to the hierarchical structure of certain organizations, especially the bureaucratic ones. "The term 'rank has its privileges' will be frequently challenged in a true TQM environment", McLaughlin (1993, p. 23) states. Managers who have been used to power and control did not feel, in many cases, the need to justify their decisions to their staff. Under TQM, however, 
they are held accountable and even required to justify their actions to the rest of the "team" who are seen now as partners rather than just "subordinates."

Traditional management was used to chart the organizational agenda and strategic plan. TQM, however, requires this process to become an organization-wide effort. The staff should be involved in the various stages of policy design and implementation and in decisions regarding "who, what, when, where, why and how decisions." (McLaughlin 1993, p.23). In decentralizing the decision making processes TQM awards the employee more power to shape the organization's destiny. That might be faced with resistance from middle and top management, who might feel threatened.

Another critique of TQM comes from Hearer $(1993,)^{1}$ :

Total quality management (TQM) programs produce[d] improvements in productivity, competitiveness, quality or financial return in only $1 / 5$ to $1 / 3$ of the companies who have tried it. ... Bureaucracy and specialized experts play a large role in implementing TQM systems. Finally, TQM adheres to low standards and is not geared to outside results but to internal management campaigns. (p.33)

The above view challenges TQM's ability to generate a cultural change because it lacks an "external focus" or because it might be approached as a quick fix.

1. Ten reasons why TOM doesn't work (total quality management) by Oren Harari v82 Management Review Jan '93 p33(6) 
Bureaucracy and rigid organizational hierarchy might kill a TQM effort. Shaffer

$(1992)^{2}$ explains why some of these quality efforts fail:

A large number of quality initiatives fail because corporate leaders treat them as programs. Companies that suffer from 'program-itis' can end up 'bureaucratizing' quality efforts. They appoint 'quality directors' to whom everyone else in the organization leaves the job of pursuing quality. They create quality departments that produce a wide variety of disconnected programs and activities. These firms can easily be identified by their gimmicky campaigns, catchy slogans and an assortment of meaningless paraphernalia. All of these usually have little to do with what quality management is really all about: giving the customers what they want. In contrast, companies that provide world-class quality consider quality as a mind-set, something that is deeply ingrained in their corporate culture. Their every decision, program and project is dictated by what the customer wants. (p. 11 ).

The above indicates that TQM fails not because it is not capable of producing success but because of the lack of total commitment on the side of top leadership and the lack of involvement on the side of employees. TQM should not be just lip service; it should be a total system involvement as stressed by Deming. Quality Improvement cannot be delegated to a single individual/department; on the contrary, it is a team effort. Without listening to the voice of the customer a TQM effort is bound to fail, especially if organizations believe that "we know what our customers need" without gathering data about that. Moreover, believing that "we exist to produce profits [only] is a narrow focus that contradicts Deming's affirmation that a company's goal

2. Quality where it doesn't comt. (Commentary) by James C. Shaffer il v29 Across the Board Od. '92,p.11(3) 
should be "to stay in business and provide jobs." This narrow focus on profit only might hinder a successful quality improvement outcome. (Clemmer, 1992).

In addition, TQM is criticized as a cause for alienating middle management in the organization. Middle managers whose power is threatened might meet TQM with great resistance. Martin $(1990)^{3}$ explains why middle managers might oppose TQM:

Total quality efforts often fail because they are blocked by middle management. Contrary to common belief, it is not because middle managers are resistant to change or are unwilling to relinquish control. A more reasonable explanation is that most total quality programs fail to define the role of middle managers in a quality-driven organization. Middle managers are at a loss as to what they should be doing in a workplace full of empowered work teams. Their problem also stems from the fact that they do not have any authority to empower their subordinates. The role of middle managers clearly must be redefined if total quality programs are to succeed. They themselves must be empowered to determine the direction of their respective areas, given the resources to achieve area goals, and authorized to empower other employees. (p. 90).

The previous points stress the fact that TQM should not be perceived as a magic potion that will cure all the ills of an organization. TQM should be perceived rather as a neutral tool that will produce success if it is used correctly, and will result in failure if it is misused. Milier (1992) ${ }^{4}$, captures this point very effectively:

3. The missing piece of the total quality puzzle. (Viewpoint) by Paula K. Martin 229 Training Sept. '92 p.90(1)

4. Total Quality Management by Cyndee Miller v26 Marketing News Nov. $9^{\prime} 92$ p1(2) 
Management consultants Emst and Young have issued a report that contests the prevailing viewpoint that Total Quality Management (TQM) is uniformly beneficial for all companies that embrace it as a quality improvement philosophy. According to the report, TQM programs only lead to improved organizational performance if they are carefully tailored to a company's performance level prior to the institution of a TQM initiative. The report recommends that companies which are only beginning to embrace the quality improvement credo first focus their attention on such basics as increasing employee training at all levels, improving customer service and cutting cycle time. The report goes on to suggest that only after the basics of quality improvement are established should more complex strategies such as benchmarking and employee empowerment be implemented.

(p. 1)

Zemke (1992, p. 8) ${ }^{5}$, brings another set of limitations he sees in TQM:

"... TQM lacks focus ... dividing thousands of employees into small groups and allowing each group to address local quality issues in the hope that the company will achieve a major breakthrough in quality plays better in theory than in practice." TQM is also criticized for its focus on form rather than function, as well as for its promotion of quality awareness instead of the acquisition of skills for achieving quality. TQM detractors dismiss the concept as nothing but a passing fad.

5 TQM: fatally flawed or simply unfocused? (Total Quality Management) (Editors' Notebook) (Editorial) by Ron Zemke v29 Training Oct. '92 p8(1) 


\section{Conclusion}

For many, TQM is seen as a paradigm shift, a revolution, a force for change. But for many, also, it is seen as too ambitious, threatening, and even dangerous. TQM, as any other approach, should be looked at without exaggeration and without false hope. The previous pages outlined the various limitations attributed to TQM as well as the various forces that might cause a TQM initiative to fail. In examining the three organizations under study this research watches for the presence of both the success factor, i.e. the adoption of Deming's ideas or the failure factors, i.e. the presence of the above limitations and causes of failure. This is done to help the reader gain useful lessons about TQM. 


\title{
CHAPTER III
}

\section{REVIEW OF GENERAL IMPLEMENTATION RESEARCH}

\author{
When I was governor of Arkansas. Our state was \\ the first in the nation to institute a government-wide \\ TQM program. And I can tell you, it works. \\ President Clinton, March, 1993
}

\section{Introduction}

Total quality management has become one of the most important goals of American corporations. Schneider (1992, p. 20) states that 'the pursuit of quality has become an imperative for companies in search of competitive advantage. According to Barrier (1992, p.25), small businesses use the techniques of Total Quality Management (TQM) "to survive; [while] larger firms use TQM techniques to recapture the qualities that made them successful." This section will discuss the implementation of TQM. It will first present some implementation models and approaches, then it will discuss the implementation of TQM in the private sector, public sector, and finally in the field of health care. By exploring the implementation of TQM the goal is to help the reader integrate the various theoretical concepts, discussed earlier, with the practical implementation of TQM. This will allow him/her to attain a working knowledge of TQM. Such a knowledge will prepare him/her to 
take advantage of the findings of our research and the lessons derived from conducting the study.

\section{Implementation Approaches and Models of TOM}

An approach could be defined as a manner or method of doing something. Quinn $(1990$, p.3) defines a model as " a representation of more complex reality .... In the social world a model often represents a set of assumptions for, or a general way of thinking about or seeing, some phenomenon." This section will explore some approaches to the implementation of TQM and will also discuss some models of $\mathrm{TQM}$, in the private as well as the public sector, as presented by a number of writers. It should be noted that each model and/or approach has its own theoretical grounds and virtues. In selecting among these competing models we suggest that the reader chooses those suitable to his/her organization. As we will see later the organizations involved in our study have varied in their adoption of TQM approaches. Examining these models and approaches will provide the first step in selecting the right one for the interested organization.

\section{Approaches to Implementing TOM}

In an earlier part of this study a presentation of the various stages a TQM effort goes through was introduced. These are preparation, planning, assessment, implementation, diversification and institutionalization. Hunt (1992, p. 74) describes the Department of Defense's TQM Master Plan, which he calls a TQM Model. This plan consists of 7 steps: Establish TQM environment and culture through maintaining long term commitment and vision for quality. Then Define the mission of each component of the organization. The third step is to identify improvement 
opportunities, goals and priorities. The fourth step is to establish improvement projects and action plans. Then you implement these projects using the improvement methodologies. Step six is to evaluate performance and outcomes; and the final step is to review and recycle. But what approaches do organizations take in going about implementing TQM?

Carr (1993, pp. 206-210) identifies a number of approaches for implementing TQM. It should be noted that some of these approaches might produce success while others might result in failure. Nevertheless, they are used to describe what approach does a particular organization follow in its quest for quality improvement. According to Carr (1993) there are five approaches that could be identified. The first is what he calls "Slow Cascading Approach." In this approach top management and leadership learn and use TQM methods, then they teach them to their subordinate management who in turn form teams and start practicing TQM. They help pass what they have learned down to subordinates, and so on. This process continues until everyone is trained and participates. TQM then cascades through the organization. The major advantages of this approach according to Carr (1992, p. 206) are: “it ensures topdown understanding and support, and allows the organizations to adjust gradually to a new way of doing business. On the other hand, this approach is a "slow process" and if "you need teams to start working immediately on critical issues in key processes, this strategy will not deliver."

The second approach is the "All-at-Once Approach." In this approach "everyone is trained in TQM in a few months, teams form quickly throughout the organization, and the action starts right away- often because this TQM has the vigorous support of the top executive/s." The benefit to this approach is that "it can jar a complacent organization into action and, possibly, get some quick results. 
However, this approach has its major disadvantages and might possibly fail. Due to the short time frame, "managers do not have enough time to become skilled in TQM before workers do, and so cannot give them guidance and direction." Moreover, there is not enough time to develop effective systems of measurement and communication which might create gaps in the information needed for decision making.

The third approach is what Carr calls "The Spotty Approach." Some people get a little training on teamwork and a few TQM tools. Alternatively, "only employees participate, as in the old model of quality circles in the United States." This approach yields few results but it always dies because it lacked the commitment of the top leadership and the comprehensive training involvement needed to ensure its continuity.

A fourth approach is what Carr (1993, p 207) calls "We are doing it Already Approach." The organization simply labels all its current improvement programs "TQM." This is a common practice right now in both industry and government. In fact, this approach is a reflection of one of the seven diseases, identified by Deming, that plague an organization. It is when people say "we have already instituted TQM." This approach is similar to the "spotty" one in that it fails most of the time.

The final approach which Carr advocates, is called "The Twin-Track Approach." It is based on the change management strategies advocated by TQM and on "combining the 'Slow Cascading' methods with pilot projects at the early stage of implementations." By doing so the organization avoids the haste of launching a massive approach without proper training but gets to put TQM methods to practice and get to learn from its improvement efforts.

1. For more information on this approach please refer to "Excellence in Government" by Carr; 1993; Cooper \& Lybrand, (Ch. 9 and Ch. 11). 
Finally it is quite possible that an organization that is embarking on a TQM effort might adopt more than one of these approaches, and sometimes a combination of these approaches might exist. This research will describe which approach/es are adopted by those organizations involved in our study. These approaches will be revisited in our presentation of the quality stories of each institution.

TOM models in the Private sector: The Malcolm Baldrige National Award Program

The Malcolm Baldrige National Award Program (MBNAP) is designed for those private companies who excelled in their TQM innovative efforts and who were able to achieve remarkable results with it. Companies who want to assess their quality improvement efforts apply for this award which provides an evaluation of their quality improvement processes. The award was first introduced as a bill in the congress in 1986 as House Bill 5321, titled "The National Quality Improvement Act" (Hart, 1992). The bill recognized the "competitive problems" facing American industry and it called for an award that "would spotlight quality performance" by American corporations. This award has four goals (Hart, 1992). The first is to provide an incentive for US companies to improve quality and to provide an opportunity for them to be recognized. Second, by recognizing the achievements of those who succeed the award provides an example for others who are striving for quality. Third, the award aims at providing "guidelines and criteria" that could be used by organizations in evaluating their own quality improvement efforts. Finally, the MBNDP provides a road map to quality improvement by "making available detailed information about the stories of how did those organizations win the award " (Hart, 1992, p. !3). 
According to Carr (1990), MBNDP, a Federal, government/private industry program is considered the best known system in USA that provides criteria for quality improvement programs. MBNDP has the following categories (Hart, 1992, p. 16): leadership, information and analysis, strategic quality planning, human resource development and management, management of process quality, quality and operational results, and finally customer focus and satisfaction. ${ }^{2}$

An organization who applies for MBNDP is evaluated in view of the guidelines and standards. These criteria ${ }^{3}$ cover the various categories described above. Since 1988 a number of companies have been able to win the Baldrige award and through their experience, described in a later part of this study, we will assess the implementation of TQM in the private sector.

\section{Implementation of TOM in the Private Sector}

The quest for quality improvement among private sector organizations began in the early 80 s, and is expected to intensify during the 90 s. Hunt (1992, pp. 1-2) cites Motorola's Vice President and Quality Assurance Manager in explaining why his company adopted a quality improvement initiative: "we put Motorola's quality process in place to satisfy customers." TQM has helped the company "to increase market share, to increase sales, and to increase profitability." Global competition and the ever-shrinking world has forced American corporations to reconsider their

2. Figure 1 in Appendix A provides a visual presentation of these categories.

3 . For a list of these criteria please refer to (Table I) in Appendix A 
strategies of doing business; and required them to search for innovative ways to keep up with the new demands of the changing global markets. As discussed earlier in the review of the historical evolution of TQM, Hunt (1992, pp. 4-8) stresses that "American manufacturing and service companies cannot afford to remain passive in the coming years ... the time is ripe for virtually all American businesses to adopt a new world view built on proven quality improvement practices." The United States, in short, is challenged, according to him, "through a commitment to quality." Commitment to quality is seen as a vital condition that needs to be met if US businesses are to regain and maintain larger market shares in national as well as the international markets.

For those companies who started their quality improvement efforts, TQM has signaled a cultural change. TQM processes embodied the teachings of key quality figures such as Deming, Juran, and others. Quality improvement projects have focused on improving products and services through improving the processes of production and by installing quality as the new way of doing business. Those organizations who were successful in instituting quality improvement into their system have paid attention to input from both their internal as well as external customers and re-engineered their systems to eliminate errors and prevent waste in human and financial resources. Those companies consider including employees in achieving customer satisfaction as part of their success. The savings can be as much as $25 \%$ when wasted efforts and poor quality control are avoided. Another key to total 
quality management is the ability to identify mistakes when they are small to insure uninterrupted work flow and customer service. ${ }^{4}$ This of course corresponds with Deming's fourteen points for quality improvement. Another example of the importance of the relationship with the customer is described in the experience of Florida power Co., as told by Conner ${ }^{5}$ (1992, pp. 33-37):

A success formula that combines internal audits and total quality management (TQM) in providing audit services has been developed by the Audit Services department of St. Petersburg, FL-based Florida Power Corp. The formula was developed in view of the direct application of the three elements of TQM, namely customer focus, continuous process improvement, and teamwork, to internal auditing, Although often overlooked, a customer/supplier relationship is involved in internal auditing. The formula resulted in improved audit reports, increased participation of customers or auditees in the auditing process, and reduced audit operation time. For Florida power, the benefits of the formula came in the form of enhanced working relationship between auditors and employees being audited, and $8.7 \%$ manpower reduction in the Audit Services department.

For those companies who are adopting what Hunt (1992, p. 9) identifies as 'World Class Quality" the concern and responsibility for quality is everyone's job.

\footnotetext{
4 . Quality: a road to profits. (total quality management) il v23 Agency Sales Magazine Jan '93 p58(2)

5 A success formula. (internal audits $\pm \underline{\text { total quality management }} \equiv \underline{\text { audit services) by Roy }}$ C. Conner Jr. v49 Internal Auditor April '92 p33(4)
} 
This of course includes the top leadership commitment to TQM. This new vision is captured by Chatterjee and Yilmaz' (1991):

US companies must respond to foreign competition by adopting new attitudes towards product quality.... US companies must abandon short-term outlook tendencies and commit to involving every level in developing high quality products that will be able to compete in global marketplaces. Total quality comprises identifying what quality is, adopting that concept for the whole company and developing a work environment that supports that concept of quality. Top management participation is crucial for implementation of total quality projects.

Quality driven companies consider quality to be an integral part of product and process design, and not something that is achieved through management oversight and inspection. To achieve designed-in quality those organizations use systematic product and process techniques based on statistical analyses to identify sources of variation, to decide when it is economical to reduce these sources of variation, and to ensure the product/service is robust in light of remaining variability. They then closely monitor process performance (Hunt, 1992, p.9). In the following pages we will explore some examples of successful implementation of TQM as summarized in the stories of the winners of the Baldrige Award Program.

As discussed earlier, TQM could be considered a revolutionary way of thinking. In fact, it could be viewed as a revolution in itself, or as a new paradigm

6. American management must change its view of quality as a 'necessary evil.' (Total Quality Management) by Sangit Chatterjee and Mustafa Yilmaz v23 Industrial Engineering Oct. '91 p44(5). 
shift (Walton, 1986). Embedded in this is a new look at things in organizations. TQM is gaining ground in many US organizations. Jablonski (1991) describes a study conducted by the American Society for Training and Development. The study has revealed that $57 \%$ of companies surveyed have total quality as a strategic goal or policy. and the $43 \%$ remaining anticipated an implementation of TQM within the next $1-3$ years. More than $61 \%$ of the cases reported showed that they have reached positive results with TQM. We see then that TQM is a philosophy that is gaining more attention. This section will briefly discuss the experience of implementing TQM in the private sector.

\section{Examples of implementing TOM in the private sectors: stories of Baldrige}

\section{Winners}

Struggling for survival, American private industry organizations have turned to TQM and to its theorists, such as Deming, Juran, Crosby and others, for solutions to its problems. One of Ford Motor Company's key figures states (Peterson, 1986), "I am proud to say that I am a Deming disciple and we at Ford are committed to his operating principles, particularly to the ethic of continuous improvement and the involvement of all employees." TQM has flourished in the private sector because of its successful implementation in Japan and because American companies have invested in quality improvement programs as early as the mid eighties (Carr, 1990).

As an expression of their appreciation Japanese companies have established the "Deming Award" which is considered to be the most prestigious award in the Japanese industry. In the United States a comparable award has been established since 
1987 and it is called "Malcolm Baldrige National Award Program (MBNDP) 7 " (Carr, 1990).

In 1988 Motorola Inc. was the winner of the Baldrige award. A leader in manufacturing and sales of semiconductors, Motorola has been described as "Fanatic about quality". Motorola was able to achieve a remarkable reduction in defect rate and then aim at reducing failures to 3.4 per million. (Hart, 1992). This resulted in savings of over $\$ 500$ million in 1990 and for that to reach $\$ 1$ billion by the end of 1992. Another winner was Westinghouse Commercial Nuclear Fuel Division . A comprehensive implementation of TQM was adopted and it relied on a "central quality council" comprised of "champion" managers and teams working on 60 "Pulse Points". The end result was reducing defects per thousand from 50 to 0.5 .

In 1989 Xerox Business Products and Systems was one of those who captured the award for its successful implementation of its program identified as "leadership through quality". This program devised a comprehensive quality process that focused on "customer-defined quality", through surveying over 55,000 Xerox equipment owners (Hart, 1992). Added to this is Xerox's achievements in advancing the process of "benchmarking - continuous self measurement against other companies and industries." This concept was so useful that it became one of the components of Baldrige itself. Another company, Milliken, a textile company, won the award for its extensive team efforts to improve the quality and customer satisfaction through their program "Pursuit of Excellence." McGraw Hill.

7. For more information about this award please refer to The Baldrige: by Hart, 1992, 
In 1990 Cadillac Motor Car Company was able to walk away with the Baldrige. Its efforts to improve quality and meet and exceed customer expectations were among the reasons that qualified it to win. Hart (1992) states that "Cadillac redefined its relationship with the autoworkers' unions, as well as its relationship with its customers, vendors, and dealers." Moreover, it has implemented a "simultaneous engineering approach, an information and implementation process to meet and exceed customer expectations." Another company that won the Baldrige award for its successful implementation of TQM programs was Federal Express. Federal Express's focus on quality is reflected through its slogan "absolutely, positively, the best in the business." Its values of "people-service-profit" have allowed FedEx. to reach remarkable achievements in quality. IBM, Rochester was another company who won the award for its incorporating quality improvement throughout its process cycle and its teamwork.

In 1991 companies such as Zytec and Marlowe Industries were able to win the Baldrige. Zytec has introduced Deming's "14 Principles" as well as management by data. Drafting a charting of all activities and empowering the employees to take risk and make decisions has allowed the company to produce products that are $99.8 \%$ defect free. Marlowe, a smaller company that produces customized thermoelectric coolers, won the Baldrige for its improvement in increasing the productivity of its employees. Over the past 10 years Marlowe has never lost a customer, and the top 10 customers rated the quality of Marlowe's coolers at 100\%. (Hart,1992). Selectron, specializes in the "custom manufacturing of printed circuit boards", and because of its utilization of Statistical Process Control in all of its departments its quality improvement efforts enabled the company to produce winning products and win over 37 awards. 


\section{Conclusion}

The above examples indicate that TQM/CQI is widely considered as a process to improve the quality of products, to increase market share, reduce errors and defects, and reach higher levels of excellence among the industrial organizations. The experience of these companies reflects the usefulness and the power of TQM in transforming organizations. One might safely say, then, that the $90 \mathrm{~s}$ will be in fact the quality revolution era (Carr, 1990). At this point, private sector organizations are not asking themselves whether to adopt a quality improvement program or not; what they are asking is how and when could we start? " Deming (1986) stresses that "quality should become job \# 1", a statement that is increasingly found in the missions of many US organizations.

\section{Implementation of TOM in the public sector}

\section{Introduction}

TQM has found strong ground in the industrial arena. The debate is moving to how effective it can be in the service oriented industry, more particularly, the public sector. Some react to examples from the private sector by saying that the Federal government and public organizations are different. They point out that "government does not operate in a competitive environment; it is constrained by Congressional restrictions; it does not have customers; it is largely a service industry emphasizing administrative processes rather than manufacturing (CQI, 1993). However, the experience of those public sector organizations that implemented TQM programs indicate that "significant gains were achieved" (FQI, 1993, p.23). The incentive for the Federal Government to adopt TQM is similar to that in the private 
sector: a "crisis of survival" (FQI, 1993, p.23). In his book "Excellence in Government" Carr (1990) stresses the need to implement TQM in the public sector in order to achieve "better service to citizens, [because of] tight budgets, getting and keeping the best employees ... and survival too." Osborne (1993) believes that " the people who work in governments are not the problem; the system in which they work is the problem." This corresponds with the major concepts introduced by Deming and other TQM leaders. The following section explores the implementation of TQM in the public sector. First, it presents some inherent differences between the two sectors; then it explores some TQM models for implementing TQM in the public sector through the Government Awards, and finally it narrates the quality stories of three winners of these awards. But before that is done an answer to the question: How different are public organizations from private/industrial organizations? need to be provided.

\section{Public Vs Private Sector: Inherent Differences}

Public organizations such as state universities and hospitals possess characteristics that are somehow different from their private counterparts. Jones (1980) introduces some differences between public and private sector organizations, which might help provide a better picture of these differences. The first difference is identifying the customer. Since "public agencies deal with constituencies rather than markets" identifying the customer of public organizations is more difficult and complicated than identifying the customer of private organizations. To clarify this point take a public hospital for example, who is our customer, and how do we identify him/her? Is it the patient or is it the doctor, the board of directors, or the administration? Another example is the university. Is the customer the student, the 
faculty, or the society at large? Nevertheless, this is not to say that it is impossible to identify the customer of public organization, the intention is to stress that it might be more difficult when compared to that in the private sector. By introducing the concept of internal and external customer, discussed earlier, TQM helps formulate a better identification of our customer.

Second, public organizations differ from their private counterparts in the type of service they offer and even in the final goal behind their operation, (Jones 1980). Industrial organizations are established to deliver an identified product to an identified market. The final goal of such organizations is the maximization of profit and the acquisition of larger market shares. The products of these organizations are well defined, in most cases, as well as their customers. In the service organization, defining the product could be one of the hardest jobs to be taken by anyone. Take a hospital for example and try to work on defining what is the product delivered. Even more difficult to define is the product delivered by a university.

Third, public organizations tend to be more complex in terms of size, organizational layers, operations, goals and the flow of communications. In addition, public organizations are less likely to have a well-specified customer, compared to private organizations, because of the complexity and the wide spectrum of their clientele. Jones (1980) states that public organizations hold their employees more accountable, do not offer as much reward as the private sector does, encourage their employees to keep a low profile, and not to "upstage their political employer in public affairs. In other words, public organizations are more complex and less flexible. Jones (1980) cites an example of a study conducted by the House Subcommittee that concludes: 
"Local governments must become more efficient ... public employees perceive change as a threat to their jobs." TQM requires a constant change process, which might be a great challenge to those organizations, that are used to stable and somehow static environments.

Another set of differences between public and private sector organizations could be found in the book Humanizing Public Organizations by Golembiewski (1985, pp. 259-262). According to Golembiewski while service is the primary motive for Human Service Organizations, profit is the primary motive for their private counterparts. Public taxes are "the primary resource base" in public organizations while private capital is the backbone of the financial base of private organizations. When it comes to goals Golembiewski charges that public organizations tend to have "relatively ambiguous and problematic goals while private or industrial organizations tend to have a relatively clear and explicit goals." Transformation process at public organizations tend to be "staff-client interactions" but in the private sector they are “employee-product interactions." Units and events are loosely coupled in public organizations contrary to the private sector where units and event are tightly coupled. In terms of output Golembiewski states that "outputs in public organizations tend to be unclear and ambiguous" but outputs at private organizations tend to be "visible and tangible." What about measures of performance? Golembiewski indicates that human service organizations rely on "qualitative measures" while private organizations rely on "quantitative measures." Finally, the primary environmental dimension for public organizations is the "political and professional communities while for private organizations it is the industry and suppliers. ${ }^{8}$ his book.

${ }^{8}$. For more information about these differences please refer to pages 258-262 and 318-329. 
The above differences have some implications for Organization Development interventions in the two sectors, especially the public sector. Golembiewski (1985, p. 260) states that "Public sector OD efforts will tend to operate in multiple domains, and thus often are more subtle and complex than OD in business and industry." OD intervention in the public sectors tend to "face a greater challenge: it has to integrate multiple subsystems, which have very strong tendencies to go their own separate ways." Therefore, it could be concluded from the previous arguments that OD interventions, and TQM initiatives, will be more challenged at public organizations. The study explores this notion in a latter section where the findings of the research are presented and discussed.

Moreover, public organizations are less threatened by competition, their survival is more secure, even in spite of a poor performance. Private industries are more worried about their existence, especially in the long run, because of the competing forces in the marketplace. Keeping that in mind, they are more eager to try new things, less hesitant to implement the new technology, and more progressive in their adopting of and adapting to new values. Public bureaucracies, on the other hand, display more resistance to change and it takes a longer period to institute a new value system into such organizations.

Another point to be raised is that of the external environments in which public organizations function, and their accountability to a broader range of clientele, such as the local, state, federal governments, besides the governing boards and various interest groups. Political activity is more dominant in public organizations, with a tendency for more conflict. Moreover, and while private organizations set their own goals public organizations are "obligated to pursue goals set for them by their legislatures" (Gordon, 1986, p.21). 
Furthermore, TQM/CQI requires a dynamic process of abolishing the organizational barriers and the hierarchical layers between the various departments and focuses on the teamwork and the collective effort of the group, (Gordon, 1986). While most public bureaucracies might advocate teamwork and the fiexibility between the various vertical organizational layers, public organizations might display more resistance to the attempts of abolishing ranks and other hierarchical levels.

One might presume, just by looking at the above arguments, that TQM has no future in the public sector. That is absolutely not true. The intention behind stating these differences is to help the researcher in assessing the organizational map in which s/he is trying to participate in drawing. A comprehensive understanding of these differences is very important for any serious effort to bring a TQM implementation into the public sector. It should be kept in mind that large complex private organizations might have similar bureaucratic rules and problems to those in the public sector. By constructing a better understanding of the nature and environment of public sector organizations, we can reach a better understanding and that might guide us through a better implementation process for any organizational change. Therefore being aware of these differences might be the first step to consider in conducting or implementing TQM innovations research in the public sector.

In conclusion, it seems obvious that there are indeed a number of inherent differences between public and private institutions. However, many writers and public organizational leaders have been advocating and calling for the implementation of TQM in the public sector. President Clinton (1993) is the first to affirm his belief in TQM. Carr (1990) sees in TQM an answer to many ills that plague our government and call for implementing it to "improve quality, combat deficits, saving money, improving the customers' (public) image of government, and even to survive in an 
ever competitive world." Osborne (1993, pp. 177-180) calls for "reinventing government" and stresses that government should be "customer driven: meeting the needs of the customer instead of the bureaucracy." It should be stressed that one of the goals of this study is to explore the significance of these differences in impacting the implementation of TQM/CQI innovation efforts in public organizations.

\section{Implementing TOM in public sector organizations}

The previous pages described the experience of some private organizations with TQM. We also stated some differences between the public sector and private sector organizations. At this point it seems logical to explore the implementation of TQM in the public sector and cite some examples of TQM in public sector organizations.

TQM implementation in the public sector is gaining more ground than ever before. The top leaders of government and state institutions are showing more interest in TQM.

For example, in the Federal TQM Handbook published by the Federal Quality Institute, ex-president Bush (1992) identifies improving the quality of products and services as a "national priority as never before." President Clinton, who is calling for reinventing government, states his belief in TQM and affirms that "... it [TQM] works" (FQI-Brochure, 1993).

The Federal Quality Institute, which could be considered the TQM apparatus in the Federal government, identifies seven operating principles that, in their entirety, characterize an organization implementing a successful TQM effort. These are:

0 demonstrating personal leadership and support for the quality effort by leaders throughout the organization; 
0 strategically planning the short- and longterm directions of the organization and tying the quality improvement effort to the strategic plan;

0 assuring that everyone focuses on customers' needs and expectations;

0 developing clearly defined measures for tracking progress and identifying improvement opportunities;

0 providing adequate resources for training, and recognizing workers' contributions to quality improvement;

0 empowering workers to make decisions, and fostering teamwork; and

0 developing systems to assure that quality is built in at the beginning and throughout operations.

(FQI, 1993, pp. 1-8).

Osborne (1993) calls for reinventing government because the existing governmental practices simply are not working. He declares that "the majority of the American people believe the Federal government simply does not work." To prove that he cites as evidence a poll which was conducted by CBS which revealed that "17 out of $20^{\prime \prime}$ adults said the federal government needed either "fundamental change" or "a complete rebuilding (Osborne/FQI, 1993, p.2).

The need for adopting TQM in the public sector is urgent, a view held by many leaders in the field. Private sector organizations, and even non profit organizations, according to Osborne (1993), have invested heavily in improving quality of their products and services and have constantly tried to reform their structures to be more adapting to their environment. On the other hand, "government, 
by and large, has remained the same: sluggish, centralized, and bureaucratic"

(Osborne, 1993, pp. 2-4).

Calls for adopting TQM in the public sector have been mounting. David

Osborne (1993), co-author of Reinventing Government, testified before the Senate

Governmental Affairs Committee on March 11, 1993. Here are excerpts:

Our federal bureaucracies grow so large and so sluggish not because those who work for them want it that way, but because the basic incentives operating on those bureaucracies literally demand that it be that way ... to change behavior within the federal government, we must change the basic incentives that shape that behavior. ... Our goal must be public organizations that constantly improve, constantly redesign, constantly innovate, constantly drive their costs down and their quality up. (p. 3)

The above statement emphasizes the need for incorporating TQM in the public sector. In the book Reinventing Government Osborne (1993) asserts that "most American governments are customer blind." He further states " most public agencies do not get their funding from their customers, like businesses do. Therefore,

" Instead of focusing on the real customer, their citizens, public government organizations aim to please the legislature and other interest groups, whom they consider as their primary customer. Moreover, while businesses strive to please their customers, whom they correctly identify, public government officials on the other hand serve the interest groups. Public government agencies face mounting problems because they have not incorporated the requirements of the true customer into their products (167).

In the public sector, as Jablonski (1991) states, the " need for TQM ... is no less compelling" [than that in the private sector]. The challenge is then "to offer the 
customer, the taxpayer, an improved quality of services at reduced costs" (p. 3). He cites the example of the City of Santa Ana, which implemented a TQM innovation in their various departments, and that could be considered one of many success stories reported by TQM writers and professionals.

For public organizations to achieve improvements in quality and services they need to listen to their customers and build their services around that customer. TQM "stands the traditional organizational chart on its head."(Osbome (1993, p. 175). This might provide a challenge to some public government organizations. But faced with shrinking resources and increasing expenses public organizations feel they are "boxed in." (p. 173). TQM offers a "way out of the box", according to one city official who was interviewed by Osborne (1993, p. 173).

Governments should focus on gathering information from their customers about what the customers need. The idea that government will achieve quality through extensive programs of spending or cutting is not efficient. Government should be customer focused and driven, in order for the quality of their services to improve. Those organizations who listen to their customers will be able to institute quality in their products and services and achieve higher standards of performance.

Public sector organizations have to change in order not only to grow but most importantly to survive the future with its demands and challenges, from what could be inferred from Osborne (1993). Implementing TQM in the public sector is a "monumental" task ... [because] the government is a huge conglomerate of activities and functions generally operating under inflexible and outdated management practices 
and principles." Implementing TQM in public sector organizations will help "break down the rigidity and excess structure of the government and to devise ways to enlist the talents and energies of the workforce to meet the challenges of the nation." (FQI, 1993, p. 23).

The following paragraphs explore the National Award Programs as a model for implementing TQM in the public sector and present the stories of the three winners of the Prototype Awards for the year 93.

Models for Implementing TOM in the Public Sector: National Award Programs Introduction

To provide a balanced examination of the implementation of TQM in the private and the public sectors it will be necessary to present a model/s for implementing TQM in the public sector similar to the case of TQM implementation in the private sector. This section will look at the National Award Programs. These programs, as in the case of the Baldrige Award, are designed to recognize public organizations that have accomplished distinguished achievements with TQM. We will also describe the experience of those winners of the 1993 awards. By doing so we might be able to shed some light on the requirements and characteristics of a successful implementation of TQM and how this could be achieved. In addition, exrmining both models will enable us to undertake the first step in constructing our comparative approach between the private and public sectors. By looking at the 
various elements that compose each model and comparing and contrasting them to one another we will attain better understanding about implementing TQM in each sector. 9

\section{Government Award Proorams}

\section{Introduction}

In its efforts to promote and institute quality improvement into the public sector and achieve cultural transformation of local, state, and federal agencies the Federal government has started a variety of award programs to recognize the efforts of public and government organizations who achieved remarkable results in improving quality of products and services and in serving their customers. This section will first discuss the "Reinventing Government Through Quality Management" model; and then it will introduce two awards programs. Finally a comparison between this model and the Baldrige model, used in the private sector and introduced earlier, will be established. This will help further the understanding of both models in the public and private sector organizations. Moreover, these models will be used to answer one of the research questions regarding significant differences between the two sectors in their implementation of TQM.

\section{"Reinventing Government Through Quality Management"}

This model is introduced by the Federal Quality Institute as the new paradigm for bringing about a cultural change in the Federal government and public sector organizations in general. This model has the same components and categories as the

9 . For a visual presentation of this model please refer to Figure 2 in Appendix A 
Baldrige program does. The initiator of the change should be leadership whose task is to mobilize the workforce in order to improve the systems of performance in order to achieve the improvement goal: customer satisfaction. This process requires strategic planning and an effective use of information systems. The final goal is a transformed government that places its internal as well as external customers first. The following two programs reward those organizations that succeeded in translating this model into action.

\section{The Presidential Award for Quality}

This program is modeled after the Malcolm Baldrige National Quality Award [MBNQA]. The Presidential Award is designed for organizations that have mature quality management efforts (at least 3-6 years) and are well-advanced in the quality transformation process. Applicants must be part of the Federal Government, and have at least 500 Federal employees. The Presidential Award may be given to as many as two organizations each year ( $F Q I, 1993, p p$. 10). It annually recognizes Federal organizations who achieved "exemplary quality improvement and provide high quality products and services to their customers." (FQI, 1993, p. 3). The criteria for these awards are "rigorous" and cover the principles and practices of quality management. These criteria are similar to those of MBNQA, but they are "less detailed" (Carr, 1990, p. 214).

\section{The Quality Improvement Prototype Award}

This is one of the most prestigious awards in the Federal government. The Quality Improvement Prototype (QIP) Award is designed for organizations that have 
recently begun the quality improvement transformation process. The concepts embodied by the Criteria are very similar to the Presidential Criteria, but do not include some of the more advanced concepts. Applicants must be a part of the Federal Government, and have at least 100 Federal employees. Organizations who apply get evaluated by reviewers who assess their implementation of TQM and their achievements in transforming their organization, and the winners are those organizations who excel in their implementation. ${ }^{10}$ The Quality Improvement Prototype Award may be given to as many as 6 organizations each year. It is presented annually to Federal organizations in "recognition of excellence in implementing principles of quality management and achieving customer satisfaction" (FQI, 1993, pp. 3-10).

\section{The "Baldrige" Model Vs the "Reinventing the Government" Model: a}

\section{Comparison}

Carr (1990) urges organizations to use these award programs to answer questions such as "How do we manage quality now?" and "How does this compare with other organizations?" (p. 211). Award programs, such as Malcolm Baldrige National Quality Award, Quality Improvement Prototype Award, and President's Award for Quality, help organizations assess their posture toward TQM and assist them in the quality management process. Furthermore, these awards provide examples of what has been done and proved successful in implementing TQM.

By comparing the categories and criteria used to evaluate a public organization that is implementing TQM to those used to evaluate a private one we realize a striking similarity between the two. The Baldrige and the "Reinventing the

10. Please refer to Appendix A, table II for a listing of these items. 
Government" models are essentially identical. This comparison clearly reveals that there are critical elements that should be present in order for a TQM effort to succeed, whether in the public or the private sector. To name a few: leadership commitment, long term vision, systematic way of thinking and customer focus. This study provides an examination of this assumption by comparing the implementation of TQM in public as well as private organizations and looking for any significant differences between the two. The crossectional data gathered from the three organizations provide supportive evidence of this notion. The findings are then used to draw lessons that should help those who are involved in implementing TQM, especially in the public sector. These findings will be discussed later in this study. Our next step is to present the three winners of the "Quality Improvement Prototype Award" for the year 1993.

\section{Winners of 1993 Ouality Improvement Prototype Awards: Success Stories in} implementing TOM

\section{Introduction}

Employee involvement is a key component to successful TQM implementation in any organization. As their quest for quality persists, Federal organizations find that involving employees in process improvement teams "saves time and money, increases customer satisfaction and improves employee morale" (NQN, 1993, Vol.). In the following section we will present the experience of three Federal organizations, as an example on the implementation of TQM in the public sector, and then we will discuss the significance and implication of this successful implementation for implementing TQM in public organization. 
First

\section{Arnold Engineering Development Center (AEDC), Arnold Air Force Base,}

\section{Tennessee}

One of its key successes could be attributed to having "an Integrated PublicPrivate Sector Team." The AEDC, with a yearly budget in excess of $\$ 300$ million, is one of the world's most advanced and largest complexes for aerospace ground test facilities. AEDC is comprised of four major components--an Air Force military and civilian component and three private sector support contractors--Sverdrup Technology, Inc., Calspan Corporation, and SSI Services, Inc. Nearly 3,500 people work at the Center, including about 400 Federal employees. AEDC staff have contributed to the development of practically every one of the nation's top-priority aerospace programs. The Center is recognized for its performance as an integrated public-private sector team in achieving the Center's mission. (QIPA, AECD 1993 report, p. ii)

More than 250 Center teams have worked on quality improvement and planning. AEDC has started its TQM efforts since 1989, and since then it has implemented a "quality management structure, an in-house quality training capability, business process management teams, customer surveys, internal culture surveys, and self-directed teams ... and developed a team building capability and a leadership center." (QIPA, AECD 1993 report, p. vi) Accomplishments include:

- Saved customers more than $\$ 7.8$ million in 2 years by increasing efficiency and timeliness.

- Saved more than $\$ 111,000$ in FY91 from implementing employee suggestions. 
- Began inviting vendors in to show them exactly how their parts would be used and to explain the critical need for high quality materials in aerospace testing. This new, ongoing process improved the compliance rate for the purchase of technical parts from 20 to 93 percent and above. (QIPA, Report 1993, pp. ii-vi)

\section{Second}

\section{Naval Air Warfare Center, Aircraft Division, Lakehurst, New Jersey}

The Naval Air Warfare Center Aircraft Division, with a budget of $\$ 210$ million and more than 2,500 employees at 18 locations the center is responsible for the effective and safe operation of aircraft to, from and on aviation platforms. The center has started its quality initiative in 1988, and called it "Total Quality Leadership." Through a comprehensive process of training and teamwork the processes were analyzed and improved. But how? First managers were required to receive training from Deming, then the "leadership has decided to make Total Quality their number one priority." The third step was to establish the Executive Steering Committee, which identified five areas of improvements. Later other strategic committees were formed to work on these areas of improvement. Process Action Teams (PAC) were formed to "make the improvement right down to the working level." More than 1,400 employees on more than 250 teams have worked at improving processes (FQI, NAWC, 1993 report pp. vi-vii).

By following a comprehensive plan of improving processes, using quality management, and continually working together the center, who grabbed the 1993 award reports the following achievements : 
- Documented savings of more than $\$ 17$ million since 1991 in improved work processes.

- Improved on-time delivery rate from 85 percent to 99 percent for more than 600 items of aircraft launching and recovery equipment being installed on new and overhauled carriers.

- Increased the Center's total productive ratio (direct customer-funded hours worked as a percentage of total hours worked) from 51 percent in FY 91 to 59 percent in FY 93. (FQI, NAWC, 1993 report pp. vi-vii).

\section{Third}

\section{Naval Aviation Depot, Cherry Point, North Carolina}

The Naval Aviation Depot, a Naval Air Systems Command field activity, is responsible for maintenance, engineering, and other logistics support of military aircraft, engines and related components. It stays in business by competing for work in the public and private sectors. It employs approximately 3,300 civilians, representing 144 different trade skills. Six unions represent approximately two-thirds of the work force. Of the six Naval Aviation Depots in the United States, Cherry Point is the only one managed by the United States Marine Corps. The Depot is the only repeat winner of the QIP Award, having first won in 1988.

The depot call their effort "Total Quality Management". They have started in 1986 and by now TQM has become an organization-wide cultural transformation. Naval Aviation Depot has provided training in TQM for all of its employees. Cherry Point's long-term and top-level commitment to TQM and making it a "way of life", enabled a cultural transformation through long term planning and system wide 
involvement of employees. As well, the Depot stresses the importance of focusing on the customer and continuous education as key factors for success.

All of the above enabled the Navy Aviation Depot at Cherry Point to win, twice. Its accomplishments include:

- Increased market share of the highly competitive aircraft maintenance work from $\$ 249$ million in 1988 to more than $\$ 400$ million today.

- Realized \$185 million in savings and cost avoidance since 1988.

- Provided almost $\$ 20$ million in productivity gain-sharing awards to employees since 1988.

$$
\text { (FQI, NAD report 1993, p. v) }
$$

\section{Significance and Implications: conclusion}

The previous sections presented the experience of some public/government institutions who have been able to implement TQM and achieve remarkable results with it. Public sector organizations are well equipped and capable of achieving positive outcomes as well as the private ones. These stories clearly reveal that TQM requires top leadership commitment and buy-in and when that was achieved the process was fruitful. These stories have been chosen for this study because they signify a very powerful example of the ability of public organizations to bring about change through transforming their culture. This might help those professionals who might be skeptical about the role of TQM in the public sector. Moreover, these stories might reveal some important information to those involved in quality improvement efforts. Public organizations can find in these stories documented examples that could be used as a justification for implementing TQM and as a guidance throughout the process. These stories are significant because of the sense of 
hope and encouragement they promote in public organizations, and their affirmation of the capability of public organizations to bring about change, if they work hard to achieve it.

In conclusion, though many organizations might fail, the impression that could be sensed from the writings, the implementation reports, and even the documented interviews and speeches about TQM is a firm belief in its power to transform organizations. Finally, it could be concluded that TQM has achieved a solid standing in the Federal government, and the trend should start spreading to state and local organizations. In the next section we will explore the role and implementation of TQM in health care. 


\section{CHAPTER IV}

\section{IMPLEMENTING TQM/CQI in HEALTH CARE}

\section{Introduction}

Traditionally, quality in health care has been defined by physicians and hospitals in professional and technical terms (Berwick, 1988). However, quality has become a focal issue for health care organization due to competition and the patients' increasing involvement in the system. McLaughlin (1990, p. 7) sees the TQM approach as a " total paradigm shift" in health care. He distinguishes TQM from other approaches by its calls for continuous and relentless improvement in the "total process that provides care, and not simply the improved actions of individual professionals." This section will explore the utilization of TQM approaches in health care. First, this chapter will start by offering a conceptual analysis of TQM in health care, and then it will explore some examples of TQM in health care.

\section{TOM in Health Care: Conceptual Analysis}

Batalden (1989, pp. 577-83) outlines what the health leadership need to learn to implement TQM in health care organizations. First "management has to learn the new meaning of quality"; in other words, management needs to see and define quality based on the needs of the customers; and that implies an accurate consideration of both internal and extermal customers. Moreover, leadership of health care 
organizations must sponsor and champion the transformation for the effort to succeed. Added to the previous points is the need for health care leaders and managers to gain a working knowledge of Statistical Process Control (SP) as well other tools used by TQM to analyze and improve a process. Health care organizations have been looking for new ways to improve quality and reduce costs. Health care reforms have been a critical policy issue for the $90 \mathrm{~s}$, and they are gaining more attention. Improving the quality of health care has been one of the major goals that has been sought by the policy makers of American health care. Many leaders in the health care field call for implementing TQM approaches to improve quality, reduce work, prevent errors, and save money and resources. McLaughlin (1990) argues, however, that TQM might pose a challenge for some health care organizations, which he identifies as areas of conflict, because of the way they are managed. These areas, are: " TQM's participatory approach versus professional and managerial authority, collective versus individual responsibility, continuous improvement versus quality assurance standards, and finally the flexible versus rigid plans.

In order for an effective implementation of a TQM effort to be achieved McLaughlin (1990, pp. 11-14) identifies the following guidelines. First, "Redefine the role of the professional." This means that under TQM professionals should be trained in both their technical expertise areas as well as a variety of other areas that relate to the new organizational environment. Physicians and nurses have to start learning about management, statistics, and group process, in addition to their technical skills. This new role of health care professionals aligns them with the new organizational mission to continuously improve quality. In addition the "corporate culture" needs to 
be redefined. This requires developing long term goals as well as acknowledging that TQM requires a cultural change that might demand fundamental changes.

Third, in order for an effective TQM implementation we need to "redefine the role of the manager". The role of the manager under TQM is not to inspect or punish, but rather to "manage the culture and to allocate resources to support the change process." Moreover, the organizational goals have to be redefined to reflect a long term perspective (McLaughlin (1990, pp. 11-14).

A health care organization implementing TQM needs to institute an effective benchmarking process, where it compares its experience with other organizations who are implementing TQM. By drawing on the experience of those organizations who have been successful with TQM an organization can look for a role model to learn and to benefit from. Leadership involvement in the bench marking is critical and essential. McLaughlin (1990, pp. 11-14) encourages health care organizations, embarking on a TQM effort, to "go outside the health care industry for models." Indeed, some of the experiences of those organizations who won the Baldrige award or the Presidential awards might offer some guidance. The reward system has to be modified to reward the team effort than to distinguish certain individuals only. Finally health care organizations involved in the implementation of TQM should "make TQM programs a model for continuous improvement." In other words, organization should always work hard to do their best and continuously strive for improved total quality. Marwick (1988) conducted a study in which he reports that "78\% of physicians, purchasers, and third party payers believe that the cost of poor quality is so great that the quality improvement should pay for itself [in savings]" (p. 14) This finding sets the ground for justifying the adoption of quality improvement strategies to achieve comprehensive and lasting organizational change. 


\section{Applying Deming's 14 points to health care}

The previous sections discussed the need for TQM/CQI in health care and outlined some requirements for the implementation of TQM/CQI in health care organizations. The following paragraphs will explore how Deming's ideas, his 14 principles, could be applied and incorporated into health care organizations. This consideration will offer the reader a parallel perspective to that found throughout the 14 points of Deming's model, discussed previously. They outline some conditions that need to be met in order for TQM to achieve its goals. The discussion of the implementation of this research will explore to what degree these guidelines have been followed and what effects their presence or absence have on the implementation and outcomes of TQM.

\section{The role of Top Management}

Berwick (1988, pp. 54-57) states that "leaders must take the lead in quality improvement. He further stresses the need to have a " shared vision" among those who "speak for the profession, [and] for health care institutions." A climate of collaboration, to improve health care, must replace that of accusation and defense among health care providers. The new perception among those providers should be, according to Berwick, that "Health care is very good today; together, we intend to make it even better." This corresponds with Deming's call for creating a constancy in one's purpose and a firm belief in one's ability to bring about the needed change.

Casalou (1991, pp. 36:1/2-5) sees that top management involvement is a critical requirement for TQM and he even goes further to state that "the burden of the implementation of TQM falls squarely on top management." Health care organizations should focus on long term goals, rather than short term goals. 
Moreover, in evaluating outcomes hospitals should look for long term achievements rather than only quick fixes and short term gains. Through "innovation, research and education, and continuous improvement of plant and services", health care organizations will be able to create consistency of purpose.

\section{Investing in Quality Improvement and the Health Care Worker}

"Investments in quality improvement must be substantial", states Berwick (1988). While TQM has proved useful in other industries, and has yielded "high dividends in cost reductions" the same outcomes may be achieved in health care as well. Berwick, states:

Improvement requires additional investments in
managerial time, capital, and technical expertise ....
The most important investments of all are in
education and study, to understand the complex
production processes used in health care; we must
understand them before we can improve them. (p.
55)

Investing in quality requires a transformation in the management of health care organizations. It means a total abandonment of traditional ways of management by inspection and the adoption of a new approach where preventive measures should replace rework and correction of errors. This new approach corresponds with Deming's calls for ceasing dependence on mass inspection.

Organizations seeking to see tangible results from implementing TQM should also invest substantially in their workers. Respect for the health care worker must be reestablished. Physicians, hospital employees, and health care workers, like workers anywhere, must be assumed to be "trying hard, acting in good faith, and not willfully 
failing to do what they know to be correct." (Berwick, 1988, p. 55). This corresponds also with the $85 / 15$ rule, introduced earlier, which looks at mistakes and errors as problems in the system rather than blaming only employees. Berwick (1988) comes to the defense of the worker by indicating that "when [workers] are caught in complex systems and performing complex tasks, of course clinicians make mistakes; these are unintentional, and the people involved cannot be frightened into duing better." In order for health care workers to improve their skills and consequently the process health care organizations should drive out fear. "In fact, if they are afraid, they will probably do worse, since they will be wasting their time in self-defense instead of learning" (p. 55) This again corresponds to "Drive out fear" principle stressed by Deming.

\section{The need to identify customers}

As discussed earlier, customers, according to TQM are internal as well as external. Marszalek (1991) identifies the following groups as customers for various services in health care organizations. First, the patients themselves are the "primary" customers, and it is critical to adhere to their requirements in order for quality improvement efforts to be effective. Physicians are also considered customers, but more likely as internal customers, who will play a key role in a TQM effort. Nurses are customers as well and they are customers to the physicians and their input should be valued to ensure a better quality improvement effort. Other health care professionals, such as social workers and health educators, could be viewed as customers. Leaders and managers, other co-workers, and professional associations 
are also important because they also are customers for hospitals. Payers, such as third party payers are among the pool of customers who could influence a hospital's policies. It could be concluded from the above that a hospital has more than one customer and for an effective TQM implementation to take place health care organizations need to gather information from those customers regarding what needs to be improved in order to improve the quality of care and organizational effectiveness (Marszalek, 1991, p.105).

\section{The need for working together}

Deming calls for establishing a partnership between customers and suppliers. Berwick (1988) stresses this principle by calling for an open dialogue between customers and suppliers of health care." Casalou (1991) brings the notion of internal customers to the picture by stating that "the hospital employees should be looked at as internal suppliers." Applying this rule to our "internal suppliers", whose labor is the largest input, will require "cultivating loyalty and providing secure environment for physicians, and other health care workers." The result, according to Casalou, is a "a long-term relationship-commitment between the heath care organization and its employees (pp.134-137). Berwick (1988) believes that "quality improves as those served [the customers] and those serving [the suppliers] take the time to listen to each other and to work out their inevitable misunderstandings. He compares this relationship to a marriage where "Just as marriages do not improve under the threat of divorce, neither, in general, will health care" (p. 55) 


\section{The need for adopting Ouality Improvement Processes}

Deming (1986) calls on leaders to "improve constantly and forever the system of production and services" and to "institute training and retraining". A successful implementation of TQM/CQI in health care organizations will require them to utilize the systematic and scientific approaches to study and improve processes. TQM /CQI includes a host of tools and techniques to analyze processes and improve them. Flow charts, Control diagrams, cause-effect charts, Quality Function Deployment tables (QFDT) could be used to achieve that purpose. Berwick (1988) discusses the efficacy of utilizing these tools in the following:

\begin{abstract}
Modern technical, theoretically grounded tools for improving processes must be put to use in health care settings. The pioneers of quality improvement, Shewhart, Dodge, Juran, Deming, Taguchi, and others, have left a rich heritage of theory and technique by which to analyze and improve complex production processes, yet until recently these techniques have had little use in our health care
\end{abstract} systems (p. 55)

The nature of health care activities is in fact a supportive force for the use of these systematic tools. Berwick, again, identifies some of these processes where these tools could be used to examine and improve a process.

Processes that can be improved by means of systematic techniques abound in medicine ... such as the ways in which hospitals dispense medications, transfer information, or equip and schedule operating rooms. But even individual doctors create and use "production processes." In this sense, the way a physician schedules patients constitutes a process, as does the way he or she prescribes medicines, gives a 
patient instructions, organizes office records, issues bills, or ensures that high-risk patients receive influenza vaccine (p. 55).

Therefore, educating employees on how to use these tools to examine and improve a process should be a top priority for those organizations who want to be able to reach tangible results with their quality improvement efforts. Thus a continuous process of training and retraining should be part of any TQM/CQI effort. In the next section we will examine organizing for quality.

\section{Organizing for Ouality}

Health care institutions must "organize for quality", states Berwick (1988, p. 56). Through Process Improvement Teams, training, and leadership commitment complex processes could be "tackled" and improved. Furthermore, health care regulators must become "more sensitive to the cost and ineffectiveness of relying on inspection to improve quality." Specifications of process (clear, scientifically grounded, continuously reviewed statements of how one intends to behave) are essential to quality improvement, on the other hand, and are widely lacking in medical care (Berwick, 1988, pp. 54-56). Therefore, all those health workers participating in the organizational processes should be part of the quality improvement effort. Without their commitment goals will not be achieved.

Finally, physicians should be an integral part of the quality improvement effort. Berwick (1988, p 56) affirms that "quality improvement has little chance of success in health care organizations without the understanding, the participation, and in many cases the leadership of individual doctors." Because of their involvement and effect on a broad spectrum of hospital processes the medical staff will have a critical role in TQM implementation. 
The above corresponds with many principles stressed by Deming, such as "removing barriers to pride in workmanship, eliminating barriers among departmentsby involving everyone, instituting education and training, and taking action to accomplish the transformation. This latter step is done through a carefully planned improvement process that will be aimed at bringing a long term cultural transformation in health care organizations.

The previous sections explored TQM/CQI in health care from a conceptual view. First, a looked at how it is seen by major writers in the field was provided followed by a discussion of some requirements for incorporating it into health care. Also discussed, is the relationship between Deming's ideas and the implementation of TQM in health care. It could be concluded that TQM in health care has many of the same elements found in the rest of TQM efforts in other industries. In order to further pursue this point the next step will explore an implementation story of TQM in some health care organizations that might aid us in our research. This will be seen through the National Demonstration project experiment.

\section{TOM/COI Implementation in Health Care: a Quality Story}

Many health care organizations are looking at TQM with a sense of scrutiny and anticipation at the same time. The stories of TQM implementation in the health care field are accumulating and more have to be reported yet. The following section will present one of these quality stories that illustrates the implementation of TQM in a health care setting. It should be mentioned that the story reported here offers a summary of a comprehensive project and is included for illustrative purposes.

\section{The National Demonstration Project (NDP)}


In the informative book, Curing Health Care, ${ }^{1}$ Berwick et al (1990) describe an experiment in the application of quality management to health care. In this experiment, which was called the National Demonstration Project (NDP), " over 100 clinicians, health care executives, and industrial quality control professionals ... assembled in Boston in 1987 to begin an experimental trial of the applicability of quality management methods to health care organizations."

The NDP consisted of 21 experts in quality management, coming from a variety of organizations, such as industry, consulting firms, universities .. etc. Those experts were "matched" with teams representing 21 health care organizations, ranging from hospitals, health maintenance organizations, to group practices. Berwick goes on describing the NDP:

The quality experts were being asked to offer their expertise and tools to a health care firm willing to try them. The health care participants' assignment was to arrive in Boston with a brief statement of an intemal quality problem that had to date eluded solution. ( $p$. 23).

During the first planning meeting, which took place in 1987, twenty one "arranged marriages" took place. Each of the 21 experts were assigned to one of the 21 health care quality improvement teams (QIT) $)^{2}$ and they worked together to "try out" TQM tools and techniques in a health care setting. The teams were introduced to various TQM improvement tools such as flow charting, cause-effect diagrams, Pareto charts, etc. For two days of training and workshops the teams produced a "formal

\footnotetext{
I. For more details about the NDP please refer to Curing Health Care, by Berwick, 1990, Jossy-Bass Publishers; CA.

2 . Some organizations refer to Quality Improvement Teams as Process Improvement Teams as well. The terms are used alternatively.
} 
definition/statement of the issue to be tackled, a work plan, and an agreement to return to Boston eight months later to report on progress at a summative conference" (Berwick, 1990, p. 24). The experience of those pioneering projects could provide an answer to the question: "Can modern quality management methods help in health care, and, if so, how? The following section/s briefly present the experience of these teams and also discuss some of the key lessons that could be learned from the NDP itself.

\section{The National Demonstration Project: An Experiment in Quality Improvement}

As mentioned earlier, the QIT health care teams started with selecting a problem or an area of improvement that needed to be worked on, and then forming Quality Improvement Teams to examine the problem and to carry out the implementation of the improvement project. The third step was to "diagnose the problem" through examining the process that relate to it, and by gathering information about the problem in order to find out the actual causes of that particular problem. The next step was to plan, test, and implement the recommended solution based on the knowledge gained about the process. Finally, an evaluation process was applied to "continuously monitor performance at the new level" to ensure an effective implementation and modify any parts of the process that need to be changed to realign with the goals of the quality improvement. Following is a more detailed description of each step. 


\section{Defining the Problem}

A clear definition of the problem statement, or the "quality opportunity statement" as they are called sometimes, is the first step in implementing a TQM project. A careful and accurate identification of the problem is critical, because it will provide the base upon which the rest of the quality improvement project will rest. Berwick (1990) states 5 principles required for a "sound" problem statement. First, the problem statement should " reflect shared values and have clear purpose." Some of NDP have had to change the definition of their problem statements to reflect a clearer purpose as will as a shared definition of the problem. The second requirement is the problem statement "should NOT mention either causes or remedies", this will be done later. The main goal of the problem statement is to present the problem. The problem statement should define problems that are "measurable" and "could be managed in size." This means that the team has to downsize the effort to be within its capacity to manage it. Finally, the problem statement should be "refined as process knowledge is gained." This implies that the statement should be flexible enough to allow modifications. Following are some of the problems that NDP teams worked on.

* At Massachusetts General Hospital, a high proportion of bills to Medicare were returned because the bill was incorrect.

* At the Children's Hospital the time taken to fetch critically ill infants needing transport from outlying hospital seemed too long (Berwick, 1990, pp. 47-66).

The second stage of the process was forming teams and working with quality professionals. Quality Improvement Teams represent a collective effort to solve a 
problem. Naturally the pooling of more than one head will be a definite plus. Moreover, teams provide a support system for the employees who gather to share ideas about what might be bothering them and what could be done improve it.

The third stage was what Berwick calls "the diagnostic journey." In this stage the teams gathered information about the process to be improved and utilized variety of TQM/CQI tools, such as flow charting, cause-effect charts, and so forth. By doing what is called the "aha!", the team is trying to complete the phrase "so that's why" [we have problems with our admission process], for example. "These 'aha!'s are moments of understanding where the problem is occurring and why. For example, one of the hospitals, Evanston, was involved in solving the problem of crowding in the operating room which was not being ready on time. Their "aha!" or "so that's why" was phrased like this: "So that's why the operating room was packed up everyday!. It is because the charts for the first surgeries of the first day were not ready in time, (Berwick, 1990 p. 108).

The next stage was to implement the recommendation to improve the process. This "remedial process" consists of developing the remedy, implementation and testing of it, and dealing with resistance to change. (Berwick, 1990, p.109). Some of these teams who have been successful in their efforts have encouraged participation of all those involved in improving the process. They allowed time for input and were flexible enough to modify the remedies to adapt to the new gained knowledge. Those teams who kept their projects focused were able to further the process and reach a positive outcome. Working together with the leadership was another ingredients for success for NDP teams. Successful teams did not resort to blaming and they treated their members, and employees at large, with respect, (Berwick, 1990, p. 132). 
Berwick (1990) lists various strategies that the teams have implemented to improve the process. First, some teams found that some of the processes were "unplanned" and so to remedy that they designed a clear and simple plan. Another strategy is to replace the process to make clearer and eliminate the waste and the unnecessary steps (Mass. General Hospital). Many teams found out that it is important to inspect the process "early enough to correct for errors and prevent them from becoming major errors." An example on that was Evanston hospital. Their team has instituted "preoperative medical records for the first-case surgery the day before the scheduled operation. This allowed them more time to correct mistakes and complete the records" (p. 132).

The final stage was to institute the change and achieve a cultural transformation. By continuous evaluation and measurements of outcomes, through statistical and systematic process, TQM gains could be maintained. Strengthening the feeling of the ownership of the process helped the team work harder and reinforced their commitment to the improvement effort. This final stage, requires a continuous repetition of the PLAN-DO-CHECK-ACT cycle, introduced earlier, in order to ensure a continuously improved process. Thus far we have examined the implementation of these teams, but what lessons could be leamed from NDP?

\section{Lessons from National Demonstration Project}

The first lesson, according to Berwick (1990, p.144), is that "TQM tools can work in health care." As could be concluded from the experience of the NDP participating teams who reported "simple, elegant, stories of successful application of the basic tools..." teams reported "we saw things in a new and different way." The second lesson is that "cross functional teams are valuable in improving health care 
processes". By sharing information, joining efforts, and building commitment to the process improvement, cross functional teams have more power to get things achieved. Third, Berwick affirms the abundance of data about how to improve the processes in health care. The teams reported that many times they just needed to analyze the existing data to examine the process. That doesn't, however, exclude the need for additional sources of data gathering and analysis. The cost of poor quality is high, and sometimes it exceed the cost for implementing TQM to improve the process.

In addition to the above, one of the challenging lessons learned indicates how difficult it is to involve doctors in the TQM process. Attracting more doctors to these teams proved crucial. Physicians' involvement in the process improvement is a necessity that could be achieved through removing barriers and changing the culture of the hospital to allow more participation and create more collaborative atmosphere for doctors to get involved.

Moreover, one of the key lesson of the NDP is the "need for training", as early as possible. Many members, according to Berwick (1988, p.153), expressed the need for more comprehensive training to be able to carry on a successful TQM process. This training should focus on building working knowledge of the various tools used in TQM. Another lesson indicates that "Health care organizations might need broader definition of quality." Due to the nature of their products and the complexity of their tasks, health care organizations might need to develop broader quality statements. One of the NDP teams states " The biggest obstacle to implementation of these [TQM] techniques in health care may be ambiguity, especially in academic health care facilities, about the collective definition of the word 'quality itself", (Berwick, 1990, p. 157). Finally, the most important lesson that could be derived from the experience of those quality champions is the role of leadership in 
creating the transformation. Berwick states "The quality transformation depends on leaders. Their commitment, support, and involvement is critical if things are to happen in a TQM way.

The above example (NDP) explored one of the pioneering experiences in applying TQM to health care. The experience of those teams suggests that TQM has proved its value for health care organizations. Our study will carry this exploration a step further by providing a comparative case study approach that examines the experience of three health care organizations with TQM. The National Demonstration Project represents a courageous and pioneering effort to bring TQM to health care. The next section will briefly introduce the study and describe its major goals as well as its main questions.

\section{ABOUT THE STUDY}

While there is an abundance of research and documented literature about TQM in the private sector, the literature that assesses the implementation of TQM at Public sector organizations is still relatively scarce. This study attempts to help fill in this vacuum by providing additional information that might be useful to those in the field. Moreover, this study attempts to address a gap that exists in the literature when it comes to implementing TQM in the public sector. As we have seen earlier, the literature review has discussed approaches to the implementation of TQM. One of the goals of this research is to assess how do these organizations go about implementing TQM, in other words what process do they follow? This assessment will include an examination of the adopted approach for implementing TQM. By doing so this research will provide relevant information about the introduced approaches and will 
help describe their applicability in the practical field. The next section will elaborate on the goals of the study.

\section{Goals of the study}

This study explores a focused aspect of TQM implementation. It examines the experience of three health care organizations who, for the purpose of this research, differ in mainly in their ownership, that is whether they are privately or publicly owned. The study has three goals: first, to determine how these health care organizations implement TQM. In other words, what are their Quality Stories. The second goal is to find out any differences or/and similarities that might exist in the implementation strategies among the three organizations and what is the relationship to type of ownership. Finally, the third goal is to present some principles derived from the experience of those organizations, or what we will identify as lessons learned.

This research, in essence, explores an area of significance to those in the public sector who might be interested in starting a TQM initiative in their organizations. By presenting the Quality Stories of these three organizations this study attempt to provide the professional with a comparative base or a frame of reference and some guiding principles. Moreover, and given the underlying differences between the private and the public sectors some public sector leaders might have concems about the reliability of importing the TQM methodologies into public sector organizations. This study explored how both public and private health care providers implemented TQM in their organizations and their qualitative response to the process. Their quality stories provide useful information to those in the public sector about the relevance and potential 
effectiveness of TQM for their organizations. By using a comparative approach and soliciting input from participants in both sectors, the study provides information about TQM's applicability in public sector organizations. In addition, the experience of these organizations' implementation of TQM and the relationship, if any, to the ownership of the organization provides information heretofore unavailable. In other words, to what degree does ownership influence the success or failure of a TQM initiative?

In conclusion, this study focuses on three aspects that relate to TQM. First it focuses on the process of implementing TQM by presenting the quality stories at the three organizations that participated in the study. Second it establishes some comparisons among these organizations by comparing them against each other. Finally it attempts to present some concluding lessons that could be learned from the experience of those organizations who participated in the study.

This research could be considered as a pioneering effort since it provides a comparative examination of the implementation of TQM at both public and private organizations, which seems to be a gap that needs to be bridged in the literature. In fact, most, if not all, of the reviewed literature describe the experiences of single public sector or single private sector organizations with TQM, but not taken together. This study bridges that gap by providing the reader with a documented case study that combines the experience of public and private organization all in one comparative approach. The reader will be able to better understand the implementation of TQM in both sectors thanks to this comparative approach. 


\section{GENERAL CONCLUSION}

The previous pages include a review of some of the relevant literature that defines, analyzes, and documents TQM processes and strategies. First, there is a presentation of the major theoretical and conceptual basics of TQM. Then a discussion of the various aspects that relate to the implementation of TQM is provided; these included guidelines and requirements for its success as well as forces that might hinder its progress. Moreover, this section includes an examination of some approaches and models for the implementation of TQM in both public and private sectors. A documented description of some examples of TQM in various types of organizations is also included in this review of the literature. The literature review, especially the latter parts, have been laying the grounds for introducing the reader to the study and familiarizing him/her with its purpose and justification/s, which will be the subject of the next chapter. 


\section{CHAPTER V}

\section{Methodology and Instruments}

\section{Introduction}

From reviewing the literature, it can be concluded that TQM/CQI is a comprehensive approach for organizational change. In fact, it is perceived by authors such as McLaughlin (1990) as a "new paradigm shift". It could also be concluded that $T Q M / C Q I$ is a cultural change that requires transforming thinking from the previous inspection and discovery of errors to continuous improvement of organizational processes that will result in more efficient organizational systems that align with the organization's quest for quality improvement. In this way it can be said that TQM/CQI relies on collective efforts of all participants, stressing teamwork and group effort in order to find valid solutions to quality improvement issues. It is in the spirit of Deming's teachings that TQM calls for shifting the focus from instructing the worker /employee in order to maximize the number of products, to educating them on how to contribute to the advancement of the total system. In so doing TQM focuses on the total system and the interconnected processes that take place among those involved. The holistic view of organizational activity is gaining more and more attention and support. 
A great deal of research has emerged since the first implementation of TQM/CQI in industry and the private sector. Many practitioners in the field stress that $T Q M / C Q I$ can be as successful in service or public sector organizations as it is in the private sector. One of the supporters is Akande (1992) who has the following comments about implementing Deming's model (14 points) in service oriented organizations. ${ }^{1}$

The 14-point 'quality management' concept introduced by W. Edward's Deming in the 1950s is not as widely adopted in the service sector as it is the manufacturing sector. This is mainly due to the belief among service industry leaders that the two industries are so different that what works for one may not necessarily work for the other. The misconception that Deming's quality management can not apply to the services industry stems from industry leaders' unfamiliarity with the concept, their inability to interpret Deming's concept into terms that apply to the service sector, or their inability to find ways of integrating quality management ideas with the corporate culture. However, it is argued that Deming's management methods can be successfully implemented in the services industry.

The above comment suggests that it would be wise for service organizations as well as public sector organizations to educate themselves in TQM principles and to reach to a deeper level in analyzing the potential of TQM in their organizations. An

${ }^{1}$. Applying Deming To Service. (W. Edward's 14-point guide to Quality) by Adebowale Akande V.30 Management Decision, May '92 p3 (6). 
organization seeking to adopt TQM strategies needs to have a better understanding of TQM as well as to be flexible enough to adapt to change associated with TQM.

Earlier in the discussion, the study explored quality stories of various types of organizations implementing TQM. By studying the achievements of winners of Baldrige Award in the private sector, and the winners of the Presidential Award in the public sector we could ascertain how TQM helped these organizations to save resources and reduce waste. The next step is to provide a rationale/ justification for the present study.

\section{Justification for the present study}

TQM is emerging as a strong methodology in the field of Organization Development. Throughout the previous discussion, the experience of some private and public organizations with TQM was introduced to provide a theoretical base for the present study. Most of the reviewed literature, however, list or describe individual cases in either public or private sector. The present research makes an important contribution to the field by providing a comparative perspective of implementation of TQM in public and private sector organizations. By comparing TQM innovation efforts in both sectors, we are able to gain a better idea about the efficacy of TQM in the public sector, in general, and in health care organizations in particular. In the following section we will present the research questions and how can be answered. 


\section{RESEARCH OUESTION}

This study examines the potential for importing TQM innovation techniques into the public sector organizations. The specific research questions that relate to the goals stated above are as follows:

- How is TQM/CQI implemented in those three health care organizations?

- Are there any significant differences between public and private health care organizations in their implementation of TQM processes?

- What effect does ownership (whether the organization is publicly or privately owned) have on the implementation of a TQM innovation effort?

All of these questions were considered when formulating the ultimate research question.

Based on the above and the preceding questions posed, the core research question that I intend to seek an answer for in this research is:

How do health care organizations go about implementing TQM/CQI; do they vary in their implementation of TQM/CQI (and if so, how); how significant is ownership (whether being privately or publicly owned) to the implementation of TQM/CQI initiatives; and finally what lessons could be derived from the experience of those three organizations?

The first part of this research question will be answered through the narrative description of each institution's experience with TQM. These will be called Quality Stories, and they will describe the organization's experience with TQM. Each quality story will consist of the following components: implementation approach, the background of TQM at that organization, the impetus for TQM, improvement methods, 
and the current status of TQM at that institution. By gathering information about these components, as well as additional others, we will be able to answer the first question that deals with the process, or the "how is it done?"

The second part of this research question will be answered through the examination of the crossectional data gathered at the three organizations that participated in the study. By comparing the data gathered we will be able to find out what differences, if any, exist among these organizations in their implementation of TQM. Moreover, we will compare what participants at these varying organizations believe about the role of ownership in the implementation of TQM. In other words, by structuring a comparative overview that derives from the crossectional data we will be able to discern whether these differences in implementation, if they exist, are due to ownership or to other factors. Furthermore, we will attempt to identify some of these factors that might cause it to differ from one organization to another, from the point of view of participants in both sectors.

The third part of this research question will be answered through a synthesis of the various findings and conclusions that could be revealed or inferred from the study. These lessons represent the culmination of the exploration of the experience of these organizations with TQM. These lessons will take the various conclusions that could be derived from the data gathered and translate them into informative recommendations to those in the field. Among these lessons there is one to help in deciding on a useful approach for the implementation of TQM. Another will address the role of ownership in influencing the TQM process; a third will comment on why does a TQM approach tend to succeed while another tend to fail. In other words, what is required to succeed and 
what could be avoided in order not to fail. These lessons, and others, will be discussed later in this study.

\section{RESEARCH DESIGN}

\section{Introduction}

Robeen (1987) defines research design as " the plan of procedures for data collection and analysis that are undertaken to evaluate a particular theoretical perspective" ( p. 70). Research design is also seen as a strategic plan for doing the research. Robeen believes that "It is a strategy, whereby the theory, can be at least indirectly tested." (p. 85). In constructing a research design a researcher must take a variety of factors in mind. These factors include questions such as: Who, When, Where, Why, What, How. comprising the data universe.

It is important to recognize, from the beginning, the complexity of this study. The selected organizations are large and very diverse in terms of size and processes, which makes it almost impossible to cover every aspect of their operations. Keeping these factors in mind a descriptive case study design will be more suitable for this study. By the same token, being closer to participants allows to see the various steps of the implementation of TQM/CQI processes, when possible. Therefore, a descriptive, qualitative research has been chosen, because it enables to gain better insights of what is being done at these organizations. The following pages will discuss the critical components that comprise the design of this study, through answering a number of questions. 


\section{Who have been studied: (Unit of Analysis) 2}

The first question was: Who is/are the population/s under examination, in other words what is the unit of analysis (UOA)? Units of analysis could be individuals, groups, organizations, and/or social artifacts (Robeen, 1987). It is obvious that our UOA is the individual public/private organization. The larger unit of analysis, in this research, the population/s, are the public sector service or not-forprofit organizations as well as the private for-profit or industrial organizations. The UOA for the examination is the individual public or private organization under study. Chart I below provides a comparative outlook among the three organizations.

\begin{tabular}{|l|l|l|l|}
\hline Characteristics & PH & PNFP & SH \\
\hline Type of ownership & Private for Profit & Private NOT for Profit & Public NOT for Profit \\
\hline Major Services provided & Health care & Health Care & $\begin{array}{l}\text { Health care and } \\
\text { medical education }\end{array}$ \\
\hline Key organizational layers & $\begin{array}{l}\text { Administration } \\
\text { Employees }\end{array}$ & $\begin{array}{l}\text { Administration } \\
\text { Employees }\end{array}$ & $\begin{array}{l}\text { Administration } \\
\text { Employees } \\
\text { Union }\end{array}$ \\
\hline Key organizational Customers & $\begin{array}{l}\text { Patients } \\
\text { Physicians }\end{array}$ & $\begin{array}{l}\text { Patients } \\
\text { Physicians }\end{array}$ & $\begin{array}{l}\text { Patients } \\
\text { Tax payers } \\
\text { Other legislative bodies }\end{array}$ \\
\hline Source of financial resources & Private owners & $\begin{array}{l}\text { Private NFP } \\
\text { organizations }\end{array}$ & $\begin{array}{l}\text { Tax Payer } \\
\text { Grants and awards }\end{array}$ \\
\hline Coverage & Mostly insured & $\begin{array}{l}\text { Mostly insured or/and } \\
\text { sponsored by other } \\
\text { nonprofit } \\
\text { organizations. }\end{array}$ & $\begin{array}{l}\text { Insured } \\
\text { Partially for uninsured }\end{array}$ \\
\hline
\end{tabular}

CHART I: Comparative Key Characteristics

2. In accordance with the provisions of HSRRC and to protect the identity of organizations and participants, codes and/or generic names are used when referring to organizations and/or individuals. Real names have been kept on file for non-public reference. 
This study examines three health care organizations $(\mathrm{N}=3)$ that were engaged in a TQM innovation effort and that differ in terms of ownership. One is publicly owned by the state, one is private but not-for-profit, and the third is a privatefor-profit organization. Those who participated in the study were either key players in the implementation of TQM or hold key positions that relate to TQM implementation in the organization.

In order to ensure the neutrality of the research it is important to stress that the researcher did not receive any direct or indirect financial benefits that could influence the outcomes, findings, and views expressed in the study. Moreover, those who participated in the study did so on a voluntary basis, and their privacy was strictly guarded. They were asked to sign an informed consent form that outlines their rights, responsibilities, and even potential risks of participating in the study. They were also free to terminate participating in the study anytime they wanted. In order to protect the identity of the organization an abbreviation was assigned to each one of three. The identity of each participant was protected by assigning a code to the participant.

For each organization a number of participants were surveyed. First there were 7 participants (three people at the public hospital, three at the not-for-profit, and one at the private hospital) who answered the General Survey, ${ }^{3}$ which was used to assess the organization in general, to explore its experience with TQM, and to examine its perceptions of TQM processes. The other kind of survey was the Process Improvement Team Survey. 4 This survey was more focused and is aimed at assessing the individual experience of those members who participated in the process improvement teams. A

3 . Please refer to Appendix B for a copy of this survey.

4 . Please refer to Appendix B for a copy of this survey. 
Process Improvement Team (PIT) at the not-for- profit organization was observed for a period of six months. The PIT team consisted of 9 members who worked on improving the quality of the purchasing process at that institution. Toward the end of the project each member was given a copy of the PIT Survey to assess their experience with TQM. Out of the 9 surveys given 6 were mailed back.

Moreover, a series of interviews were conducted, and later transcribed, with some of those involved with TQM initiatives at each institution. As mentioned above, those interviewed were key figures in relation to the implementation of TQM or/and members of a PIT team. Some of those participants were interviewed more than once because of two major factors. The first is the need to gather information from those interviewees over various periods of time as the process progressed at their organization. This allowed to see how TQM initiatives have evolved through time. The second factor has to do with the amount of information those interviewees have and how relevant it was for the study. Given the high demand on those professionals' time it was difficult sometimes to fully cover all the points that needed to be discussed in a single meeting. An additional interview was the solution to continue this exploration process, especially with those participants who were active in the quality improvement initiatives.

In addition to the above, the number of participants who were interviewed is not equally distributed among the three organizations. For example, one person was interviewed at the private hospital (PH), while three participants were interviewed at each of the other two (please refer to the table below). The reasons for these differences have to do with the degree of involvement in TQM an interviewee has, the level of information they were capable of providing, and finally their availability for interviewing. First, the PH participant was the primary Quality Champion at her organization. She is 
the most visible figure who provided training on TQM to the QIT members and who played the liaison between the administration and the quality improvement teams. The size of the hospital is smaller than the other two and therefore she has been fulfilling the roles in TQM that required more than one participant at the other hospitals. Second, the amount of information obtained from this participant at PH was roughly equivalent to that we got at each of the other two. It was necessary to interview three participants at the Not- for- Profit Private (NFPP) and the State hospitals because these interviewees did not have the level of involvement the private participant has. Finally, an accessibility barrier was encountered more at the $\mathrm{PH}$. Since she was the main figure in relation to TQM she was referred to every time an interview was sought. In the case of the other two organizations we were able to get through to more than one participant.

It should be stressed here that the fact that there is one interviewee only at PH should not be considered as a major weakness in the methodology. The same also goes for the team observations that were conducted at the NFPP hospital. In contrast to experimental research it is difficult in qualitative research to have full control of all the population or even the population sample. In order to provide a greater level of reliability and validity this research employs more than one single instrument to draw its conclusions. In writing the Quality Stories for example more than one tool was used to gather data and provide the information necessary for this story. Interview responses, survey results, team observations, and any other available documentation/s were used to build the story. It should be noted that almost all of those who were interviewed, at all three organizations, have also completed the General Survey. Tables III through V below show a detailed breakdown of interviews, interviewees, and surveys. 
Finally, the third group of participants who contributed to this study were the members of a Process Improvement Team at the Private But Not for Profit hospital (PNFP). As mentioned earlier, the team has consisted of 9 members and its activities were extended over a period of 6 months. The team observations and the documented team activity, combined with their responses to the PIT survey, were used as another way to describe the organization's involvement with TQM.

In summary, three organizations were targeted for this research. At each of these organizations, a number of people were invited to participate in the study. These participants were interviewed, surveyed and/or observed. The data gathered by these instruments will be explored and the information derived will be used to answer the research questions and reach its goals. The following tables summarize the numbers of those participated in the study and also indicate the number of surveys and/or interviews that have been completed.

\begin{tabular}{|l|c|c|c|}
\hline Organization & $\begin{array}{c}\text { \# Participants } \\
\text { Interviewed }\end{array}$ & $\begin{array}{c}\text { \# Participants who } \\
\text { completed General Survey }\end{array}$ & $\begin{array}{c}\text { \# of particlpants } \\
\text { Who completed PIT Survey }\end{array}$ \\
\hline Private For Profit & $1 \star$ & 1 & N/A \\
Private Not for Profit Hospital & 3 & 3 & $6 *$ \\
Publicly owned State Hospital & 3 & 3 & N/A \\
\hline Totals & 7 & 7 & 6 \\
\hline
\end{tabular}

TABLE III

TABULATIONS OF PARTICIPANTS IN THE STUDY 
Notes about previous table:

* One of PIT members has completed the General Survey and was also interviewed once in addition to completing the PIT survey.

** One person (only) was interviewed at PH because:

1- She is the principal Quality Champion while there were more than one at the other two.

2- She roughly performed an equivalent job, in terms of TQM, to the other participants at the other two organizations.

3.. Due to the small size of the hospital she is the most visible and accessible person who knows the most about the process. She provided training on TQM and is the lobbyist to the top leadership.

4.. Because of her involvement the information we got from her was comprehensive and sufficient enough for the requirement of the study.

5.. finally, due to administrative and access limitation this participant was the only available professional who could provide us with useful information about TQM at PH.

Table IV below summarizes the various tools utilized to gather data and provide a tabulation of how many of each were used at each institution.

\begin{tabular}{|l|c|c|c|}
\hline \multicolumn{1}{|c|}{ Organization } & $\begin{array}{c}\text { \# of } \\
\text { Intervlews * }\end{array}$ & $\begin{array}{c}\text { \# of General surveys } \\
\text { completed }\end{array}$ & $\begin{array}{c}\text { \# of PIT surveys } \\
\text { completed }\end{array}$ \\
\hline Private For Profit & 3 & 1 & N/A \\
Private Not for Profit Hospital & 4 & 3 & N/A \\
Publicly owned State Hospital & 6 & 3 & 6 \\
\hline Totals & 13 & 7 & 6 \\
\hline
\end{tabular}

TABLEIV

TABULATIONS OF INSTRUMENTS USED IN THE STUDY 
Notes about previous table:

* Some participants were interviewed more than once because:

-- They are key figures who participated in or planned for the TQM initiative/s.

-- In order to examine the development and evolution of TQM over time.

-- Due to time constraints more than one interview was needed to cover all relevant issues.

\section{How: about the sample and methodology}

As stated in the previous section the processes of implementing TQM in these organizations have been examined and comparisons among these organizations were drawn. These findings then were analyzed to derive relevant conclusions that answered our research questions. The samples used in this research are quota samples. A quota sample is chosen because it meets certain requirements that need to be studied. Due to the specificity of the issue of the study it was needed to select those organizations engaged in a TQM effort, since we will reach a better idea about their experiences with TQM methodologies rather than those with no TQM experience.

This study will take a comparative approach. Organizations who have been involved in planning for or implementing TQM processes are to be examined. Participants from those organizations where interviewed, surveyed, and observed. More details about the institutions and the participants are provided in the Quality Stories section. 
When: Time frame of the study

It believed that the optimum results would be achieved from following a longitudinal study. However, the time constraints and the longer duration of TQM projects, (3-5 years) make it almost impossible to do so, at least for the time frame of this research. Moreover these organizations do not share a universal timetable in their implementation of TQM. Some have been in the preparation and planning stages while others might have already started the implementation of quality improvement plans. Therefore, the best alternative was to observe these organizations as much as possible and as long as possible, and to interview different participants in different time intervals. By doing the study aims at maximizing the informative power of the data gathered and to gain a better insights about the organization through time.

\section{Where: The Setting}

This study took place in three health care organizations who, for the purpose of this research, differ mainly in terms of ownership. One organization is publicly owned, another is private but not for profit, while the third is private for profit. Participants from these organizations were interviewed and/or surveyed on the premises of their organizations. Moreover Process Improvement Teams (PIT) were observed, where possible and available, while performing various quality improvement tasks. 
Tools for Data Collection: Instruments of Measurement

As stated in the previous discussion, complexity has been one of the challenging forces for this study. Added to that the time constraints placed on the duration of the research. Given these challenges we relied on multiple methods (instruments) of data gathering. In conducting case study research, using more than one means of data collection is desired, according to Babbie (1986). The study used a variety of data gathering tools, such as surveys, interviews and team observations. Following is a more detailed description of these instruments as they apply to the study.

\section{The Survey}

Keeping all the previously mentioned factors in mind, surveys were constructed to provide answers to the questions posed in the research. These surveys, designed by the researcher ${ }^{5}$, derived their materials from the reviewed literature as well as variety of other resources. For example, in his book "Quality in America" Hunt (1992) includes a survey that is aimed at helping organizations conduct an assessment of the organizational climate and the state of readiness for TQM (pp. 146182). In order for the survey to be an effective tool it needed to ask the right. The two surveys used in this research, the General survey and the Process Improvement Team surveys, were both constructed to get some valuable information that will help answer the research questions. The General Survey first focused on gathering demographic information about the organization under study. Then the survey asked the participants to define their customers. This is done to compare these institutions Appendices.

5 . For a copy of the surveys used please refer to the corresponding section in the 
based on their view of the customer. Another section of the General Survey asks the respondents to rank the role of key organizational participants based on how much influence they might exert over a quality improvement process. Moreover, the survey asks questions aimed at finding out how do private and public organizations perceive the potential of TQM in each sector, but more specifically, in the public sector. Respondents are asked to list what similarities or differences might exist between private and public sectors, as they see it. One key point of the General Survey was to ask the respondents to indicate who should champion the quality improvement effort and where should it start. Another key topic of the survey to explore what might promote change and what might hinder the progress of TQM. Finally the survey asks respondents to indicate what factors they believe to affect the adoption, planning, or and the implementation of TQM.. In general the survey is aimed at soliciting information that will shed some light on the nature of TQM and any perceived differences between public and private sectors as they relate to TQM.

The PIT survey which is a more focused survey was mainly designed to explore the experience of those organizational participants who took part in a TQM effort. It asks them, as in the case of the General Survey, to comment on what they learned, what would facilitate TQM and what would hinder it. Moreover, PIT survey was designed to help explore the experience of the members of the Process Improvement Team, and thus it is more direct and focused. But what does these survey help us achieve.? In other words what is the purpose of the survey? This will be answered in the next question.

The survey, in general, serves four purposes. First, it provides a useful information about the institution and its operation and, in addition, it provides a 
preliminary information about how participants defined TQM and how they perceived their organization's TQM efforts.

Second, the survey is useful as a first step in the research process by introducing participants to the researcher and the research questions. Furthermore, it helps lay the groundwork for the interviews.

Third, the survey provides a road map for the interview itself, in that, it helps both interviewee and interviewer to have a structured and organized process for the interview. It provided consistency for the researcher in that the major points from the survey were used as to formulate interview questions.

Finally, the survey helps provide documented responses to the study's major questions. These have been used, along with other gathered materials, in deriving the conclusions and the findings for this study. By combining responses to the surveys, those gathered during the interviews, and the information gained through team observations, more comprehensive and in-depth findings were possible.

Two kinds of surveys were used: the General Survey, which was used to gain a better idea about the organization, its experience with TQM, and perceptions of participants. The second survey was the PIT Survey. This survey was more focused and was aimed at assessing the individual experience of those members who participated in the process improvement teams.

It should be stressed that the nature of the study is observational, and the survey was used as a secondary source of data rather than the backbone of the study. I believe that the combination of surveys, interviews, and team observations enhanced the richness of the information gathered during the study. This process of "using 
more than one method to examine the same dimension of a research problem" is termed "Triangulation" by Jick (1983, p. 136)

\section{Surveving procedure}

Respondents were contacted and upon their agreement to participate, a survey was sent. As a rule, when an interview was scheduled, it was conducted after the participant had completed the survey. However, some interviewees chose to go over their responses to the survey and elaborated on them during the first interview.

\section{The interview}

Although the survey provides important information about the institution and its implementation or exposure to TQM, personal interviews were held with some organizational participants who had been involved or even exposed to TQM processes. The interviews help gain more in-depth understanding of the views of managers, employees and even consultants who have been implementing TQM. Through these personal encounters first hand data about the process was gathered. Information about how did the interviewees felt about the process and the implementation was also attained. The in-depth interviews are a very useful tool in exploring issues, because they help the interviewer to follow up on certain dimensions and allow him/her to expand their search and gather more information by asking more questions. The survey, on the other hand, is limited in this aspect.

Another benefit of interviews is that it provides a way to establish a network of recommendations and referrals, through which one is able to conduct more interviews. In the case of the Not-for-Profit (NFP) organization, for example, a 
recommendation of an interviewed manager made observing a complete TQM process possible.

Third, the interviews help introduce new ideas about the subjects. The people interviewed were professionals who have extensive knowledge about the organization and the field, in general. Through their eyes, it was possible to see many new insights that added to my knowledge and understanding of the subject of my study.

It should be stressed here that one of the primary requirements of the selected sample ( 3 hospitals) is to effectively be a representative sample. This means that the three hospitals should provide relevant information about TQM. In other words the data gathered at these institutions should be a reflection of the larger number of private and public organizations implementing TQM. By gathering data via the three tools, survey, interview, and team observations, this sample has been greatly examined.

Table V, below, provides a detailed break-down of participants at each hospital; and it also provides information about the number of interviews or/and surveys, each participant completed. 


\begin{tabular}{|c|c|c|c|}
\hline & $\begin{array}{l}\text { * of Interviews } \\
\text { completed }\end{array}$ & $\begin{array}{l}\text { Howmany General } \\
\text { surveys completed }\end{array}$ & $\begin{array}{l}\text { Howmany PIT } \\
\text { surveys completed }\end{array}$ \\
\hline \multicolumn{4}{|l|}{ Who participated } \\
\hline $\begin{array}{l}\text { Private Hospital } \\
\text { Participant } 1\end{array}$ & 3 & 1 & 0 \\
\hline Totals & 3 & 1 & 0 \\
\hline $\begin{array}{l}\text { Private Not for } \\
\text { profit: }\end{array}$ & & & \\
\hline Participant 2 & 2 & 1 & 0 \\
\hline Participant 3 & 1 & 1 & 0 \\
\hline Participant 4 & 1 & 1 & 1 \\
\hline Totals & 4 & 3 & 1 \\
\hline Public Hospital & & & \\
\hline Participant 5 & 2 & 1 & 0 \\
\hline Participant 6 & 3 & 1 & 0 \\
\hline Participant 7 & 1 & 1 & 0 \\
\hline Totals & 6 & 3 & 0 \\
\hline
\end{tabular}

TABLE V

\section{A BREAKDOWN OF PARTICIPANTS ACCORDING TO HOSPITALS}

\section{How: the interviewing process}

various managers were contacted, as well as regular employees, and once an interview was granted the survey would be sent. Most of those interviewed were TQM program specialists or at least have some exposure to TQM methodologies. The interviewee was asked variety of question, in addition to any follow-up questions about their responses to the survey. The interviewee was encouraged to give personal 
perspective of things and processes. The questions asked in the interview were guided by the major themes of the study: how is it being done? Does it differ from one institution to another, and how? Also, interviewees were asked to comment on the significance of ownership, i.e., being private or public, to the implementation of TQM initiative. Interviewees were also asked questions about their role and involvement in the process, their perception of TQM and how does that tie into the organizational processes.

It is worth noting that each organization has a unique setting, and conditions, and because of that there was a need to adapt the interview questions so they recognize the givens of a certain organization. In other words, asking the same specific questions to each interviewee seemed illogical. However, each interview, as a whole, has to ask universal questions that will allow crossectional comparisons among the responses of the three organizations. More analysis of the interviews will be provided later in the rest of this study.

\section{Team Observations:}

No matter how much rhetoric there is written about TQM there is no better way to explore its capability than to see it in action. In spite of the readings, surveys, and even interviews seeing TQM in action is of special importance. This allowed to see if the involvement in TQM efforts have any role in modifying certain behaviors and attitudes amongst the organizational participants. Above all, it was aimed at seeking answers to these questions: What do those organizations think of it? Does it really work? How? Is it a fad or is it an organized and a promising organizational development effort. Team observations, therefore, could be the most vital components because they allowed the researcher to see TQM principles put to the 
test. Seeing the teams in action has helped me to get as close as possible to those involved in TQM innovation effort.

\section{Who was observed}

Though the theoretical foundations of TQM have been established and furthered long time ago, the practical implementation of the various TQM organizational methodology is still in its early stages. It was not an easy job to find institutions who have been involved in such practices. Gaining access to the field has been one of the greater challenges to my research. However, a combination of luck and hard work paved the way for me to look at one of Not-for-Profit (NFP) Process Improvement Teams(PIT), and to explore additional projects at the State Hospital (SH) as well as at the Private Hospital (PH). A PIT team has been formed to improve the purchasing process/es at the Not-for-Profit (NFP) system. The team was observed for about 6 months, and through this provided a closer look at how TQM is implemented and what are the various stages a process improvement effort goes through. Moreover, team observations have helped provided an opportunity to explore TQM's potential and limitations.

\section{Data Limitations and weaknesses}

Babbie (1986) sees qualitative research as a powerful tool to see things "in action" and thus gain more in-depth insights about certain subject. However and as in the case of most field studies and survey research, it is harder to control the groups under study, in comparison to pure experimental research. 
The main difficulties encountered are: the length of time involved in implementation of TQM, gaining access to the organizations, time constraints, and continuation of TQM projects. It should be noted that more discussion of these limitations will be provided in later sections of the study.

First, it should be noted that TQM/CQI innovation efforts, especially in service organizations, have not been around for a long time. Much research is being done, and many organizations are stepping into the field. Therefore, it is difficult to find an initiative that has been around long enough to assess their "success" or "failure". Taking into account that $T Q M$ proposes long term ongoing planning and implementation, this poses some challenges for someone whose intention is to evaluate a TQM effort in any given organization.

Given a limited time span, a researcher will not be able to find the final outcomes of a TQM project, unless it has been implemented long enough, say 2-5 years. The best way to measure how much effective a TQM innovation process has been is to see whether it achieved its stated goals or not. The newness of TQM practices poses a challenge to any researcher who wants to conduct research in TQM.

In solving this problem, it would be more appropriate to focus on the process of how TQM/CQI is done and how it varies from organization to another. In other words, it will be better to focus on the process, or any partial evaluation of the ongoing implementation of the process rather than the final outcome/s.

The second limitation encountered is gaining access. Though much help was offered in designing the preliminary stage of my research, it should be stressed that not many TQM teams feel comfortable to have an outsider come in and observe or evaluate 
their work. TQM calls on abolishing barriers between the various department, it calls for disclosure and opening oneself. People will feel insecure to have someone watching them disclosing information about themselves. In addition to the personal barriers, official or bureaucratic limitations were encountered. Many organizations do not allow outside observers into their operations. To get in the researcher needs a special permit, to be obtained from the management and other responsible officials, who are hesitant to let outsiders in. Many companies even have stated rules about secrecy of their new projects, TQM being one of them. Their fears of any leakage to the other competitors stand as a very strong factor in opposing the disclosure of their plans.

The third factor, that has posed a challenge to this research is related to the first one. A TQM innovation project calls for a long term process, built on continued planning, evaluation, and change. The time frame for a TQM project is at least 2-5 years. This might limit my ability to reach final conclusions about the efficacy of a given TQM innovation effort. Organizations who have an established history with TQM have been doing it since the $60 \mathrm{~s}$ and $70 \mathrm{~s}$. This research is being done to fulfill an academic requirement and it has to be completed within a timely deadline. It would be unrealistic, unless desired and paid for, to spend 3-5 years observing 3 to 4 organizations involved in such comprehensive efforts like TQM.

\section{CONCLUSION}

It is believed that combining these three means: survey, interview, and team observations, has strengthened the research by providing more than one channel to look for findings and answers sought by this research. Though all three instruments mentioned above were utilized, some were used more heavily than others as the 
situation dictated. For example, when faced with limited access, and less ability to conduct personal interviews, a more written instruments such as surveys or documented implementations of TQM projects were relied upon. On the other hand more interviews were conducted, and more time was spent doing observations at organizations who have been more involved, and/or more open, in implementing TQM.

This chapter has constructed a strategic outline for the study by stating the research questions, by answering various questions related to the research design, and by presenting the various tools used to gather data. A good road map will help the traveler reach his/her destiny and so is a good research design. In the next part of this research the presentation of the data gathered using the above instruments will begin. 


\section{PART II \\ Presentation of data and major findings}

\section{Introduction}

The first part of this study reviewed the fundamental theoretical concepts of TQM and the research design and methodology used. Considerable attention was dedicated to a theoretical assessment of TQM and a review of some of the relevant existing literature. The research design and a number of issues that related to the selected design were also discussed in some length. In addition, the data analysis methods, data gathering instruments and strategies were discussed. In this section, results of the data gathered through the in-depth interviews, the surveys, and the team observation methods will be discussed using the Quality Stories format. These results provide information pertaining to the first part of the research question (how do these organizations go about implementing TQM?). Quality Stories offer a comprehensive assessment of the experience of the study organizations with TQM. The information used to report these Quality Stories has been derived from data gathered using the three available instruments (interview, survey, observations). The Quality Stories serve to describe the experience of these organizations with TQM/CQI which might be of value for those readers who are looking for ways to 
start their quality improvement initiatives. Moreover, these quality stories offer the reader an insightful examination of various elements that relate to implementing TQM. For example, how and why did it start? Who are the quality champions? What was the implementation approach? What are some of the improvement methods and techniques? What results have been achieved? These stories will enable the reader to gain a better understanding of the various processes used in implementing TQM and the pitfalls and successes of the study organizations. This information can then be applied to his/her organization.

Chapter Seven presents and discusses cross-sectional data gathered via surveying procedures at the three organizations that participated in this study. By presenting a tabulation of the cross-sectional data, the chapter provides an answer to the second part of the research question, that is: do these organizations vary in their implementation of TQM? How and Why? Moreover, we will explore what role, if any, does ownership (whether being public or private) play in influencing the planning for TQM, implementation of TQM, and/or outcomes of TQM at these organizations, where/when applicable. Furthermore, the two TQM models that were introduced earlier in the literature review section will receive additional assessment as we exploreparticipants' responses to questions that relate to the components of these models. Constructing such a comparative approach will help bridge the gap between the public and private sectors in relation to the implementation of TQM. 


\section{CHAPTER VI}

\section{QUALITY STORIES}

\section{General Introduction:}

Combining the information derived from the various tools employed in this research provides what is called in the TQM literature, a "Quality Story," (Schmidt, p. 301). A quality story is a narrative description of the experience of an organization with the implementation of TQM. In its full range, a quality story is expected to cover all phases of implementation, outcomes, and any significant conclusions that could be derived from that experience. A quality story provides an accurate picture of the experience of the organization with quality improvement efforts or initiatives.

Because Quality Stories are more descriptive than analytical, researchers conducting qualitative research rely heavily on them to provide a comprehensive picture of what is going on in a particular setting.

The Quality Stories described herein are case studies that are modeled after the Federal Quality Institute's reports on the Quality Improvement Prototype Awards 
for the year 1993. ${ }^{1}$ There are eight major components of the quality stories describedin the present study: 1 . an overview of the organization and/or the background of quality improvement efforts; 2. quality impetus; 3. adopted approach; 4. improvement methods and techniques; 5. present status of quality improvement efforts; 6. quality champions; . results that have been achieved from implementing TQM; and 8. a description of any challenges and limitations that were encountered at each institution. Quality stories provide detailed and valuable information about an organization and its posture towards TQM by providing a comprehensive overview of what is being done in regard to TQM at these organizations.

The quality stories in this study derive their contents from all of the three data collection instruments utilized in the research. In order to construct each quality story this explored the process each organization used in implementing TQM by examining and collating the responses of participants who were interviewed, by using answers to the completed surveys, by using notes and documentation from the team observations at one of these institutions (PNFP). Combining and integrating all of the above resources enabled the construction of the quality stories included in this research. The final product of each Quality Story is a case study aimed at providing an answer to the first part of the research question: How do they go about implementing TQM/CQI? The following chapter provides a comparative examination among these organizations which addresses the second part (do these

'. FQI, Presidential Prototype Awards Reports for 1993. 
organizations vary in their implementation of TQM and what role does ownership play?)

\section{Quality Story 1}

Private for Profit Hospital (PH)

\section{INTRODUCTION}

The first quality story describes the experience of a private for profit hospital, identified as PH. A series of interviews and surveys provided the needed materials for writing the story. It should be stressed, again, that although only one participant was interviewed at $\mathrm{PH}$, the information gathered through these interviews and the other two data collection methods was sufficient to produce an informative quality story. As explained earlier, the participant from PH played a key role in planning, training, coordinating, and documenting TQM initiatives at $\mathrm{PH}$. The comprehensive role played by this participant in the institution provided a unique opportunity for broad knowledge that provided information about every aspect of the TQM effort. Each of the eight components of Quality Stories outlined previously will be discussed in detail.

\section{ORGANIZATION OVERVIEW}

Nestled in a residential neighborhood at the outskirts of the city $(\mathrm{PH})$ provides a variety of services to the local community. These services range from inpatient surgical services, cosmetic surgery, and alcohol and drug treatment services, to 
emergency services. The hospital is licensed for 209 beds and is privately owned.

Private ownership has its advantages as well as disadvantages, in terms of implementing TQM. According to the Quality Management Coordinator at PH, the advantage of being a private is having to worry less about the general public scrutiny, and not having to "lose sleep over state or federal funding" both of which she sees as a "blessing."- On the other hand, she states that the main disadvantage is that PH has to worry more about profit and making financial gains, since these mean survival of the institution. Answering to the share holders is another responsibility added to what PH has to worry about. "Though we are private, we still differ from a private industrial company", adds the interviewee there. This difference is in the focus of the hospital since the "main focus of a hospital is the human being, and the processes of a hospital are more complex"(Participant \# 1, Q. 1).

\section{BACKGROUND}

When asked about their experience with TQM, people at $(\mathrm{PH})$ responded by "we have been doing this for a long time" and "We have been involved in the improvement of quality for quite a while, but we did not call it TQM, then, as we do now." Reducing cost, improving quality of service, and increasing market share have always been big motivating factors for $\mathrm{PH}$. The administrator, who has been looking for ways to improve quality at $\mathrm{PH}$, agrees with the principles of quality 
improvement. Using TQM strategies is seen as a way of streamlining the hospital's services which in the end will result in greater efficiency and increased profits. However, when it came to adopting a specific TQM approach more had to be done to translate the heretofore non-specific strategies into agreed upon TQM actions. This has happened over the past year with implementation of a limited scale implementation of TQM. Because of their early efforts to improve quality, it is not easy to pinpoint the beginning and the end of a specific time frame for TQM. Due to the limited scale implementation of the process and the lack of comprehensive documentation, the timing of the TQM process is based on the responses of the Quality Coordinator at PH who has narrowed the implementation to when the Quality Improvement Teams (QIT) started six months ago. The quality management department was charged with solving problems that posed a challenge to the organization. In fulfilling their charge TQM tools and techniques were used.

\section{THE IMPETUS TO CHANGE: How and Why Quality Improvement Started?}

Faced with increasing competition from other health care providers, $\mathrm{PH}$ looked for ways to gain a larger market share and greater financial stability. One way they saw to achieve these goals was to look for various ways both to save money and to improve overall performance. Although, as noted earlier, the administrator agreed with the principles of TQM, people had to be shown that it was a useful way to 
accomplish what they wanted. The major question raised by those who were going to be involved in the process was "whether TQM is [seen as] a profit or a cost?" to the institution. Their initial projects have been aimed at "streamlining the process, reducing waste and litigation." Time and resources are of concern for $\mathrm{PH}$, and it is believed that management will give more support if they can see that there is improvement at "the bottom line, more preferably if the improvements could be translated to actual numbers."

The quality coordinator, who is a part of the Quality Management department, has been the key organizational figure in the improvement efforts. She states that PH has not adopted any particular TQM approach. "Though quality is a concern for us, we are not launching a massive comprehensive TQI program, because of COST concerns" 2, adds the quality coordinator at PH. They have been using Quality Improvement Teams (QITs) examples, to improve certain processes at the hospital. "We are worried about results more than the process. In general, we believe in using the process to get better quality," she adds.

It could be concluded, then, that PH is in its early stages of adopting TQM and has not yet initiated a comprehensive TQM process. The need for achieving financial gains and improvement results has prompted the hospital to look at quality

2. Please refer to Interviews at PH, Appendix D Q. 13. 
improvement as a way of saving money and solving some functional problems. But that same reason has crippled the hospital's ability to get more involved on a larger scale. In the following sections we will explore the improvement methods as envisioned by $\mathbf{P H}$.

\section{APPROACH TO OUALTY IMPROVEMENT AT PH:}

It should be mentioned from the beginning that it is quite possible for any institution to use a combination of the various approaches to the implementation of TQM. In the case of this private hospital (PH), we could identify an interest and a desire to adopt what has been called the cascading approach. However, upon close scrutiny, the pattern that exists at PH is in fact what Carr (1993,p. 206) identifies as the "spotty pattern." Characteristics of this pattern include the following: some people in the institution get formal training and education on the TQM principle of teamwork and a few of the tools used in TQM efforts. However, contrary to Deming's advice and counsel, top management did not learn anything about TQM or use it first, as would have been the case in the cascading approach. According to Carr, this spotty pattern approach delivers "few results, and always dies." In the case of PH, however, there is an awareness that it is important that top leadership be closely involved in the process. One of the quality champion's (our interviewee) major goals is to get administration's commitment to TQM and get higher levels of 
management educated in it. This goal signals a desire to move towards a Cascading approach. This could also be concluded from one of the responses we gathered through one of our interviews: “... we prefer an OK process with bigger results, rather than a huge process with little results" (Q.10). Moreover, PH prefers to adapt any approach to the needs and requirements of the institution. Any approach that is adopted will be expected to align with these requirements and to be flexible enough to adapt to the internal and external environments of the hospital.

\section{QUALITY IMPROVEMENT METHODS:}

As discussed earlier, PH has not as yet launched a comprehensive quality improvement process because of the perceived additional cost of an all out program and the time restraints individuals expressed through the interviews and surveys. Moreover, $\mathrm{PH}$ is still in the initial stages of adopting and/or implementing TQM. The major indicators of PH's focus on quality improvement are the activities of its Quality Improvement Teams, and its drafted Quality Policy/Plan that outlines the team's perception of TQM and the plan for implementing Quality Policy quality improvement processes. One of the major components of this policy concerns the role and the structure of Quality Improvement Teams (QITs). This section includes a discussion of this quality policy and explore some improvement examples, as provided by interviews, surveys, and PH's documented literature. 
Oakland (1989/93) states that an organization either implementing TQM or planning for it should have a TQM Quality Policy. This policy establishes the major guidelines and the theoretical framework for using TQM to improve organizational processes. Most organizations engaged in a TQM process draft their own policies. At PH the TQM Quality Policy has six guiding principles as its focal points.

The first point stresses that Quality is important, and this dictates the need for improved quality. The second key point connects customers and quality by stating that Quality is customer driven. When asked to identify their customers, PH participant/s responded by including patients, their families and third party payers as their external customers. On the other hand, they listed physicians, nurses, and other departments as their internal customers. One more focal point that is stressed throughout this policy is the need for a scientific way of thinking, and the adoption of the scientific approach in dealing with problems or areas of improvement. Another key issue of this policy states that "Errors are a result of a flaw in the system not the people." This point is a reflection of the $15 / 85$ Pareto rule discussed earlier. Quality improvement should be perceived as a continuous process. Finally, PH policy calls for involving everyone in the quality effort and calls on everyone to contribute. In their responses to the questions of the General Survey PH believe that top management is the most important force in the quality improvement process. One could easily see 
that these points of PH's quality policy are an adoption of the guidelines found in the writings of Deming, Juran, and other TQM "gurus".

Nevertheless, the institution is still in an introductory phase of their adoption of TQM. The following section provides a description of the phases through which quality improvement has gone thus far; and it describes PH's plans for the future as derived from the various sources examined.

How did Quality improvement start and what are the various phases it has gone

\section{through at PH?}

Jablonski (1991) has identified 5 stages through which a TQM effort goes. These stages are: preparation, planning, assessment, implementation, and finally diversification. These stages have been discussed in the Literature Review part of this study. By looking at the experience of $\mathrm{PH}$, we can recognize some of these phases, especially the initial one. For example, when asked about how quality improvement started at PH, the quality coordinator described how they went about preparing for quality. A common response to this question is that "... interest in TQM began a -long time ago at our hospital". During this initial stage, the quality coordinator was sent to two conferences on the utilization of TQM in health care organizations. Although the administrators support the quest for quality, they have NOT been involved in the initial process. Those individuals who did attend the TQM seminars 
served as quality pioneers, or champions and they were assigned to work with various members of Quality Improvement Teams (QITs) who were working on departmental problems. Therefore, this stage is characterized by an interest in quality and some efforts to leam about it. The top leadership (the administration) has "agreed to the adoption of TQM as a concept, and they expected good results" $(\mathrm{Q}$. 12). However, the top management has not assumed the role of the TQM champion, which is something this participant is trying to commit them to do. It seems that the management has a "show me it works first" attitude about TQM. In other words, management is supportive of improved quality but they are skeptical about TQM. Thus they have been looking at TQM through the activities of the Quality Improvement Teams in order to test for TQM's potential and benefits. As this participant puts it "we are talking about it ... the hospital as a whole has not gone TQM yet." The commitment of the top leadership is reflected through approving TQM as a concept and sending some members to some seminars and other educational activities.

The second phase through which quality improvement goes is Problem Identification and Team Formation. TQM innovation projects at PH started as individual initiatives to deal with certain problems encountered on a departmental level. These projects or "opportunities for improvement" as they are called at PH are 
conceived in any of several ways: suggestions from employees, patients' complaints, survey results, management's strategic decisions, and so on. Teams were formed to deal with problems ranging from the admission process, medication administration, to follow-up with customer complaints from receipt to ultimate decision. The analysis of a process is performed by the Quality Improvement Team.

These teams have had the responsibility for coming up with working solutions to these problems (quality improvement opportunities). Once formed, a team can be expanded or changed as needed to support increased knowledge of the process. However, every QIT that cuts across department lines should be approved by administration. When asked about how these teams examine a process, the responses were interesting:

In studying or examining a process we explore inputs, we consider actions and decisions, and we deliver and expect outputs, as illustrated below:

Inputs $\Longrightarrow$ Actions and Decisions $\Longrightarrow$ Outputs

The process is ultimately judged according to the degree the outputs meet the needs and expectations of the customers.

(Excerpts from interviews at PH, Q. 3)

The Quality Improvement Teams formed at PH have to follow certain guidelines. First, the final team has to consist of 4 to 8 people who must have handson knowledge of the process under consideration. This condition is inspired by 
Deming (1986) who stated that the best people to make a decision about a task are those who are involved in doing the task and that all the important steps of the process must be represented by people in the team. Second, the composition of a QIT is then assessed in light of this process, and questions like: "are there other people who should be involved?" are asked. This involves other members who are perceived to be important to the improvement process.

The initial teams at PH were nurses and employees. Management [middle management and supervisors] got involved later in the process. Although top management has been supportive of the activities of these teams, they were not involved on a comprehensive scale in the implementation of TQM techniques. Once the QITs were formed they undertook the Nine Step Plan, (which will be described later). This plan projects out, over several months, the steps that will be taken. The Nine Step Plan will be updated as the team goes through its work. Finally, the team embarks on its work"

Each team has included a number of key roles. First, there was the team leader who is responsible for scheduling meetings, forming a plan of work, and making sure the agendas are followed. Then there is the recorder who keeps brief minutes of the meetings and records the agendas for the next meeting. The third role is the timekeeper whose responsibility is to make sure the meeting stays on the agenda and ends on time. One of the key roles of the Quality Improvement Teams is 
the role of the facilitator who is not a member of the team; the facilitator provides technical counseling to assist the team in the TQM/CQI process. The Quality Management Coordinator played this role at $\mathrm{PH}$.

One of the major responsibilities of Quality Improvement Teams at PH was to draft a Quality Plan (Plan of Work). "First we identify an area of concern, second we form teams to improve the process, and then we design a plan of work." ${ }^{13}$ These words are used to describe how the QIT deals with improvement initiatives. The Quality Plan consists of nine steps which provide a road map to quality improvement. These steps include: constructing a charter in which the problem is identified, constructing a visual presentation of the existing process by drawing flow-charts, analyzing the customer needs, writing a quality opportunity statement, and establishing measurements for the process. Additional steps are, constructing a variety of charts, such as run charts and Pareto charts that would be used to analyze the process itself. Once the process is analyzed, the implementation of the improvement recommendations will follow. Constant measurements and evaluation will be needed to ensure the cycle of continuous quality improvement.

This plan was designed to assist the Quality Improvement Teams at PH in their improvement efforts. When asked how they drafted such a plan, responses

3. Please refer to Appendix D for a detailed description of this plan at PH. 
gathered at PH indicate that they used various concepts acquired through learning about it, attending seminars, and other suggestions from the QIT members themselves. The various components of this plan outline some techniques and methods aimed at the improvement of quality of service and the delivery of health care at PH. For example, some teams drew flow-charts of certain processes they were trying to improve while other teams used brain- storming and customer surveys to find out relevant information that was needed to improve the process. Finally, this plan represents the hospital's documented approach toward quality improvement (TQM), and hence it serves as an indicator of how PH implements TQM. The next step in this Quality Story is to assess the present status of quality improvement at Private Hospital.

\section{THE PRESENT STATUS of TOM at PH}

Quality improvement is a long journey that requires commitment and hard work. Changes do not happen overnight and real improvement, according to TQM, occurs when a cultural change takes place in the organization (Weaver, 1991). This is particularly true in the case of PH. A sense of anticipation and skepticism could be felt in the responses gathered at the hospital. For example, when a participant at PH was 
asked to assess the present status of TQM the following response and justification were given:

We are talking about it. Though the hospital as a whole has not gone TQM/CQI yet, we have some implementation of TQM/CQI techniques through the QIT activities."

(Participant 1, please refer to Appendix D)

Moreover, the hospital is adopting a more cautious posture towards implementing TQM. 'Let's wait and see" is the major attitude that could be felt throughout the documented responses from PH. When asked about which method in implementing TQM the hospital prefers, the respondent gave the following answer:

... there are different ways of doing TQM/CQI. One way might be having a huge process, but ending up with little results. But the other way, that we prefer, is having an $\mathrm{OK}$ process that might yield bigger results. This way stresses that you do not spend all of your time and energy on process; instead try to achieve nice results, without ongoing outlay of labor before you start seeing anything.

(Participant 1, please refer to Appendix D)

When the research at PH concluded, additional Quality Improvement Teams were to be started. Moreover, some staff and management members were scheduled to attend an educational seminar. More in-house training was scheduled. Top 
management support and commitment was one of the priorities on the Quality coordinator's list.

\section{QUALITY CHAMPIONS at PH}

A great deal of TQM/CQI success could be attributed to the innovation and vision of individuals who make it happen. Those Quality Champions, as they are frequently called, display a high level of commitment and dedication to the improvement effort. They could be top managers, middle mangers, or even regular staff members. The champions are distinguished with their contribution to the quality improvement efforts and their advanced level of interest and knowledge of the process. They are highly motivated, and they help in educating others about TQM/CQI. Many TQM efforts have succeeded because of the top management role as the champion for change and continuous improvement.

At PH the first Quality Champion is the Quality coordinator. She has been active in training QIT members, documenting and writing the quality policy, and more importantly lobbying to the top administration for support. However, through the various interviews conducted with her, a sense of cautious optimism could be felt. For example, when asked about how she feels about TQM, her response was: " $a$ little ambivalent, portions of it we have been doing for a long time," and when asked 
whether she believes TQM is a fad or a paradigm shift, her response was " I see it as a fad, but not self limiting."

But when asked to mention some of the advantages she sees in TQM she proceeded to say:

One advantage I see for TQM/CQI is that it makes it easier to work across departments. Team members expressed their satisfaction with the way TQM/CQI deals with complex systems. One of TQM/CQI strengths is that it looks at a very complex problem and comes up with a solution that will cover all the bases rather than learning by trials of this and that. It is a valuable way that will allow you to test an improvement process on paper before you go and implement it in the field. TQM/CQI is more statistically driven than other approaches, which provides it with an advanced edge over other approaches.

( Please refer to Q. 11 in Appendix D)

The second Quality Champion are those QIT members who participated in the improvement process. Those participants worked hard on key improvement issues that helped some problems that existed at PH. One of those teams was the Admission Improvement QIT. This team was charged with improving the admission procedure at PH. By following the Nine step approach, outlined in the Quality Plan and discussed earlier, the team was able to reduce patient waiting. The team's experience is summarized in the example below: 


\section{EXAMPLE}

\section{Area of Improvement: the Admission Process}

\section{Method:}

The first step was to define the problem and then to draw a flow-chart of the existing process. The admissions process, from arrival to leaving the department, was charted. The second step was to analyze customer needs. This has been done by conducting a customer survey to explore their needs and expectations. The next step was to come up with a Quality Opportunity Statement (QOS). After studying the process and considering the customer input the team has arrived at their QOS: "Studying the admission process will reduce patient annoyance with waiting, allow better information collection, and free up time for patient care, easing scheduling burdens."' Once this has been done a more comprehensive examination and measurement of the Process was needed. The QIT members defined the following Key Quality Characteristics (KQC): Time elapsed from entry into the office until patient goes to the room, recorded on special time sheets designed for the study.

The fifth step was to provide additional charts of the process. These included flow-charts, run charts, and Pareto charts. By doing so the QIT was able to analyze the process, and to examine points of stability and/or instability. After completing this

\footnotetext{
4. Interview with Participant 1 at PH, please refer to Appendix D Q. 9.
} 
step, the team came up with a set of improvement recommendations. Among those the Admissions QIT team instituted is a program whereby physician offices send patient information by facsimile to enable the creation of a nearly complete admissions package before the patient arrives.

As a result of this program, patient waiting has been reduced, and more improvement on the process has been under investigation. Finally, the team remeasured the KQC and conducted more analysis in order to ensure the continuity of the quality improvement effort.

Top management at PH could NOT be identified as a Quality Champion. This could be derived from the comments of the first quality champion herself:

We believe that management involvement at $\mathbf{P H}$, or any institution for that matter, is very critical. It is important to get the top management to agree to it. At PH, the top management has agreed to the adoption of TQM/CQI as a concept, and they expected good results. The management, is in support of quality, at least as a concept."

( please refer to Q. 12 of Appendix D)

The above statement indicates that top management is supportive of TQM, at least as a concept but is not involved in a massive training of the total organization. Top leadership at PH is interested in tangible results and will be more involved in the quality improvement process once they can see more positive results. 


\section{RESULTS and ACHEVEMENTS of TOM at PH}

As mentioned earlier TQM is in its initial stages at PH, and has not become a comprehensive process. More time is needed to examine the outcomes of TQM at PH. However, the major observed results have been the documented achievements of the QITs. The Admission Improvement QIT is one of these examples. By publicizing such success stories, people at PH hope to gain more acceptance of TQM and secure more support for it. Being concerned about cost and tangible returns, the hospital requires some tangible savings in financial resources to commit to a much more comprehensive process of TQM/CQI. For the time being, at least, the short term outcomes of the limited scale pilot projects and QITs efforts will be the major indicator of the outcomes produced by implementing TQM practices at $\mathrm{PH}$.

\section{CHALLENGES and LIMITATIONS of TOM/COI at PH}

When asked about any challenges that have faced $\mathrm{PH}$ in its experience with TQM

two challenges were cited. The first one was to "document the results, and show that TQM/CQI not only reduced your cost but it has also reduced wasted time." The second challenge was related to the first one and also has to do with the documentation of team activities and keeping an accurate account of the minutes of QITs meetings. Although no opposition was encountered, some employees were 
concerned that TQM might increase paperwork, and wondered if it could be done in a faster time. Another challenge is the lack of stronger leadership commitment to TQM. As seen earlier, the institution shows symptoms of a "Spotty Pattern" of implementing TQM. The real challenge is to move to a more effective approach, such as the Cascading approach or the Twin-track approach.

In order to overcome these limitations and challenges a number of measures are needed. Top management as well as physicians buy-in is important to strengthen the process. Moreover, constant education and training of participants will help ensure a solid commitment to TQM, because of an improved understanding of TQM's potential. The system needs to be flexible and adapting. Finally, the improvement activities need to be well documented and that should be assigned to team members. ${ }^{s}$

\section{SUMMARY of MAJOR FINDINGS at PH}

This study has utilized a variety of resources to gather information about the areas under examination. Based on the responses to a number of in-depth-interviews and the responses to the general surveys, findings pertaining to TQM at Private Hospital

5. Please refer to Appendix C Q. 14 for further details. 
1. PH has an interest in TQM/CQI, but this interest has not been furthered beyond partial limited scale implementation of some quality improvement projects. Its approach to implementing TQM is "Spotty." However, there is an awareness and a desire to involve top management and to move to a cascading approach in the long run.

2. PH is concerned about cost and the financial commitment to TQM/CQI. It is important for the initial TQM efforts to prove they are financially effective before larger scale commitment is granted.

3. The top management at PH requires immediate returns especially in the short run, in order to buy into TQM/CQI, though they support the principle of improved quality.

4. PH is privately owned, and making a profit is important to the parent owner and the stock holders. For TQM to be adopted tangible financial improvements are required.

5. PH has a smaller size when compared to the other two health care organizations involved in this study. This means less complexity in terms of the process, but on the 
other hand, it means less financial capability to incorporate TQM/CQI into the system.

6. PH does not have the pressure of tax payer scrutiny as much as the other two types of hospitals discussed here.

7. $T Q M / C Q I$ is seen as a positive way of solving organizational deficiencies and quality improvement issues, but not as a comprehensive cultural change, and to a certain degree, TQM/CQI is labeled as a fad.

8. The responses gathered at PH stress the importance of top management buy-in and commitment to the adoption of TQM/CQI at PH.

9. PH believes in following an "OK" TQM/CQI approach ( a limited scale departmental projects) and getting "great results", rather than following a great process and getting small results. How would you define "OK"?

10. For TQM/CQI to succeed at $\mathrm{PH}$, it has to reduce cost, reduce waste, improve patient care and involve all the key participants: Patients, doctors, and employees, i.e. internal and external customers. 


\section{CONCLUSION: ASSESSMENT AND COMMENTS}

For a smaller size hospital, reducing cost and achieving financial profit is critical. Committing to TQM/CQI requires more comprehensive involvement by management. People at PH are saying "we have been doing this for years so what's the difference?". The challenge for TQM/CQI leaders is to prove, in tangible figures that TQM/CQI will work. TQM/CQI proved its potential in solving some organizational problems at $\mathbf{P H}$, and that could be a start. Educating the top management about the potential of TQM/CQI is critical, and those involved in TQM/CQI seem to recognize that. It is difficult to equally compare PH to the other two organizations. PNFP and SH are bigger and more financially capable. Finally, PH, as a whole, has not incorporated TQM/CQI as a cultural change and there seems to be a hesitation in believing its value for changing the organization, and that could explain why they are concerned about the cost constraint when it comes to TQM/CQI. 
Quality Story 2

PRIVATE NOT FOR PROFIT HEALTH CARE SYSTEM (PNFP)

\section{INTRODUCTION}

The second Quality Story is derived from the experience of a Private Not-for Profit health care system (identified as PNFP in this study). As in the first quality story, the experience of this organization will be presented through describing various elements that relate to the implementation of TQM. These are: organization overview; background of TQM at PNFP; the impetus for TQM at PNFP; improvement methods; present status of TQM at PNFP; quality champions at PNFP; achievements and results of TQM, if any; and finally a discussion of any limitations or challenges that have been encountered. This quality story derives its materials from interviews, surveys (general and PIT surveys), and team observations completed at this institution. and the annual report published by the organization.

\section{ORGANIZATION OVERVIEW}

This health care system is a conglomerate of more than 10 hospitals and health 
care providers. It is a Not-for-Profit privately owned organization. It offers a wide array of health care services to the community, including: ${ }^{\circ}$

- Diabetes services

- Cancer Care

- Emergency, Trauma, and after hours care Employer Services

- Heart Care

- Home Health

- Hospice care

- Mental Health \& Chemical Dependency treatment

- Neurological Disorder

- Others.

This organization has more than 1400 physicians, who are hired or contracted to deliver health care. Its hospitals are licensed for hundreds of beds, and it delivers inpatient and outpatient care to its customers in the metropolitan area and the surrounding neighborhoods. PNFP hires more than 7200 employees ' and has an operating budget of more than $\$ 400$ million.

One of the major distinctions that differentiates this organization from the State Hospital is its higher degree of autonomy and being less pressured by tax

6. PNFP's Annual Reports 1992, 1993.

7. Figures from 1992 Annual report. 
payers. This is because most of the financial resources supporting this organization's operations come from private parties and not the State. Data gathered at this organization suggest that since the institution has more control over its policies its decision to commit to quality was easier and depended largely on the commitment of the top leadership. PNFP also differed from the PH in its larger size, bigger market shares, and most importantly more financial resources available to education and training.

\section{Mission Statement: ${ }^{8}$}

In its mission statement PNFP focuses on the need for an improved quality of health care:

We are committed as a health care system to enhance the quality of life by improving the health status of the communities we serve. We are further committed to serving all in need within our resources. Our purpose is to provide and manage comprehensive, accessible, integrated health care services that emphasize clinical excellence, value and human sensitivity.

8. Figures from 1993 Annual report 
Customers: Patients in the metropolitan area, their families and relatives; third party payers and other health plans are also considered as customers for PNFP. Internal customers are physicians, various department, and employees in general.

\section{WHO PARTICIPATED IN THIS STUDY}

Variety of participants have contributed to this quality story about PNFP hospital. They came from various departments and organizational layers and ranged from managers, trainers, management system analysts, to staff members. Moreover, it is at this institution where observations of a Process Improvement Team (PIT) in action occurred. For a period of more than six months these team observations provided the opportunity to see the team working on an improvement initiative.

\section{BACKGROUND}

This organization has been involved in TQM/CQI since 1991. When asked about the reason why they adopted TQM one respondent, who has been involved in the process for a while, replied: "We adopted TQM/CQI, because it has become a critical approach to cut cost and improve the quality of service in health care."

9 . For a complete transcriptions of interviews at PNFP please refer to Appendix D 
In July of 1990, there was a change in top leadership. The new CEO was committed to the principles and the implementation of TQM/CQI in the organization. $\mathrm{CQI}$ is seen as one of four strategies aimed at containing cost and improving the quality of health care delivery. These are: managed care, CQI, administrative consolidation, and the integration of clinical services. A comprehensive effort of implementing TQM/CQI has been adopted and the top management commitment to the effort was critical to the adoption of TQM/CQI. The 1993 annual report states that "CQI began to deliver on its commitment to contain cost while finding better ways to do the job." Through integration, cost control, and overall response to the demands for change in health care PNFP moved from a loss of $\$ 3.38$ million in 1990 to a net income of $\$ 24.08$ million for Fiscal Year 1993.

\section{THE IMPETUS FOR TOM/COI AT PNFP}

As mentioned above, PNFP has been involved with CQI since 1991. The new leadership inherited a troubled budget that had a $\$ 3.38$ million loss for the Fiscal Year 1990. In its effort to contain costs and improve quality top leadership adopted TQM to bring about desired change. Along with TQM other strategies were also adopted, such as Managed Care, which as a strategy used to contain cost, "is based on delivering medically appropriate care that works in a cost-effective manner" (1993, Annual report, pp. 10-11). In other words, it is doing the right thing at the right time. 
Continuing success in managing care requires a partnership between physicians and other people of an organization (PNFP in this case) in order to contain cost. CQI at PNFP is seen as a guiding force for that kind of partnership. Therefore, TQM/CQI is a strategy that has been adopted to "give the people who do the work the power and the ability to identify and solve problems so they can better satisfy those whom they serve."

\section{HOW DID TOM/COI START AT PNFP}

Interviews with participants, who have played key roles in adopting and/or implementing TQM/CQI at PNFP, asked how did TQM/CQI process evolve at PNFP? Coupled with additional information derived from through other sources, such as surveys, revealed the following picture of this process.

In 1990 a new leadership, who was educated in and committed to the principles of TQM/CQI took over. The top leadership decided to adopt the TQM/CQI process to improve quality and cut cost in order to combat a deficit of

more than 3 million dollars in the 1990 Fiscal year. As an initial step the key leaders of the system's hospitals were contacted and their buy-in and support was secured.

In a special retreat those key leaders were presented with TQM/CQI concepts and a picture of the training that might be forthcoming. Structures that might be put into place by quality council were also explored. After being enlightened, the top 
management has granted their support to the adoption of TQM/CQI. The next step was to draft a TQM/CQI mission statement and a quality policy. After reviewing the theoretical framework of TQM/CQI philosophy participants at PNFP decided to draft their own. The teams stated TQM/CQI's policy and goals, and selected a name for TQM/CQI at PNFP, calling it: (TQM/CQI PNFP). Moreover "We decided to commit to a unified approach, quality goal statement, principles, and plan", adds one of the participants at PNFP. A consultant was hired to help kick off the process.

Coordination with the QA department was needed to shift responsibility, since TQM/CQI considers everybody responsible. This is a prospective rather than a retrospective approach which holds all responsible for making it work. The next task was to teach the rest of the organization about TQM/CQI. Those key managers who were trained and educated, at the retreat conference, taught the rest of the managers at their institutions, who have in turn taught their staff. This approach of continuous learning process calls for:

'Leaders teach managers $\gg$ Managers $\gg$ teach employees" 10

Process improvement teams (PITs) were established to deal with areas of improvement at PNFP. A quality plan in each department is drafted and includes the following components:

\footnotetext{
${ }^{10}$. Please refer to interviews conducted at PNFP, Appendix D
} 
+ Identify customer and service

+ Survey of customers.

+ Determine whether you are meeting those expectations or not

+ Create a plan that establishes indicators and measurement of improvement

A system-wide universal strategy was coordinated among various member organizations, a process that, as one of the participants affirms, "was not that easy." Finally, TQM/CQI has been applied as a system-wide philosophy aimed at "changing the way we do business", adds one participant. "CQI has taught us to see ourselves as less discrete and as more of a team" was another comment gathered at PNFP. In conclusion, one could easily observe how TQM/CQI has evolved as a major strategy for organizational change, and how top leadership is the main champion.

\section{APPROACHES TO IMPLEMENTING TOM at PNEP}

It is not difficult to point out a Cascading Pattern that has existed at this organization. This is evident through the commitment of the top leadership to TQM and the pioneering role it has played from the initial stages of implementing the quality improvement processes. Moreover, one could characterize the approach as "All-at-Once" because of the comprehensive level of training and the increasing number of quality improvement teams, called Process Improvement Teams (PITs). 
A closer look at this institution will reveal that what is really being implemented is what Carr $(1993,208)$ identifies as the "Twin-Track Approach," described earlier in the literature review section. This approach has a twin track focus: short term pilot projects (in PNFP's case the efforts of the various PITs) as well as long term vision of organizational and cultural change (reflected through the CQI policy and annual reports stating the long term goals of the organization). It is clearly evident that a Twin-Track approach is the primary pattern that exists at PNFP health care system, while a cascading approach might be a secondary pattern that is also stressed.

\section{IMPROVEMENT METHODS}

As mentioned earlier, CQI is seen as a "set of tools" that will help empower employees and improve work. CQI operates through Process Improvement Teams (PITs), "frequently formed by people from different departments who must solve common problems." (1993 Annual Report, pp. 10-11). No single PIT could improve the total process or contain cost, but each can improve "the way we do our jobs, seeking to better manage information and prevent errors." The belief in the power of PITs is echoed in the following statement, derived from the 1993 annual report: "The commutative effect of the PITs is astounding." 
Numerous PITs have been started at PNFP to deal with a variety of improvement issues. One of these teams was the Material Services PIT. The team tackled the problems of supplies. "The supplies needed in the hospital's critical care unit occasionally ran out during the night shift." The PIT consisted of people from both Material Services and CCU worked together on improving inventory control, ensuring a proper stock of supplies in CCU while reducing lost charges by $50 \%$. Another PIT worked on a problem that has to do with X-ray films, when doctors checked out originals and failed to return them. "The team instigated a system of inexpensively duplicating the films for physicians, saving over $\$ 30,000 /$ year." A third PIT examined DRGs (Diagnostic Related Groups). Physicians and staff worked together to "carry out procedures and administrative ways to save money." The recommendations introduced by the team have saved the organization $\$ 207,000$ the first year. A latter part of this study includes the experience of the Purchasing Team in a greater detail.

It should be mentioned, however, that PITs operate on the "micro level" and for major changes to take place in the organization other major administrative and total system improvement have to occur. By integrating the interdepartmental and/or interorganizational functions an organization will be able to achieve grand scale changes; and that is the case of PNFP, which has posted more than \$24 million in net income this year. 


\section{CHAMPIONS FOR TOM/COI AT PNFP}

One of the major requirements that seem to play a key role in deciding the fate of a TQM effort is the buy-in and the commitment of the top leadership. In the case of this organization the top management has played the leading role in promoting and implementing TQM/CQI strategies. Its dedication to the principles of TQM and its constant effort to institutionalize these principles to become part of the organizational culture are clearly evident in the documented literature, through the comments and responses of those interviewed/surveyed, and through observing the organizational setting. TQM/CQI is everywhere you go at PNFP. The brochure describing TQM/CQI philosophy and policy of that institution is taped on the restroom door at the corporate office.

Other champions are the Process Improvement Teams, who through their dedication and hard work have saved the system millions of dollars. Another champion for TQM/CQI has been the department of Organization Development. This department has helped educate, train, and assist groups and individuals in the theory and practice of TQM. It offers preparation seminars and it employs a quality advisor who helps the teams reach their goals. 


\section{THE PRESENT STATUS of TOM at PNFP}

As mentioned earlier, TQM/CQI has been in implementation at this health system since 1990. More work is needed to carry out the recommendations offered by various teams. An organizational culture is emerging at this health system as a result of the adoption of the four strategies mentioned earlier, and TQM is being one of them.

TQM/CQI has certainly helped the institution save money and cut cost. In fact, for the Fiscal Year 1993 a net income was observed contrary to the last two years when losses were incurred. More PITs are forming and more goals are still being met. TQM/CQI is one of four strategies that helped achieve this gain. With improvement in cost management and cash management TQM/CQI stands on a solid ground because of the financial gains observed. Finally, a process of evaluation is and replanning are being institutionalized to make sure the organization is on track.

\section{RESULTS and ACHIEVEMENTS}

As discussed earlier, TQM/CQI, along with other strategies, has helped the health system gain a financial profit for this fiscal year. Improvement in a variety of areas attest to the total commitment of this institution. Moreover, TQM/CQI helped in managing cost at PNFP. Areas of improvement are: staffing productivity, which was either improved or kept at the same level. Contracts and purchased services 
were among the areas that have undergone an improvement process, and the results were keeping the cost to a minimum.

In planning for the future, this health system declares that “our [PNFP's] challenge for the future is to maintain this performance ... and will continue to look for ways of providing high-quality, affordable, and accessible health services." (1993, Annual Report, p. 16). The following is an example of using a Process Improvement Team to improve the system-wide purchasing process. It reflects the utilization of TQM principles and methodology.

\section{An Example of TOM/COI at PNFP}

\section{Observations of a Process Improvement Team"l}

\section{Introduction}

The following section explores the experience of PNFP with TQM through a presentation of the observations of the Purchasing Process Improvement Team. A third way of gathering data for this research was through team observations, where available. For a period of about 6 months a Process Improvement Team (PIT) working on the improvement of the purchasing process, system wide, was observed. Team members were either assigned to the team or/and wanted to be involved

\footnotetext{
". For a more detailed documentation of this process please refer to Appendix D
} 
because it relates to their job. The following pages are a summary of this process, and a presentation of the various tools through which TQM/CQI has been implemented. At the end of the PIT project, a PIT participant survey was also conducted. In this survey participants were asked to respond to questions that examines their experience. Following is a summary of this Team Observation experience.

\section{Part 1: PROCESS OVERVIEW $^{12}$}

The Corporate Office Purchasing Process Improvement Team (TEAM) began its process on January 13,1993 . The TEAM started by outlining members' expectations and establishing ground rules to operate the process by. Time was spent reviewing and discussing the draft charter submitted at the inception of the process and ultimately revising this working document to satisfaction. It was decided that it would be valuable for the TEAM to review any existing process documentation and related policies or procedures to gain a better understanding of what process is currently in place.

Based on a thorough review of the process currently in place, the TEAM determined that it would be useful to flow chart the process functions to enhance the

12. This example relies on the documentation of the minutes of the team's meetings, and their report (the story board as it is called) to the Quality Council. 
members' understanding. The TEAM conducted a thorough walk-through of the high level flow chart. This walk-through led to a complete construction of detailed flow charts of the purchasing activities. By flow charting the activities in detail and reviewing the current process, the TEAM was better able to determine what elements of the current process were functioning well, and possibly required some enhancements, as compared to what necessary elements did not exist and needed complete development.

The TEAM then agreed that it should use the flow charts and the problem statements reflected in the charter to identify "HOT POINT" problem areas as experienced by its members. The TEAM decided to explore these HOT POINTS in more detail utilizing CQI tools and techniques, such as fishbone diagrams.

The next logical step was to create and submit customer surveys to confirm whether or not the TEAM fully understood the depth and breadth of problems personnel in the corporate office are experiencing with the current purchasing process. The TEAM used its review of the Fishbone diagrams as a basis for identifying the key problems. This key problem identification was then used as a structure for creating the customer surveys. The survey process was completed by TEAM members conducting interviews with corporate office personnel.

Once the surveys were completed and results were tabulated, the TEAM reviewed and discussed the results in an effort to identify some problem themes from 
the responses. Many items were identified for potential action and resolution.

However, it became apparent that the identified items needed to be narrowed into a list of those items that had the greatest relative importance to the customers. The TEAM decided that constructing and using Pareto charts would assist in determining which processes were the most significant for improvement based on the customer survey results.

Then, the TEAM identified the following areas to focus its attention on for problem solving and improvement recommendations:

- Product Source/Availability/Price

- Obtaining Purchase Authorization

- Shipment Receipt, Documentation and Delivery

The CQI Advisor then reviewed with the TEAM some problem-solving methods that are currently being used in PNFP as CQI tools for its consideration when addressing the areas noted above. The TEAM spent sufficient time to identify and develop its specific recommendations for improvements to the problem areas. Once the recommendations had been developed they were prioritized, with responsibilities and time frames determined, as well as requirements identified using a force field analysis. The TEAM decided that the areas of communications/education and monitoring implementation and success should be addressed once the recommendations were finalized. The TEAM also determined that it should 
recognize and promote any areas of improvement that could be realized system-wide within the organization. Time was then spent doing an extensive final review of the recommendations and making any modifications necessary.

Finally, devising an evaluation and monitoring mechanism was completed. In doing so the Process Improvement Team ensured that the implementation of their proposed recommendations will run smoothly. A monitoring plan was drafted and it consisted of two phases. The first phase is the implementation period and the second phase is the post implementation period. During the first period the team needs to educate those with primary responsibilities for implementation and develop mechanism of tracking the progress of implementation. Periodic meetings of PIT were also scheduled as an integral part of this monitoring plan. In the second phase, post implementation, the team decided to hold frequent periodic meetings to ensure that the implementation is on track. Finally, more surveys will be used to gather information about the effectiveness of the adopted measures and for further improvement.

The final step for the TEAM was to prepare the presentation of the recommendations to the Quality Council (Q.C.). It is up to the Q.C. to see that the recommendations proposed get implemented. When we left the organization the presentations were set the week after. That same week a number of story boards and flip charts were displayed in the hallways of the department of Organization 
Development. Each of these describe the efforts of a particular PIT. Of course our team's story was among them.

\section{Part two: PIT PARTICIPANTS SURVEY}

Thus far the study has described the experience of the Purchasing PIT, as it happened. After completing the process described above, it is suitable to survey those who participated in order to assess their experience and find out what they learned from their involvement with a TQM project; and what could be concluded about it. The responses gathered reveal a number of points. First is the importance of top leadership support and commitment to the initiative and the team work. Second is the importance of a well organized and structured approach of operating teams. The third

general finding is the need for a focused team and a well organized team leader who is knowledgeable of TQM and team dynamics. The Team's commitment to the issue is also critical, and their ownership of the project is the major factor for building that commitment. Finally, friction, hidden agendas, and the absence of a strong team leadership might carry a death warrant to the quality improvement effort. Most members have expressed a positive attitude towards their experience with this team's effort, and they saw it as educational and empowering. 
Discussion of major findings: Process Improvement Team Project \& Survey

The above stresses to a great deal that commitment to TQM and being serious about it are among the important elements for success. Also, top/senior management involvement in the process is vital to its continuation. For the process to succeed meetings should be held regularly, should be well-led, and kept on track. Education and commitment are seen as key factors.

The hindering forces, as seen by PIT members, for the implementation of TQM could be summarized as lack of top management buy-in, uncommitted members, and lack of education and awareness on the part of the participants. Lack of knowledge of TQM principles among team members is a dangerous problem. It might cause the team to collapse. Hidden agendas and turf battles have been identified through the other instruments as major causes of failure for teams.

Assessment and Comments about PIT team observations:

Through a period of almost 6 months I a PIT team going through a TQM/CQI process was observed. The group worked together as a unit. There were times when the team stumbled; however, it was re-guided by the TQM/CQI quality advisor. By the end of the process the members seemed to have a better sense of direction and they were more educated about the process. Particularly impressive was the charting process where areas of improvement were identified. By putting the problem in a 
visual but yet a systematic way, TQM reaches a higher level of accuracy and efficiency than other theories and approaches.

In conclusion, it could be seen clearly that there is a consistency in the finding. The three means of data collection (survey, interview, and team observation) have produced similar findings. This, as mentioned earlier, increases the reliability of this research. All the data presented so far points to the importance of top management involvement, the need for well articulated TQM advocates, and a commitment from all organizational levels.

\section{SUMMARY OF FINDINGS AT PNFP}

1. The most important finding is an overwhelming interest and commitment to TQM/CQI, and that is mainly due to the involvement and buy in of the top leadership.

2. Implementation of TQM/CQI has been going on for more than two years at PNFP. A twin-track approach could be identified at this organization. This approach encourages the adoption of a long term vision for TQM coined with the implementation of pilot projects and other short term achievements. The success of these projects will help sell TQM strategies to the rest of the organization. By looking at the total experience of PNFP with TQM/CQI one could see there is a cultural change taking place. This is reflected through a system wide implementation and 
adoption of TQM/CQI as a philosophy and a way of doing things and a long term commitment to its principles.

3. PNFP has invested in training and education, which enabled their employees to understand the nature and the promise of TQM/CQI. Education should be considered the comerstone for any TQM initiative, and without it participants, teams, and the total organization tend to fall into fatal mistakes and deviate from the right path.

4. Committing enough financial and human resources enabled the installation of TQM/CQI at PNFP. This has been done through system-wide training programs and educational seminars. Employees have been encouraged to participate in these classes and their wages were preserved. The O.D. department has assumed a leadership role in guiding the implementation of TQM/CQI efforts.

5. PNFP has chosen to draft and design their own version of TQM/CQI, which they called "CQI PNFP". This stresses what have been said earlier about the need for a flexible and a robust approach to adopting and implementing TQM/CQI. 
6. TQM/CQI at PNFP has four guiding principles: 1. Satisfying customers 2. Leading and empowering people 3. Continually improving/preventing errors 4. Managing with data.

7. TQM/CQI at PNFP has the following goals:

* Improved customer satisfaction

* Improved clinical outcomes

* Empowerment of employees to improve the organization

* Improved market share

* Financial viability

* Improved Employee satisfaction

8. It seems that there is a need to establish a criteria for the measurement and monitoring of outcomes. How do you know if you are successful, how are you going to ensure that you are on the right track? The last interview conducted at PNFP indicated that there was an increasing attention on the various benchmarking strategies and other evaluative techniques to ensure the compliance with the stated goals of CQI PNFP.

9. PNFP is a prime location to see TQM/CQI in action. There is comprehensive education and training in the theories and principles of TQM/CQI that is taking place 
there. There are ongoing Process Improvement Teams (PITs) working on various improvement issues.

10. Finally, there are indications of an emerging cultural change out of this comprehensive process of implementation of CQI at PNFP. In a follow-up interview with the CQI advisor at PNFP, she affirmed that the institution, indeed, is moving toward a cultural transformation.

\section{CONCLUSIVE ASSESSMENT OF PNFP'S OUALITY STORY}

PNFP provides a good example of a successful implementation of TQM/CQI ; PNFP is an example of TQM/CQI put into action. PNFP has been successful in its adoption and implementation of TOM/CQI because of the buy-in and the involvement of the top leadership. PNFP shows that TQM/CQI could achieve positive results in larger and complex organizations as well as smaller ones. The lower degree of public scrutiny and control over its operation enabled PNFP to have more autonomy over its policies.

An additional factor that could be contrasted with what is going on at $\mathrm{PH}$, is the fact that PNFP has committed the needed financial resources to install the system into the organization. TQM/CQI is then seen as a profit not as a cost, and thus committing time and money is justified by the belief of its potential benefit for the 
improvement of the system. The above is evident in the organization's mission statement and could be felt through the responses gathered at this institution. The focus on education and training is apparent at PNFP, which is one of the major requirements of TQM/CQI. In fact, the Organization Development department at PNFP has launched its own CQI training program to educate leaders and members of process improvement teams. They are educated on what is TQM/CQI, Process Improvement Team practices, and how to implement an effective CQI initiative. ${ }^{13}$ Process Improvement consisted of a mix of management and staff employees. This removes departmental barriers and drives out any inhibitions on the side of the employees. Employees were encouraged to communicate freely and not to be inhibited to disagree with their superiors, especially during the Process Improvement Team session which were observed.

In spite of all of the above, PNFP needs to establish a more systematic and solid way of monitoring and measuring outcomes to ensure the achievement of their stated goals. While the concept of evaluation is stressed in the writings and recommendations of PNFP's quality policy and the PIT teams story boards, the organization will need to establish a system wide evaluation process that monitors and

${ }^{13}$. These are the major components of a 3 hours seminars offered by the OD department at PNFP. 
measures implementations and outcomes against the stated goals. TQM/CQI is a never-ending story, and a critical component in this approach is a continuous evaluation and identification of areas for improvement. Having a great process is a very important factor for paving the road to success, but adding that to an effective evaluation and measurement criteria will not only ensure that you reached your destination, but it will also let you know that you are there

\section{Quality Story 3}

\section{Publicly Owned State Hospital: SH}

\section{INTRODUCTION}

The third quality story in this research is about a publicly owned state hospital, identified as SH in this study. The Review of Literature section presents some differences between public and private institutions. Keeping in mind the comparative nature of this study we made sure to get some feedback that could be used to establish comparisons among the three organizations. Participants were asked to list some of these differences or/and to give their views of these differences and how they might affect TQM. For example, the question "How similar/different is a public hospital (SH) from other private hospitals, especially the two examined here?" was asked. The following responses were obtained: 
1. The role of customers: the public has a lot to do with what goes on at SH.

2. The status of physicians: In public organizations, physicians are hired employees, but in private organizations they are more likely to be contracted.

3. Public institutions tend to be more complex in size, operations, and in environment and this might create more "system problems" for a public hospital than for a private hospital.

4. Public institutions have less financial resources to spend on training and education.

(Please refer to Appendix D Q. 4)

In addition to the previous distinctions SH as a public institution derives some of its financial resources from the State budget and unlike the other two private hospitals has to adhere to more rules and regulations that influence its decisions and policies. SH is under much scrutiny and has less ability to make decisions that might imply high risks because they call for drastic changes. The public exercises more control over SH's operations than they do over a private institution, such as the previous two hospitals. Because of this scrutiny, decisions take longer time to be made and the process takes longer time to be in place. The result of all of this is a 
longer time to bring about any change because of the lengthy political and legislative steps that need to be fulfilled first before any initiative could be implemented.

This quality story describes the experience of a public institution with TQM/CQI. In order to keep consistency in the stories the same format will be applied. First, an overview of the organization will be provided, and is followed by a comment on the background of TQM/CQI at SH. Next is an exploration of the impetus for TQM and how it started, accompanied by an examination of the current status of the quality improvement and those major figures in the quality efforts recognized as quality champions. The last component presents any results that have been achieved from implementing TQM methods, if available, and comments on any challenges or limitations that have faced the hospital in its experience with TQM.

\section{ORGANIZATION OVERVIEW}

The hospital has 349 operating beds and has more than 6500 employees. Its mission is threefold: medical/nursing/dental education, biomedical research, and patient care. The campus spreads over 240 acres and contains 30 buildings. It provides an array of services to the metropolitan area, and it is the largest provider of uncompensated care (\$94.0 million in 1991) in the state of Oregon. In the year 1991 SH has served 110,000 patients $(271,575$ visits). Some of these services offered are:

- Alcohol and drug services

- Anesthesia services

- Blood bank

- Emergency services 
- Inpatient surgical services

- Intensive Care Unit

- Lab services (Clinical)

- Operating rooms

- Outpatient clinic services

For the Fiscal year $91 / 92$ SH's budget was $\$ 350$ million, $18 \%$ of which came from the state and $82 \%$ came from grants, gifts, fees, and contracts. When asked to identify the key organizational layers that are significant to a TQM effort at SH the following organizational layers were identified: Board of Directors, Senior Management, and Physicians.

\section{BACKGROUND}

As in the case of the previous organizations, SH has been trying to look for ways to reduce cost and save money. The Quality Assurance Department was responsible for the inspection of the quality of services provided. No major quality improvement has been adopted yet at SH, contrary to the case of PNFP. However, the hospital is trying more than ever to find some ways to deal with problems created by the financial strains of Measure 5 and shrinking resources due to decreasing State budget.

The quality improvement process started as individual departmental initiatives to deal with some functional problems, but no major system-wide TQM/CQI process 
was in place. These improvement teams (" techniques and they were able to achieve some success. The experience of those teams has encouraged other members in various department to try using TQM/CQI techniques.

A major project that took place at $\mathrm{SH}$ aimed at cutting costs and reducing waste, and it employed some of TQM tools. The outcomes of this restructuring effort were positive and it resulted in savings of more than $\$ 5$ million.

Looking at their limited scale implementation some managers at SH assumed that by implementing these scattered projects they are implementing a grand scale TQM. This is best described in one of the answers during an interview with one of a participant at SH.

People, who were going at it, did some readings and had some results with it (staff department head level). They got interested in using the tools and trying them and getting some teams together. They have some success. Then they thought, this is great, we are going to do TQM/CQI. This was a mistake, because they never had the buy in and the commitment from the top management, which TQM/CQI itself stresses. Though the top management said "we are committed to this" there was not really a commitment; that was not recognized.

After attending a conference we at SH have realized that for the process to succeed we are not talking about using the

14. As mentioned in earlier chapters QIT and Process Improvement Teams (PITs) are relatively the same 
tools of TQM/CQI only, but we are talking about a major cultural, political shift. It meant a major shift in management style and required the involvement of the entire institution.

The SH, then, realized they have a long way to go on the road to TQM. They decided to step back and start at the top level and do some education there about what TQM/CQI really means and what requirements it needs. This has backed everybody up. Thus, the cultural change has not happened yet, and for that cultural change to take place, the involvement of key leaders and their commitment is needed.

Finally, it should be noted here that the data gathered at this institution strongly suggest a belief in TQM's potential at SH. One participant believes that "TQM is something that could work at SH."1s In the crossectional data gathered at SH respondents also stressed their belief that TQM might yield similar positive results for public organizations as well as it did for private organizations, as long as they follow its rules and guidelines. ${ }^{16}$

\footnotetext{
15. For a detailed transcription of these interviews and responses please refer to Appendix D

${ }^{16}$. The responses for Question 19 of the crossectional data, Appendix C, support this argument.
} 


\section{THE IMPETUS FOR ADOPTING TOM AT SH}

Public organizations are going through a state of struggle for survival right now. SH is among those institutions that have been affected by Measure 5 (which lowers tax on property, but deprives public organizations from some of their funds) This measure has harsh effects on public organizations reflected in decreasing budgets and shrinking resources. SH is turning to quality improvement as a way to deal with these challenges. It is widely believed that TQM could help the institution in solving the above problems. One of the interviewees believes that "TQM is something that could work at SH. It is a theory that has its flaws... [but] there are a lot of good things that come out of it." ${ }^{\prime \prime}$ TQM is seen as a method that could help "streamline the process" Top management buy in and commitment is seen as a key factor, and once that is secured a comprehensive TQM plan would be devised.

People at SH are not asking whether they need TQM/CQI or not, they are rather asking "How to do it, and what would be the best approach?". In other words, TQM has proved its usefulness in achieving desirable outcomes at SH. The best example is a project called the "Operation Restructuring" initiative that used some TQM tools; and also in the case of a number of departments that implemented improvement projects that utilized some of TQM techniques. The next step for SH is

\footnotetext{
". For a detailed transcription of these responses please refer to Appendix D
} 
to launch a system-wide TQM process that will involve the whole organization and secure the top leadership commitment. To summarize, SH is turning to TQM to combat inefficiency, wasted resources and to reduce costs, and even, to survive. The following section contains some improvement methods that were adopted at SHE.

\section{APPROACHES TO THE IMPLEMENTATION OF TOM AT SH}

The experience of SH is a fascinating one. It clearly shows how the "Spotty pattern" fails to deliver. In its early stages with TQM, few people were trained or even active in carrying out TQM innovative efforts. The lack of top leadership knowledge and commitment has forced the organization to regress and take a more efficient route-the Cascading approach. The last interview conducted at SH revealed that the top leadership has been getting more educated in TQM and more trained on teamwork and TQM tools. The belief is that the top management will educate lower levels of management who will educate the following levels and so forth. This of course is what a Cascading approach calls for. Therefore, SH has taken an aggressive action in moving towards making the Cascading pattern its primary approach.

\section{IMPROVEMENT METHODS}

As in the case of the private hospital (PH), this State hospital (SH) has not launched a comprehensive TQM process yet. However, participants from SH pointed 
out some individual projects that used TQM tools to solve problems. For example, one of those participants, who was in a visible position, has been actively involved in a restructuring effort aimed at saving money and reducing waste. When interviewed he was asked to give an example where the concepts of TQM/CQI have been employed at SH and how they went about it. He offered the following summary: is

\section{SH's Operation Restructuring:}

We have what we call "Operation Restructuring" [OR]. This process has two goals: first, to increase efficiency, and second to reduce costs, by 5.7 million dollars/year. This is to be done by looking at ways of doing business and re engineering the process to achieve the stated goals. Multiple teams were formed, functions and tasks were coded to locate redundancy and waste and come up with ways to reduce them.

The operation described above was intended to offer some solutions to budget cuts enforced by the State due to Measure 5. Participant \# 5 goes on to describe the project:

${ }^{18}$. Ibid., Q. 10 
We wanted to use TQM/CQI techniques, but not comprehensive processes, because a TQM/CQI process would require a massive involvement from top management and employees alike and it would consume a longer time. We did not have a real formalized approach or a timeframed deadline. ... we were learning by doing. It was very individualized. Trying many altematives was encouraged. SH did not launch a massive TQM/CQI approach but it has been employing some of the techniques of TQM/CQI. We wanted to phase into implementation and not to do it all at once.

Operation Restructuring consisted of three phases. The first phase included training management and employee to identify areas of improvement, gather data, and identify targets for improvement. The second phase included formation of Quality Improvement Teams (QITs)to identify what could be improved and to come up with working solutions. Phase three included the implementation of QITs recommendations and the re-engineering of organizational areas and functions. OR was concluded in the summer of 1993 and resulted in significant amounts of savings. In a follow-up interview with the same participant he indicated that the goals of the project have been achieved. This initiative served as an encouraging factor for adopting a more comprehensive plan of TQM at SH. 
In a separate interview another participant was asked to give examples of Quality Improvement Teams (QITs). She gave two examples. One where the QIT was a success; and another where it was not. According to this participant, the first project succeeded because a number of factors were present. Everybody agreed there was a problem and that. Another factor was good facilitation and the facilitator who was able to keep the group on track. Good participation, commitment to solve the problem, and no hidden agendas were also additional factors that helped the quality initiative succeed. On the other hand, she cited another project that failed because there was no group leader, there were hidden agendas, and the meetings were plagued by arguing and disagreement.

In the above examples Quality Improvement Teams (QITs) were used to deal with some organizational issues at SH. These teams have utilized a variety of tools, such as "flow charts, Pareto Charts, and force field analysis tables. In their improvement methods these initiatives have relied on the systematic approach stressed by TQM. Finally, it could be clearly seen that in order for a QIT effort to succeed the top management support is needed as well as the need for strong and educated team leadership. Hidden agendas and friction led some teams to failure. This is very similar to the case of the PH. 


\section{THE OUALITY CHAMPIONS AT SH}

Though the quality improvement movement is trying to take off at SH, there are a number of champions who have been actively calling for adopting TQM as a way of doing things at the organization. Interviews and surveys at SH identified the following champions:

The first champion is the Director of the Quality Management Department and her assistant. They have been trying to promote TQM/CQI in their organization for a long time. Moreover, the quality department is providing training, consulting, and support to those who embark on a quality initiative. The role and the scope of the quality department is expected to be widened as the organization leaps forward in adopting a more comprehensive TQM approach

The second Quality Champion is one of the administrators at SH. His commitment and dedication has inspired many members, management and staff alike, to buy-in to the quality improvement efforts. One of his contributions was to chair the steering committee responsible for ensuring the effective implementation of "Operation Restructuring," which has yielded significant financial gains for the institution. This participant has been the connection between the administration and other members in the organization. This role has helped him to work with other managers and team members on improvement issues. 
The third champion is the many members of QITs who took it on their own to pioneer TQM efforts in their organization. Those members worked hard to educate themselves in the process and to apply their knowledge to their work and to solve any challenges they face. One of the people interviewed was the team leader in the Trauma Quality Improvement Team who showed great interest in TQM/CQI and in learning about it. It would be those people who might be the main contributors to the success of the future TQM initiative at SH. Their support and expertise should be sought and harnessed in order to reach the desirable results of the TQM innovation effort at SH. They will be the pioneers who will get involved in the process and will help others join in.

\section{THE PRESENT STATUS OF TOM AT SH}

In their experience with TQM SH poses an interesting case. First, they initiated changes on a limited scale. After they forged ahead they regressed back; but now they are back in the race again. One of the reasons, as introduced by the participants, is the lack of top management buy in at the initial stages. After implementing limited scale initiatives people rushed to say "we have done TQM at SH." This was a mistake, because, and as they declare, "we were far from TQM, yet." Jablonski (1991) identifies 5 stages of implementation an organization adopting TQM initiatives goes through: preparation, assessment, planning, 
implementation, and diversification (institutionalization). In the latest interview the interviewee was presented with these stages and was asked to pinpoint which stage is SH at now. He identified Planning for TQM as the stage where SH is now. The organization has formed its Quality Council and has contracted a consulting firm to kick off the process. Currently consultants from this firm have been conducting meetings with various key members in the organization in order to gather information and help construct a strategic plan. Top leadership is getting more involved and a sense of anticipation is filling the air. At the time when the research at SH was concluded a rising interest in TQM has been reemerging and in fact, it seemed that top management is now leading the trail of TQM rather than trailing behind it.

\section{RESULTS AND ACHIEVEMENTS OF TOM AT SH}

Since the hospital has not yet launched a massive implementation of TQM, no large scale results could be presented. However, TQM has yielded some results and achievements through the efforts of QITs and the Operation Restructuring initiatives. For example, the Trauma team has solved a problem that has to do with notifying the patient's family. Operation Restructuring has helped the institution save more than $\$ 5$ million.

These indicators reflect the potential of TQM to help SH work out some improvement issues. However, it is too early to predict what outcomes will be 
achieved from the implementation of a massive TQM plan that will involve the total organization. Those interviewed hoped for improved process, reduced bureaucracy, reduced costs and increased access. They stressed the need for improving the organizational processes in order to stay competitive with private providers. With the introduction of the new Health Care Plan by the new Administration this need seems to be more urgent than ever. This leads to the conclusion that TQM will be playing a critical role at $\mathrm{SH}$ in the months or even years to come.

\section{CHALLENGES AND LIMTTATIONS OF TOM AT SH}

People at SH recognize their need for TQM, and they believe it is a different approach to organizational change than other Quality Assurance methods. TQM is seen as stressing the "collaborative effort" "focusing on process issues than looking for the bad apples."19 It is important to stress that the data gathered at SH reflects a sense of acceptance of TQM/CQI at SH; but the real challenge for SH seems to be implementing an effective approach to achieve the goals of quality improvement.

However, TQM has encountered many challenges at SH. The first of these challenges is turf and departmental friction. Another host of challenges are of political nature and Measure 5 stands as a very good example. The fear of attrition and lay-

\footnotetext{
${ }^{19}$. Please refer to Appendix D, Q.5 for more detail.
} 
offs has caused employees and even departments not to be receptive and willing to support the change because they feel threatened. Moreover, one participant has presented an interesting challenge when he indicated that "the management of public organizations [on average] tend to be less qualified than that in the private sector." Because of that the public sector management might lack the knowledge and skills to carry out a complex process such as TQM. In addition, the lack of top management's knowledge of and commitment to TQM has delayed the implementation of a systemwide TQM approach, because it was not supported by the top leadership. Additional challenges to TQM might have to do with the nature of the institution as a public one. The sensitive and sometimes controversial political environment surrounding public institutions impose longer timetables for bringing about any change. The quality story of the State Hospital clearly illustrate some of these challenges. To conclude, a public organization has greater challenges to overcome when it adopts and implements TQM.

\section{SUMMARY of MAJOR FINDINGS at SH}

1. SH is a publicly owned hospital, with more responsibility toward the general public than the other two hospitals in terms of caring for the uninsured and how much influence the general public has on its policies. 
2. SH is turning to TQM to improve quality of services, reduce waste and increase efficiency. SH shares this belief with the other two participating organizations. Its "Operation Restructuring" is aimed at streamlining the process and saving money, and TQM/CQI is seen as a valuable tool for that.

3. However, $\mathrm{SH}$ as a public institution, is more influenced by the general public. Because the tax payers provide partial funding for its financial operations SH has to appeal to the tax payer in order to get things approved. Private organizations do not have to go through the same lengthy process and that make their decisions to implement quality improvement initiative much easier.

4. Implementing $\mathrm{TQM} / \mathrm{CQI}$ at $\mathrm{SH}$ is a demanding process that requires educating top management, securing the buy-in of all the stake holders, and the removal of fragmentation and hidden agendas.

5. The data gathered at SH suggests that people at SH believe that TQM/CQI has the same potential for public organizations as it has for private organizations, as long the major guidelines have been followed. This could be found from the interview responses as well as the crossectional data compiled. 
6. The lack of securing the top management's buy-in, commitment, and involvement from the beginning has forced SH to regress back to the starting point.

7. Using TQM/CQI techniques does NOT mean having a comprehensive process. Preliminary successes do not guarantee total gains in terms of TQM/CQI. This is clearly seen at $\mathbf{S H}$.

8. In addition to the above SH serves as a clear example on the danger and failure of the "Spotty technique" implementation approach. The initial attempts at TQM failed at SH because top management was not well educated and sold on adopting TQM. Few members became trained in TQM tools and their initiatives, though impressive, were not sufficient to bring about lasting changes. The experience of both PH and SH clearly show that the Spotty approach does not work, especially on the long run.

9. Like $\mathrm{PH}$, people at SH prefer to start small and let the process grow from within, and they stressed the need for TQM/CQI to be more flexible. 
10. As a result of its experience, SH now realizes that TQM/CQI is a major cultural change. To bring this paradigm shift about, SH now recognizes the massive volume of such a job and is calling for outside help (i.e. they are hiring a consultant).

\section{CONCLUSIVE ASSESSMENT OF SH'S OUALITY STORY}

This example further demonstrates one of the major principles outlined in TQM/CQI theories and practices. It's the need to secure the top management commitment and buy-in from the beginning. In addition, TQM/CQI process should not be mistaken for limited scale techniques of process improvement, and even if those techniques have solved some of the symptomatic problems at the institution, this does not mean the institution is ready or is doing a full blown TQM/CQI. TQM/CQI requires a intensive efforts on the part of public organizations, in order to change the organizational culture. This is done through educating top management and through producing a state of readiness among organizational participants, by eliminating fragmentation. Once the change takes place keeping the focus on the continuity of the improvement is crucial to institutionalize the effort and thus establishing the cultural change.

SH, as a public institution, has more responsibility toward the public. It is required to adhere to legislative laws and is more influenced by public policies and regulations. Private hospitals might not have the same rules. Furthermore, political and financial decisions that take place in the State legislature have great effect on such 
an institution. Implementing TQM/CQI at such an organization requires paying attention to the political aspects that might influence the process. Moreover, it requires building commitment and consensus among the organizational participants. This might be harder to achieve, if TQM/CQI is accompanied by budget cuts and layoffs and even a lack of financial incentives to reward successful gains.

Finally, it appears that public organizations can be open and willing to adopt TQM/CQI processes and methods. Nevertheless, they need to be more aware of some of the inherent differences between public and private institutions that make incorporating TQM/CQI methods into the public sector more challenging. By reviewing the responses of those interviewed and/or surveyed, they all believed, as long as you have the right goals and you follow a solid and robust TQM/CQI methodology you will get similar results, reflected in an improved quality of product or services, whether you are a public or a private institution..$^{20}$

\section{GENERAL CONCLUSION}

The previous pages examined the experience of three health care organizations with TQM/CQI. It is apparent from these stories that the involvement of top leadership of any organization is the most critical factor in deciding the fate of a TQM

\footnotetext{
${ }^{20}$. Once again, this is evident through responses to $Q .19$ of the General survey. Please
} refer to Appendix D for detailed responses supporting this conclusion. 
initiative in any organization. If top leadership champions the change, then the process takes off and change happens. However, if top leadership is not committed to the initiative, then the road to TQM will be full of weeds. The first step in adopting TQM is to educate and win the support of top leadership.

In addition to the above, these hospitals have varied in their implementation approaches to TQM. It seems there is an association between the involvement of top management and its knowledge and the training in TQM and the likelihood of adopting a more efficient implementation approach. Where the management is educated and committed, a Twin-Track approach is more likely to be in place (PNFP). Where the management is getting more involved, a Cascading pattern is being adopted (SH). Finally, Spotty approach is a symptom of top leadership' skepticism and lack of championing the TQM innovative efforts (PH).

Also, all organizations involved in this study have expressed their belief in TQM as a different way of bringing about organizational change. TQM is seen as more systematic and more process oriented. In some cases TQM was described as a new paradigm shift. However, TQM was also described as having the elements of a "fad." By reviewing the three quality stories it could be seen that TQM worked better in PNFP because it has been adopted as a cultural change, and the total organization is moving toward that goal. TQM fails when it is taken as a fad and is expressed through lip service and empty slogans. In addition, when TQM is used to provide 
quick fixes, problems seem to resurface again and not totally disappear. This shortsighted approach conflicts with the long term approach stressed by TQM. Therefore achieving an everlasting change requires the quality improvement to be continuous and to have a long term vision.

The experience of these three organizations indicates that most of them prefer to start with smaller pilot projects and then let the process grow. This might be safer, especially in the case of those organizations that have high percentages of skeptics. When the top leadership is committed and leading the change; sufficient financial resources for a comprehensive implementation are allocated, and people at the organization are informed and ready, then a system-wide process could be initiated. Nevertheless, if these elements are not secured yet then it is better to start with pilot projects that will help promote quality improvement ideas to the rest of the organization. However, these projects should be used as a testing ground for a larger process, and they should not be confused with a long term organizational change. The final goal of a TQM effort is to create a cultural change rather than making a few bubbles that will shortly disappear.

Finally, it could also be seen that public organizations are more challenged when it comes to adopting TQM initiatives. Public institutions might have more obstacles to deal with than what private institutions might have to deal with. For example, Measure 5 is a good representative of some of the challenges that face 
public organizations more than private organizations. However, that should not be interpreted as a call for rejecting TQM in the public sector. In fact, the success stories described in the Prototype Awards case studies should serve as an encouraging force for public organizations thinking about adopting TQM approaches. It could be concluded then that TQM is a neutral tool. What really makes the difference is how it is used. Consider this metaphor: a computer is just a box that might set, useless forever, at a desk; but when a skilled user who knows how to use it comes along, then the work gets done. By the same token TQM is just a "bunch of theories and techniques" for those who do not know how to put them into action. Being private does not guarantee success while being public does not mean failure. Throughout the various quality stories a major realization could be drawn. The process itself and the way it is being carried out is what mainly decides the outcomes of TQM initiatives rather than whether an organization is privately or publicly owned. This notion receives more analysis in the upcoming chapters. The following chapter will present a comparative approach among the same three organizations by providing a crossectional examination of the data gathered. 


\section{CHAPTER VII}

\section{Introduction}

The previous chapter described the experience of the three organizations that participated in this study by narrating their quality stories. The question of how they go about implementing TQM was explored. The next step is to present the crossectional data gathered at these organizations with a special focus on the second part of the larger research question which is: are there any significant differences among these organizations, in relation to TQM, that could lead to a better idea about the implementation of TQM in both sectors. This chapter will introduce and briefly discuss the responses to the various questions posed in the General Survey that was given to participants at the three institutions. The chapter starts with a discussion of the perceived inherent similarities and/or differences between the two sectors, as seen by participants from both sides. Next is a discussion of how different/similar are public and private organizations from each other in terms of their implementation of TQM. This will be achieved through: a) a presentation and discussion of some of the major issues that relate to implementing TQM at the three participating organizations; and b) a presentation and discussion of some key differences that could be found between public and private organizations in regard to their implementation of TQM. 
Special attention will be paid to what role does ownership, being public or private, if any, have on influencing TQM efforts at these organizations. Finally, the chapter concludes with a comparative summary of the various points discussed earlier in the chapter.

\section{Crossectional Data: Presentation and Discussion of Major Findings}

\section{Introduction}

As discussed earlier in the review of the literature there are some inherent differences between public and private organizations. Private organizations, unlike public ones, have a clearer idea about their customers, deal with more tangible products, and have less political players affecting their decisions. On the other hand, public organizations generally are less threatened by competition, have more secure ways of obtaining their finances (tax-payer money), and finally are less threatened by their external environment than private organizations.

TQM was introduced to private sector organizations for more than a decade ago. Many organizations were able to achieve positive results with it while others failed. The important factor, however, is that an increasing number of private organizations are more eager to adopt TQM practices than before. Many professionals in the public sector are calling for adopting TQM to help transform the public sector and cite as evidence the successful experience of TQM implementation 
in the private sector. Therefore, TQM is promoted as the new tool to create a new paradigm shift in those organizations adopting it.

On the other hand, many skeptics in the public sector criticize that assumption, and they justify their suspicion of TQM because they claim public organizations are indeed different from the private and what has worked in one sector might not be guaranteed to succeed in another. For those skeptics TQM is just another 'passing fad." For example, one of the Quality Improvement Teams that were started at SH failed because some of its members were skeptical about the potential of TQM processes to improve the system. This led to a great deal of argumentation and ultimately the team collapsed. The following pages contain the beliefs and ideas of respondents on both sides, private and public, who have been involved with TQM. These pages also describe how TQM is carried out and whether it is different in a public organization than in a private organization, and if so how. Moreover, the data gathered attempts to answer the following questions like: Are there any significant differences in the implementation of TQM? What are the forces that might account for these differences? 
Are Public and Private organizations that different?

\section{Questions 14/15}

As discussed previously public and private organizations share many similarities as well as many differences. Respondents were asked the following question" : "In which ways are public and private organizations similar/different, in relation to TQM?" The responses gathered indicate that both public and private organizations share the same goal of striving for better quality and less costs. Moreover, both organizations strive to satisfy their customers (patients and others) whose input is very critical to the process. It is also believed that bureaucratic rules and regulations do exist in private organizations as they do in public sector organizations. Therefore, private sector organizations are not that different from their public counterparts, and in a health care setting the differences seem to be marginal. However, public organizations, such as $\mathrm{SH}$, have more responsibility to the general public. For example, caring for the uninsured is one of SH's responsibilities that differentiates it from its private counterparts. Public and private hospitals differ in their focus on profit and financial gains. While private hospitals, especially the for profit ones, are more concemed about profit and financial gains, public organizations are more concerned about their accountability to their constituents. Though both

\footnotetext{
this survey.

${ }^{1}$. Question \# 19 in the General Survey. Please refer to Appendix B for a detailed copy of
} 
types might want an improved process as an outcome of implementing TQM their motives for doing it might differ. Public organizations are more closely scrutinized than private organizations. They have to "answer to" the demands and or expectation of more customers than private organizations do. One of the participants at SH indicated that when the Operation Restructuring ${ }^{2}$ was announced at the hospital it received a greater media coverage and many people were calling to inquire about it. But when PNFP made the decision to launch the CQI process, it did not receive such attention and scrutiny.

Finally, the literature review suggests that public organizations tend to be more complex than private organizations because they have multiple customers. Their ability to change might be less flexible than in the private sector. Change needs to be approved and sponsored by more than the Board Of Directors; it needs to pass through public legislative bodies and any additional policy making apparatus. The quality story of SH reflects this notion. The political environment of public institutions is more diverse and more influenced by external forces, such as interest groups and legislative bodies. However, physicians in the private sector have more power than those in the public sector. One of the reasons for this is that "many MD's in the public sector are salaried [employees]." In conclusion, responses to

\footnotetext{
${ }^{2}$. For more details about Operation Restructuring please refer to the previous chapter or to
} Appendix D. 
questions 14 and 15 suggest that while differences between public and private organizations do exist similarities between the two should also be recognized.

\section{a) Key Issues in the Implementation of TOM: Comparative Assessment}

\section{Introduction}

This section provides a comparative exploration of major issues that relate to the implementation of TQM at both public and private organizations. Once again these comparisons will be based on the data obtained from participants who answered the General Surveys ${ }^{3}$ at these organizations. This section compares the two sectors based on their perception of TQM, their belief in where it should start, and finally their presentation and ranking of key organizational players believed to have the most power over the implementation and outcomes of TQM. Another comparison will be on the critical forces that might hinder or facilitate the implementation of TQM. Finally, this section will provide a comparative discussion of how do participants who represent public and private organizations think about the possible outcome of TQM in both sectors.

It should be stressed that the views from participants in both sectors provide some resourceful information that helped in reporting their quality stories and in structuring the comparison process among them. Since those participants are heavily involved in the TQM process and they are well- informed about it, they were in a

${ }^{3}$. Some of those participants were also interviewed. The information used in this chapter is derived from crossectional data of responses gathered via General Survey at the three organizations. 
good position to provide useful data that helped describe what is going on at their organizations. Most of those participants hold key positions that enabled them to provide relevant information that reflect the existing views at their organizations. Another supporting factor is that most of these findings are echoed in the responses to the interviews conducted at the three organizations. Arriving at similar results by using a variety of instruments of data collection, triangulation, injects more reliability into the study. Finally, despite the smaller size of the research sample, it provides sufficient data about the topic under examination. By using the three instruments together the process of obtaining reliable data became easier, and in many cases the responses from one instrument were used as a stepping stone for the rest of the instruments to be used.

\section{First: Is TQM/CQI Different from Other Approaches to Organizational Change?}

Many organizational leaders, who have been exposed to various organizational development theories and improvement methodologies look at TQM to see some unique qualities in TQM that puts it above the others. Hunt (1992, p. 28) believes that TQM should be considered as a new paradigm shift because it represents and requires a "different set of beliefs and assumptions about the nature of business organization ... and [since] it requires a cultural change." This view reflects a growing 
belief that TQM is different from other OD and/or Quality Assurance approaches, such as MBO, Management by Results, Quality Circles, .. etc. One of the study's

goals is to find out how is TQM perceived by participants at public and private organizations? Is TQM viewed as a fad or is it a paradigm shift? What is so special

about TQM that differentiates it from other quality assurance theories? Table VI below shows the tabulations of the responses to the question: Does TQM differ from other Quality Assurance approaches, and if so how? ${ }^{4}$

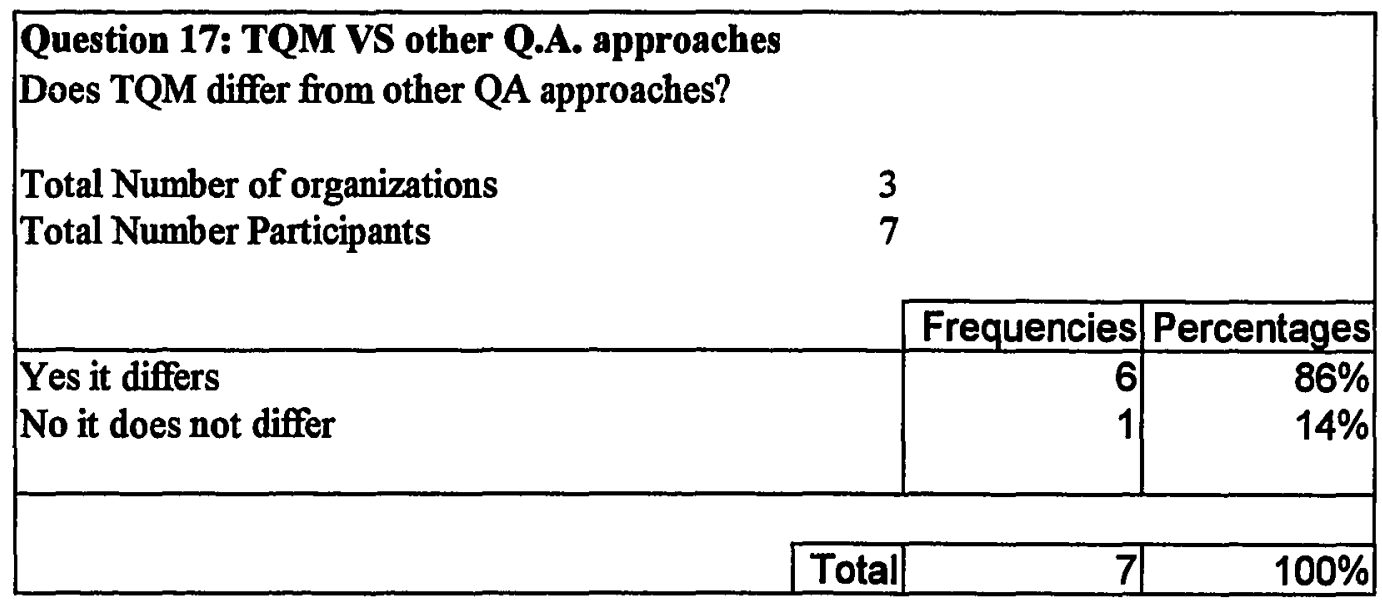

TABLE VI

TQM VS OTHER QUALITY ASSURANCE APPROACHES

\footnotetext{
4. Please refer to Q. 17 in Appendix C for more details
} 
The above responses of surveyed participants, who have been involved in TQM show a range of beliefs: from a firm believer to a skeptic. An overwhelming majority, 6 out of $7(86 \%)$ of the respondents believe that TQM is different from other QA approaches. All respondents of PNFP as well as SH believe that TQM is different than other QA approaches. As for PH, TQM is seen as similar to other QA theories and possibly as a "fad, but not self limiting." In spite of this response this participant has mentioned some positive characteristics in TQM (Q.11). For example, "TQM breaks down interdepartmental barriers, focuses more on the process and error prevention, and it is more statistically driven than other QA or OD approaches."

As indicated in the responses to the above question, among the reasons why most respondents believe TQM differs from other QA approaches are its prospective and preventive nature, and an organized, formalized, and internally driven system for achieving organizational change. TQM is described as: scientific, data driven, manages by facts, driven by top management, and mandates complete cultural change.

In conclusion, public as well as private organizations believe that TQM is different from previous QA approaches and some go further to affirm that it is indeed a paradigm shift. For both PNFP and SH, where there is a higher degree of interest and involvement in TQM, there is a higher degree of belief in TQM. On the other hand, PH has not initiated a system-wide initiative yet and is still in its initial stages of TQM. This might explain why there is more skepticism about TQM at PH. 
This suggests that the degree to which an institution values TQM as a superior approach correlates, positively, to the degree of its involvement and success with its quality improvement efforts. The next step will be to introduce the views about where a TQM effort should start and who are the key players.

\section{Second: Where Should a TOM Effort Start?}

\section{Introduction}

The literature indicates that the primary responsibility of implementing TQM falls on the shoulders of the top leadership. The data gathered from those interviewed, surveyed, and even observed affirm it. But how do public and private organizations compare in terms of their belief on where should a TQM effort start? If there is a principle that both public and private participants agree on without much debate it is that TQM should start at the top leadership office.

Leadership commitment is the starting point for TQM. The data provided in the table ${ }^{5}$ below strongly support the above supposition.

5. For a more detailed distribution of data please refer to Q. 18 in Appendix C 


\begin{tabular}{|c|c|c|c|}
\hline \multicolumn{4}{|c|}{ Question 18: Where should a TQM effort start? } \\
\hline \multirow{3}{*}{$\begin{array}{l}\text { Total Number of organizations } \\
\text { Total Number of Participants }\end{array}$} & \multicolumn{3}{|l|}{3} \\
\hline & \multicolumn{3}{|l|}{7} \\
\hline & & Frequencies & Percentages \\
\hline 1- At the administration office (the top Mgent) & & 7 & $100 \%$ \\
\hline 2-At the production Line & & 0 & $0 \%$ \\
\hline 3-At Quality Assuranoe Department & & 0 & $0 \%$ \\
\hline \multirow[t]{2}{*}{ 4- Others:No responses } & & 0 & $0 \%$ \\
\hline & Totals & 7 & $100 \%$ \\
\hline
\end{tabular}

\section{TABLE VII}

\section{WHERE SHOULD A TQM EFFORT START}

One of the most important and even clearest findings of this research has been about the role of top management in the TQM process. $100 \%$ of the respondents answered that TQM should start at the top and transcend downwards. TQM/CQI educated and committed management will help enable a successful implementation of TQM. The variety of research methods used in this study clearly show that top management holds the key to the success or, more importantly, the failure of TQM efforts in organizations.

Regardless of its ownership or its size, an organization that wants to launch TQM processes should focus on educating its top management team in the various theories of TQM. The lack of top management's understanding of TQM will cause a sense of skepticism and indifference. This will hinder their buy-in and total 
commitment to the process. In the case of SH, for example, this forced TQM leaders to retreat and try to re-address this issue more comprehensively by educating their top management first. Top management holds the necessary organizational power that gives TQM implementation credibility and respect, which of course will translate to acceptance.

Those organizations that try to implement the process on a limited scale, or scattered cases of implementing TQM/CQI techniques throughout certain departments, and then generalize to the whole organization, will have a difficult time

if they have not involved their top leaders from the beginning or at least secured the top management's buy-in and commitment. In conclusion, top management is seen by both private and public organizations as the key to the success of any TQM effort.

\section{Third: Key Players in the Implementation of TOM}

This point is related to the previous one in that it focuses on those key organizational players that might influence the quality improvement efforts at the organization. As indicated earlier top leadership plays the key role in any TQM effort but Who else? 


\begin{tabular}{|l|l|c|c|c|c|}
\hline & & & \multicolumn{3}{|c|}{ Ratings } \\
\hline Ranking & Organizational layer & \# Low & \# Medium & \# High & $\begin{array}{c}\text { No } \\
\text { response }\end{array}$ \\
\hline 1 & Top or Senior Mamt & 0 & 0 & 7 & 0 \\
\hline$\underline{2}$ & Physicians & 0 & 4 & $\underline{3}$ & 0 \\
\hline$\underline{3}$ & Middle Management & 0 & $\underline{7}$ & 0 & 0 \\
\hline 4 & Employees & 6 & 1 & 0 & 0 \\
\hline 5 & Customers & 3 & 2 & 0 & 1 \\
\hline 6 & Labor Unions & 4 & 1 & 1 & 1 \\
\hline 7 & Consultants & 2 & 0 & 0 & 5 \\
\hline 8 & Share Holders & 1 & 0 & 0 & 6 \\
\hline 9 & Payers (Others) & 0 & 0 & 0 & 7 \\
\hline
\end{tabular}

TABLE VIII

\section{RANKINGRATING OF KEY PLAYERS IN THE TQM PROCESS}

This question ${ }^{6}$ consisted of two parts. The first part asked the respondents to provide a ranking order of a list of organizational layers and participants that might influence the implementation of TQM. The other half of the question asked the respondents to rate (on a scale of $1=$ low; $2=$ medium; $3=$ high) the degree of influence they believe those key organizational participants possess over the quality

\footnotetext{
${ }^{6}$. For more detail s please refer to responses to Q. 6 \& 7 in Appendix C
} 
improvement efforts. Because of their influence those key players in the organization might decide the success or the failure of the TQM process.

Here again we find that top management is seen as the most important organizational participant in implementing TQM. Top or senior management has been ranked as the \# 1 organizational participant that will influence the implementation and the outcomes of the process. Moreover, the Board Of Directors is also one of the first key players on the list. All respondents have rated the top management as having the highest influence on the TQM process. This again supports the findings of the interviews. TQM was more successful in those organizations where top management played a key role in adopting the process and getting involved in it. Physicians are also seen as a key factor in the TQM process, whether they are consiäered as employees, such as in the case of SH, or whether they are affiliated with the system, such as in the case of the two private institutions.

Customers, external (patients) as well as internal (employees, physicians) seem to have a special recognition in the findings. Respondents from SH, the publicly owned hospital, placed a special importance on the role of customers in influencing the implementation and outcome of TQM/CQI. By the same token, they believe their customers have high to medium degree power to influence the organizational policies. This supports the findings of the interviews. Publicly owned organizations have more 
responsibility to the general public, and they are in fact more scrutinized by their external customers, the patients, that are in fact the general public. Bringing the notion of internal customers to the picture, physicians, the internal customers in the public organizations, play an important role in influencing organizational policies. This logic applies to private organizations as well, that place a special importance on the involvement of physicians in the process.

The responses also reflect a belief in the importance of middle management, that was ranked as one of the top 5 key organizational players. As the literature indicated earlier, the involvement of middle management is critical for the success of TQM. In its training manual the Federal Quality Institute stresses the importance of involving the middle management in the improvement process. Alienated middle managers that are not being involved in the process could become a real threat to the improvement effort, as indicated throughout the literature.

Therefore, the above responses reflect the importance of top management to the success of a TQM effort. As indicated earlier top management has been as the dominant coalition whose decisions are critical for the future of the organization. The rest of the key players are: BOD, physicians, extemal and internal customers, and 
middle management. The next step is to present those supporting forces deemed relevant to the success of TQM, as well as the forces believed to hinder success.

\section{Fourth: Supporting / Hindering Forces for the Implementation of TOM}

\section{Introduction}

The previous section introduced the key organizational figures that are believed to have the most influence on the implementation and the outcomes of TQM efforts in both public and private organizations. The ranking of those figures is based on the responses of those that participated in the study. This section discusses the factors these participants see as critical elements to the success of TQM and the forces they perceive to hinder its implementation.

\section{Critical Elements for the Success of TQM/CQI, Supporting Forces}

Responses to Question $20 \mathrm{~A}$ and $\mathrm{B}^{7}$ provide a list of factors that respondents have cited as critical to the success of a TQM effort. Supporting factors, are those elements that help facilitate the success of TQM/CQI. These factors could be grouped into major areas, listed below.

It is important to realize that those supporting factors include most, if not all, of the components of TQM models introduced earlier. A focus on leadership

\footnotetext{
7. For more detailed tabulations of responses please refer to responses to Q. 20A and Q. 20B in Appendix C.
} 
involvement and commitment, systematic approach, focus on customers, process orientation, continuous evaluation for continuos improvement, etc. are the major components of the "Baldrige Award Model" and the "Reinventing the Government Model." The data collected by this study provide evidence about the relevance of those models to the implementation of TQM in both sector. The results validate the relevance of these elements to the success of a TQM innovation effort.

\section{Supporting Forces for the Success of A TOM effort (Critical Elements)}

1. Top Management/leadership knowledge of TQM, their commitment and active involvement in it.

2. Comprehensive and accessible educational process of TQM theories and applications .

3. Allocation of financial and human resources needed for carrying out TQM processes.

4. A well articulated TQM plan

5. Breaking down interdepartmental barriers and open channels of communication.

6. Long term vision and patience.

7. Commitment and participation of management and employees.

8. Widespread marketing and publicity of organizational TQM successes.

9. Accurate and well maintained system of measurement and tracking of implementation, to ensure measurable outcomes.

10. Ongoing evaluation of process to ensure the Continuous Quality Improvement

11. Flexible system with mechanisms that detect and correct errors. 


\section{Challenges to a Successful Implementation of TOM (Hindering Forces) ${ }^{8}$}

The above summarized the critical factors believed to promote TQM and help the process achieve its goals. Maintaining a comparative balance requires the introduction of the hindering forces believed to inhibit and limit quality improvement efforts at both private and public organizations. Listed below are some of the major forces that are believed to hinder the success of a TQM process.

As discussed earlier in the literature review, TQM adopts the concept of force field analysis. An organization trying to implement a change is affected by both supporting factors as well as hindering forces. The previous section explored the supporting factors: the critical elements that assist the organization in reaching desired TQM outcomes. At this point, it would be appropriate to explore what factors might prohibit an organization from reaching the desired outcomes of the process. To a certain degree, the success of the TQM process and implementation depends on the absence of these hindering forces and/or weakened levels of hindrance among them; and by the same token, it depends on the presence of supporting factors and/or strengthened levels support among of them. Listed below are the common areas, under which the responses of the surveys fell:

\footnotetext{
${ }^{8}$. For more detailed listings of these forces please refer to the responses to $Q 20 B$ in Appendix $C$.
} 


\section{Findering Forces for the implementation and success of TOM}

1. Ignorant, uncommitted, and indifferent top management/leadership.

2. Limited, restrictive, and unclear educational and training system regarding TQM.

3. Lack of sufficient financial resources needed for the process

4. Fragmentation, turf conflicts, and lack of communication: vertically and horizontally.

5. Lack of a well - articulated TQM plan.

6. Not involving ALL the key participants, say physicians, soon enough in the process.

7. Short term vision and impatience, and looking for quick fixes.

8. Alienated and change resistant middle management and employees.

9. Lack of publicizing successes, weak marketing approaches.

10. Lengthy, error infested, and unclear system of measurement and monitoring that fails to track and produce measured outcomes.

11. Haphazard evaluation of outcomes, leaving things to the last minute.

12. Inflexible system which lacks the mechanisms that detects and corrects errors.

Looking at both the supportive and the hindering forces shows that top leadership commitment is the primary key. Added to that is the importance of education to the success of TQM, which could be contrasted with the threat of ignorance and its damaging effect on the improvement process. Examining the responses of participants from both public and private organizations indicate that they both stated similar factors. This suggests that when it comes to implementing TQM, there is not much of a difference between public and private organizations, at least in the basic requirements for TQM. Nevertheless, some differences do exist between the private and the public organizations, involved in this study, in their implementations of TQM. This will be discussed in a later part of this chapter. But what do participants in 
organizations representing both sectors think about possible outcomes of TQM at both sectors? This is the next topic.

\section{Fifth: Will the Outcomes be the Same?}

\section{Introduction:}

Many want to know if the implementation of TQM will yield similar or different results in one sector compared to the other. Though the scope of this study is not to evaluate the outcomes of TQM at these organizations, the question was asked to build the comparative approach. Soliciting the views of those participants from both sectors enables the construction of a stronger, more comprehensive, and more accurate comparative approach among the three organizations that were examined. Based on their experience with implementing TQM, thus far, participants were asked to comment on the predicted outcomes of TQM efforts. More specifically they were asked about if they believe that outcomes of TQM will be different/same between public and private sector organizations.

Table VIII below shows the frequencies of responses to the question in regard to the expected outcomes, as seen by the participants from both sectors. ${ }^{9}$

\footnotetext{
${ }^{9}$. For more detailed breakdown of responses please refer to responses to Q. 19 in Appendix C.
} 


\section{Question 19: TQM outcomes, Public VS Private}

Will the outcomes of TQM/CQI processes be the same, or different in the public sector, and why?

Possible responses : 1- Same 2- Different

Total Number of organizations 3

Total Number of Participants 7

\begin{tabular}{|l|r|r|}
\hline & Frequencies & Percentages \\
\hline Same & 5 & $71 \%$ \\
\cline { 2 - 3 } Different & 1 & $14 \%$ \\
\cline { 2 - 4 } No response & 1 & $14 \%$ \\
\hline & & 1 \\
\hline
\end{tabular}

TABLE IX

\section{EXPECTED OUTCOMES OF TQM: PUBLIC VS PRIVATE}

The data gathered indicate an overwhelming belief that TQM will yield similar results in both sectors, as long as there is a systematic and guided implementation of TQM. Respondents from both private and public sector organizations, indicated that, "as long as the critical elements [mentioned earlier as supporting forces] of TQM are in place, then there would be no difference in the outcomes of TQM in both sectors" In fact, some believed that health care organizations are more aligned with private industry organizations and that holds a promise for adopting TQM at these organizations. 
In previous sections respondents from both sides see TQM as a unique and different approach for organization development and bringing about organizational change. They see it as prospective rather than retrospective, data and fact driven, stresses and utilizes systematic and scientific methodologies, calls for the total involvement of the organizational participants, and demands long term vision. All these, and the other characteristics mentioned throughout the research are the "critical elements" that should be present in any organization that adopts TQM in order for the quality improvement to succeed. When these characteristics are present in a quality improvement effort organizations will be able to realize the goals they are aspiring to achieve and the outcomes they desire.

The respondents believe that if these elements are incorporated into the system of implementing TQM outcomes should not differ sharply. In other words, public organizations will gain positive organizational outcomes from implementing TQM if they pay attention to the above requirements. However, public organizations are NOT exactly like private organizations, and that means TQM implementation and outcomes will not be identical to those in the private sector. A closer look at public organizations reveals that, on average, they tend to be larger and more complex, more scrutinized and restricted in their decisions about implementing TQM, more influenced by the political environment they exist in than private sector organizations are. These factors will lead to some differences in the implementation and possibly 
some differences in the outcomes of TQM at public organizations. This is the next topic.

\section{b) Implementation of TOM at Three Health Care Organizations : Major}

\section{Differences}

\section{Introduction}

The following section explores some differences found among the participating institutions in their implementation of TQM/CQI. Doing so will shed some light on any possible differences that might exist among private and public sector organizations in their implementation of TQM. The goal is to provide an answer to the second part of the research question (are there any differences that could be identified among the organizations of public and private sectors that are adopting TQM?).

As shown earlier, there is a greater degree of similarity between private and public organizations in their implementation of TQM. Most respondents believe that the outcomes of TQM will not be that different between the two sectors, as long as the correct (critical) conditions and requirements are met. This finding supports what the literature reveals about organizations, from both sectors, that won the quality awards. This is also true for those health care organizations that participated in the National Demonstration Project (NDP) in the field of health care. 
In spite of the above this research has also discovered some differences that still exist among public and private organizations in their implementation of TQM. The following pages describe some of these differences that could be identified among those organizations. The next step is to explore whether these differences are due to ownership or to some other factors.

\section{Differences in Implementing TOM}

\section{First: Varving approaches to implementing TOM}

Each institution has varied in the implementation approach they took in their way to quality improvement. Each one of the three institutions that were studied has been trying to bring about organizational changes that will improve the quality of its products and services. As the implementation approach at these institutions was assessed following differences appcared.

First, the private-for-profit hospital (PH), the smallest of the three, used a Spotty approach in implementing TQM. As described earlier, this approach is characterized by a limited scale implementation because few people are trained on TQM and team building tools and techniques. Therefore, few employees are involved in quality improvement teams (QITs), while the top management is not.

Second, a Twin-track approach could be seen at the Private-Not-for-Profit, the largest of the three. This approach combines a system-wide training and 
implementation that is led and championed by top leadership. Moreover, long term goals are to transform the culture of the organization to one in which quality is the norm of doing business. This vision is strengthened and encouraged by the implementation of pilot projects. In its annual reports PNFP stressed its long term commitment to transforming the organization but on the short term Process Improvement Teams have been working on quality improvement projects that will be used as pioneering efforts for more projects to come.

Third, the public hospital (SH) began with a Spotty approach and as the organization moved forward SH replaced it with more of a Cascading approach. The main feature in the Cascading Approach is the focus on training and committing top leadership first and then cascade this to lower organizational levels and continue with that until all members are trained. This approach is slow, which is the case at SH, but it is better than the spotty approach.

When top leadership is more committed to TQM there is a movement toward adopting more effective approaches to implementing TQM. Moreover, each organization has its unique characteristics that dictates which approach to adopt. However, it is realized that more successful organizations adopt a winning approach while organizations that have trouble with implementing TQM end up without a useful approach. 
Second: Varying Degree of political influence over the TOM process

Schmidt (1992) indicated that some believe that it is harder to implement TQM in public organizations due to more political activity that shape and influence the implementation process. The discussion of the differences between public and private organizations indicated that public organizations are more influenced by political forces than private organizations are. For example, in the case of the public hospital (SH) at the time of planning for implementing TQM the institution was dealing with the effects of Measure 5 and other budgetary cuts that were imposed on the institution by higher legislative bodies. Moreover the hospital is more exposed to public influence and what goes on in the local, State, and even the Federal government. The interviews and the responses to the surveys revealed that people at SH are more aware and concerned about the political forces than people in the other two private institutions. They were more concerned about a change in the political leadership which might lead to a change in their priorities and directives. These political forces create a level of uncertainty that might affect the implementation of TQM. Therefore, the implementation of TQM at the public hospital (SH) is more influenced by the external and the internal political environment.

Private hospitals do also have some political forces that affect their implementation of TQM. For example, forces such as friction, turf issues, and resistance to change were cited as political factors that might affect TQM efforts. 
However, private organizations are less concerned about the taxpayers' influence than SH.

Third: Varving levels of flexibility to take risk and implement TOM changes Another point that has been raised by Schmidt (1992) is in regard to the degree of flexibility public institutions have to implement TQM compared to the private institutions. Public organizations are more scrutinized, more accountable to constituents-taxpayers and the general public, and they have less flexibility to take risk. This study explores this notion, and, to a certain degree, found it to be true.

Respondents at SH acknowledged that they are under a greater deal of scrutiny and their actions are more watched by the media. For example, one of the administrators at SH indicated that if a decision about TQM is to be made and it involved allocating a large amount of money it will attract more media coverage than a similar decision in a private organization. Another respondent cited that it takes longer to make decisions because SH has to answer to more than just one superior. Such scrutiny affects the ability of SH to make decisions about implementing TQM, especially allocating financial and human resources.

Another point realized through the responses gathered from participants, is that the SH is more accountable to the general public than the other two organizations. Since its resources come, at least partially, from the taxpayer money 
the hospital is held more accountable. In the case of SH it provides coverage to the uninsured and the indigenous. Schmidt indicates that public organizations are affected by " multiple sources of control and accountability, with the same agency having to answer to local, state, and federal 'customers' that have multiple needs and priorities," $(1992$, p. 58). This notion could be clearly seen through the responses of SH participants. The implementation of TQM at a public institution might take a longer time and will be more challenging. This is true in the case of SH, when compared to PNFP, whose improvement process was faster to start because top management support was the major principal requirement to launch the process. Even if top leadership gives the green light for TQM, more sources of support are to be consulted before it is fully functional.

In addition to the above, public organizations are less flexible and less able to take risks. Because they are more accountable and more scrutinized, public sector organizations have less tendency to take risks. Compared to a private institution a public organization might hesitate to launch a TQM effort because as one participant put it "the cost of taking a risk that fails can be a highly publicized disaster," (Participant \# 3). One of the basic requirements of TQM is to promote a culture in which taking calculated risk is permissible and even encouraged. By the same token, TQM calls on allowing managers and employees to make decisions that relate to their work. This includes the power to provide rewards and promotions. At SH there has 
been a wage freeze for a while but employees were asked to do more. This, according to the SH participants, will hurt implementing TQM because it will be difficult to enlist the commitment of the employees. In comparison, a motivation system was installed at PNFP in which members of PITs were rewarded with bonuses and promotions for their participation and commitment to TQM/CQI.

In conclusion, public organizations such as SH have less flexibility to take risks and when they are allowed to they have less desire to do so due to the degree of scrutiny and influence they face. This contradicts the major guidelines advocated by TQM. Private organizations are less affected by these forces and that enable them to take risk and thus improve their process faster.

\section{Fourth: Ease of Identifying the Customer}

This section explores how do these organizations identify their customers, and what differences might exist between the public and private ones. Schmidt (1992) believes that "for some organizations identifying the customer is easy- it's the person that purchases the product or service. This is the person that must be satisfied." But with organizations such as schools, hospitals, churches, and others identifying the customer "can become a very complex task" (p. 339). Therefore, the process of identifying the customer is not an easy one, especially for those organizations that deal with multiple customers with varying needs. Public organizations fit this 
description more than private ones do. This was obvious from the responses gathered from participants representing the private and public sectors.

When asked to identify their customers each organization has identified patients and their families as one of their major external customers. For PNFP and PH other customers included other employees, physicians, and third party payers such as insurance companies. For SH, however, the additional customers were identified and they include the local, state, and federal governments, the system of higher education, and a variety of social agencies. Officials at SH believe that it is more challenging to identify the exact customer towards whom the improvement efforts should be directed and how to decide on that "should get attention when needs differ" (Schmidt, 1992, p.339).

It is evident by the data gathered that implementing TQM at public organizations might be more complex than in the private organizations. Public organizations are more challenged when it comes to identifying their customers to whom the process is directed. But this should not be a major deterrent because private organizations, especially those in the service industry, might face a similar challenge as well. Identifying the right customer is one of the major steps in TQM, because it provides direction for the improvement efforts. When multiple customers exist, this process becomes more complicated and makes the process of implementing TQM more challenging. 
Fifth: Harder to change organizational culture in public, due to a more cumbersome bureaucracy and complexity

TQM is perceived by many as a paradigm shift in that it reflects a transformation in the organizational culture. Changing an organization's culture is not an easy task nor is it a short- term attempt. The final goal of a TQM process is to institutionalize improved quality innovations in the everyday activities of the organization that adopts it. Complex organizations have complex cultures. An organizational culture might also be composed of a number of subcultures each with its distinctive characteristics and requirements. As more subcultures and interest groups exist change becomes more difficult and it takes a longer time to transform the organizational culture. Organizations with more complex cultures tend to have more political activity because of the competition among the various interest groups for resources, power, and recognition. This might create conflict and if it is mishandled by top leadership it will derail any improvement effort regardless of how effective and/or beneficial it is. The point is that larger organizations with more complex organizational cultures will place additional demands on the quality improvement processes.

Public organizations tend to have more complex organizational cultures. One of the participants ${ }^{10}$ at SH, the public organization in this study, reaffirms this fact "

10. Please refer to responses for Questions 14/15 in Appendix C for more details. 
... it is harder to change the organizational culture in the public sector." (Participant \# 7, Q. 15). When compared to the other two organizations SH has more concerns about this factor than the other two private organizations. This is not to say that the organizational culture in the private sector is not complex and will be changed very easily. Nevertheless, the belief that implementing TQM at the public organization is more challenging because of a more complex culture is evident in this study. More political activity is evident at SH than the other two and it is subject to more rules and regulations as well. The implementation of TQM in the public sector might be different in that more attention needs to be given to the complex cultural web that exist in a public organization. According to the same respondent, "public organizations have more cumbersome bureaucracy." The culture of many public organizations tends to be rigid and more bureaucratic and this will be challenging for TQM. The data gathered via interviewing and surveying supports this claim. In their experience with TQM the two private organizations displayed a certain degree of concern for bureaucratic regulations and cultural restraints. However, there is more concern about turf issues, political fragmentation, and existing rules and regulations at the State Hospital than the other two. Participants at SH believe that implementing TQM will be more challenging because changing the culture of a public organization takes longer and requires more efforts and resources. 
In conclusion, the culture of public organizations tends to be more complex and consists of politically active interest groups and subcultures. Added to the surrounding political environment these forces will have greater influence on the implementation process and even outcomes of TQM. For instance, all the participants at SH cited planning as the key issue for TQM. ${ }^{11}$ They indicated that planning is crucial because of the complex culture of the organization and the need to come up with effective ways to deal with these cultural factors so they do not backfire and ' $k$ ill the improvement process."

\section{Sixth: Other differences}

The previous pages have presented some of the major differences between public and private organizations as they relate to the implementation of TQM. Most of these differences pose a challenge for public organizations that embark on a quality improvement effort. Further examination of the data revealed additional differences which will be discussed briefly in the following paragraphs.

Because of more scrutiny, more bureaucracy, and less ability to take risk, public organization bringing about change through TQM might take longer. TQM tends to have a longer time frame at SH for example because more players are on stage and each wants a role to play. Moreover, approving certain plans and decisions require more time because it has to go through many administrative and political

11. For more details, please refer to responses to question Q. 21 and 22 in Appendix C. 
bodies In private organizations the support of top leadership is the main requirement because the decisions made at the administration level (top leadership) will signal the green light for TQM to take off. On the other hand, public organizations have to go through additional authorities to get the plans approved even if the top leadership is committed and in support of the change. These additional steps will consume more time, resulting in a slower process.

Though public and private organizations, alike, hope for better quality and improved products and services, their motives for launching TQM might slightly differ. Private organizations are more profit oriented. Private participants indicated increasing market shares and more profits as primary results that they hope to achieve by implementing TQM. Better products and services means more satisfied customers, and in essence a repeat business and greater ability to compete. In addition, a host of other positive organizational outcomes were stated, such as improved productivity, satisfaction of internal customers (employees) as well, more efficient systems. For private organizations, TQM then is a means to securing more financial gains reflected in larger market shares.

Public organizations, in their quest for quality improvement are motivated by a desire for more efficiency, more savings, and to satisfy their constituents. In other words public organizations might be more interested in political gains than financial 
gains as the final outcome of a TQM process. Financial achievements are very much desired, but they are not an end in themselves. SH participants, for example, indicated that they look for TQM to save resources and reduce waste. These savings will go back to the system to improve its performance. The SH participants indicated that if better results are achieved then it will be easier to convince the legislature to approve other quality improvement ideas. Therefore, public organizations are more politically motivated while private organizations are more financially motivated.

Though both private and public organizations pay attention to their extemal and internal environments their emphasis on forces and players within these environments vary. In their implementation of TQM public organizations are more concerned about internal forces, such as other departments, legislative bodies, and BODs. Private organizations, on the other hand, are more concerned about other competitors, suppliers, and external market forces. This realization is echoed in the responses gathered via the general survey Internal forces were rated as having more influence at $\mathrm{SH}$, while external forces were rated as having more influence at $\mathrm{PH}^{12}$

However, public organizations are getting more concerned about competition because of the new Health Care Reforms introduced by the new administration. Under the new policies new health care structures and alliances will be erected and

12. Please refer to responses to Q. 13 in Appendix C for more details. 
responses gathered via the general survey Internal forces were rated as having more influence at $\mathrm{SH}$, while external forces were rated as having more influence at $\mathrm{PH}^{12}$

However, public organizations are getting more concerned about competition because of the new Health Care Reforms introduced by the new administration. Under the new policies new health care structures and alliances will be erected and public hospitals will be forced to compete for patients as private organizations do. For TQM to succeed at the public sector, it needs to address these new conditions by including components that will meet the need for larger market shares and focus on ways to attract more customers.

Due to a more active political environment/s, public organizations might experience more resistance to change than private organizations might. For example, middle managers and other interest groups (active labor unions such as AFSCME) might see in TQM a threat to their existence and might fight it fiercely. In fact this is a common problem between the two sectors. Middle management involvement is critical to the success of TQM but at the same time middle managers might end up alienated in the process of TQM implementation. TQM transforms the organizational culture by encouraging independent decision making and calls for eliminating inspection and supervision. These are duties that were historically performed by middle management. In a public setting middle managers might fight TQM because of

12. Please refer to responses to Q. 13 in Appendix C for more details. 
their fear of losing their jobs. In fact, at SH adopting TQM coincided with major layoffs due to budget cuts. This has negatively affected TQM implementation because many linked it with unemployment and loss of jobs. This is reflected through a satirical comment by a middle manager at $\mathrm{SH}$ 'by supporting and doing $\mathrm{TQM}$, you might be digging your own grave."

\section{CONCLUSION}

The previous pages presented some of the major differences that existed between public and private organizations in their implementation of TQM. These differences were discerned through the crossectional data gathered via surveys and interviews conducted at the three organizations. In spite of these differences the general impression is that participants from both sectors believe that TQM could help them improve their work and system performance. They also believe that as long as the critical elements and requirements are provided, the outcomes of TQM in both sectors should be similar. In other words, it is believed that TQM is capable of solving quality problems in the public sector as it does in the private sector. The next and final step in this chapter is to explore what role, if any, ownership have in influencing the implementation and outcomes of TQM. 


\section{OWNERSHIIPAND TOM: Are they related and How?}

It is logical to say that by looking at the various differences that exist among these three institutions one has to cite more than one factor that lead to these differences. This section discusses the remainder of the second question of this research: what role does ownership play in TQM?

Ownership, as defined throughout the research, is whether the institution is privately or publicly owned. Generally speaking, a private organization is profit oriented and is owned by a private individual, group, or organization. The opposite could be said about public institutions. A public organization is owned by a local, state, or federal government or agencies. It is not profit oriented though financial gains are important to it.

Some of the differences described above exist because of ownership. Public organizations possess certain characteristics that influence the implementation of TQM. For example, public organizations are more complex, more politically oriented, tend to have multiple customers, more accountable to the general public, have a more complex culture, and so on. So when the implementation of TQM varies from a public organization to a private organization the variation in the implementation could be mainly due to one of these qualities. Ownership, then, is the

major factor behind this change. Sometimes, however, TQM implementation and even outcomes differ not only because of the nature of the organization alone but because 
of another factor/s. Many times, however, the difference in the implementation and outcomes of TQM is a result of a combination of factors, including but not limited to, ownership, which was the case in this study.

For example, there is more scrutiny surrounding SH in its quest for quality improvement. Moreover, this hospital is more accountable to the general public; and it is also subjected to more political influence by the legislature and labor unions. These factors affected the implementation of TQM in that they required more time to be given to planning and a longer time for the process to start. The approach implemented will have to be a cascading approach because with such a complex environment a slow pace of change is better than all- at- once approaches. TQM implementation did not start fast enough because the top management commitment was not secured from the beginning. This lack of involving top management caused the implementation to regress. The point is that TQM differed not only because the institution is public but also because another factor (top leadership involvement) was not provided.

Ownership does play an active role in the implementation of TQM in a given organization because it dictates certain givens that will influence the processes and outcomes of the quality improvement initiatives. However, ownership alone cannot be used to justify the success or failure of TQM/CQI at any organization. This finding might provide a challenge to the traditional way of thinking that does not encourage 
one sector to borrow or/and to assimilate the experiences of the other. They succeed if they involve top leadership, plan right, implement right, and evaluate and continue improving. Private and public organizations own certain characteristics that will affect a TQM effort and dictate some requirements in the implementation of TQM to adapt and respond to these unique features of being public or private. The bigger picture, though, is that a host of factors cause TQM to differ from one place to another. Ownership is important but its not everything. In order to understand the differences in implementation and outcomes it is critical to consider additional factors, such as the ones mentioned previously to explain the variation. Looking at ownership, alone, will be naive at best.

For example, PNFP succeeded with TQM because it involved the top management from the beginning. On the contrary, PH's top management did not have the same level of commitment that PNFP's top management has. Therefore PH's TQM process did not become as comprehensive and successful as PNFP's. Both organizations are private, and one has achieved with TQM more than the other did. PNFP did not succeed because it is more/less private than $\mathrm{PH}$, but because it secured the commitment of top leadership as well as other important key players such as physicians, labor unions, BODs and son. ${ }^{13}$ On the other hand, SH owns certain characteristics that makes implementing TQM at it more challenging. The process

13. The above is reflected in the tabulated responses to Q. 20A\&B in Appendix C. 
requires more planning, more education, and better support. It is true, then, that ownership plays a key role in influencing the process. In conclusion, ownership is a contributing factor to the differences in TQM processes, implementation, and outcomes. However, it is not the sole force that will lead to these differences. Being public or private in itself is not sufficient to cause a TQM innovation effort to succeed or fail, but it is a factor that should be considered. Public and private organizations still have some differences among them and for TQM to succeed these differences should be recognized.

\section{CHAPTER CONCLUSION}

This chapter explored some differences that exist among public and private organizations in their implementation of TQM. Moreover, this chapter has compared these organizations in regard to a number of issues such as their perception of TQM, their adopted approach to implement TQM, that has the most power, what critical elements are needed for TQM to be efficient, what forces to guard against, and finally and what participants in each sector believe about the possible outcomes of TQM. Exploring these issues involved comparisons among the three organizations based on a variety of crossectional data obtained using various researching tools, such as survey and interviews. This chapter has answered the second part of the research question, which asked: Are there any significant differences among these (public and 


\section{CHAPTER VII}

\section{LESSONS TO BE LEARNED}

\section{Introduction}

The people interviewed, surveyed and/or observed in this study came from various organizational layers. Some are senior managers, some are middle managers, others were educators, while the rest were staff employees. However, they all shared one thing: being involved in the implementation of TQM or at least having a deep interest in TQM/CQI approaches and/or principles. The research intended to include such a mix of organizational backgrounds in order to gain a more comprehensive and representative assessment of these organizations and to examine TQM/CQI from different angles.

The previous two chapters presented an assessment of the experience of the three organizations in implementing TQM. Chapter Six included a narrative overview of these organizations' quality stories and shows how they went about doing TQM. Chapter Seven continued this effort by exploring some significant differences that exist among these organizations in their implementation of TQM. It also discussed what role ownership play in an organization's quest for quality improvement. Chart II 
below provides a summary of the major key results characterizing the implementation of TQM at three health care organizations.

\begin{tabular}{|c|c|c|c|}
\hline Characteristics & PA & PNEP & SH \\
\hline 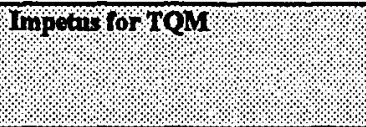 & $\begin{array}{l}\text { *. Financial gains } \\
\text { *. Increased market share }\end{array}$ & $\begin{array}{l}\text { *. Financial gains } \\
\text { *. Increased marka share }\end{array}$ & $\begin{array}{l}\text { *. Financial gains } \\
\text { *. Political Forces; } \\
\text { Measure } 5 \text { and to gain } \\
\text { support of tax payers }\end{array}$ \\
\hline 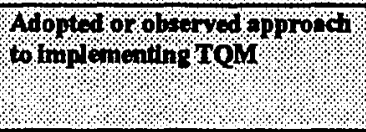 & Spotty Padtem & $\begin{array}{l}\text { Cascading Approach } \\
\text { Twin-Track Approach }\end{array}$ & $\begin{array}{l}\text { Spotty Pattem } \\
\text { (initially) } \\
\text { Cascading Approach } \\
\text { (Later) }\end{array}$ \\
\hline 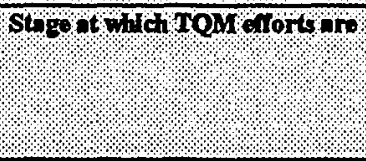 & $\begin{array}{l}\text { Preparation and Plaming } \\
\text { (Partial implementation through } \\
\text { QITs efforts) }\end{array}$ & $\begin{array}{l}\text { Comprehensive } \\
\text { Implementation } \\
\text { Begiming of a caltural } \\
\text { transformation }\end{array}$ & $\begin{array}{l}\text { Plaming and } \\
\text { Assessment } \\
\text { (Some partial } \\
\text { implementation through } \\
\text { QITs efforts) }\end{array}$ \\
\hline Whochiniforithe quility & $\begin{array}{l}\text { Quality Coordinator } \\
\text { QITs leaders and members }\end{array}$ & $\begin{array}{l}\text { Top Mrnagement } \\
\text { PIT members and all other } \\
\text { participating employees }\end{array}$ & $\begin{array}{l}\text { Individual QITs leaders } \\
\text { and members (Initially) } \\
\text { Top Management } \\
\text { (Later) }\end{array}$ \\
\hline 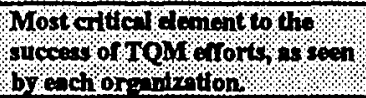 & $\begin{array}{l}\text { Top Leadership Suppost and Buy- } \\
\text { in. }\end{array}$ & $\begin{array}{l}\text { Top Leadership Support and } \\
\text { Buy-in. }\end{array}$ & $\begin{array}{l}\text { Top Leadership Support } \\
\text { and Buy- in. }\end{array}$ \\
\hline 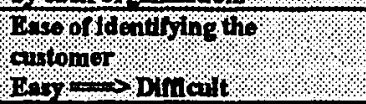 & Fairly easy & Fairly Easy & $\begin{array}{l}\text { Difficult: due to the } \\
\text { multiplicity of } \\
\text { customers. }\end{array}$ \\
\hline 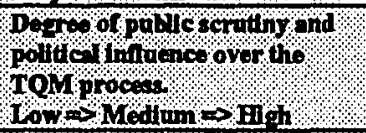 & Low & Low & $\begin{array}{l}\text { High: } \\
\text { Due to goneral public } \\
\text { and media scrutiny }\end{array}$ \\
\hline 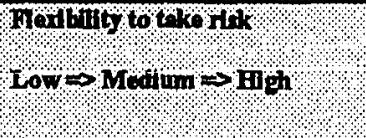 & $\begin{array}{l}\text { Medium } \\
\text { (Tangible short term results are } \\
\text { required to launch a comprehensive } \\
\text { TQM ffort) }\end{array}$ & $\begin{array}{l}\text { High } \\
\text { (Risk taking is encouraged) }\end{array}$ & $\begin{array}{l}\text { I.ow } \\
\text { Risk taking is not } \\
\text { en,rouraged due to } \\
\text { bureaucratic rules }\end{array}$ \\
\hline 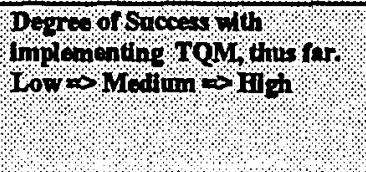 & $\begin{array}{l}\text { Low: } \\
\text { Due to the lack of involvement of } \\
\text { top management and the focus on } \\
\text { shot term gains. }\end{array}$ & $\begin{array}{l}\text { High: } \\
\text { Due to the involvement of top } \\
\text { menagement and having a long } \\
\text { term focus. }\end{array}$ & $\begin{array}{l}\text { Medium: } \\
\text { Top management was } \\
\text { not involved at the } \\
\text { begiming, but later it } \\
\text { did. }\end{array}$ \\
\hline 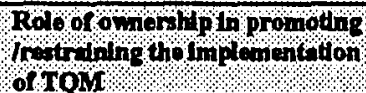 & $\begin{array}{l}\text { Promoting } \\
\text { Because of less scrutiny and less } \\
\text { political forces. }\end{array}$ & $\begin{array}{l}\text { Promoting } \\
\text { Because of less scrutiny and } \\
\text { less political forces. }\end{array}$ & $\begin{array}{l}\text { Restraining } \\
\text { More scrutiny of general } \\
\text { public }\end{array}$ \\
\hline
\end{tabular}

CHART II: COMPARATIVE SUMMARY OF KEY IMPLEMENTATION/RESULTS AT THE THREE ORGANIZATIONS 
The above chart indicates that the two private organizations got involved in TQM in order to achieve financial gain and to increase their market share. However, the public hospital has additional forces, such as Measure 5 and other political forces, that serve as an impetus for implementing TQM. It could also be realized that organizations that succeeded in their implementation of TQM adopt either a TwinTrack approach and/or a Cascading approach. The Spotty pattern, a problematic approach, could be seen at organizations that have not been fully involved with TQM, such PH. Top leadership involvement is very critical and the chart reveals that when the top leadership gets involved in early stages, such as at PNFP, then TQM initiatives will achieve their goals. Moreover, the chart indicates that public organizations are more scrutinized than private ones. This causes their decisions to initiate and implement TQM efforts to take longer time than private organizations do. Ownership was found to be a restraining force in the case of the public hospital. As mentioned earlier, due to scrutiny, multiplicity of customers and less flexibility to take risk public organizations experience more difficulty implementing TQM than their private counterparts. Finally, the chart reveals that the decisive factor in implementing TQM is not the type of ownership, but it is rather the role of top leadership in the quality improvement efforts.

This chapter will explore the lessons that could be learned from the experience of these organizations. These lessons represent some guidelines and recommendations that participants at these organizations expressed as the wisdom they gained from 
their experience with TQM. Moreover, these lessons will utilize the various findings introduced so far. This chapter is critical to this study because it represents the culmination of the research. Readers who are looking for some help to guide them in their quality improvement journey will find this chapter especially useful. The major points of this chapter are introduced as lessons and/or findings. These lessons were chosen because they cover some critical issues that are vital to the success of any TQM effort.

\section{First Lesson}

- For any TQM/CQI effort to succeed, top management should be involved and committed.

The first lesson is firmly established in the findings about the role of top management in the improvement effort. As indicated in the above summary chart, top management support is seen as a critical factor for the success of TQM/CQI. Public and private organizations, alike, need to involve their top leadership from the beginning in TQM/CQI efforts. All gathered data supports this assumption. Institutions whose top management was not involved or committed have a harder time to further TQM/CQI implementation beyond a certain point. Top management support translates into financial resources and decisions that will enable and empower TQM/CQI participants. On the other hand, for those organizations whose leadership 
was grounded in the theories and methodologies of TQM/CQI, it was easier to start the process and give it life.

One might wonder, who is top management? How can we define commitment from an operational perspective. First, it should be stressed that participants at each of the three organizations have a clear idea about who is the top leadership. For the purpose of this research, however, top leadership could be defined as the dominant coalition at the organization who has the responsibility of charting the critical direction of the organization, especially in the long run. Top leadership is those individuals or groups whose decisions and actions are critical to the future of the organization. Top leadership from a TQM perspective is the organizational layer that helps envision the change and has the power and the primary responsibility to initiate system-wide decisions, strategies and actions.

Second, how can we define commitment, in terms of TQM? To answer this question it is important to offer an operational perspective. In other words, commitment could be realized through a number of indicators --actions that top leadership takes to ensure its dedication to TQM. Among these indicators are:

- Taking an initiative in leaming about TQM and then educating the rest of the organization

- Allocating enough financial resources to train employees, hire consultants and other professionals to guide the organization in its implementation of TQM. 
- Urging supervisors to allow their subordinates to take time off, but still get paid, to participate in TQM improvement teams and activities.

- Top management champions the TQM process rather than reacts to it.

Recognizing the above indicators is not difficult, and in fact, they are highly visible at those organizations where top leadership champions the change. For example, PNFP's top leadership is the one who initiated the change and through a cascading approach helped launch it. In fact, the president of the organization proudly announces in radio commercials that adopting CQI process has enabled the organization to make remarkable profits and savings.

There is no doubt that TQM/CQI starts at the top and transcends downward. Installing TQM/CQI in the organization requires acknowledging this fact. Public organizations share this with private organizations. Public organizations, however, have a greater number of participants and their policies are more questioned than private organizations. Due to the size and complexity of public organizations, TQM/CQI leaders need to spend more time planning and educating the key organizational figures. That might take them longer than in the private sector, but once a TQM/CQI process is being implemented and the changes take place, positive outcomes should be expected similar to those in the private sector organization.

This finding is relevant to the study because it points out where TQM/CQI should start and who are the key champions. By doing so it reaffirms the major 
principles of TQM/CQI, discussed earlier in our review of the literature. For TQM/CQI to succeed, top management has to either initiate it or at least be committed to it. Top leadership involvement, then, is the first critical ingredient that a TQM effort should consider.

\section{Second Lesson}

\section{- Customers should be the center of any TQM/CQI effort}

Customers are the comer stone of any quality improvement effort. The review of the literature and the various responses gathered at the three organizations reveal that satisfying customers is the major goal for any serious TQM effort. Nevertheless, TQM/CQI promotes a new approach to identifying the customer. According to TQM, an organization has both its external customers and it also has its internal customers. In addition, each organizational participant is seen as both a supplier on one end but also as a customer/buyer on the other end.

Listening to the customer is a major step in any TQM effort. In fact, quality function deployment (QFD) is among many techniques that are used to incorporate the customer's requirements into the various stages in the production of a product or a service. Gathering input from both external and internal customers is required throughout the various stages of TQM efforts. All the information retrieved from the various participants as well as the various literature reviews suggest that customers should be the focus of any TQM effort. 
Both sectors stressed the importance and influence their customers have over their operations. Public organization participants cited the influential role of their customers, the tax payers, while private organizations defined their customers as their patients and their families. Moreover, private and public organizations placed an important value on the role and power of physicians, an internal customer, in influencing the process. This new vision allowed those organizations to plan better for TQM/CQI by first building customers' requirements into the process or the general TQM plan. Second, it enabled the organization to draw a more accurate map of key participants and where they are located in the organization and what function they could serve in the TQM efforts.

By focusing on their customers organizations will be able to pinpoint the key players in the system and ultimately design a better TQM/CQI process. Identifying the external/internal customer is important for private as well as public organizations. However, public organizations need to pay more attention to what roles their customers might play in supporting or hindering the process. Educating the general public and marketing TQM/CQI to them might be a critical step in the process. While dissatisfied customers will turn away from a private company, in the case of public organization dissatisfied customers might tear down a public organization. In conclusion, one of the key findings of this research is that for a TQM innovation effort to succeed it should be customer driven, and that includes an accurate 
identification of both external and internal customers as well as building the customers' requirements into the system and the quality improvement processes.

\section{Third Lesson}

\section{- For TQMUCQI to Succeed, a commitment of Financial and Human Resources is required}

TQM has its price. In other words, quality improvement implies a cost to the organization adopting it. However, there are also significant returns that could be obtained from implementing TQM, especially in the long run. Improved products and services will save money, cut waste, and preserve resources. This finding is of special importance because it is directly derived from the experience of some of the participants in the study. Some institutions stay away from TQM/CQI because they see it only as a cost that will not produce immediate return. TQM/CQI is a comprehensive organizational process that requires a massive involvement from everyone in the organization. Education and training should be seen as the backbone of TQM/CQI. Committing to TQM/CQI requires allocating both financial and human resources. For example, if employees are not granted the time to participate in teams activities, educational and training activities, and any similar activities TQM will be heading toward failure. If the allocation of financial resources is restricted to seeing immediate results, the improvement process will either last for a short period or take a 
quick fix pattern. Both approaches will lead to failure because they contradict the basic principle of TQM: long term vision and a comprehensive transformation of the organizational culture. Problems will tend to resurface and that will be blamed on TQM and of course will be a an excuse for opting out of the quality improvement effort.

Organizations that are examining the efficacy of TQM/CQI have to recognize the value of education, planning, implementation, and evaluation as the comerstones on which a successful TQM/CQI process rests. Moreover, there is a cost associated with TQM/CQI, and organizations have to be aware of that. If an organization has a narrow financial focus, then TQM/CQI will become more of a cost than a profit. Those organizations will become skeptical of TQM/CQI and will more likely hesitate to launch a massive TQM/CQI process.

In addition, the long term perspective and vision, another guiding principle of TQM/CQI, might conflict with the short term vision of some organizations, who want to see tangible results in a short period of time. Their adoption of TQM/CQI might be temporary and they will incorporate partial TQM/CQI techniques. They might commit limited resources to the process for a short period of time, and they will condition their support to it with getting immediate financial gains. This is a dangerous practice, because most of the problems that seem to be solved will resurface again. Those organizations, embattled by conflicts, and trying to find a way out, will turn the accusation finger to TQM/CQI. 
This research has found that organizations that succeeded in envisioning the long term aspect of TQM/CQI, have looked for long term solutions and will be more successful in implementing a comprehensive TQM/CQI process. Moreover, those organizations will commit sufficient resources to ensure a massive educational process. As stated earlier, in the summary of the major findings for each health care provider and as outlined in the responses to the survey, those organizations that display the above qualities are more likely to have better results with TQM/CQI than those who do not.

\section{Fourth Lesson}

\section{- Having a Solid Plan is critical for the success of TQM/CQI}

Chapman \& Hall (1991, pp. 21-22) consider "planning the improvement process for your organization [is] a very important matter." They present six elements that comprise a "model management framework for TQM." These are: "communication of aims, missions, goals and objectives, collection of external intelligence, measurement of internal business performance, identification of improvement opportunities, continuous implementation of changes/improvement, and finally steering and co-ordination of TQM processes" (p. 22). By examining the previous elements we see that an accurate assessment of the organization's customers is also crucial for any TQM process. Therefore, planning for TQM is a crucial step that should be carefully examined. 
As responses to Questions 21/22 of the General Survey show ${ }^{1}$ planning for $T Q M / C Q I$ is the first priority for the public organization. It is a second priority for the private-not-for-profit institution. The same could be concluded for the privatefor-profit hospital, by reviewing at the content of the interviews. It could be concluded, then, that having a solid TQM/CQI plan, is vital to the success of the TQM/CQI efforts in any organization, regardless of its ownership.

But how could we define a solid TQM/CQI plan? The responses to question $20 \mathrm{~A}$ and $\mathrm{B}$ in the general survey ${ }^{2}$ help identify some of the critical components that a solid plan should have. A solid plan as seen through the findings of this research is one that possess the following qualities :

** Grounded knowledge of TQM/CQI principles, as taught by the gurus of the field, such as Deming, Juran, Crosby, and many others.

** An in-depth understanding of the organization and its internal and external environment.

** A clear identification of the organization's internal / external customers and their posture toward the desired changes.

** A clear understanding of the problem/s under consideration.

** A clear, accurate, and comprehensive charting of process that points out areas of deficiency where improvement needs to take place.

** Well articulated goals and objectives which lead to measurable outcomes.

** Clear identification of required human and financial resources.

** Comprehensive assessment of supporting and hindering forces.

${ }^{1}$ Please refer to Q. 20-22 in Appendix C.

${ }^{2}$. Please refer to table $\mathrm{Q} 20, \mathrm{~A} / \mathrm{B}$ in $\mathrm{Appendix} \mathrm{C}$ for detailed tabulations of the responses. 
** Accurate and reliable system for data collection.

** Accurate and well maintained system of tracking and monitoring implementation, with a clear statistical process control mechanisms for corrective action.

** An accurate and systematic method of evaluation, which accurately measures outcomes against stated goals.

The above characteristics have been derived from the data collected throughout this research. They summarize, to a sufficient degree, what is required in a solid TQM/CQI plan. Briefly put, if you have a good plan, you are more likely to have a good trip. One of the points of this research has been to identify some criteria an organization, especially a public organization, should adhere to ensure and measure its success with TQM/CQI. The above characteristics help shape that criteria because they could be considered as the starting point. Finally, these elements have been valued by participants of both sides, and that should increase their credibility.

\section{Fifth Lesson}

\section{- For TQMUCQI processes to work they need to be flexible}

Previous parts of this study presented various approaches and models to implementing TQM and described which approach each organization has followed in their implementation of TQM. At this point it is important to point out that each organization has modified its approaches to implementing TQM to fit the 
organizational culture and the specific conditions that exist at the institution. Carr (1993) indicates that it is quite normal, and even encouraged, that an organization chooses a TQM plan (approach) that meets its requirements. In other words, for TQM processes to succeed they should be flexible enough to adapt to various environments and robust enough to withstand some variation in implementation.

When asked about what process they follow, or would like to follow, in implementing TQM/CQI, participants at the three organizations stressed that what they drafted has been in fact their TQM/CQI process. For example, PNFP has their own version of TQM/CQI which they call "PNFP's TQM/CQI." People at PH also have their own version of TQM which they call Quality Improvement Plan (QIP), while those at SH have their "Operation Restructuring." The point to be made here is that organizations that adopt TQM/CQI would like to adapt it to the conditions and characteristics of their institution. Nevertheless, these personalized versions of TQM/CQI should not deviate from the major principles and guidelines outlined in the mainstream ideology. A distorted version of TQM/CQI should not be confused with a TQM/CQI process that has been modified to adapt to a particular organizational setting. The first is a fake imitation, while the second is just a variation on the theme.

But what about the various approaches to TQM? It seems that the best approach to TQM is the one that meets the needs of the organization. The TwinTrack model, explained by Carr (1993, Ch. 9), represents one of the most useful 
approaches to implementing TQM. It combines short and long term projects and goals, but it also includes a great deal of strategic planning and systematic evaluation.

Based on the above discussion TQM/CQI has to be fiexible and robust enough to meet various needs of various organizations. Each organization has its own unique requirements and settings. For TQM/CQI to succeed, then, it has to respond to those needs. Many organizations may want to write TQM/CQI in their own organizational language and put in terms that could be understood by their employees. A flexible methodology that adapts to the needs of those who apply it will be well received.

This research has found that it is possible for TQM/CQI, to be customized to meet the organizational characteristics of the implementing organization. For example PNFP has adapted the tools and techniques utilized in TQM to fit with its own organizational setting. For example, the quality improvement at PNFP is called "CQI PNFP" and it has been worded and reflected in terms that relate to the needs and environment of that organization. In the case of PH the data gathered seem to suggest and support the desire of people at PH to adapt TQM to their organizational environment. SH participants also reflected their intention of customizing TQM tools and methods to meet the demands and the organizational culture at SH. The implication of this to public organizations is that TQM/CQI needs be flexible enough to adapt to the unique conditions of public institutions. In conclusion, the gathered evidence seem to suggest that TQM/CQI has within it the elements of adaptability and it is up to the organization to personalize some aspects to help promote the change. 


\section{Sixth Lesson}

- In spite of the differences between the two sectors, public organizations will benefit from implementing TQM/CQI.

In spite of the differences among the three organizations, there is one finding on which all participants seem to agree: TQM is needed to improve products and services. Each organization believes that adopting a TQM process will help improve its products and services. Many participants from both sectors believe that their organization need TQM. Therefore, while variations and differences among organizations might exist their need for installing TQM into their organizational systems remains the same. Public organizations will benefit from implementing TQM as did their private counterparts.

Many skeptics have doubted TQM and its ability to deliver sound organizational changes. They saw it as just another methodology for organization improvement that will end up taking its place on a dusty shelf next to past approaches, such as MBO, Zero Base Budgeting, One Minute Manager, and so forth. But the successful implementation of TQM in various organizations and the reports about the increased level of efficiency and productivity is reversing a lot of skeptical thoughts. Assurance is replacing doubts, and hope is replacing futility. In the various responses most participants expressed the need for TQM/CQI at their organizations 
and have viewed it as a unique approach to Organization Development (OD). In addition, the above chart indicates that SH, as a public institution, has a medium degree of success in implementing TQM thus far. The Operation Restructuring, which was a limited scale implementation of TQM saved SH from \$5-7 million. In conclusion, while there might be variations among organizations in their implementation of TQM, the need for TQM stays universal among these organizations.

\section{Seventh Lesson}

- TQM/CQI could be implemented successfully in the public sector as it has been in the private sector.

Many leaders and managers recognize the differences between public and private organizations. Some of those leaders, however, tend to believe that applying OD approaches, such as TQM/CQI, will only work in the private sector due to the varying nature of public and private organizations. They consider TQM/CQI as a private sector methodology that has few things to offer to public organizations. "You cannot compare apples and oranges," is a favorite statement among those who promote this logic. The information revealed by this study refute this assumption, and challenge it, to a certain degree. In fact, each sector has a lot to learn from the other. So the lesson that could be learned here is that TQM is not only for private organizations. It has shown its potential in public organizations, such as those Federal government institutions described in a previous section. This study found this belief to 
be shared by participants from both sectors. An overwhelming number of respondents believe there should not be major differences between public and private organizations in terms of the outcomes of TQM/CQI, as long as you have a solid plan. In other words, we could say that public organizations are expected to gain similar benefits from TQM/CQI as much as private organizations have done. However, the responses to the interview and the survey indicate that public organizations do have some features, such as size, complexity, greater bureaucratic rigidity, and more political influences, that make them somehow different. But that should not be a discouraging factor for their implementation of TQM/CQI.

Public and private organizations will benefit from utilizing TQM/CQI. The degree of marginal returns for each sector might be different, but the basic rule is: whoever follows a well structured TQM/CQI plan is expected to reap some gains. Therefore, the findings suggest that public organizations should invest in TQM/CQI as private organizations did. This point is relevant to the research since it proves that TQM/CQI will produce positive outcomes in both sectors as long as it is wellstructured. In spite of their differences, public and private respondents showed a positive attitude towards TQM/CQI. Some even saw it as bridging the gap between the two sectors. For any organization, regardless of its ownership or type of product or service it fumishes, quality should be number one. 


\section{Conclusion}

The previous three chapters provided answers to the three questions that comprise the larger research question concerning the experience of the participating organizations with TQM. The gathered data furnishes some information that will provide some guidelines for those who want to commit to TQM.

Through the fourth chapter the quality stories of the three participating organizations were presented showing how organizations implement TQM. A universal and structured narration of each quality story was presented. The fifth chapter provided comparisons between organizations from both sectors in terms of their implementation of TQM. Various differences that existed were introduced and discussed. The main goal of this chapter was to explore how public and private organizations differ in their implementation of TQM and ultimately what is the future of TQM in the public sector. Chapter six presents some lessons or recommendations that would be extremely useful for anyone who thinks about adopting a TQM approach. These lessons derive from the experience of those participants who have been involved in TQM efforts for a while.

Taken together, the chapters in part II present the research findings and inform the reader with relevant ideas about implementing TQM in either sector. The documentation of the experience of these organizations, taken together, will help provide some guidance and informative insights to those in the field of quality improvement. Part II includes a discussion of the data gathered. It describes some 
differences that could be seen between public and private organization in their implementation of TQM, and finally it concludes by providing some lessons that could leamed from the experience of these organizations. The next and final part will explore some implications and a discussion of some conclusive remarks about the major findings. Finally the research limitations will be described as well as a comment on possible future research. 


\section{CHAPTER IX}

\section{IMPLICATIONS AND CONCLUSIONS}

\section{Introduction}

The previous pages provided answers to various questions posed in this research. This chapter will draw some concluding remarks that highlight the major findings of the research and briefly discuss some of these findings. This concluding chapter continues to review what implications the findings imply for the study and/or implementation of TQM. Moreover, it assesses what contribution this research makes to the existing body of knowledge. It will also explore some of the challenges and limitations which have been encountered. In addition, a futuristic outlook will be offered.

\section{Is TOM/COI a passing fad or is it a paradigm shift?}

Much has been said throughout the study about how TQM/CQI is different from other Quality Assurance (QA) approaches. Though some believe that TQM/CQI will be a passing fad, the greater majority of those that came into touch with it have stressed that TQM/CQI has more far-reaching outcomes that have been transforming their organizations. The case of the Private Not For Profit (PNFP) is a very good 
example to illustrate this claim. The quality story of this institution shows what could be achieved with TQM/CQI.

A careful review of the experience of these three organizations confirms that an organization's view of TQM/CQI depends to a great extent on the degree of commitment of the top leadership and the involvement of the total organization in the quality improvement efforts. This suggests that at those organizations where TQM was launched and adopted as a massive effort to transform their cultural environment TQM was perceived as a fundamental organizational change. On the contrary, TQM was viewed as a passing fad by those organizations where leadership was not fully committed. This applies to both public and private organizations.

What could be implied from the above is that for TQM to reach its goals it should be viewed as a long term cultural change and should be pursued as such. TQM/CQI, thus, requires long-term vision and an ability to see beyond the immediate short term returns. Deming (1986) stresses that the focus on short term gains without planning for the long term will cripple an organization's ability to stay in the market and/or to maintain its competitive edge. Hunt (1992) ${ }^{1}$ describes the "Quality First" approach which he identifies as a paradigm shift that has been taking place among American private and public organizations. A paradigm shift, according to Hunt, indicates a shift in the "belief system [culture]" of an organization. "Quality First", another name for TQM/CQI, represents a shift in leadership and management roles. In

\footnotetext{
${ }^{1}$. Quality in America, Hunt, Business One Irving, 1992, pages 28-32.
} 
order for TQM to succeed a "top-down" model has to be applied. This means that top management should be involved and committed to bringing about cultural change through quality improvement. Moreover, the top leadership's role should also shift from a focus on inspection and supervision to a focus on leadership and support. Therefore, for TQM to succeed it has to be perceived as a cultural transformation and it should include a long term vision. This is evident throughout this research. Only when top leadership gets involved on a deep and serious level and not a cosmetic level TQM starts taking the path of a cultural transformation path. For example, in the case of the State Hospital (SH) the quality improvement movement could not go beyond a certain point until top leadership bought the idea of adopting TQM/CQI strategies to bring about the desired organizational changes.

It could be concluded then that TQM will be viewed as a passing fad if there is a lack of commitment on the part of leadership. Moreover, if there is a lack of understanding of the total involvement it requires from the whole organization TQM/CQI will be labeled as a passing fad. In other words, TQM has become a fad if it was treated as a fad. On the other hand, TQM became a cultural transformation in those organizations where TQM was seen as a paradigm shift that includes a fundamental transformation in the belief systems of an organization and the way it conducts its business. 


\section{Who needs TOM/COI?}

One of the key findings that could be concluded from the study is the need for quality improvement in both sectors. Regardless of how much public and private organizations differ from one another, they both share one major similarity: that is the need for improving the quality of their products and services as well as saving resources and cutting waste. This idea is stressed by President Clinton (1993) who believes that "the ideas of W. Edwards Deming have become a powerfully effective force for change in the American Industry. With Appropriate adaptation TQM offers the framework and the tools to be equally effective in government."2

As indicated earlier, many respondents who participated in this research believe that as long as there is a well-thought, flexible, continuously improving TQM/CQI process, the outcomes of the implementation should be similar in both sectors. In other words, the significant factor in the formula for a successful TQM innovation effort depends largely on a well structured process rather than what type of ownership an organization has. Public organizations that embrace a well-thought TQM strategy should be able to reach their goals of satisfying their customers and improving their products and services. In his book, Race Without a Finish Line, Schmidt ${ }^{3}$ (1992) states that " although the most widely publicized TQM efforts have been in the business [private] industry, it is encouraging to see that Federal, State, and

\footnotetext{
2 .. Back cover page quote from the book Excellence in Government by Carr . 1993.
}

${ }^{3}$ Race Without a Finish, Schmidt, (1992). Please refer to Chapter 3 for more details. 
Local governmental organizations have also produced dramatic results by following the same principles" (p. 57). In fact, most of our participants indicated their belief that public and private organizations, especially health care organizations, are not that different from each other. ${ }^{4}$ Their responses and views of TQM/CQI were based on their experience with TQM/CQI.

There are indeed some major differences between the public and the private sectors, and it is logical to expect some variations between public and private organizations. Chapter six summarized these differences in relation to the implementation of TQM. What could be concluded from the findings of this study is that public organizations will be more challenged in their quality efforts. This might be mainly due to the multiplicity of customers they serve, the complexity of their structure and operation, and finally to the political forces affecting their operations as well as their decisions.

However, the above conclusion implies that TQM has a potential for success in public organizations. As long as its principles and guidelines are observed, then any organization that adopts TQM/CQI should expect successful results. In conclusion, this study has revealed that public organizations have the potential as well as the capacity to implement a successful TQM approach in order to bring about sound changes in their functions.

\footnotetext{
${ }^{4}$ Please refer to answers to questions $(14,15)$ in Chapter Five.
} 


\section{What is the best TOM approach?}

This research has explored the TQM/CQI process as implemented, planned, or thought of in each of the three participating organizations. It has been found that each institution prefers to implement its own personalized version of TQM/CQI. Though there are universal primary principles of TQM/CQI, the process and implementation of TQM/CQI vary from one institution to another. As long as the basic principles are being adhered to, the process could be modified to the givens of a certain situation or an organizational setting. The quality stories of each institution showed that the approach to implementing TQM has varied from one organization to another. This lead to the conclusion that it is quite possible for an organization to adapt TQM approaches to fit the special characteristics of its internal/external environments. The lesson learned from this is the need to be aware of the general principles but at the same time to be able to synthesize a certain version of TQM/CQI that will meet the organizational needs.

It is implied within this conclusion that the best approach to implementing TQM in any organization, whether public or private, is one that is congruent with the institution's needs and unique characteristics. In other words, the best TQM approach is a working approach. It is up to each organization to examine its environment and then devise a strategy that will adhere to the requirements of that organization. However, this should not be a distinctive departure from the mainstream guiding 
principles of TQM/CQI. An organization embarking on a TQM effort should observe a number of key issues, such as top leadership commitment and buy-in.

\section{TOM might be "risky business"}

By reviewing Deming's 14 points one can sense a call for taking risk. So it is safe to assert that $T Q M / C Q I$ requires risk taking. TQM/CQI also requires a longer time perspective in addition to a commitment from the top leadership. In spite of the long run benefits of TQM/CQI, one should realize the costs associated with it. This kind of logic might run contrary to the norms and beliefs of the traditional culture that still exist at many of today's organizations. Investing in TQM/CQI requires a leap of faith as one of the participants put it and that involves risk. Some leaders grow scared, and because of that they become turned off and then away. They seem hesitant when they are asked to commit the money and to wait for a while to start seeing some changes and positive outcomes. Without accepting the element of risk it will be difficult to adopt and/or initiate TQM/CQI efforts. But the research confirms that institutions that believed in this long term vision, such as PNFP, were able to reach significant gains.

What could be implied from the above is that public sector organizations need to start encouraging more risk taking not only among their top leadership but also among their employees. Innovation and the freedom to make decisions should be encouraged, even if it involves risk taking. Employees should not be terrified of the 
fear of punishment, because it will prevent them from taking risk and being innovative. Public organizations should be more flexible in this area. In fact, if there is any explanation why private organizations might be faster to reach tangible results with TQM it is their flexibility in allowing their employees to make decentralized decisions. As Carr (1993) argues a "true TQM organization is a decentralized organization. Decentralization gives the people the power they need to improve processes, and eliminates layers of bureaucracy" (p. 305).

The results derived from this study support the above guidelines. For example, in the case of the PNFP organization there more decentralization and teams and employees were encouraged to make decisions, even if they involve risk taking, to improve the quality of the processes. CQI efforts were more successful and part of that, as seen by participants, should be attributed to allowing the employees the freedom to make decisions and have the management act on them. However, in the case of the smaller private hospital PH the fear of taking risks and insisting on seeing tangible short term results have hindered the institution's ability to implement a more comprehensive TQM process. Finally, participants from the public hospital have indicated that too much bureaucracy and rigid regulations have slowed down the implementation of TQM. They indicated that for TQM to work at SH it should allow for more decentralized decision making and should empower employees to take risks and be more innovative. In conclusion, TQM calls on organizations to encourage their employees to be innovative and to be risk takers. This is achieved when organizations 
drive out fear of punishment and retaliations. This is one of Deming's 14 points discussed earlier in this study. Since the best person to make a decision about a particular process/product is that person that does/make that process/product, then it seems logical to allow that person to make decisions about how to improve that process or product. The findings of this study support this principle. True TQM organizations look at taking a calculated risk as an innovative effort rather than a threat.

\section{The Value of Education and Training}

Deming (1986) calls on leaders to educate and reeducate, and he stresses that education is the backbone of any improvement effort. For TQM/CQI to reach its goals, a comprehensive educational process should be installed. It has been found that those organizations that spent time educating their key participants in the process, faced a smoother implementation of TQM/CQI and less resistance to it. On the contrary, TQM/CQI has failed at those organizations that did not have comprehensive or/and accessible educational programs for their leadership and/or their key participants.

TQM/CQI calls for a continuous process of improvement, and education is the vehicle through which this could be achieved. For TQM/CQI to achieve its goals in public organizations, these organizations need to train their leadership, their staff, and their customer about TQM/CQI. Once people are educated, then it will be easier for 
them to see the value of TQM/CQI, and thus it will be easier to gain their support, involvement, and commitment.

Education might be the single most important factor that should be addressed if a TQM/CQI effort is to succeed. Without proper education those implementing TQM will face a rough road. In fact, public organization need to use a more comprehensive educational process than private sector organizations. Given the political nature of public organizations and the multiplicity of their customers, public organizations need to rely on education more heavily. To win the support of the voters, the customers, public organizations need to educate the general public on the nature, benefits, and limitations of TQM in the public sector.

One of the major findings that could be derived from this study is that TQM was more successful in those organizations where both management and staff have a working knowledge of TQM principles and tools. Training classes, consulting visitation, and team activities were all part of the educational processes taking place at all three organizations. It is safe to conclude that for a TQM effort to succeed it should be based on a solid educational structure. For example, at the SH things started moving in the right direction only when the top leadership was more informed and educated about the true meaning of TQM. When they realized that TQM is a cultural transformation then they stepped back and restructured a more comprehensive plan. PNFP has launched a series of classes and training seminars and 
encouraged all members of PITs to attend. Team leaders were required to possess some training in TQM/CQI and various team building tools. Therefore, education is a basic requirement for any organization that is involved with TQM. In fact, education and training might be the first step an organization needs to take to secure the future of it quality improvement efforts.

\section{Ownership Revisited}

The previous chapters explored the role of ownership in influencing the implementation and outcomes of TQM efforts. Ownership, whether an organization is publicly or privately owned, is a significant factor in influencing the implementation and outcomes of TQM efforts. However, attributing the success or the failure of quality improvement efforts to ownership alone is short sighted. Being public or private might influence the outcome, but it is not the primary single force responsible for whatever result might be achieved. For example, the commitment and buy-in of top leadership might be one of the key factors that cause a TQM effort to succeed or fail. Ownership then is a variable that should be considered with a group of other main variables. Ownership alone does not explain why TQM succeeds or fails in a public or a private organization, and the analysis should look for more factors.

What could be implied from the above discussion is that public organizations should not over-exaggerate the role of ownership nor should they fail to consider the role and effect of other key factors such as educating TQM pioneers and participants, 
securing top leadership commitment, effective planning, and systematic evaluation and benchmarking.

\section{What potential does TQM have in the public sector?}

The movement toward integrating TQM into the life of public organizations is going to be a matter of time. For example, SH officials have been showing a greater interest in TQM than before. Additional institutions are launching TQM initiatives, especially in the public sector. Cases and efforts involving implementing TQM have started to surface. The Federal Quality Institute has an increasing number of success stories of implementing TQM in the public sector.

The above seems to suggest that TQM is gaining more ground among many public and private organizations. TQM/CQI is believed to be an efficient tool to bring about a lasting change in organizations. The documented literature and the findings of the study support this claim. TQM, if effectively used, is capable of producing impressive changes in an organization that embarks on a quality improvement effort. Therefore, TQM holds a promise for public organizations, if these institutions follow the right path to utilizing it.

\section{What about TOM/COI in health care organizations?}

TQM seems to gain more attention in the health care industry. Health care reforms have assumed a more intensive pace and as the Congress is moving to tackle 
the various problems facing health care, such as cost, accessibility, affordability, and equity, TQM is seen as one of the important tools at the disposal of health care organizations. In fact, the President's plan for health care reforms includes a special section that calls for adopting TQM as a way to reduce costs and increase efficiency among health care organizations. The plan views TQM as a strategy to cut waste and reduce costs. Public and private health care organizations should learn from the experience of each other, because they share similar customers (patients) and they aim at reaching similar results (well being of individual and society at large through the delivery of top quality services).

This study has revealed that health care organizations are similar to other organizations in terms of the dynamics affecting their implementation of TQM/CQI initiatives. The research covers three organizations that provide a similar product (health services to patients) but that differ in ownership. The experience of these organizations with TQM/CQI shows that all of them see in TQM a better way to bring about organizational change. Even when TQM/CQI is perceived as having elements of a fad in it, such as the responses gathered at $\mathrm{PH}$, it is still perceived as a better way of doing things. Moreover, the findings of this research seem to suggest that TQM has produced significant results for health care organizations, specifically PNFP, where areas of improvement were identified and a well-structured improvement strategy has been in place. Implied in this conclusion is the notion that health care organizations, whether privately or publicly owned, can achieve significant 
results with TQM/CQI if they adhere to the guidelines and principles stresses by TQM leaders and practitioners.

\section{A word of Caution}

The previous pages discussed many issues in favor of implementing TQM. However, organizations should not glorify TQM/CQI and see it as the magical potion that will cure their illnesses. TQM processes are aimed at helping organizations establish efficient systems of production and delivery of services. The improvement process is an on-going cycle that is always innovating and always planning, doing, checking, and acting. Organizations that succeed with implementing TQM should not get wrapped up in the present and forget about planning for the future. A good example, though a sad one, is the Wallace Company, a winner of the Baldrige award, that was forced to declare bankruptcy because they got wrapped in the state of the present, and more importantly, winning became the end rather than a means to an end. This teaches us that successful implementation of TQM is a means to an end and should not become an end in itself. In other words, continuously improved quality is the goal (end), and TQM should be seen as the means to get there.

\section{The Value of the Study: What Contribution did this research accomplish?}

This research has covered a timely subject. Improving quality and reducing cost have been major issues on the 90 s agenda. Moreover, this research has explored 
an area where not much has been done before. Examining the implementation and the efficacy of TQM/CQI in public and private organization from a comparative approach will help offer some answers to the previous questions. TQM/CQI has proved valid in the private sector; and now it's time to explore what potential it has for the public sector.

Moreover, the research has attempted to arm the OD professional with a set of guidelines, strategies, and techniques that will empower him/her to carry a successful implementation of TQM/CQI. In addition, this research has intended to help organizations, more specifically public sector organizations, get the most out of TQM/CQI ideology and methodology. This study attempted to provide the reader with a picture of what TQM/CQI is, how is it carried out, how does it differ from one institution to another, and what lessons could be derived from the experience of the participating organizations. This study attempted to explore what produces good outcomes and what might cause failure, and then what comparisons could be drawn between public and private organizations along that line.

Finally, the major contribution of this research is its attempt to bridge the gap between the public and the private sector, especially in a vital field like health care. There are many success stories in the private sector that could be translated into the public sector and vice versa. Narrowing the differences between the two sectors is the first step to acknowledge the efficacy of using TQM in the public sector. Recognizing that the differences among the two sectors should not be a deterrent to implementing 
TQM in the public sector is the next step. By doing so public and private organizations will be able to share resources and available organizational technology aimed at improving the quality of work and performance of those organizations, regardless of being public or private.

In conclusiori cius research is a pioneeriig effort in structuring a comparative approach between public and private organizations. It is a daring challenge to the old notion that rigidly separates public and private sectors. In this time of global changes and market dynamics, public and private organizations are becoming more alike rather than so different from each other. Nevertheless, the research encountered a few challenges and limitations, which will be discussed in the following section.

\section{Challenges and Limitations}

The first part of this research introduced some of the limitations and challenges encountered in doing this study. At this point, it would be important to explore these factors in more detail. This study encountered a host of limitations that posed a challenge to reaching its full potential. One of the major challenges for these case studies is that each institution has its own quality story which included some unique characteristics that pertains to that institution. Moreover, these institutions have varying timetables in regard to implementing TQM, which makes it difficult to compare them one to another. This point will be discussed later. Finally, each institution is at a different stage of implementing TQM and that, as in the previous 
point makes comparison much difficult. Actually, some participants at SH said that it will be unfair to compare them to PNFP that was further in implementing TQM. In order to combat these challenges more than one instrument was used to gather data at these institutions. Following are additional limitations encountered.

\section{Time Limitation}

As mentioned earlier, TQM/CQI is long term oriented, and its implementation could extend to a period of up to 5 years. To be able to see the changes outlined in terms of the cultural change or paradigm shift one has to spend a longer time with the institution. Through a period of almost two years significant information was retrieved; however, to fully capture the outcomes of TQM at each institution requires more time.

\section{Gaining access}

One of the major difficulties has been gaining access to the field. Getting people to grant their time and to open up and speak freely has been very difficult. To overcome this problem, a system of referrals and a network of key organizational figures was used. However, this has been a major challenge for me since this difficulty was encountered numerous times. 


\section{Lack of documentation and scarcity of data}

With the exception of the PNFP hospital, most of these institutions did not yet have a comprehensive documentation of their TQM/CQI process implementation. Some of them have a policy plan, others have scattered minutes of certain projects. Obtaining data that relate to a particular project was difficult because it required chasing that data from one department/person to another, and that was not an easy task, given the size of these institutions.

\section{Difficultv in controlling for other intervening variables}

Assuming that ownership is the only thing that affects the outcomes of TQM/CQI is not completely accurate. Size, complexity, the external/internal environment, as well as a host of other variables might cause the outcomes of TQM/CQI to differ from public to private. This study has revealed that ownership does not work alone but with a host of other forces that interact with each other all the time. Keeping this in mind will provide a better understanding of the role of these forces in influencing TQM's processes and outcomes. This implies that in order to fully examine and understand the outcomes of TQM efforts more variables should be included. Controlling the population or even the selected sample was difficult enough; and holding all the other variables constant, excluding ownership, is almost impossible. 


\section{5. "Apples and Oranges" phenomenon, and the un-even implementation of TOM}

Another major difficulty has been to find out comparative bases between these three institutions. Comparing a huge institution with more than 8000 employees, like PNFP, to a small hospital might raise some eye brows. It is more accurate to compare PNFP to SH rather than PH. However, these hospitals have been chosen because they meet a criterion that the research wanted to examine: one is totally private and for profit, the other is private not for profit, while the third is totally public. Other variables are assumed constant or irrelevant in order to examine the relationship between ownership and the implementation of TQM/CQI at these various institutions.

Moreover, some of these organizations were into TQM/CQI implementation longer than others, which made it very difficult to standardize the questions of the research. Some of them have already started and were a long way ahead in their TQM implementation, while others were just starting. Some had more unique forces than others, and that require a greater degree of flexibility on the researcher's part. To control for this challenge, the research examined the organization's implementation of TQM/CQI, or/and their TQM/CQI plan and policy.

\section{Futuristic Outlook}

Since this research began two years ago there has been an explosion in the interest in TQM/CQI. This has been reflected in the abundance of literature on TQM, 
the rising interest in TQM/CQI, and the growing number of cases of implementing TQM/CQI. As more organizations report more success stories with using TQM, it will gain more ground. The big challenge, however, is to see how TQM/CQI will work in the long run and whether a cultural transformation could be accomplished by it. Spending more time learning about TQM will make it possible to develop a better understanding of TQM and its efficacy in either sector: public or private. Following is a number of recommendations for possible future research.

\section{Recommendation for Future Research}

In his book Managing for the Future, Drucker (1992) indicates that the “Japanese companies are moving from Total Quality Management to Zero Defect Management" (p.183). So while TQM is seen as a revolutionary trend of the $90 \mathrm{~s}$, the future of TQM is to move to a zero tolerance for errors in products. This means there will be more focus on prevention and building quality into the production process itself and through a comprehensive process of Quality Function Deployment.

The need for continuous exploration is the mark of human advancement. It is hoped that this research has shed some light on the efficacy and significance of TQM/CQI for the public sector. Future research is needed to examine the outcomes of TQM/CQI. Following are major recommendations:

1. A twin study to this research would be to examine a pure private industry organization, such as NIKE, and a public organization, such as OHSU, and see if 
there might be any apparent differences in the outcome of TQM at both institutions, and then draw results.

2. A follow-up study on what criteria are used for measuring TQM/CQI outcomes should be designed in order to determine to what extent could TQM/CQI change an organization.

3. The role of physicians and their influence on the implementation and outcome of TQM/CQI efforts should be explored through the use of survey or participant observation.

4. As the new administration focuses on reforming health care to reduce cost and increase efficiency a study that examines the role of $T Q M / C Q I$ in such reform policy could be conducted.

5. This research could be used as the nucleus for other research that explores the role of TQM/CQI in reforming the system of higher education on the state and national level. 
6. A study could be conducted on the concept of "Zero Defects Management" as perceived and implemented by the Japanese industry, and how could it be achieved and translated to another country such as the USA.

\section{GENERAL CONCLUSION}

"Quality is never an accident; it is always the result of an intelligent effort."

Organizations that make it in the business world are those that pay attention to what their customers want and build those requirements into the processes of their systems. Moreover, it is also critical for an organization to be aware of its surroundings to produce a comprehensive TQM/CQI plan. Furthermore, an organization should involve and commit its top management from the beginning of the process. Mobilizing a critical mass is the first step to initiate the necessary cultural change, and this is a critical requirement for TQM/CQI to be accepted in the organization and education should be the vehicle to get there. TQM/CQI has to adapt to the needs of the organization, and it should become their own. This sense of ownership will permeate motivation and desire to see it succeed on the part of the organizational participants as well as leadership. 
TQM/CQI is a unique philosophy which managed to put most of the available OD approaches into a systematic, formal, and organized approach. Implementing TQM/CQI requires sufficient allocation of resources and a comprehensive educational system. The next requirement is a good TQM/CQI plan and a good process of evaluation and measurement. In addition, a criterion on establishing acceptable output is important to measure what has been achieved.

This study has explored the experience of three health care organizations with TQM/CQI. Its major findings indicate that TQM is a powerful tool that is capable of transforming organizations. However, it is just a tool and the primary responsibility falls upon leadership and senior management to make quality improvement efforts work. The findings of this study support the various theories, principles, and recommendations stressed throughout various writings on TQM/CQI. In building for quality the structure of TQM rests on four comerstones: education, commitment, planning, evaluation. The findings of this study stress the importance of these factors to the success of TQM in any organization.

Though TQM could be implemented in both sectors, public organizations will face more challenges in carrying out a TQM innovation effort. This should not mean issuing a death sentence for the future of TQM in the public sector. Ownership is found to be an intervening variable rather than a primary force influencing the implementation of TQM/CQI. Forces such as securing top leadership commitment, educating a critical mass, a well-structured flexible plan, and an ongoing evaluation 
process are found to hold higher clout in the quest for total quality improvement in private as well as public organizations. This is due to the degree of influence these variables have in influencing TQM's process and outcomes.

Paying attention to the presence of the above variables is a key factor for a successful implementation of TQM. This notion is supported by the findings of this study. The results of the research teach us to commit top leadership to the TQM/CQI effort, allocate sufficient financial and human resources, educate, take risk, and adopt a long term vision. These are the qualities that could be identified in successful organizations that have achieved remarkable results through TQM/CQI.

TQM/CQI carries a promise for the public sector organizations, as well as for the private sector ones. An improved process is not a product of wishful thinking, it is rather a result of hard work and a great deal of time and effort. The major conclusion for this study is that TQM/CQI should be perceived as a major cultural change. It is a different way of thinking, and it represents a paradigm shift in terms of management style and organizational culture. TQM/CQI requires collaboration and involvement of all the group members, and that calls for a team spirit in order to achieve the desired goals. The challenge for American institutions, whether publicly or privately owned, is to re-educate the American worker/employee to recognize the group as the center of the organizational activity, rather than the individual player.

Through exploring the experience of the three participating organizations it is revealed that TQM/CQI is a tool, a means to an end (cultural transformation); it has 
four primary requirements (education, commitment, planning, and evaluation).

Managing in a Total Quality way could be summarized in twelve words, 'Understanding, Commitment, Organization, Measurements, Planning, Design, Systems, Capability, Control, Teamwork, Training, Implementation (Oakland, 1989/93, p.X). 


\section{REFERENCES AND SELECTIVE BIBLIOGRAPHY}

Aguayo, Rafael. Dr. Deming: The American Who Taught the Japanese About

Quality. New York: Carol Publishing, 1990.

Barry, Management Excellence Through Quality, Wisconsin: ASQC Quality Press, 1991.

Berry, Thomas H. Managing the Total Quality Transformation, by New York:

McGraw-Hill, 1991.

Berwick, Donald, et al, Curing Health Care, San Francisco: Jossey-Bass Publishers, 1991.

Berwick, Donald. Measuring Health Care Quality. Pediatrics in Review, Vol. 10 No.1, July 1988.

Berwick, Donald. Sounding Board: Continuous Improvement as an Ideal in Health Care, Massachusetts Medical Society: New England Journal of Medicine, Vol. 320, no. 1, Jan., 1989.

Bishop. "Incorporating Everyone,". The TOM Magazine(North American Edition), May/June 1992: 78-83.

Bond, David F "Military Budget Drawdown Spurs Movement Toward Increased Efficiency," Aviation Week \& Space Technology, December 9, 1991: 58-59. 
Bowsher Charles A. Performance Measurement: An Important Tool in Managing for Results. Statement of Comptroller General of the United States. Washington, D.C.:

U.S. General Accounting Office, 1992. 9 p. (DOC GA 1.5/2:T-GGD-92-35)

Brassard, M, The Memory Jogger. Methuen, MA, GOAL/QPC 1988.

Brassard, M, The Memory JoggerPlus (Software) Methuen, MA, GOAL/QPC 1988.

Brocka et al. Quality Management: Implementing the Best Ideas of the Masters,

Homewood, IL: Business One Irwin, 1992.

Brown. "Overcoming Total Quality Roadblocks," The Maryland Workplace, Winter 1992: 1-4.

Browning. "Quest for Quality," National Journal, December 21, 1991: 3071-74.

Bryson, M.Strategic Planning for Public and Nonprofit Organizations: A Guide to

Strengthening and Sustaining Organizational Achievement, San Francisco:

Jossey-Bass Publishers, 1988.

Burda, David. Total Quality Management Becomes Big Business. New Jersey:

Monmouth Medical Center. Modern Health Care, Jan. 28, 1991 Vol. 21, no. 4, p25(5).

Byme. "High Priests and Hucksters," . Business Week, Special Issue on Quality,

October 1991: 52-57.

Carr, David K. Excellence in Government, Total Quality Management in the 1990s,

Arlington, VA: Coopers \& Lybrand, 1990/93.

Casalou, Robert F., Total Quality Management in Health Care. Hospital \& Health

Services Administration, Spring 1991, Vol. 36, p 134(13). 
Catalog of Federal TOM Documents, prepared by the Information Network, Federal Quality Institute. Washington, DC: Federal Quality Institute, 1991.

Clinton Bill. "Putting People First," by. Journal for Quality and Participation, Oct/Nov 1992: 10-12.

Cohen Steven. "Total Quality Management in the U.S. Environmental Protection Agency," Public Productivity and Management Review, Fall 1990: 99-113.

Coppola Anthony. Total Quality Management (TQM): An Overview, Griffiss Air

Force Base, NY: Rome Laboratory, Air Force Systems Command; Springfield, VA: NTIS, 1991.

Coppola, Anthony. Rome Laboratory Guide to Basic Training in TQM Analysis Techniques, Springfield, VA: NTIS, 1991.

Crosby Philip B. Quality Without Tears: The Art of Hassle-Free Management, by New York: McGraw-Hill Book Company, 1984.

Crosby Philip. Let's Talk Quality: 96 Questions You Always Wanted to Ask Phil Crosby, New York: McGraw-Hill, 1989.

Crosby, Philip B. Completeness: Quality for the 21st Century, New York: Dutton, 1992. 251 p.

Crosby, Philip B. The Eternally Successful Organization: The Art of Corporate Wellness, by. New York: McGraw-Hill Book Company, 1988.

Deming, W.E., Out of the Crisis. Cambridge, Mass.: Massachusetts Institute for Technology, Center for Advanced Engineering Study. 1986. 
Denton, Keith, et al. The Learning Organization Involves the Entire Work Force. Quality Progress, December 1991.

Dixon, George. Total Quality Handbook: The Executive Guide to the New American Way of Doing Business, compiled by and Julie Swiler. Minneapolis, MN: Lakewood Books, 1990.

Dwyer, Paula "The New Gospel of Good Government," Business Week, January 20, 1992: 66-70.

Dyson, Robert Strategic Planning: Models and Analytical Techniques, New York: John Wiley \& Sons, 1990.

Education and Training for Total Quality Management in the Federal Government. Washington, DC: U.S. Office of Personnel Management, Federal Quality Institute/for sale by U.S.G.P.O., 1992.

Electronic Bulletin Board User Guide: Federal Quality Institute's Information

Network. Washington, DC: Federal Quality Institute, 1992.

Farrell, Christopher. "Even Uncle Sam is Starting to See the Light," by. Business

Week, October 1991, Special Issue on Quality: 132-137.

Federal TOM Database Users Guide, prepared by the Information Network, Federal Quality Institute. Washington: Federal Quality Institute, 1991.

Federal Workforce Quality: Measurement and Improvement: A report to the U.S. Merit Systems Protection Board and the U.S. Office of Personnel Management by the 
U.S. Advisory Committee on Federal Workforce Quality Assessment. Washington:

U.S.G.P.O., 1992.

Feigenbaum. Total Quality Control. Third edition, (Fortieth Anniversary Edition) revised New York: McGraẅ-Hill, Inc., 1991.

Gabor Andrea. The Man Who Discovered Quality: How W. Edwards Deming

Brought the Quality Revolution to America - the Stories of Ford, Xerox, and GM, New York: Random House/Times Books, 1990.

Gardiner. "Total Quality Management Enabled by Information Technology,"

Newsletter of the Maryland Center For Quality and Productivity, Summer 1992: 1-7.

General Services Administration Quality Management Assessment: Report of

Regional Results, 1992, prepared by the Office of Administration. (U.S. General

Services Administration, 1992).

GOAL/QPC Research Committee. Total Quality Management Master Plan: An

Implementation Strategy, prepared by the. (Research Report No. 90-12-02)

Methuen, MA: GOAL/QPC, 1990.

Hakes Chris. Total Quality Management: The Key to Business Improvement, New

York: Chapman \& Hall, 1991. 182 p. (HD 62.15 .T68 1991).

Hammons. "Total Quality Management in the Public Sector," by Charles and Gary A.

Maddux. Management Decision, v. 28, no. 4, (5 p.)

Harrington H. James. Excellence--The IBM Way, Milwaukee, WI: ASQC Quality Press, 1988. 
Hiam, A. Closing the Quality Gap. New Jersey: Prentice Hall, 1992

Higgins. "An Organizational Approach to Developing People," The Bureaucrat, Winter 1990-91: 54-56.

Holpp. "Reasons Why Total Quality is Less Than Total,". Training, October 1989:

93-103.

Horovitz Jacques. Winning Ways: Achieving Zero-Defect Service, Cambridge, MA:

Productivity Press, 1990.

How to Establish a Local TQM Information Center, prepared by the Information Network, Federal Quality Institute. Washington, DC: Federal Quality Institute, 1991.

How to Get Started Implementing Total Quality Management. Washington, DC:

Office of Personnel Management, Federal Quality Institute, 1991. 2 vols. (HD 62.15 .F32h 1991)

Howard, Gitlow. The Deming Guide to Quality and Competitive Position,. Englewood Cliffs, NJ: Prentice-Hall, Inc., 1987.

Hutchins, Greg. Purchasing Strategies for Total Quality: A Guide to Achieving

Continuous Improvement,. Homewood, Il: Business One Irwin, 1992.

Improving Government Performance: Evaluation Strategies for Strengthening Public Agencies and Programs, by Joseph S. Wholey, Kathryn E. Newcomer and Associates. San Francisco: Jossey-Bass Publishers, 1989. 216 p. 
Introduction to Total Quality Management in the Federal Government. Washington, DC: Office of Personnel Management, Federal Quality Institute, 1991.

Ishikawa K, Ed. Guide to Quality Control. White Plains, NY.: Kraus International Publications, 1986.

Ishikawa, K., What is Total Quality Control? The Japanese way. Englewood Cliffs, NJ:Prentice-Hall, Inc., 1985.

Jablonski_, Joseph. Implementing Total Quality Management: An Overview, San Diego, CA: Pfeiffer \& Co., 1991.

Johnson, Thomas. Relevance Lost after Five Years, Portland: P.S.U., 1991.

Juran J.M. Juran on Planning for Quality, byNew York: Free Press, 1988.

Juran, .M. Juran on Quality by Design: The New Steps for Planning Quality into

Goods and Services, JNew York: The Free Press, 1992.

Juran, J.M., Strategies for World-Class Quality. Quality Progress March 1991.

Juran. "Some Thoughts at the Outset: on Bringing TQM to Government." The GAO

Journal, Winter 1991/92: 48-54.

Jutkiewicz, Charles. Total Quality Management (TQM): Research Guide \&

Sourcebook, 1991-92 Edition, edited by. Waltham, MA: Timeplace, Inc., 1991.

Kaydos, Will. Measuring, Managing, and Maximizing Performance: What Every

Manager Needs to Know about Quality and Productivity to Make Real Improvements

in Performance, Cambridge, MA: Productivity Press, 1991. 
Kendall, Phillip. Vision 2000: American's Top 1,000 Companies' Quality Progress,

Methuen, MA: GOAL/QPC, 1990.

King, Bob. Better Designs in Half the Time: Implementing QFD Quality Function

Deployment in America, by. 3rd edition. Methuen, MA: Goal/QPC, 1989. 1 vol.

Koboyashi Iwao. 20 Keys to Workplace Improvement. Cambridge, MA: Productivity

Press, 1990.

Koska, Mary T., Total Ouality Management in Health Care. Hospitals, Dec., 1990, Vol.

64, No. 23, p 38(2).

Koteen, Jack. Strategic Management in Public and Nonprofit Organizations:

Thinking and Acting Strategically on Public Concerns, New York: Praeger, 1989.

Labovitz et al. "Leam From the Best. Quality Progress, May 1990 (Reprint), (5 p.)

Laffel, Glenn et al. The Case for Using Industrial Q.M. Science in Health Care

Organizations. JAMA, Nov., 24, 1989 Vol. 262, No. 20.

Levine. "Labor and Management Response to Total Quality Management," Labor Law Journal, February 1992: 107-116.

Mann Nancy R. The Keys to Excellence: The Story of the Deming Philosophy, by 3rd edition. Los Angeles: Prestwick Books, 1989.

Marszalek-Guacher, et al, Transforming Health Care Organizations. San Francisco, CA: Jossey-Bass Publishers, 1990

Massey, Karlan . "A Healthy Comeback," by Government Executive, May 1992: 40-

41. 
Masud. "TQM Strategy Saves Air Force Group \$3M on LAN," Government

Computer News, February 3, 1992: 38.

Mayo-Smith. Achieving Improved Performance in Public Organizations: A Guide

for Managers, West Hartford, CT: Kumarian Press, 1986.

McKenna, Joseph F., Total Quality Government. Industry Week 1991, Vol. 240, no. 21, p12(5).

McKenna. "TQM Government," Industry Week, November 4, 1991: 12-19.

McLaughlin, Dave, Take the High Ground: an Executive guide to TOM/CQI. Florida:

Man-corp. Publishing, 1990.

Mcloughlin, Curtis, et al. TQM/CQI in Health: Making it Work. Health Care

Management Review, Summer 1990 Vol. 15, no.3 p7(8).

Mendelowitz 118.. "TQM at GAO," The GAOL Joumal, Winter 1991/92: 39-47.

Mercer, James. Strategic Planning for Public Managers, New York: Quorum Books, 1991. 217 p. (JS 331 .M47 1991)

Milakovich. "Total Quality Management for Public Sector Productivity Improvement," Public Productivity \& Management Review, Fall 1990: 19-32.

Modic, Stanley J., What Makes Deming Run. Industry Week June 20, 1988.

Morely, Elaine. A Practitioner's Guide to Public Sector Productivity Improvement, by. New York: Van Nostrand Reinhold, 1986. 255 p.

Nadler, G., et al. Breakthrough Thinking. Rocklin, CA: Prima Publishing \& Communications, 1990. 
Nutt et al. Strategic Management of Public and Third Sector Organizations: A

Handbook for Leaders, San Francisco, CA: Jossey-Bass Publishers, 1992. 486 p. (JF

1411.N87 1992)

Oakland, John S., Total Quality Management. Britain: Betterworth \& Heineman, 1990.

Osborne David. Reinventing Government: How the Entrepreneurial Spirit is

Transforming the Public Sector, Reading, MA: Addison-Wesley Publishing

Company, Inc., 1992. 405 p.

Patrick L. Townsend et al. Commit to Quality. New York: John Wiley, 1990. 221

Penzer, Erika. "Making a Federal Case for Quality," Incentive, August 1991: (3 p.)

Perry. "Don't Implement TQM Before You're Ready," E. Government Computer

News, February 3, 1992: 22.

Persico John. The TQM Transformation: A Model for Organizational Change, White

Plains, NY: Quality Resources, 1992.

Peters, Tom, Thriving on Chaos: Handbook for Management Revolution. New York:

Alfred A. Knopf, 1988.

Reynolds Larry "The Feds Join the Quality Movement," Management Review, April 1992: 39-40.

Rhylander. "TQM Pays Off for Crane," Army Logistician, November-December 1991: 2-5.

Rivenbark, Leigh "OPM Institute Gets Quality Management Secrets Out of the Bag," Federal Times, December 9, 1991: 5. 
Roger, Tunks. Fast Track to Quality: A 12-Month Program for Small to Mid-Sized

Businesses. New York: McGraw-Hill, Inc., 1992.

Saylor James H. . TQM Field Manual,. New York: McGraw-Hill, 1992. 232 p.

Schein Lawrence et al. Total Quality Performance: Highlights of a Conference, New York: The Conference Board, Inc., 1988.

Schein Lawrence. The Road to Total Quality: Views of Industry Experts,. New York: The Conference Board, 1990.

Scherkenbach, William. The Deming Route to Quality and Productivity: Road Maps and Roadblocks, D.C.: CEEP Press Books, George Washington University, 1988. Shecter Edwin. Managing for World-Class Quality: A Primer for Executives and Managers, by. New York: Marcel Dekker, Inc., 1992.

Shoop Tom. "Uphill Climb to Quality," Government Executive, March 1991: 17-19. Shoop, Tom "Gauging Government's Performance," Government Executive, June 1992: 28-33.

Shumskas LTC. "Applying Total Quality Management to the Software Life Cycle," by. Program Manager, March-April 1991: 18-27.

Stratton, Donald A., Kaizen and Variability. Quality Progress, April 1990.

The Strategic Plan of the U.S. General Services Administration. (Washington, DC:

U.S. General Services Administration), 1991.

Total Quality Management, prepared by the ASI Management Team. Dearborn, MI: American Supplier Institute, 1989. 
Travieso Charlotte "An Experinient with Self-Directed Work Teams," Government Executive, May 1992: 42-43.

Waltman. "Will TQC Work for You?" Government Communicator, July/August 1992: 16-18.

Walton, Mary. The Deming Management Method,. New York: Putnam Publishing Group, 1986.

Walton, Mary. Deming Management at Work: Perigee Books, New York, 1990.

Weaver, C. TQM: a step by Step Guide to Implementation. Wisconsin: ASQC Quality Press. 1991.

Wooldridge Blue. "Overcoming Obstacles to Public-Sector Improvement Efforts," by. National Productivity Review, Winter 1991/92: 59-70.

-------. Total Quality Management: Department of Defense. Springfield, VA: NTIS, 1988.

-.---.-Workforce Quality and Federal Procurement: An Assessment, a special study by the U.S. Merit Systems Protection Board. Washington, DC: U.S.

Government Printing Office, 1992. 56 p. (DOC MS 1.2:W 89/4)

-.-----.. "The Quality Dilemma." Management Review, November 1991: 30-34.

-.---.-.. Total Quality Management: A Time for Decision, by the Federal Quality

Institute. Washington, DC: U.S. Office of Personnel Management, the Institute, (1989). 
-.--.-. Quality Improvement in the United States: hearing before the Subcommittee on Science, Research, and Technology of the Committee on Science, Space, and Technology, U.S. House of Representatives, One Hundred First Congress, second session, March 20, 1990. Washington, DC: U.S.G.P.O., 1990. Total Quality: An Executive's Guide for the 1990s. Homewood, IL:

Business One Irwin, 1990.

------. Total Quality Management: Using the Tools to Get Started: Student

Manual, prepared by Lynnette Yount Associates for the General Services

Administration Interagency Training Center. Washington, DC: The Center, 1990. 


\section{APPENDDX A}

MALCOLM BALDRIGE AWARD MODEL IN PRIVATE SECTOR ORGANIZATIONS

CRITERIA FOR THE MALCOLM BALDRIGE AWARD

"REINVENTING GOVERNMENT THROUGH QUALITY" MODEL IN PUBLIC SECTOR ORGANIZATIONS

CRITERIA AND CATEGORIES FOR THE PRESDENTIAL AWARDS 


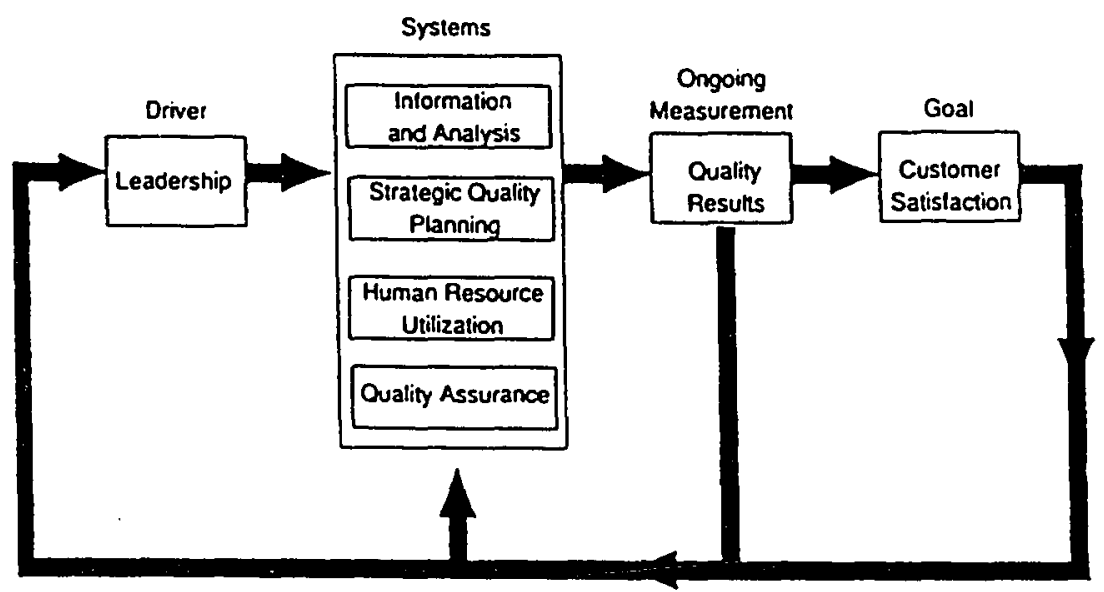

Source: National Institure of Standards and Technology

Figure 1: Malcolm Baldrige Model 
Examination Calegories/liems

Maximum Points

1.0 Leadership

100

1.1 Senior executive leadership

1.2 Quality values

1.3 Management lor quality

1.4 Public responsibility

70

2.1 Scope and management of quality data and information

2.2 Competitive comparisons and benchmarks

2.3 Analysis of quality data and information

60

3.1 Strategic quality planning process

3.2 Quality goals and plans

2.0 Information and Analysis

3.0 Strategic Quality Planning

4.0 Human Resource Utilization

150

4.1 Human resource management

4.2 Employee involvement

4.3 Quality education and training

4.4 Employee recognition and performance management

4.5 Employee well-being and morale

140

5.0 Quality Assurance of Products and Services

5.1 Design and introduction of quality products and services

5.2 Process quality control

5.3 Cuntinuous improvement of processes

5.4 Quality assessmen

5.5 Documentation

5.6 Business process and support service quality

5.7 Supplier quality

6.1 Product and service quality results

6.2 Business process, operational, and

support service quality results

6.3 Supplier quality resulis

7.1 Determining customer requiretnents and expectations

7.2 Customer relationship managemen

7.3 Customer service standards

7.4 Commitment to customers

7.5 Cumplaint resolution fur quality improvement

7.6 Determining. customer satisfaction

7.7 Customer satisfaction results

7.8 Customer satisfaction comparison

TABLE I

THE BALDRIGE AWARD CRITERIA AND CATEGORIES

Source: Hunt. Quality in America, 1992, Ilinois 


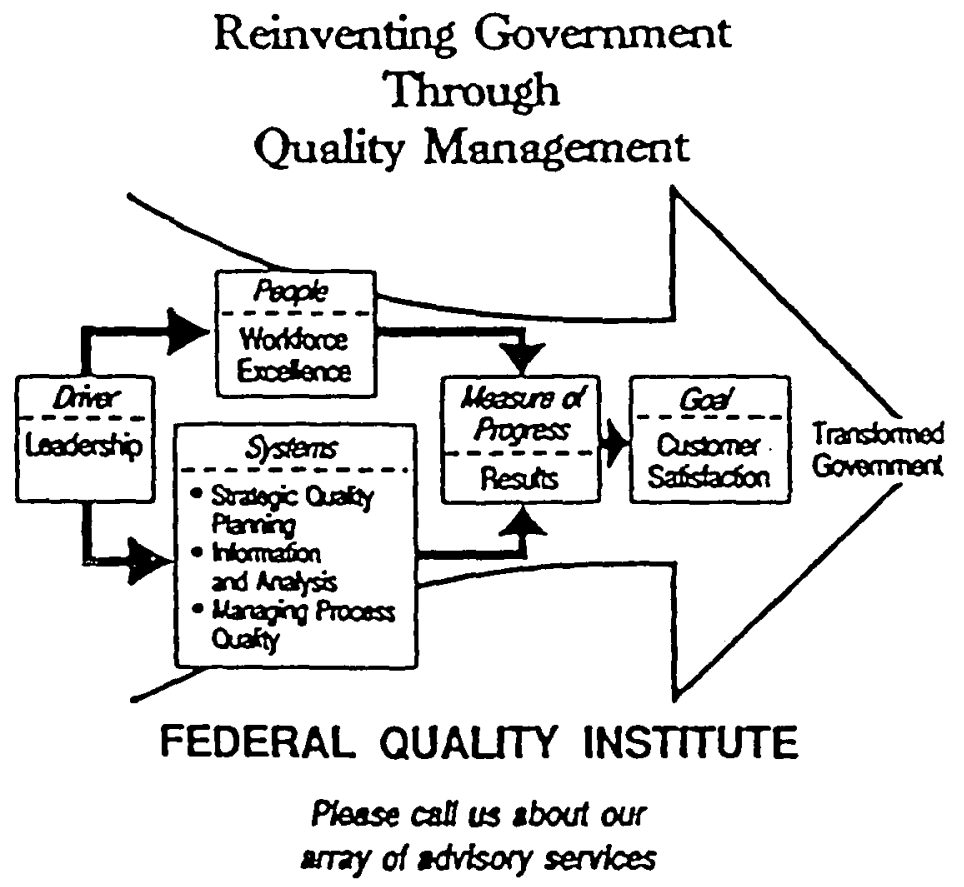

Figure 2: Reinventing Government through TQM Model Source: ------- FQI. 1993, Washington DC. 


\section{A: CRITERIA FOR PROTOTYPE QUALITY IMPROVEMENT AWARDS}

- Quality is defined by the customer.

- A focus on continuous improvement needs to be part of all operations and activities.

- Prevention of problems and waste is achieved through building quality into products, services, and processes.

- Success in meeting quality and performance objectives depends on work force quality and involvement.

- Senior management must create a customer orientation, clear and visible quality values, and high expectations.

- Reinforcement of values and expectations requires substantial personal commitment and involvement.

- Employees are valued and recognized for their involvement and accomplishments.

- Management decisions are made based upon reliable information, data, and analysis.

- Long-term commitments are made to customers, employees, suppliers, and the community.

- Public responsibilities are fulfilled.

- Partnerships are built with other agencies and the private sector, to better accomplish overall goals.

\section{B: Categories of Prototype Quality Improvement Awards}

- Top Management Leadership and Support (20 points)

- Strategic Quality Planning (15 points)

- Customer Focus (35 points)

- Training (10 points) and Recognition (5 points)

- Employee Empowerment and Teamwork (20 points)

- Measurement and Analysis (15 points)

- Quality Assurance (30 points)

- Quality and Productivity Improvement Results (50 points)

Table II

\section{(CRITERIA AND CATEGORIES FOR PROTOTYPE QUALITY IMPROVEMENT AWARDS}

Source: Federal Quality Institute, Criteria for PTQIA 1993, (pp. 8-9) 


\section{APPENDIX B \\ COPY OF GENERAL SURVEY USED IN THE STUDY \\ COPY OF PROCESS IMPROVEMENT TEAM (PIT) SURVEY}




\section{Total Quality Management General Assessment Survey}

Dear respondent;

Thank you for taking part in this research effort. This study is aimed at gaining a better understanding of the implementation of Total Quality Management(TQM) in the public sector. This survey is intended to provide an introductory assessment of the organization under consideration. The backbone of the research, however, will consist of a qualitative approach, through the use of interviews and field observations. You will be contacted, shortly, to schedule an interview. Once again, thank you for taking the time to answer these questions.

Please $\underline{F a x}$ (if possible) the completed questionnaire to :

Fax \# (000) 000-0000

Or you can mail it to:

Mohammed Abu Zayed

P.O. Box ****

Portland, OR $97^{* * *}$

\section{Thank You}

\section{NOTES:}

* There are no right or wrong answers. Please answer according to how you feel or believe.

* RANK means you provide an ascending order of the given variables. For example if you are given a list of 5 books that you read and you are asked to rank them, based on how much you liked them; you will start with the one you liked the most, giving it number 1 then you will give number 2 to your next favorite, and so on.

* $R A T E$ means you give a scoring category to each variable. In the above example, if you are asked : To what degree did a particular book discuss a relevant issue, say TQM, then you are expected to give a rating score. The scores are $1=(\mathrm{low}), 2=$ (medium) $3=$ (high). So if the book coverage is medium, then its rating score is 2 .

*. If you have an additional variable/s you want to add to a given list please do so where (otheris) appear.

*. Please feel free to use the back of the page as needed. 
Q. 1 What kind of a business are you in? Please circle one

1.. Industrial / manufacturing : cars, computers, .. etc.

2.. Service: Health care, Education, church .. etc.

3.. Others, please specify

Q.2 Is your organization? Please circle one

1.. Publicly owned

2.. Private not- for- profit

3.. Private for profit

Q.3 How would you define your organization's product or service?

Our organization furnishes:

Q.4 How would you define agency's customer?

My agency's customer is:

Q.4-b How would you define your customer?

My customer, to whom I furnish my product/service, is: 
Q.5 How competitive is the business market, in which you operate? (Please circle one only)
1.. Very competitive
2.. Somehow competitive

3.. Not competitive

4.. Not know

Q.6 If a decision is to be made in your organization, in regard to an organizational change, the implementation of a new program, or any other important organizational decision. Please $R A N K$ the following key organizational participants in regard to how much power they have in approving or disapproving that decision, in reference to your organization. 1 being the most important; 10 being the least important.

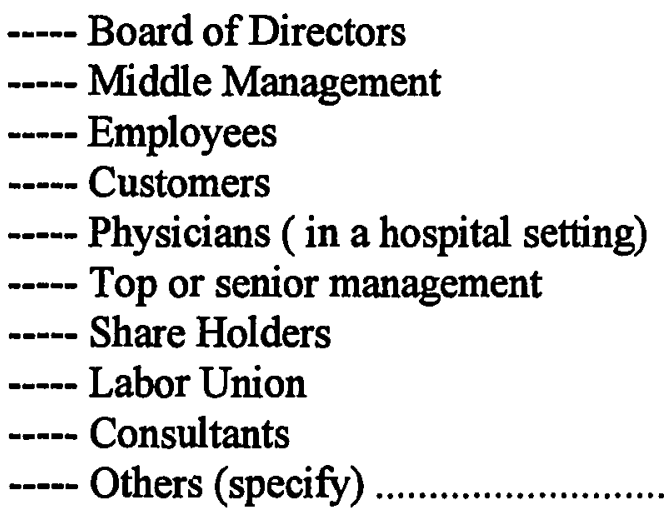

Q.7 Consider Q. 6. How much power does each of the following key organizational participants have in regard to approving or disapproving a decision, in reference to your organization. (Please give a rating score of either 1,2 , or 3 )
(1) Low
(2) Medium
(3) High

Top or senior management

Board of Directors

Middle Management

----- Employees

---- Physicians (in a hospital setting)

-.--- Share Holders

Customers 
----- Labor Union

----- Suppliers

Others (specify)

Q.8 How would you rate the communication in your organization
(1) Low
(2) Medium
(3) High

A. Vertical (eg. management to employees; employees to supervisors)

B. Horizontal (eg. among department heads; employees of other departments.)

Q.9 Within the coming 6 months what is your organization's most critical goal

It is:

Q.10 Within the coming 2 years what is your organization's most critical goal?

It is:

Q.11 In your view, which is more important? (please circle)
1.. Long term goals
2.. Short term goals

Q.12 What term below best describes your organization's posture toward change? (Please circle one)

1.. Our organization initiates changes

2.. Our organization reacts to changes

3.. Our organization hardly changes 
Q.13 If a new TQM innovation effort is to be implemented in your organization. In your view, which of the following forces will have more impact on the implementation and the outcome of such an effort.

1.. Internal organizational forces: eg. processes and regulations; labor union

2.. External organizational forces: eg. competitors ; interest groups; government

3.. Others (specify)

Q.14 In your view, in which ways are public and private organizations SIMILAR?

(1)

(2)

(3)

(4)

(5)

Q.15 In your view, in which ways are public and private organizations

\section{DIFFERENT?}

(1)

(2)

(3)

(4)

(5)

Q.16 How would you define Total Quality Management? Please note that for the purpose of this research, TQM and Continuous Quality Improvement (CQI), mean the same thing.

Total Quality Management is: (use back if needed) 
Q.17 In your view, does TQM differ from Quality Assurance theories? Please circle one.

1.. Yes it differs 2.. No it does not differ

Q.17-b If $\mathrm{YES}$, in which ways is TQM different?

Q.18 Where should a TQM effort start?(select one)

1.. At the administration office

2.. At the production department

3.. At Quality assurance department

4.. Others (specify)

Q.19 Do you agree / disagree with the following statement?

The outcome of a TQM effort in a public sector organization will be different from that in private sector.

1.. Yes, the outcome will be different Why?

2.. No, the outcome will be the same

Why?

Q.20 What are the 5 most critical elements for the success of a TQM effort, in relation to your organization. 
$1 .$.

2.

3.

4.

5

Q.20 What are the 5 most critical elements that cause the failure of a TQM effort, in relation to your organization?

1..

2.

3.

4.

5.

Q. 21 In implementing a successful TQM effort, Please RANK the following considerations as they apply to your organization? 1 being the most important; 10 being the least important.

---- Grasp of TQM theories

---- Planning for TQM effort

---- Implementing of TQM effort

----- Understanding the nature of the organization

---- Gaining approval and support

----- Dealing with resistance to change

Evaluation of outcomes

Type of organization

Size of organization

---- Others( specify)

Q. 22 For the previous question, how would you RATE these factors in their influence on the TQM effort?
(1) Low
(2) Medium
(3) High

---- Grasp of TQM theories

Planning for TQM effort

Implementing of TQM effort

----- Understanding the nature of the organization 
----- Gaining approval and support

----- Dealing with resistance to change

----- Evaluation of outcomes

---- Type of organization

----- Size of Organization

-.-- Others( specify)

PLEASE FEEL FREE TO ADD ANY INFORMATION THAT YOU FEEL RELEVANT TO THIS STUDY. RESPONSES WILL BE KEPT STRICTLY CONFIDENTIAL.

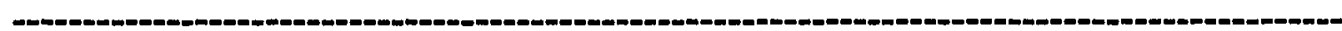

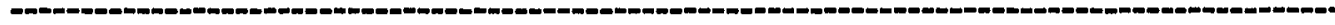

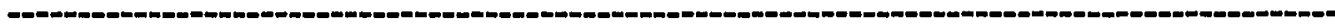

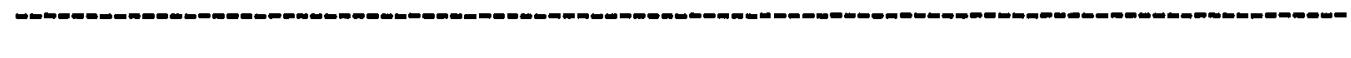




\section{Process Improvement Team Survey}

Dear participant/s;

The following questions are aimed at assessing your experience with the implementation of CQI through your participation of the Purchasing PIT. Your answers are strictly confidential, and they will only be used for research purposes only.

Q1.. Are you: (please circle)
a. Management employee
al. senior
a2. middle
b. Staff employee
c. educator
d. other, specify

Q2.. How did you know about this PIT
a. Through supervisor
b. Through coworkers
c. Through written media: newsletter, flyers, etc.
d. Others, specify

Q3.. Did you receive any training in CQI prior to joining the PIT a. Yes

If Yes, How long

What form of training, seminars, workshops, etc.

b. No

Q4.. Was the training, if any, relevant to the CQI process, in which you where involved.

a. Yes, how:

b. No, Why

Q5.. If you are asked to mention the 5 most valuable lessons you've learned from your involvement with PIT and CQI, what do you think are they?

1. 
2.

3.

4

5 .

Q6.. If you are asked to name 5 elements, you believe most relevant to the success of a PIT efforts, what do you think are they?

$$
1 \text {. }
$$

2.

3.

4.

5.

Q7.. Based on your experience through this PIT, please list 5 limitations, you believe might hinder PIT efforts?

$$
1 .
$$

2.

3.

4.

$$
5 .
$$

Q8.. In your view, was the process relevant to the task/ the problems?

a.. Yes

b.. No

Please justify your choice of $a$ or $b$

Q9.. How do you feel about the outcome of this PIT efforts, in relation to its stated goal/s.

a. It achieved its goals completely

b. It achieved its goal partially, but more work is needed

c. It did not achieve its goals

Please justify your choice of $a, b$, or $c$ 
Q10.. Based on your experience and involvement in this project, Which one of the following institutions will get better results in implementing CQI.

( ) A state owned public institution, like OHSU

( ) A privately owned and for profit hospital, like Woodland Park

( ) A privately owned but not for profit hospital, like Legacy

Please justify your choice 
APPENDIX C

TABULATIONS OF CROSSECTIONAL DATA GATHERED AT THREE ORGANIZATIONS 
Question 6:

Renting of Koy orgenizational perticipem

accoring to bovemuch pover thoy have

to influenco org pociciosin rengerd to TQMUCOI

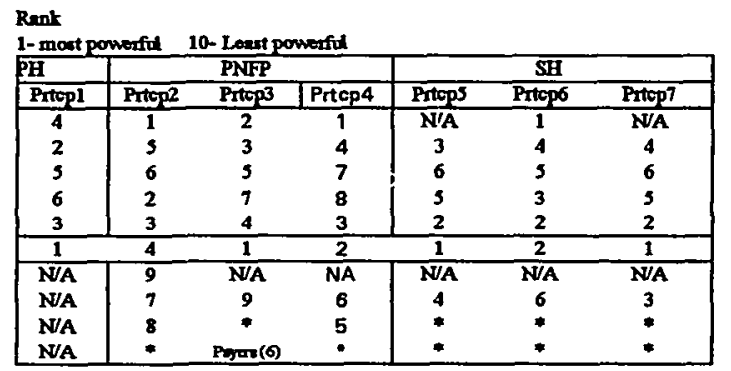

Boend of Dirocton

Middo Mgen

Employoon

Curtomon

Top or Senior Mom

Sharre Hoddors

Labor Union

Consultim

Othorx(Spocify)

Koy:

Privato-Not-for-Profit (PNFP)

Responses to Question 68
Question 7

How much pows doos each of those organization

perticipents heve in rogerd to influencing policy and

Reto
1-Low 2-Modum 3-

\begin{tabular}{|c|c|c|c|c|c|c|}
\hline $\mathrm{H}$ & & PNFP & & & SH & \\
\hline Prtepl & Prtop2 2 & Prtep3 3 & Prtcp4 & Prtaps & Prtep 6 & Prep? \\
\hline 2 & 3 & 3 & 3 & $*$ & 3 & \\
\hline 2 & 2 & 2 & 2 & 2 & 2 & 2 \\
\hline 1 & 1 & 1 & 1 & 2 & 1 & 1 \\
\hline 1 & 1 & 1 & - & 3 & 2 & 2 \\
\hline 2 & 2 & 2 & 2 & 3 & 3 & 3 \\
\hline 3 & 3 & 3 & 3 & 3 & 3 & 3 \\
\hline N/A & 1 & $\mathbf{N} / \mathbf{A}$ & $\div$ & N/A & $\mathbf{N} / \mathbf{A}$ & NA \\
\hline N/A & 1 & 1 & 1 & 2 & 1 & 3 \\
\hline N/A & 1 & 1 & : & * & * & * \\
\hline $\mathbf{N} / \mathbf{A}$ & & * & • & * & * & * \\
\hline
\end{tabular}

Notes:

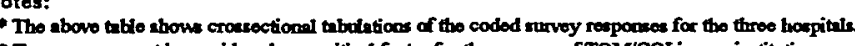

institurion regardess of in type.

- Phyzicims dleo phy a koy rolo in the organization. 
Question 8 : Communication in the organization

How would you rate the communication in your organization?

1-Low 2-Medium
Vertical (Mgre to Enployees)
Botizortal (Interdepartmental)

\begin{tabular}{|c|c|}
\hline \multicolumn{2}{|c|}{ 3- High } \\
\hline Prtcp 1 & P \\
\hline 3 & \\
2 & \\
\hline
\end{tabular}

$\frac{\operatorname{Prtg} 2}{3}$

PNEP

PNEP

\begin{tabular}{|c|c|}
\hline Prtcp 3 & Prtcp 4 \\
\hline 2 & 2 \\
2
\end{tabular}

\begin{tabular}{|c|c|c|}
\hline \multicolumn{3}{|c|}{ SH } \\
\hline Prtcp 5 & Prtcp 6 & Prtcp 7 \\
\hline 2 & 3 & 1 \\
2 & 2 & 1 \\
\hline
\end{tabular}

Tabulations of resposes to Question 8 
Question 11: Long Term VS Short Term Goals

Which is more important to your organization, in relation to TQM.

Long Torm Goals

\begin{tabular}{|c|c|c|c|c|c|c|}
\hline PH & \multicolumn{4}{|c|}{ PNFP } & \multicolumn{3}{|c|}{ SH } \\
\hline Partcp 1 & Partcp 2 & Partcp 3 & Partop 4 & Partop 5 & Partop 6 & Partcp 7 \\
\hline 1 & 1 & 1 & 1 & 1 & $*$ & 1 \\
$*$ & $*$ & $*$ & $*$ & $*$ & 2 & $*$ \\
\hline
\end{tabular}

Tabulations of responses to Question 11 
Question 13: External VS Internal Forces

If a TQM effort is to be implemented at your organization, which forces will have more influence?

1-Internal forces 2-Extemal forces 3-Others

Intomel Forces

External Forces

Othors

\begin{tabular}{|c|c|c|c|c|c|c|}
\hline PH & \multicolumn{3}{|c|}{ PNFP } & \multicolumn{3}{c|}{ SH } \\
\hline Partcp 1 & Partop 2 & Partcp 3 & Partop 4 & Partcp 5 & Partcp 6 & Partcp 7 \\
\hline$*$ & 1 & $*$ & 1 & 1 & 1 & $*$ \\
2 & $*$ & $*$ & $*$ & $*$ & $*$ & 2 \\
$*$ & Loadorship & $*$ & Mgmt Cmtmnt & $*$ & $*$ & $*$ \\
\hline
\end{tabular}

Tabulations of responses to question 13 


\begin{tabular}{|c|c|c|c|c|}
\hline \multicolumn{3}{|l|}{$\begin{array}{l}\text { a 14 } \\
\text { similar }\end{array}$} & \multicolumn{2}{|l|}{$\begin{array}{l}\text { Q } 15 \\
\text { Differtant }\end{array}$} \\
\hline Purtcp 1 & N/A & P & $\mathrm{N/A}$ & \\
\hline Particp 2 & 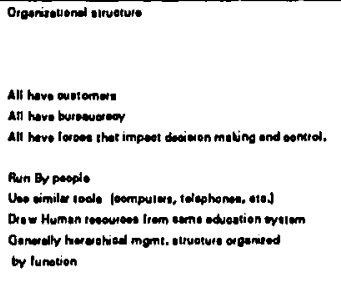 & $\begin{array}{l}\mathbf{P} \\
\mathbf{N} \\
\mathbf{F}\end{array}$ & $\begin{array}{l}\text { Partep } 2 \\
\text { Partep } 3 \\
\text { Particp } 4\end{array}$ & 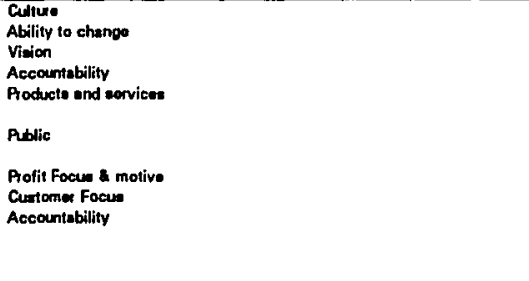 \\
\hline $\begin{array}{l}\text { Partep } 5 \\
\text { Purtep } 6\end{array}$ & 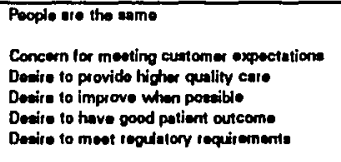 & $\begin{array}{l}8 \\
H\end{array}$ & $\begin{array}{l}\text { Partep 6 } \\
\text { Partep } 6\end{array}$ & 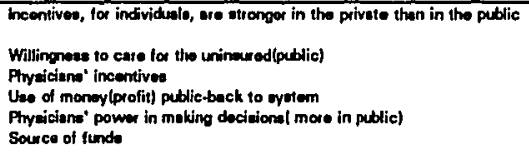 \\
\hline Partep 7 & $\begin{array}{l}\text { Both compere for came patient population } \\
\text { Both want to be profituble } \\
\text { Both are concerned sboun the bottom line }\end{array}$ & & Partep 7 & 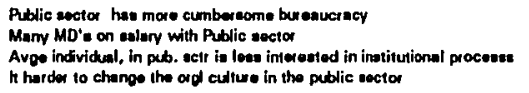 \\
\hline
\end{tabular}

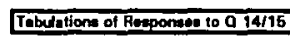




\section{Question 17: TQM VS other Q.A. approaches}

Does $T Q M$ differ from other $Q A$ approaches?

Yes it differs

No it does not differ

\begin{tabular}{|c|c|c|c|c|c|c|}
\hline PH & \multicolumn{3}{|c|}{ PNFP } & \multicolumn{3}{c|}{ SH } \\
\hline Partop 1 & Partcp 2 & Partop 3 & Partcp 4 & Partcp 5 & Partcp 6 & Partcp 7 \\
\hline$*$ & 1 & 1 & 1 & 1 & 1 & 1 \\
2 & $*$ & $*$ & $*$ & $*$ & $*$ & $*$ \\
\hline
\end{tabular}

If YES justify

Partop 1 N/A

Responses to 0. 17

Partop 2 N/A

Patop 3 Doing the right things right the first time

Quality improvement is everyone's responsibility, and not an inspection function

Attertion on the customer: intemal /extemal

Partcp 4 Q.A. Taught a process that is less empowering \& less uplifting than TQM

Partop 5 TQM accomplishes quality

It is an organized methodology to get there

Partop 6 TQM is Intemally driven, while other $Q A$ approaches are extemally driven Process rather individual focus

Problem solving by copployees rather than mgent only

Interdepartmental vs departmental focused

Proactive vs reactive

Customer driven

Patcp 7 Proactive not readive

More data driven

More scientific

More driven by top mgent

Mandates complete cultural change 
Question 18: Where should a TQM effort start?

1. At the administration office (the log Ment)

\begin{tabular}{|c|c|c|c|c|c|c|}
\hline PH & \multicolumn{3}{|c|}{ PNFP } & \multicolumn{3}{|c|}{ SH } \\
\hline Partep 1 & Partcp 2 & Partcp 3 & Partcp 4 & Partcp 5 & Partcp 6 & Partcp 7 \\
\hline 1 & 1 & 1 & 1 & 1 & 1 & 1 \\
& & & & & & \\
& & & & & & \\
\hline
\end{tabular}

2.At the prodiction Line

3- AL Qualiy Atsirasce Departmat

4 Ohers

Responses to Q. 18] 


\section{Question 19: TQM outcomes, Public VS Private}

Will the outcomes of TQM/CQI processes be the same, or different in public sector than those in the private sector, and why?

\begin{tabular}{l|c|c|c|c|c|c|c|}
\multicolumn{1}{c|}{ 1- Same } & PH & \multicolumn{3}{|c|}{ PNFP } & \multicolumn{3}{c|}{ SH } \\
\cline { 2 - 9 } & Partcp 1 & Partep 2 & Partcp 3 & Partcp 4 & Partep 5 & Partcp 6 & Partcp 7 \\
\cline { 2 - 8 } & $*$ & 1 & 1 & $*$ & 1 & 1 & 1 \\
Same & $*$ & $*$ & $*$ & 2 & $*$ & $*$ & $*$ \\
\hline
\end{tabular}

Why:

It will be the same

Partcp $1 \quad$ N/A

Partcp 2 Product/Service might be different, but outcome of high quality of those products/services is the same.

Partcp 3 If critical elements are in place, there would be no difference.

(leadership, resources, a need)

Partcp5 As long as you follow the plan with good people and commitment result should be same".

Partc 6 "Improved customer satisfaction Better utilization of services More efficient provision of services Cost effectiveness and improved patient outcome" Should be goal of any TQM effort.

Partcp 7 Both provide same services to same population Both share same customers

It will be different

Partcpt 4:

* No direct connection to motivation provided by market forces.

* No link between customer and financial status of organization. 


\section{Question 20A: Critical Elements for the Success of TQM}

What are the most critical elements for the success of TQM

Partop 1 Administrative support

Allow all employees to participate

Value all input from comployees

Show success of first effort/s

Partop2 Total Senior Mont buy in /support

Mid-Mgnt buy in

Solid training

Patience

Measuresable outcome

Partcp 3 A need in the organization to change (fmancial ills) Top leadership sincere commitment and dedication Educational resources

Walking the walk and talking the talk by sr mgnt

Long term perspective

Partipt 4 Londentip Undenterding

Losdonhip Committment

Loadorstip Exemplo

Effectivo Trining of Mgent \& Stell

Rigorous Followeup /followon by leadentip

Partop 5 Leadership

Committment

Patience

Education

Good data

Partip 6 Top leadership education

Top leadership support

A core of enthusiastic participants

Start smaa

Widely publicized successes

Partop 7 Top administrative Committment

Education, echucation, reechucation, re:TQM

Cultural change involving all emplyees

Cross-functional involvement and not just indvl dept

Responses to Q. $20 \mathrm{~A}$ 


\section{Question 20B: Hindering Forces for TQM}

What are the most critical elements that might cause the failure of TQM?

Partcp 1 Process minght take toolong.

Unwillingness by senir mgnt to release people from their jobs

Any increase in costs

Partcp2 Lack of Top management buy-in

Lack of Middle Mgmt Buy-in

Lack of solid training component

Lack of patience

Lack of measurable outcomes

Partcp 3 Insufficient support for education

Unwillingness by senir mgnt to release people from their jobs

to work on problem solving teams.

Half hearted belief in TQM by sr Mgnt

Short term perspective, need for immediate results.

Partcp $4 \quad$ Lack of training

Lack of continued example by Leadership

Incomplete preperation of the organization for cultural change

Cynicism by influential people in organization

Lack of leadership follow-up /follow on

Partep $5 \quad$ Lack of Leadership

Lack of Commitment

Lack of Patience

Lack of education

Lack of good data

Partcp $6 \quad$ Lack of leadership at top

A financial focus

Not involving physicians soon enough

Mass education without opportunity to implement

Unwillingness to allott time for what needs to be done in teams.

Partcp 7 Lack of committment from top

Lack of education

Launching too rapidly

Responses to Q. 20B 
Question 21/22: Considerations for implementing TaM

in implementing a TOM eftort, pleaen RANK the following considerations as the

apply to your orgenization, 1 being most importent 10 being tha loast

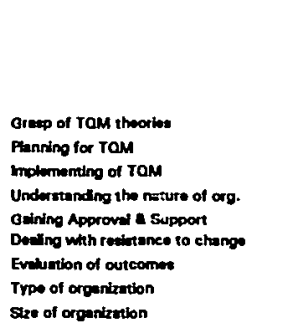

Rank

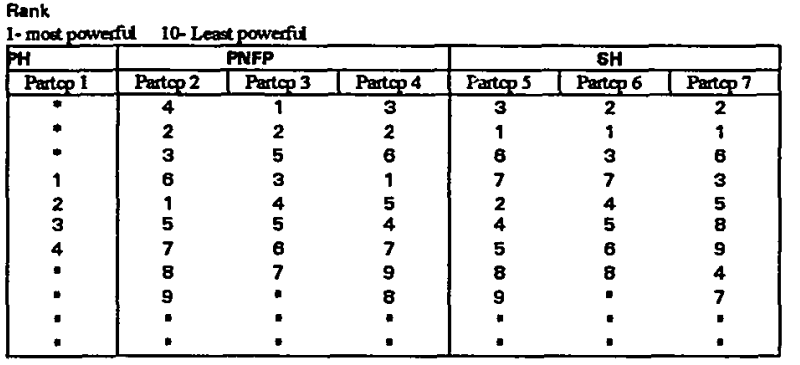

Question 22

Qing

in thoir influence on TOM effort

Rato

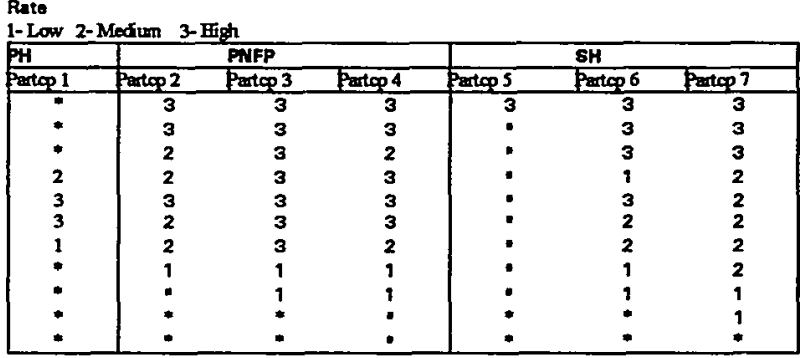

Responate 10 0. 21822 


\section{APPENDIX D \\ TRANSCRIPTIONS OF INTERVIEWS GATHERED AT THE THREE ORGANIZATIONS}

1. Interviews with participants from $P H$

2: Interviews with participants from PNFP

3: Interviews with participants from SH 


\title{
Interviews at Private Hospital
}

\section{A Private-for-Profit Institution: Private Hospital}

The Interview: Relevant responses

Q1.. How is a hospital different from a private industry company, in regard to TQM/CQI?

\begin{abstract}
Answer:
"The main focus for a health care institution is the human being, patients, employees, doctors, etc. The focus of a private industry, say, auto industry, may be objects-cars.

Products, such as cars and light bulbs are easier to compartmentalize, but you cannot do the same with human beings."
\end{abstract}

"Also The processes of a hospital are more complex; even if you implement TQM/CQI very well, you might not necessary end up with the same results. In other words it is harder to control the outcomes in the health care organization due to its complexity and its focus on human beings."

Q2.. How similar or different is $P H$ from other health care institutions, for example, a private-notfor profit institution, such as PNFP, or a public institution, such as SH?

Answer:

"Private Hospital:

*. It is for profit private institution

*. The key organizational layers are:

board of trustees

Management

Parent owner (stock Holders)

Private- Not - for - Profit hospitals

*. Not for profit, but privately owned, by a church or other social entity

*. More into reimbursement issues rather than accountability

*. Somewhat involved in what goes on in the legislative body, but not as much as a public hospital like SH.

\section{Publicly owned Hospitals}

*. State owned

*. The Tax payer plays a key role in affecting its policies

*. Budget process is more complex

*. Provides care for uninsured patients and other indigenous groups"

Q3.. Do you have a theoretical framework, policy, for TQM/CQI, and if so what are its basic tenets? 


\begin{abstract}
Answer:
"We at PH have the following six steps of TQM/CQI, which we consider to be the major framework that outlines our philosophy/policy about TQM/CQI.
\end{abstract}

Step \# 1: Quality is important:

We must devote ourselves to improving the quality of the services we deliver. We can only be successful if quality is the driving force behind our decisions.

Step \# 2: Quality is customer driven:

We exist to serve our customers, patients, payers, physicians, employees, and the community. Quality is measured by our ability to meet and exceed the needs and expectations of these customers.

Step \# 3: Scientific thinking is required:

we need to make judgments based upon measurements of customer needs and how well we meet them. Statistics are used to guide the collection of these critical data.

Step \# 4: Process over people:

Quality improvement comes from studying and changing the processes of our work, not disciplining our employees. $85 \%$ of unwanted variation in complex organization results from the system, not the people.

Step \# 5: Quality improvement is continuous:

Customer needs change, the competitive market changes, and the organization must be continuously looking for ways to improve.

Step \# 6: Everyone must contribute:

The collective intelligence and experience of everyone in the organization must be applied to quality improvement. The employees who do the everyday work and interact with the customer must be central to the quality improvement effort."

\title{
Q4.. How would you examine/study a process?
}

Answer:

"In studying or examining a process we explore inputs, we consider actions and decisions, and we deliver and expect outputs, as illustrated below:

Inputs $\Longrightarrow$ Actions and Decisions $\Longrightarrow$ Outputs

The process is ultimately judged ACCOrding to the degree the outputs meet the needs and expectations of the customers.

The analysis of a process is performed by a Quality Improvement Team (QIT). 
Projects(" opportunities for improvement") are conceived in any of several ways: suggestions from employees, patients complaints, survey results, management'S Strategic decisions, and so on. Every QIT that cuts across department lineS Should be approved by administration."

\section{Q..5: What guidelines do you follow in forming a Quality Improvement Team?}

\section{Answer:}

"Formation of quality improvement teams (QIT) is critical to the success of the effort. Once formed a team can be expanded or changed as needed to support increased knowledge of the process."

"The followings are some guidelines:

1.. The final team should consist of 4 to 8 people

2.. The people on the team must have hands-on knowledge of the process under consideration.

3.. All of the important steps of the process must be represented by people in the team.

4.. The team composition is then assessed in light of this process, are there other people who should be involved?

5.. The team undertake the Nine step plan, described later, which projects out, over several through its work. months, the steps that will be taken. Nine step plan will be updated as the team goes

6.. The team embarks on its work"

Q6.. Who were in the teams?

Answer:

A mix of management and employees.

Q7.. Are there special roles of the team members?

\section{Answer:}

"The above waS Some considerations about the team, now it is important to mention the key figures in the team. This doesn't, however, minimize the importance of other members. Each of our QIT should have:

TEAM LEADER: This person is responsible for scheduling meetings, forming a plan of work, and making sure the agendas are followed.

RECORDER: Keeps brief minutes of the meetings and RECOrds the agendas for the next meeting.

TIMEKEEPER: MakeS Sure the meeting stays on the agenda and ends on time.

FACILITATOR: Not a member of the team, the facilitator provides technical counseling to assist the team in the TQM/CQI process ( probably the QI manager). 
Q8.. - Can you give me an example of TOM/CQI innovation effort at $P H$ ?

\begin{abstract}
Answer:
"There has been a lack of communication among several departments, concerning sending patients from one department to the other. Both departments did not have clear ideas about the RECOrds of the transferred patient or what has been done. In other WORDs, there was a problem with the process of getting the patient from point $\mathrm{A}=\mathrm{B}$, as well as a turf problem."
\end{abstract}

Q9.. - Please describe the process by which you have dealt with this problem?

\title{
Answer:
}

"Once we identify an area of concern, through the various channels, described above, then we form the team to improve the process, we design a PLAN of WORK. This process consists of the following steps."

1.. Problem identification and establishing desired solution or outcomes At this point, we wanted to go through an explicit description of the process. Where it starts, where it ends, and who is responsible for the process.

For example, we wanted to solve the problem described above, by improving the process of getting the patient from one department to another, do the tests, document the treatment, and then get him/her back.

\section{2.. Analysis of customer needs}

The customer here iS Seen from both perspectives: external, the patients, their families, etc., but also there is the internal customer, being the other departments. In thiS Stage there is a need for an explicit listing of the important customers of the process and their needs. Moreover, we ask ourselves questions like:

"Who receives Something from this process?"

" What are the important features of the output from this process?"

"What does a customer want from the process?" What are their criteria for a successful process?"

"This step is critical in focusing the team on the customer and will serve to anchor all future steps. In subsequent meetings, all discussions about what should be done or what is wrong need to be framed from the customer needs listed here. If there was a difficulty in deciding on these needs, or if the team has difficulty in adopting the customer outlook, we would then develop a simple survey, in which we try to identify the important customer needs that are not otherwise clear to the team."

"By doing so, the various members of the team, and ultimately those who are involved in the process, have gained a new perspective in looking at things. They now look at the problem from the customer's point of view, and not ONLY from their own point of view.

Looking at the process/problem from this perspective allowed the participants to feel that they are all part of a process and that they all need to improve the process, which belong to them. 


\section{3.. Quality Opportunity Statement}

In thiS Step a concise description of how improving the process will beneficial in terms of the customer needs. Have all customers and their needs been considered? What are the cost effects associated with this change? Will rework be reduced? Is the opportunity statement something that you will be proud to be associated with?

\section{4.. Measurement of the Process:}

This is a critical step. The team must select the Key Quality Characteristics (KQC), the most important feature of the output of the process defined operationally, The KCQ must be a clearly defined, measurable result of the process that relates directly to the needs of the opportunity statements. Once the KQC, there might be more than one, is chosen, the team must decide how and by whom the data will be collected. The data should be presented in a run chart format, with upper and lower control limits.

\section{5.. Charting:}

The chart is a picture of how the process currently functions. It will serve as the point of reference for future discussions and data collection. Once a team has flow charted the process, they should have a better understanding of the whole process, and not only their own piece.

\section{6.. Analysis of the process: ProcesS Stability}

Here the team will create the run chart and put the upper and lower control limits on the chart. The team will use the run chart to decide if the process is in statistical control (stable) or not If the process is out of control, this needs to be further investigated. Isolated points out of control indicate special causes and should be individually examined Evidence of a trend implies that something is changing about the process or its inputs. A run chart that appears to be out of control may result if the output of two or more processes is being combined. Is your measured data just a product of one process?

A process that iS Stable, or a process that its out of control points explained, is then ready for further study. To improve a stable process requires changing the process or the inputs to the process. Finding the key part of the process that controls the output of the KQC is the next step.

\section{7.. Pick and implement improvement:}

After coming up with working solutions, in terms of financial and operational stand, the team selects one or two intervention based upon the causes of variation found above. During thiS Step, the team need to be aware of these questions: Will making this change affect other processes? Will these changes require new resources? If so, can the team justify these resources? Are there people who will resist these changes? If so, are these people represented on the team? Why were these changes not tried before? 


\section{8.. Re measure KQC:}

By doing so you ensure the continuous nature of the improvement. As forces change and other organizational forces create new needs for improvement, re measuring the KQC will allow you to update your improvement processes.

\section{9.. Analyze and repeat:}

Implementation of the changes recommended by the team will generally require the involvement of Hospital Quality Council. Once implemented, the team will continue to measure the KQC for the process to see what effect the changes are having. If there are changes in resource consumption, the team should try to quantify these. Once a change is made, the process is likely to go out of control until the change settles in and the process moves to a new level of capability. At this point, when the process is once again in control, the team can decide whether a further intervention is desirable.

"It is advisable that the process continue to be monitored for a while even if there is no further intervention contemplated. Moreover, the team need to ask these questions: Is the change really occurring? Are there any things that are going on that might affect our measurement besides the change? Have you followed the process long enough after the change to be confident that the system haS Settled to new level and iS Stable?"

\section{EXAMPLE:}

\section{Area of Improvement: the Admission Process}

Step \#I: Process definition

The admissions process from arrival to leaving the department

Step \#2: Customer needs analysis

Survey the customers to explore their needs and expectations

Step \#3: Quality Opportunity Statement

Studying the admission process will reduce patient annoyance with waiting, allow better information collection, and free up time for patient care, easing scheduling BURDens.

Step \#4: Measurement of the Process

KQC for the admissions team:

Time elapsed from entry into the office until patient goes to the room, RECOrded on special on special time sheets designed for the study.

Step \#5: Charting

A sample chart for mailing the patient record is drawn

Step \#6: Analysis of Process

Not Available

Step \#7: Pick and implement

The admissions team instituted a program whereby physician officeS Send patient information by facsimile to enable the creation of nearly complete admissions package before the patient arrives. 
Step \#8: Re measure KQC

Step \#9: Analyze and repeat

Patient waiting has been reduced, and more improvement on the process has been under investigation."

\section{Q10.. Would you comment on the measurement process?}

\section{Answer:}

"I believe the evaluation process is very critical to the success of any TQM/CQI effort. " The challenge is to get the participants to see that the solutions chosen will make things better, and to put it in a statistical mode. Questions posed are : "How do you know it is going to work? How well is it going to work. A criteria for measurement, then, is needed.

Another issue is the cost of measurement. Spending on measurement might exceed the cost of implementing the process or/and the savings that might be gained by the improvement of the process. In my view, you cannot spend on the monitoring more than you spend on the process. Therefore coming up with a criteria has been challenging."

\section{Q11.. How do you feel about TQM/CQI?}

\section{Answer:}

"A little bit ambivalent, portions of it we have been doing for a long time. One advantage I see for $\mathrm{TQM} / \mathrm{CQI}$ is that it makes it easier to work across departments. Team members expressed their satisfaction with the way TQM/CQI deals with complex systems. One of TQM/CQI strengths is that it looks at a very complex problem and comes up with a solution that will cover all the bases rather than learning by trials of this and that. It is a valuable way that will allow you to test an improvement process on paper before you go and implement it in the field. TQM/CQI is more statistically driven than other approaches, which provides it with an advanced edge over other approaches. However, to get everyone to agree and get over TQMS Statistical aspects might be met by resistance by some people, unless they are statistically oriented.

There are some positive outcomes of TQM/CQI. For example, it breaks down the interdepartmental barriers. As well, it changes the way a society, and ultimately a system, work. It focuses more on the process and the prevention of error rather than resolving errors. Finally, it makes the organization participants think that what they are doing will make a difference to the survival of the organization."

\section{Q12.. What about the management involvement in TQM/CQI at $P H$ ?}

Answer:

"We believe that management involvement at $\mathrm{PH}$, or any institution for that matter, is very critical. It is important to get the top management to agree to it. At PH, the top management has agreed to the 
adoption of TQM/CQI as a concept, and they expected good results. The management, is in support of quality, at least as a concept."

\title{
Q13.. How far are you in adopting and/or implementing TQM/CQI?
}

\begin{abstract}
Answer:
"We are talking about it. Though the hospital as a whole has not gone TQM/CQI yet, we have some implementation of TQM/CQI techniques through the QIT activities. Moreover, there is no adoption of any particular school of thought in TQM/CQI. Though quality is a concern for us, we are not launching a massive comprehensive TQM/CQI program, because of COST concerns. We have been using Quality Improvement Team (QITs) examples, as described above, to improve certain processes at the hospital. We are worried about results more than the process. In general, we believe in using the process to get better quality."
\end{abstract}

"In addition, there are different ways of doing $T Q M / C Q I$. One way might be having a huge process, but ending up with little results. But the other way, that we prefer, is having an $O K$ process that might yield bigger results. This way stresses that you do not spend all of your time and energy on process; instead try to achieve nice results, without ongoing outlay of labor before you start seeing anything."

"Since profit is a very important factor for this kind of institution, $\mathrm{PH}, \mathrm{TQM} / \mathrm{CQI}$ has to prove it is a profitable methodology. The question is whether TQM/CQI is a profit or a cost? Our initial projects have been aimed at streamlining the process, reducing waste and litigation. Time and resources are of concern for $\mathrm{PH}$, and I believe management will give more support if they can see that there is improvement at the bottom line, more preferably if the improvements could be translated to actual numbers."

Q. What would help to get you to where you want to be, i.e. what makes it work?

Answer:

*. Management buy-in and commitment.

*. Physicians buy-in into it, and giving incentives to doctors to adopt the changes. Since patient care is a common goal for doctors, management and employees, then that becomes an incentive in itself.

Show Doctors that TQM/CQI will improve patient care.

*. Underlying commitment of people involved in quality matters.

*. A clear well organized and result driven methodology

*. Education of our employees, and having the financial resources to send members of administration team, chairman of medical staff, and other key figures, to a training seminars. They will get the relevant knowledge and then come back and educate others. In other words we will get enthusiasm from outside.

*. Flexibility of the system.

*. Well documented successes and improved processes

*. Proof that things are done cheaper, faster, and better by incorporating TQM/CQI techniques 
Q15.. Has there been any opposition to TQM/COI at PH?

\section{Answer:}

"No, so far. However, there have been some concerns from some employees, who hoped it will not increase paperwork and that it could be done in a faster way."

Q15.. What are some of the challenges you see for TQM/CQI at $P H$ ?

Answer:

"The biggest challenge is to document the results: to show that TQM/CQI not only has reduced your cost but it has also cut on wasted time. Moreover, the lack of well kept documentation of team's activities and meetings' minutes might be a deterrent force for the implementation of TQM/CQI."

\section{Q16.. What criteria for implementation do you have?}

\section{Answer:}

"We follow the outlined process, described previously, to ensure that our TQM/CQI project succeeds. Let'S Say you have a TQM/CQI innovation idea or project then:

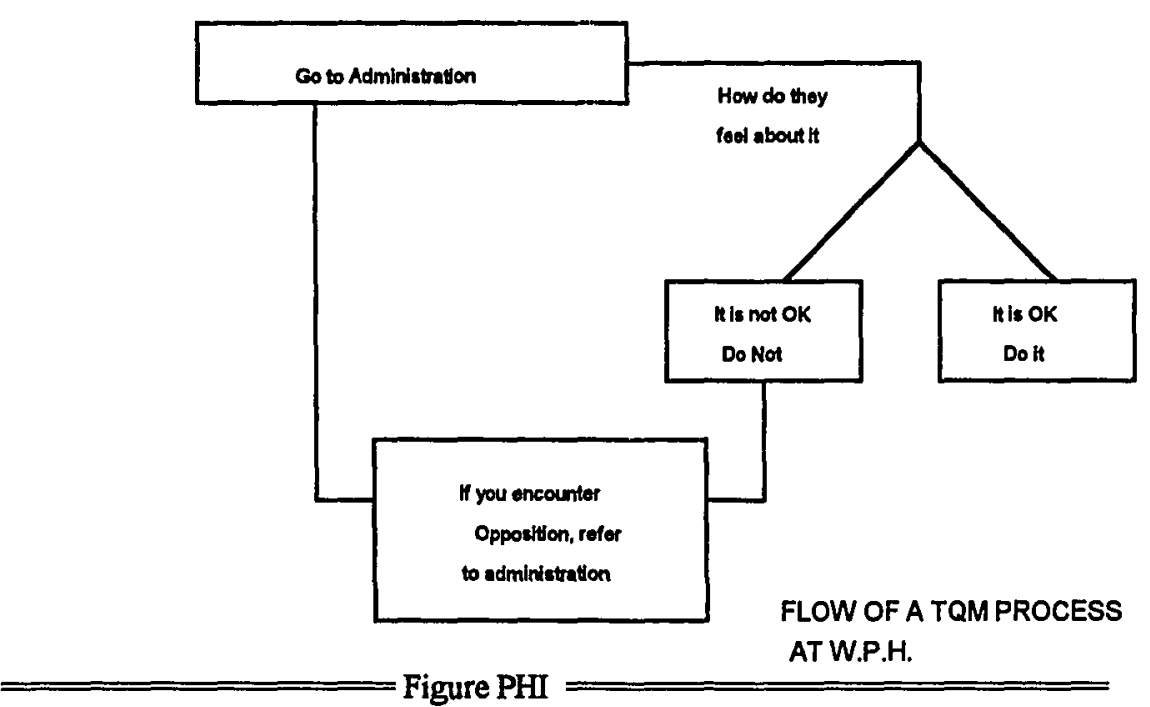

"The major criteria is the buy-in of top management and the commitment of the participants." Also, as outlined in the description of the process measurement is done through reevaluation."

Q18.. Do you have any recommendations to those involved in TQM/CQI projects? 


\author{
Answer: \\ Leaders or/and managers who are involved in TQM/CQI and process improvementS Should be \\ aware of the following considerations: \\ * What kind of people you are dealing with \\ * How do they respond to change \\ * What kind of institution you have and how does it respond to change
}

Q19.. Is TQM/CQI a fad :

\title{
Answer:
}

I see it as a fad, but not self limiting. It is an answer to a distinct need for very much to look at quality and look at outcomes. Not all TQM/CQI is result oriented, instead there are parts that are system oriented. As long as the teams focus on the task the process will improve.

\section{Appendix IV, $B$}

Quality Plan at Private Hospital

Problem identification and establishing desired solution or outcomes iS Seen as the first step in this plan. In thiS Step the Quality Improvement Team (QIT) comes up with an explicit description of the problem. This of course includes charting the process in order to visually illustrate where it starts, where it ends, and who is responsible for the process. By doing so the QIT will be able to identify the areas in the system were the flaws occur.

Once the problem is chartered and the existing process is identified, the next step is to conduct an Analysis of customer needs. As derived from the survey responses and the interview responses, PH embraces a TQM definition of the customer. The customer here iS Seen from both perspectives: external, the patients, their families, etc., but also there is the internal customer, being the other departments. In thiS Stage there is a need for an explicit listing of the important customers of the process and their needs. In order to achieve that teams at PH teams would ask questions like:

Who receives Something from this process?

What are the important features of the output from this process?

What does a customer want from the process?" What are their criteria for a successful process?

ThiS Ste is critical in "focusing the team on the customer" and will serve to anchor all future steps. They now "look at the problem from the customer's point of view", and not ONLY from their own point of view, adds Participant 1 at $\mathrm{PH}$

In subsequent meetings, all discussions about what should be done or what is wrong need to be framed from the customer needs. If there was a difficulty in deciding on these needs, or if the QIT team has difficulty in adopting the customer outlook, a simple survey would then be developed, in which the team tries "to identify the important customer needs that are not otherwise clear to the team." By doing so, the various members of the team, and ultimately those who are involved in the process, have gained a new perspective in looking at things.

Looking at the process/problem from this perspective allowed the participants to feel that they are all part of a process and that they all need to improve the process, which belong to them. Once this concept of internal/external customer is will understood, then the teams would move to the next step.

The third step is Quality Opportunity Statement. In thiS Step a concise description of how improving the process will be beneficial in terms of the customer needs. Have all customers and their needs been considered? What are the cost effects associated with this change? Will rework be 
reduced? Is the opportunity statement something that you will be proud to be associated with? All these questions are considered by the team.

Measurement of the Process is the fourth step. This is considered to be a critical step. The team, here, must select the Key Quality Characteristics (KQC), are defined by PH as "the most important feature of the output of the process defined operationally." The KCQ must be a clearly defined, measurable result of the process that relates directly to the needs of the opportunity statements. Once the KQC, there might be more than one, is chosen, the team must decide how and by whom the data will be collected. The data should be presented in a run chart format, with upper and lower control limits. From these KQC, the main goals of the process are to be derived. These goals would be the desirable outcomes, reflected in improved process for which TQM/CQI innovation processes will strive.

Charting is another critical component of such a plan. The chart is a picture of how the process currently functions. It will serve as the point of reference for future discussions and data collection. Once a team has flow charted the process, they should have a better understanding of the whole process, and not only their own piece. At thiS Stage the processes would be charted and the various points of instability would be identified. These points would be the problems facing the process, and by solving them, the process would be improved, or "stabilized".

The sixth step includes an Analysis of the process: ProcesS Stability. Here the team will create a run chart, described earlier in the Literature Review section, and put the upper and lower control limits on the chart. The team will use the run chart to decide if the process is in statistical control (stable) or not. If the process is out of control, this needs to be further investigated. Isolated points out of control indicate special causes and should be individually examined Evidence of a trend implies that something is changing about the process or its inputs. A run chart that appears to be out of control may result if the output of two or more processes is being combined.

A process that is Stable, or a process that its out of control points explained, is then ready for further study. To improve a stable process requires "changing the process or the inputs to the process. "Finding the key part of the process that controls the output of the KQC" is the next step, (Rd at PH).

Selecting and implementing improvement intervention/s is the seventh step in this work plan adopted by QIT at PH. After coming up with working solutions, in terms of financial and operational stand, the team selects one or two intervention based upon the causes of variation found above. During thiS Step, the team need to be aware of these questions: Will making this change affect other processes? Will these changes require new resources? If so, can the team justify these resources? Are there people who will resist these changes? If so, are these people represented on the team? Why were these changes not tried before?

Once step seven is completed then the following step would be to Re measure KQC. By doing so you ensure the continuous nature of the improvement. As forces change and other organizational forces create new needs for improvement, re measuring the $\mathrm{KQC}$ will allow you to update your improvement processes.

Finally, the plan stresses the need to Analyze and repeat the variouS Steps in Order to ensure the continuous improvement in quality. Implementation of the changes recommended by the team will generally require the involvement of Hospital Quality Council. Once implemented, the team will continue to measure the KQC for the process to see what effect the changes are having. If there are changes in resource consumption, the team should try to quantify these. Once a change is made, the process is likely to go out of control until the change settles in and the process moves to a 
new level of capability. At this point, when the process is once again in control, the team can decide whether a firther intervention is desirable.

It is advisable that the process continue to be monitored for a while even if there is no further intervention contemplated. Moreover, the team need to ask these questions: Is the change really occurring? Are there any things that are going on that might affect our measurement besides the change? Have you followed the process long enough after the change to be confident that the system haS Settled to new level and iS Stable?"

\section{A private-not-for Profit: PNFP Health System}

\section{The interview: Major Responses}

\section{Q1.. How do you define your customer and products?}

\section{Answer: Participants \# 2,3,4}

"Our customers are: patients and their families, physicians, payers, insurance companies, health plans, and employees and their families."

"Product service: we provide health care services, aimed at increasing the well-being and health in the community as a whole."

Q2.. How long have you been involved in TQM/CQI?

Answer: Participants \# 2,3,4

"Since March, 1991"

\section{Q3.. What made you adopt TQM/CQI}

Answer: Participant \# 3

We adopted TQM/CQI, because it has become a critical approach to cut cost and improve the quality of service in health care. In July of 1990 , there was a change in top leadership. The new C.E.O. was committed to the principles and the implementation of TQM/CQI in the organization. Briefly put, a committed leadership was the driving force behind the adoption of TQM/CQI at PNFP.

\section{Q4.. How do you feel about the potential of TQM/CQI?}

Answer: Participant \# 3

It has a tremendous potential if people are willing to change.

Q. How different is TQM/CQI from other Q.A. approaches?

\section{Answer: Participants \# 2,3,4}

* TQM/CQI stresses managing by facts \& data.

* TQM/CQI calls for treating people with respect and driving out fear.

* TQM/CQI encourages risk taking 
* It calls for getting people who are closer to service/produci to make the decisions; empower them with the ability to make those decisions.

* Many of those principles are what OD people have been trying to get organizations to do all a long. TQM/CQI offers a formalized venue that leaders are jumping on and seeing some potential there.

* Other theories did not touch and come closer to people who are involved.

A. Quality Circles: Though it got closer to employees, there was no connection with leadership.

B. Guest Relation Theories: It called for treating people better, without changing the infra structure.

*. TQM/CQI provideS Structure for the organization

Q. How did the TQM/CQI process evolve at PNFP?

Answer: Participants \# 3

"1.. The top leadership has decided to adopt the TQM/CQI process to improve quality and cut cost.

2.. The key leaders, top management, of other member hospitals were involved, and their buy-in waS Solicited.

3.. In a special retreat, those key leaders were presented with the TQM/CQI concepts, painted a picture of the training that might be forthcoming, structures that might be put into place by quality council.

4.. After being enlightened, the top management has granted their support

5.. After reviewing the theoretical framework of TQM/CQI philosophy: We decided to draft our own.

6.. The task was to teach the rest of the organization about TQM/CQI

7.. The teams Stated policy and goals, and selected a name for TQM/CQI at PNFP, we chose to call

it: (TQM/CQI PNFP).

8. We hired a consultant to help us kick off the process.

9. We decided to commit to a unified approach, quality goal statement, principles, and plan

10.. We have coordinated with Q.A. department to shift responsibility, since TQM/CQI considers everybody responsible. This is a prospective rather than a retrospective approach which hold all of responsible for making it work.

11.. Those key managers who were trained and educated went and taught the rest of the managers at their institutions, who have taught their staff

Leaders teach manager $>>$ Mangers $\gg$ teach employees

12.. Process improvement teams (PITs) were established to deal with areas of improvement at PNFP.

13.. A quality plan, in each department, is drafted:

+ Identify customer and service

+ Expectations of customers are surveyed

+ Determine whether you are meeting those expectations or not

+ Create a plan that establishes indicators and measurement of improvement

14.. We coordinated with system wide members and urged them all to agree on a universal strategy, which in fact has not been easy." 
Publicly Owned Hospital

The interview: Relevant Responses

QI.. What kind of a business are you in, who is your customer, and what is your product?

Answer: PARTICIPANT \# 6

"We are a publicly ouned hospital and a state university.

We provide health care as our product

Customers: Patients, their families and friends

Physicians, our own and those in the community

In general: everybody is everybody's customer"

Q2. Who are the key organizational layers, who are the most powerful in your organization in terms of TQM/CQI.

Answer: PARTICIPANT \# 6

1.. Board of Directors ( president)

2.. Senior Management

3.. Physicians

Q3.. How different is a hospital from a private industry company, in regard to TQM/CQI?

Answer: PARTICIPANT \# 6, PARTICIPANT \# 5

Public Vs Private

Similarities

1.. Concern for meeting customer (patients and others)

2. Desire to provide high quality care

3.. Desire to improve when possible

4.. Desire to have good patient outcomes

5.. Desire to meet regulatory requirements

6.. A hospital is closer to private sector than other public institutions.
Differences

1.. Willingness to care for the uninsured patients

2.. Physicians' incentives at private hospitals are more than those at public.

3.. How the money is used:

Private: shareholders

Public: Back to system

4.. Physician power:

Doctors have less power in public

organizations, since they are employees.

Sources of Funds: Private institutions get

more resources from research and referral rather than the state budget.

5.. Public organizations are more exposed to public scrutiny.

Q4.. In your view, how similar or different iS SH, from other health care institutions, for example, a private-for-profit institution, such as PH., or a private-not-for-profit institution, such as PNFP, in relation to TQM/CQI?

Answer: PARTICIPANT \# 6

1.. The structure and role of the Board Of Directors (BOD).

* In a private for profit hospital the BOD consists of the primary shareholders 
* In a private but not for profit hospital BOD consists of people who are not directly involved, such community leaders and so on.

* In a publicly owned hospital/university like SH: the president, who is the chairman is appointed by the board of higher education.

The implication of who iS Selected, how they are selected, and how much authority they have is important to the implementation of TQM/CQI.

2.. The role of customers: the public has a lot to do with what goes on at SH

3.. The role of physicians: In the public organizations, physicians are employees, but in the private organizations they are not; however they are enticed to be on staff.

4.. Public institutions have more system problems than a private hospital

5.. Public institutions have less financial resources to spend on training and education.

Q5. Is TQM/CQI different from other $Q A$, and if so how?

Answer: PARTICIPANT \# 6

Yes it does, and the following is a summary of how.

1.. $\mathrm{TQM} / \mathrm{CQI}$ is internally driven while other $\mathrm{QA}$ approaches are externally driven.

2.. $\mathrm{TQM} / \mathrm{CQI}$ encourages more collaborative interdepartmental efforts, while other $\mathrm{QA}$ focus on compartmentalization.

3.. TQM/CQI focuses on process issues than looking for the bad apples.

4.. $\mathrm{TQM} / \mathrm{CQI}$ is proactive rather than reactive. It tries to prevent the error rather than remedy it.

5.. TQM/CQI is customer focused

Answer: PARTICIPANT \# 5

1.. TQM/CQI is a paradigm shift in people's mind

2.. TQM/CQI puts all the previous organizational theories in a well organized predictive system which is easier to understand

3.. What is so unique about TQM/CQI is its focus on the problem and analyzing the surrounding circumstances and information that relate to it in an organized fashion. It is important to mention that this uniqueness applies to both public as well as private sectors.

Q6.. Who are the most important organizational layers, for the success of TQM/CQI?

Answer:

Top management is the key factor for the success of TQM/CQI.

Q7.. Where and how should TQM/CQI start?

Answer: PARTICIPANT \# 6 
TQM/CQI effortS Should be adopted by top management, and it should start there. You need to get a grass root movement first. You start small, and then you grow. What would help are widely publicized succesS Stories.

\section{Q8.. How could you convince top management that TQM/CQI works?}

Answer:

Top management wants proof. That could be in terms of literature and documented successes of $\mathrm{TQM} / \mathrm{CQI}$ in health care. A key factor here is having someone who could articulate it and be a real champion for it. Moreover, you need to involve stake holders, by showing that the problem is Shared between many departments. By mobilizing critical masses around TQM/CQI, top management will buy into it.

Q9.. Will the outcomes of TQM/CQI between the public and the private institutions be the same or different?

Answer: PARTICIPANT \# 6

If they both have the same objectives, then the outcomes will be the same. If they have the right objectives public organizations, as well as private ones, should:

* improve customer satisfaction

* achieve a better and more efficient utilization and provision of services

* maintain cost effectiveness

* improve patient care

The above should be the goals and outcomes of TQM/CQI in public as well as private organizations.

\section{Answer: PARTICIPANT \# 5}

** Not dramatically different, but given Measure 5 it will be more difficult to implement TQM/CQI in the public sector, because of the instability of the work force as a whole. However, the health care pressures are greater than measure 5 pressures.

** Due to Measure 5 there is a wage freeze on those public employees. That means no financial incentives could be offered, as is the case in the private sector, who would provide a financial rewards/incentives for successful implementation of TQM/CQI.

Q10.. Could you give me an example where the concepts of TQM/CQI have been employed at SH? How did you go about it and how would that compare to other institutions like PNFP?

\section{Answer: PARTICIPANT \# 6 \& PARTICIPANT \# 5}

We have what we call "Operation Restructuring" [OR]. This process has two goals: first, to increase efficiency, and second to reduce cosis, by 5-7 million dollars/year. This is to be done by looking at ways of doing business and re engineering the process to achieve the stated goals. PNFP, as well, haS Started a similar process.

\section{SH's Operation Restructuring:}

"We wanted to use TQM/CQI techniques, but not comprehensive processes, because a TQM/CQI process would require a massive involvement from top management and employees alike and it would consume a longer time. We did not have a real formalized approach or a time-framed deadline. We did not say start there and evaluate by such and such date. Rather, we said: it is a 
great idea, let it evolve, and let uS See how does it go. In other words we were learning by doing. It was very individualized. Trying many alternatives was encouraged. SH did not launch a massive TQM/CQI approach but it has been employing some of the techniques of TQM/CQI. We wanted to phase into implementation and not to do it all at once."

"We wanted to streamline the operations and save money. Multiple teams were formed, functions and tasks were coded to locate redundancy and waste and come up with ways to reduce them, which ultimately will reduce cost and improve efficiency."

O.R. consisted of three phases:

I.. Phase one: Training management and employees to identify which organizational areas could be re-engineered and to come up with new ways of doing business based on data collected. The major steps of this phase, then, were:

pointing out data $\gg$ Compiling data $\gg$ training of employees $\gg$ Identifying targets for improvement.

Phase II: Putting together key areas and committees to think about what could be done differently, in order to improve the service and enhance efficiency. We formed Quality Improvement Teams (QIT), and a steering committee.

Phase III: Implementation: by June or July of 93

Q11.. Did you encounter any opposition?

Answer:

Sometimes. We (SH) encountered uneasiness and unhappiness, especially on the part of physicians, due to cutting jobs, attrition, and reassigning jobs. Reluctant administrators, defensive department heads employees, who feared TQM/CQI might mean more budget cuts, and concerned employees might oppose TQM/CQI.

Q12.. Where does Quality Management department stand?

Answer:

We provide planning, facilitation, encouragement, education, consulting and expert input, and we are team players for TQM/CQI implementation.

\section{Q13.. How do you feel about TQM/CQI?}

Answer:

It iS Something that could work. It is a theory that has its flaws, but it tries to transfer from industry to health care. There are a lot of good things that have come out of $i t . \mathrm{TQM} / \mathrm{CQI}$ has the potential to break down the departmental barriers. It has the potential of getting more people involved so they will buy into it more. TQM/CQI will help streamline the process and look at improved outcome for less cost. TQM/CQI is a flexible approach that offers a better way of looking at things, and allows organizational participants to try among various alternatives and select the one/s that will meet the organization's needs.

Q14.. What are the hindering forces that might limit the adoption of TQM/CQI in the public sector: 


\begin{abstract}
Answer:
* Turf, and departmentalization

* Political issues that conflict with its implementation such as Measure 5, which might result in attrition of certain segments who are not productive or/and willing to change.
\end{abstract}

Note:

After my first interview with JS, there have been major changes in terms of the implementation of TQM/CQI at SH. The major change has been that the institution haS Stepped back and decided to focus more on the preparation for launching TQM/CQI rather than continuing with what has been going on. The following question /s explore these changes and deriveS Some lessons, to be shown in the summary of the findings.

\title{
Q15.. How do you explain regressing back to the initial stages of TQM/CQI?
}

\begin{abstract}
Answer:
"People, who were going at it, did some readings and had some results with it (staff department head level). They got interested in using the tools and trying them and getting some teams together. They have some success. Then they thought, this is great, we are going to do TQM/CQI. This was a mistake, because they never had the buy in and the commitment from the top management, which TQM/CQI itself stresses on. Though the top management said "we are committed to this" there was not really a commitment; that was not recognized."
\end{abstract}

NOTE: "After attending a conference we at SH have realized that for the process to succeed we are not talking about using the tools of TQM/CQI only, but we are talking about a major cultural, political shift. It meant a major shift in management style and required the involvement of the entire institution."

"SH, then, realized they are way long from that. They decided to step back and start at the top level and do some education there of what TQM/CQI/TQM/CQI means. This has backed everybody up. At this point, we are:

* Looking at a consultant to help the education of top management

* Top management should be involved

* There has been some interplay at the top level that might interfere, they are not working together as a team. They have to have a united front, a united commitment.

*. It is hoped that the training, with assistance of an outside consultant, will produce that commitment to change management style and philosophy."

"Thus, the cultural change has not happened yet, and for that cultural change to take place, you need the involvement of key leaders and their commitment. They need to put aside the territorial issues and focus on what is in it for the good of the organization, than for me."

Q16.. Could you describe a brief example where TQM/CQI worked, and another example where it did not? 


\section{Answer:}

A.. An example where it succeeded:

In the trauma department, the team worked on "Improving the process of notifying the patient's family."

They used TQM/CQI tools $\gg$ got a lot of people involved $\gg$ agreed on the problem $\gg$ came up with ground rules $\gg$ used TQM/CQI process and tools: charting, gathering data .. etc. $\gg$ came up with algorithm of how to do notification $\gg$ Implemented it, and made sure management bought into it $\gg:$ Designed an evaluation form to monitor the outcomes $\gg$ Solved the problem

** Key factors thit caused success:

* Everybociy agreed there was a problem.

* Good facilitation: Knowiedge of tools, a facilitator who can keep group on track

* Good participation

* Commitment of those involved, who came from various levels

* No hidden agendas or fragmentation

B.. An example where it failed:

Radiology department wanted to improve one of its Processes. The project failed due to:

* No group leader

* Hidden agendas

* Arguing and disagreement

Q17.. What Criteria, if any do you/will you follow to make sure you are on track when implementing TQM/CQI?

\section{Answer PARTICIPANT \# 5}

1.. We try to involve the employees from the beginning to ensure commitment and involvement

2.. We have identified idea champions, who would organize the ideas for improvement.

3. We identified idea owner/s, those responsible parties, where the idea came from, and gave them ownership of it.

4. We formed committees to systematically work on finding out improvement alternatives. ( Similar to the PITs, at PNFP or QITs, at PH.)

5.. Process improvement teams needed to take the ownership of the ideas, though they might have got help from a consultant, the final product was theirs. That rade them more committed.

6.. A coordinator is assigned/hired to ensure the implementation of PITs recommendations. .

7.. We assigned monitors to track tasks, using a computerized data base, and report the changes in the system after implementing TQM/CQI. 